\title{
Stability and Resilience of Seagrasses in Shallow Coastal Bays
}

\author{
Joel A. Carr
}

Richland, WA

B.A., University of Virginia 1999

M.S. University of Virginia 2002

M.A.T. Pacific University 2005

Dissertation presented to the Graduate Faculty of the University of Virginia in Candidacy for the Degree of Doctor of Philosophy

University of Virginia

August 2011

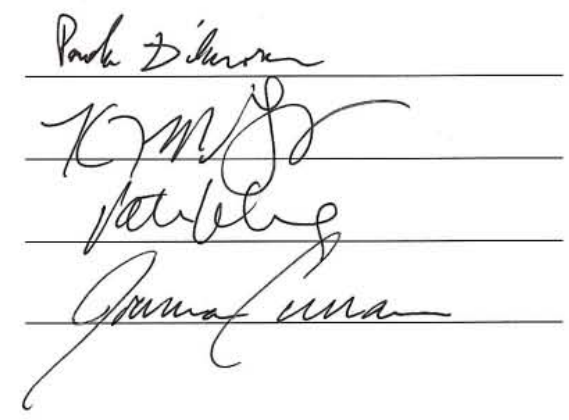




\section{Summary}

Shallow coastal lagoons are environments where a dynamic equilibrium exists between water quality and seagrass cover. Turbidity in shallow coastal lagoons is typically dominated by internal resuspension by waves and currents. Light attenuation due to water column turbidity can significantly impact primary productivity of benthic plants that have high light requirements. However, benthic plants such as seagrasses in shallow coastal lagoons decrease flow and provide shelter for the underlying sediment decreasing water column turbidity. As such, the presence and extent of dense seagrass canopies can limit the resuspension of bed sediments thereby creating a clearer water column and a positive feedback for seagrass growth. Positive feedbacks are often associated with the existence of bistable dynamics in ecosystems. For example, a bare and a seagrass covered sediment bed could be both stable states of the system. The following research investigates the emergence of these alternative stable states and their dependence on the strength of positive feedbacks among seagrass cover, stabilization of bed sediments, turbidity of the water column, and the existence of a favorable light environment for continued growth of seagrasses. 


\section{Abstract:}

Shallow coastal lagoons are environments where a dynamic equilibrium exists between water quality and seagrass cover. Dense seagrass canopies limit the resuspension of bed sediments thereby creating a clearer water column and a positive feedback for seagrass growth. Positive feedbacks are often associated with the existence of bistable dynamics in ecosystems. For example, a bare and a seagrass covered sediment bed could be both stable states of the system. This study develops: 1) a one-dimensional hydrodynamic model of vegetation-sediment-water flow interactions and uses it to investigate the strengths of positive feedbacks between seagrass cover, stabilization of bed sediments, turbidity of the water column, and the existence of a favorable light environment for seagrasses. 2) couples the hydrodynamic model to a seagrass vegetation growth model to examine the effect of dynamically-varying seasonal and interannual seagrass density on sediment resuspension, water column turbidity, and the subsequent light environment on hourly time steps and then run over decadal time scales. 3) a landscape scale model to investigate the effects of multiple meadows on the bulk sediment light environment and consequent emergence of bistability. The models were applied to Hog Island Bay, a shallow coastal bay on the eastern shore of Virginia. The effects of temperature, eutrophication, stresses associated with climate change, and bed grain size on bistability of seagrass ecosystems in the bay are explored. The results indicate that the positive feedback that exists due to the seagrass modified hydrodynamics is strong enough to induce bistable dynamics in limited depth range. This range is dependent on both stochastic environmental drivers (irradiance, water temperature, water depth, wind waves, tidal currents, bed grain size distribution and water column 
eutrophication), within meadow seagrass morphology (Shoot density, leaf density, above and belowground biomass, and leaf length), as well as seagrass effective fractional cover on the landscape. Within this bistable range, seagrass have limited resilience, such that a disturbance or sequences of disturbances in space and/or time, can push the system past some critical threshold resulting in collapse to a stable bare sediment system. Full collapse can take up to decades. Both flickering, and slowing down are seen as a leading indicators of this collapse. 


\section{TABLE OF CONTENTS}

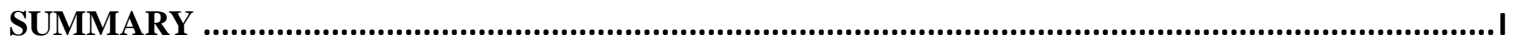

ABSTRACT:

TABLE OF CONTENTS........................................................................................................................

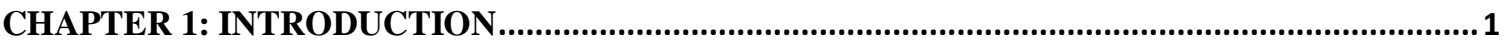

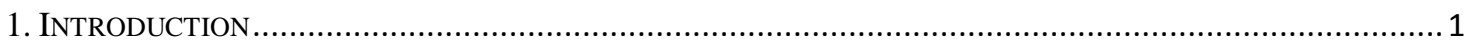

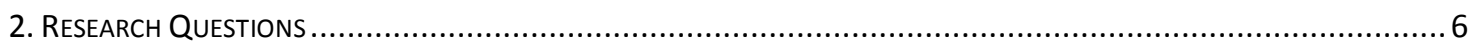

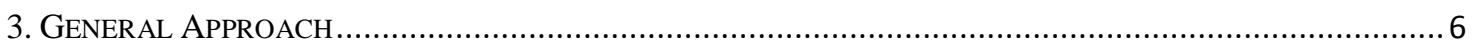

4. STUDY SITE

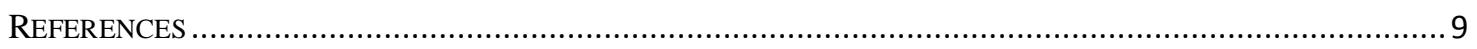

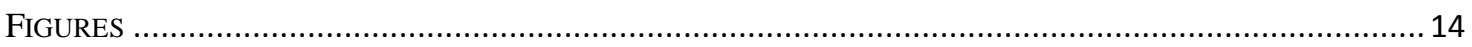

CHAPTER 2: STABILITY AND BISTABILITY OF SEAGRASS ECOSYSTEMS........................... 17

ABSTRACT:

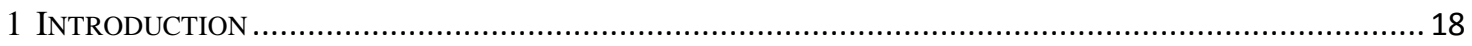

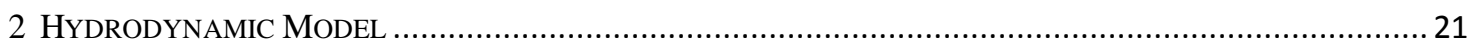

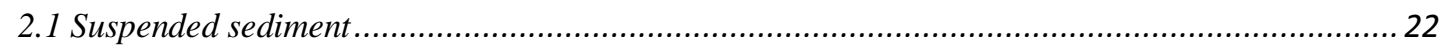

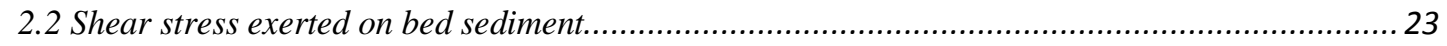

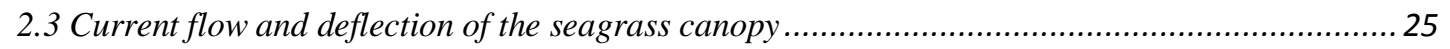

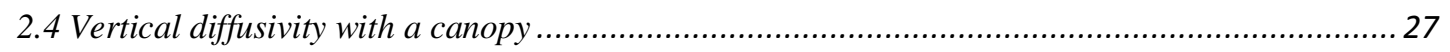

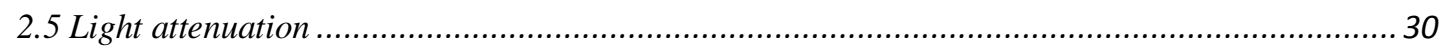

2.6 Changes in seagrass biomass due to photosynthesis and respiration.......................................... 31

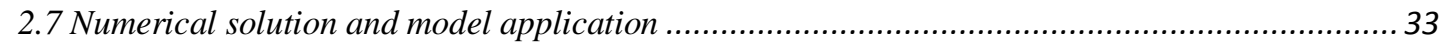

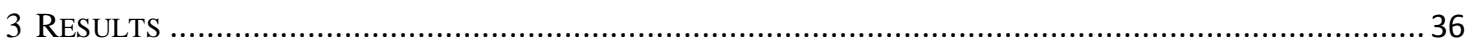

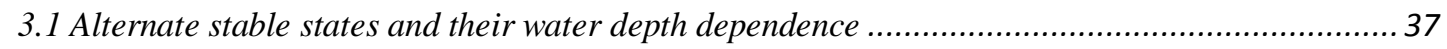

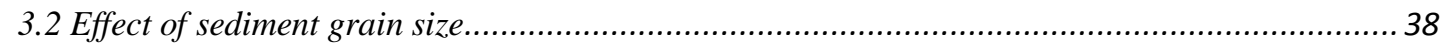

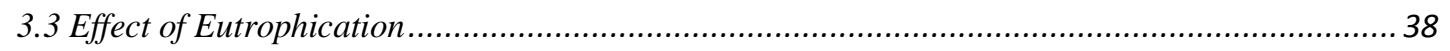

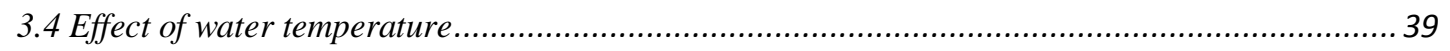

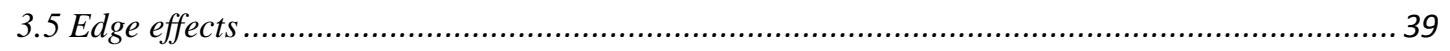

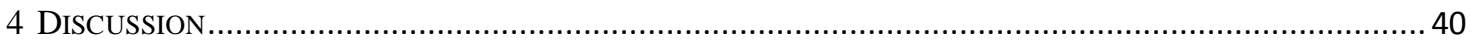

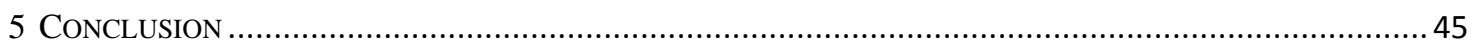

APPENDIX A: METHOD USED FOR THE ITERATIVE CALCULATION OF CANOPY BENDING ............................. 47

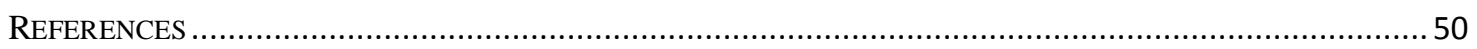

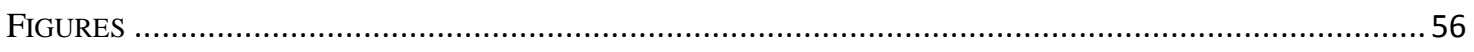

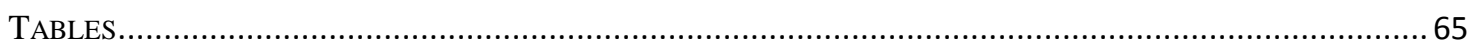

CHAPTER 3: STABILITY AND RESILIENCE OF SEAGRASS MEADOWS TO SEASONAL AND INTERANNUAL DYNAMICS AND ENVIRONMENTAL STRESS ............................................68

ABSTRACT:

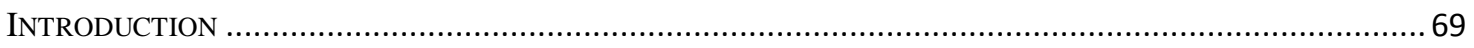

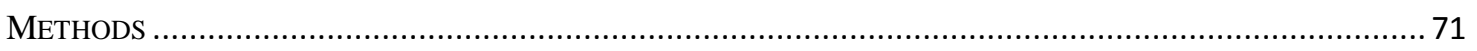

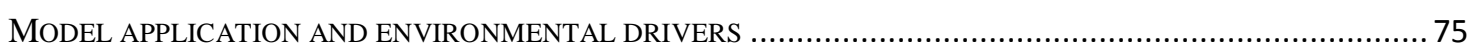




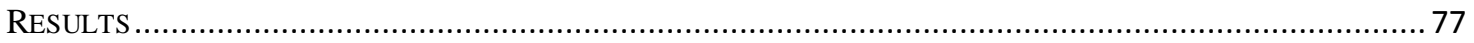

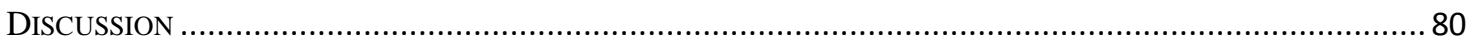

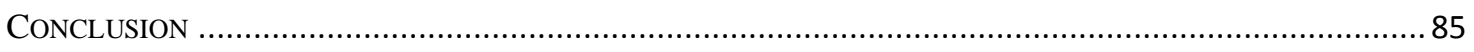

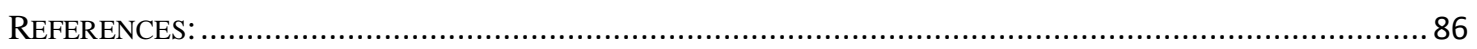

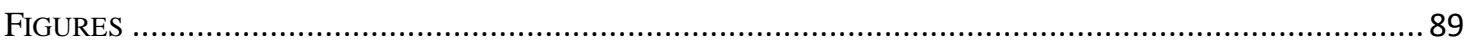

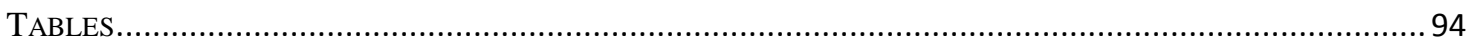

\section{CHAPTER 4: MODELING THE EFFECTS OF CLIMATE CHANGE ON SEAGRASS STABILITY AND RESILIENCE: FUTURE SCENARIOS AND LEADING INDICATORS OF}

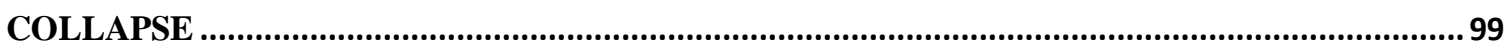

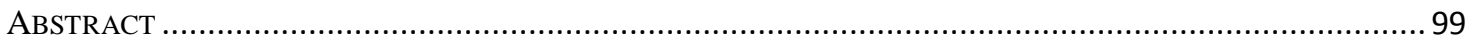

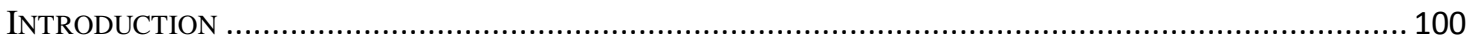

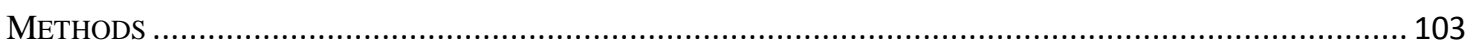

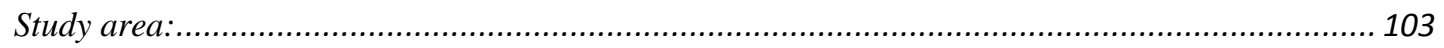

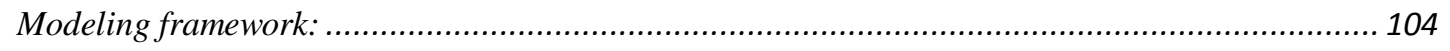

Model simulations:

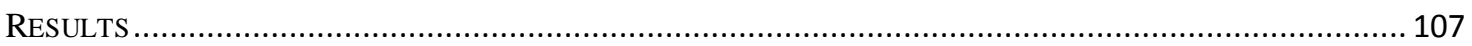

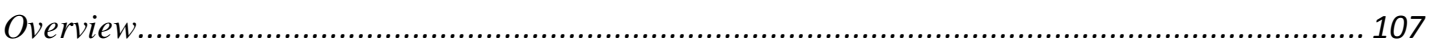

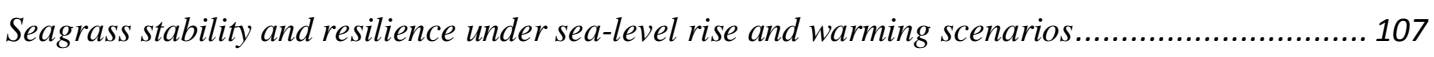

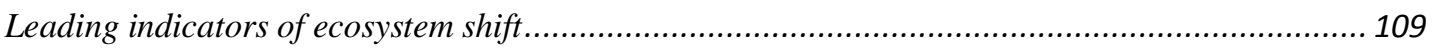

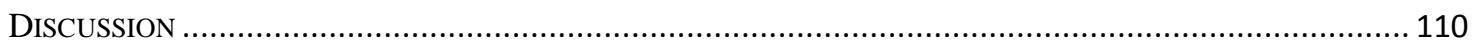

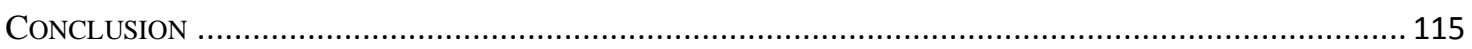

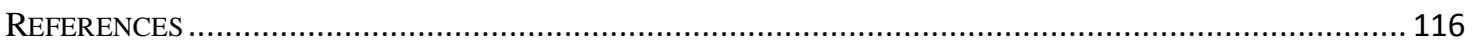

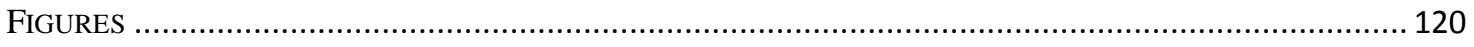

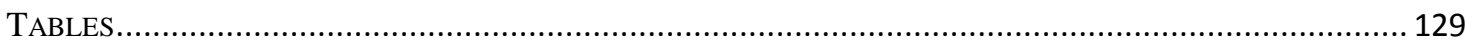

CHAPTER 5: SPATIALLY EXPLICIT FEEDBACKS BETWEEN SEAGRASS MEADOWS SEDIMENT AND LIGHT: HABITAT SUITABILITY FOR SEAGRASS GROWTH..................... 135

1. INTRODUCTION

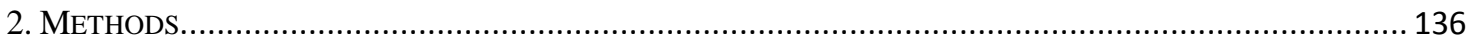

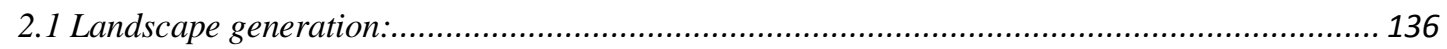

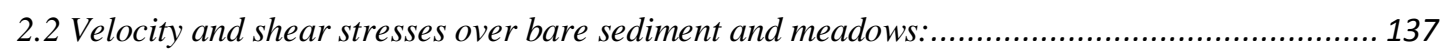

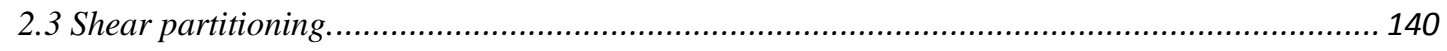

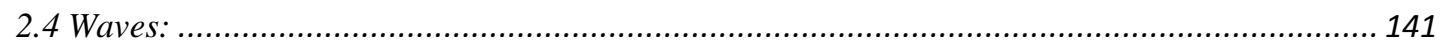

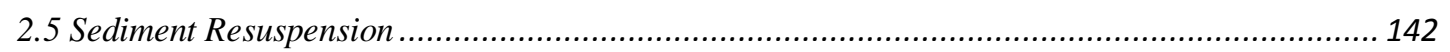

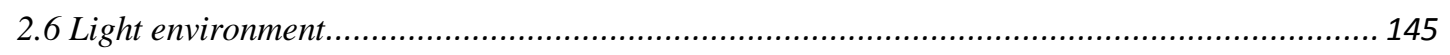

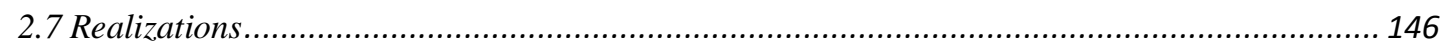

2.8 Study area:

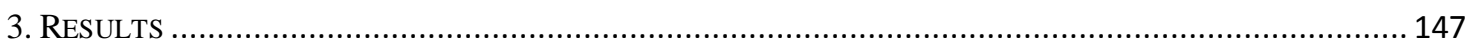

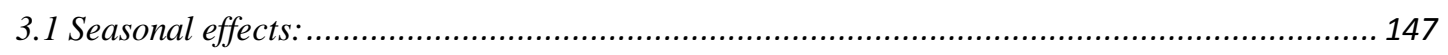

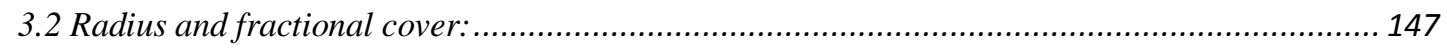

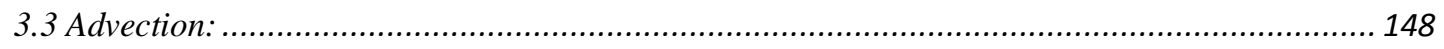

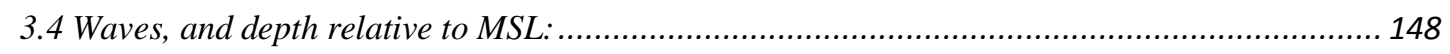

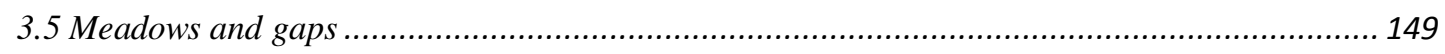




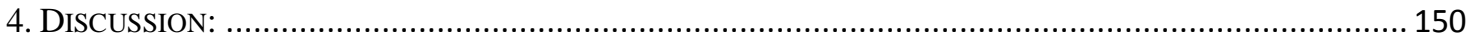

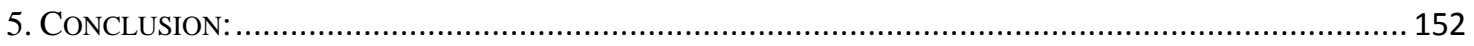

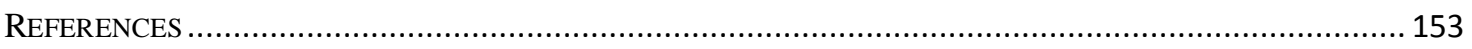

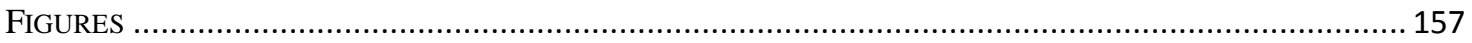

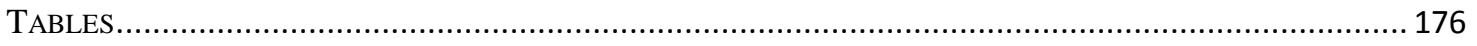

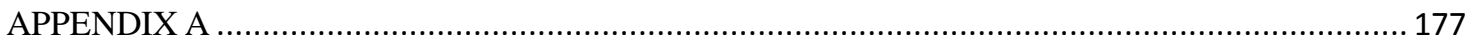

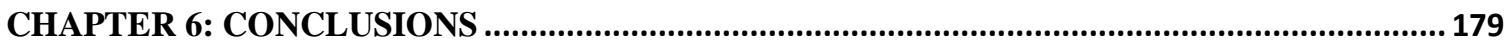

EMERGENCE OF BISTABLE DYNAMICS, CONTROLS AND LIMITATIONS: ..................................... 179

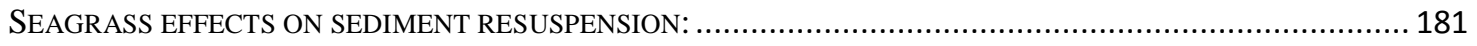

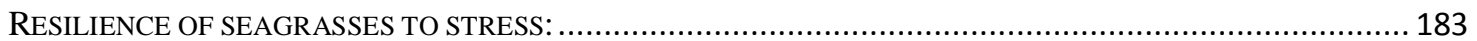

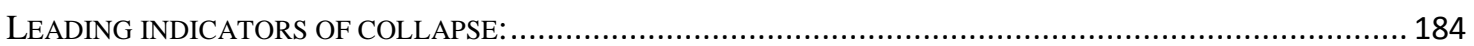

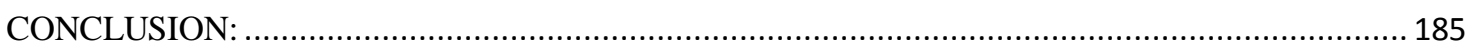

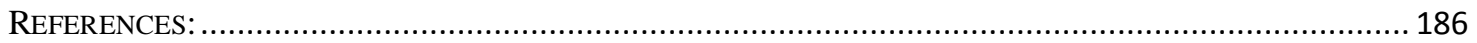

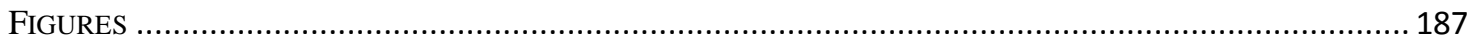




\section{Chapter 1: INTRODUCTION}

\section{Introduction}

Shallow coastal bays, which represent an important transition between terrestrial and aquatic ecosystems, are particularly vulnerable to the rapid changes in population and land use occurring in coastal areas [Havens et al., 2001; Nixon et al., 2001; Valiela et al., 1997]. The subtidal seagrass meadows and estuarine salt marshes that dominate landmargin systems are among the most productive ecosystems known, and provide critical ecosystem services that include providing of habitat to a diverse and economically important faunal community, sequestering carbon and nutrients, and stabilizing shorelines. Eutrophication caused by the rapid changes in population and land use occurring in coastal areas [Havens et al., 2001; McGlathery et al., 2007; Nixon et al., 2001; Valiela et al., 1997], increases in water temperature [Keller, 2009; Najjar et al., 2000], water depth [Cazenave et al., 2008; Najjar et al., 2000] and storminess due to climate change [Hayden, 1999] can detrimentally impact subtidal seagrass meadows [Moore and Jarvis, 2008].

Primary production in coastal bays is typically dominated by benthic plants (seagrasses and algae), except where external nutrient loading and phytoplankton populations can be high. [McGlathery et al., 2007; Sandjensen and Borum, 1991]. The shallow depths of coastal bays make the bay-bottom sediment susceptible to current and wave suspension. The resulting high light attenuation in the water column can limit benthic primary productivity, particularly for species with high light requirements, such 
as seagrasses, which typically require about $20 \%$ of incident light at the sediment surface [Dennison et al., 1993; Duarte, 1991; Zimmerman et al., 1995].

In general, turbidity in coastal bays is controlled by internal sediment resuspension [Lawson et al., 2007] because many coastal bays lack riverine discharge, a major control on turbidity in deeper estuaries. The magnitude and importance of resuspension may increase when rooted vegetation is absent because of the lack of the sediment stabilizing effects of the plants [Gacia and Duarte, 2001; Gacia et al., 2003; Heiss et al., 2000]. As such the dynamics of seagrass ecosystems may exhibit important positive feedbacks between vegetation and sediment suspension/deposition, and between nutrient loading and seagrass growth.

Seagrass slows flow and shelters underlying sediment, consequently reducing its susceptibility to resuspension, and enhancing deposition of fine sediment (Figure 1), which are both factors that increase the transparency of the water column [Folkard, 2005]. Additionally, seagrass immobilizes nutrients produced in the sediment through remineralization, thereby reducing availability of nutrients in the water column that could promote algal growth and reduce light penetration to the seafloor [McGlathery et al., 2007]. Thus, seagrass positively influences light penetration, which, in turn, supports further seagrass growth. An increase in water-column turbidity reduces light levels at the bay bottom with potentially detrimental effects on seagrass populations and consequent enhancement of sediment resuspension (Figure 2). It has been argued [van der Heide et al., 2007] that these positive feedbacks can rapidly shift a system from a state with clear water and a seagrass-covered bottom to an alternate state with turbid water and no seagrass cover. This state change can also be triggered by a loss in seagrass resilience 
associated with the reduction of light penetration resulting from increases in nutrient loads, with consequent algal growth and decreases in dissolved oxygen [McGlathery et al., 2007].

Positive feedbacks between the state of the system (e.g., seagrass cover) and limiting resources (e.g., light) can induce the emergence of alternate stable states in ecosystem dynamics [Wilson and Agnew, 1992]. In the case of sea grass ecosystems the alternate states would exhibit either bare sediment beds with high suspended loads and poor light environments for seagrass growth, or a seagrass meadow with relatively clear water and enough light penetration through the water column to sustain seagrass growth.

The emergence of bistability in ecosystems has important ecological implications. Bistable systems exhibit strong nonlinearities in their response to changes in environmental drivers and may undergo abrupt shifts from one state to the other as a result of only small environmental changes. Moreover, bistable ecosystems have only a limited resilience [Gunderson, 2000] in that they are able to recover from disturbances and return back to their pre-disturbance state only when the disturbance intensity (e.g., fraction of seagrass bed disturbed) is smaller than a critical value, while more severe disturbances would take the system into the attraction domain of the alternate stable state. Past the critical point, once the external forcing causing the disturbance is eliminated the system would not be able to recover its pre-disturbance configuration [Scheffer et al., 2001; Scheffer and van Nes, 2004].

Because of the abrupt and often irreversible character of these transitions, ecosystem managers need to be able to recognize whether a system is about to shift from 
a seagrass-covered bottom to a bare sediment state. However, such ecosystem shifts, may or may not be associated with early warning signs (Hastings 2010). As such, it is important to not only identify the threshold between the two attraction domains (Brock \& Carpenter 2010), but also to recognize early warning signs, if they exist, that the system is about to cross the threshold between regimes.

It is difficult to predict these transition points because the state of the system may display little change prior to the transition (Scheffer et al. 2009). In some systems there is a critical slowing down effect (van Nes and Scheffer, 2007), whereby as the system approaches the bifurcation point, its response to small perturbations (i.e., small displacement from stable equilibrium) becomes increasingly slow. This slowing down results in an increased autocorrelation of the state variable and possibly an increase in variance when nearing the critical threshold (Scheffer et al. 2009). Another possible symptom of being near the critical bifurcation point is flickering, which occurs when environmental or stochastic drivers are strong enough to induce relatively rapid oscillations between attraction domains of a system near the critical bifurcation point (Scheffer et al. 2001, Scheffer et al. 2009, Brock \& Carpenter 2010) (Fig. 1). Regardless of the specific metric, evidence of a system being near catastrophic collapse is important for mitigation management practices, and also provides insight to guide and monitor successful restoration efforts. However, the sensitivity of these systems to natural and anthropogenic drivers complicates the development and implementation of successful management strategies. 
Thus, in the case of shallow coastal bays, non-linear behavior could emerge from positive feedbacks between vegetation, sedimentation and environmental drivers [van der Heide et al., 2007]. However feedbacks between water quality and seagrass ecosystems are understudied and the impact of these feedbacks on the stability and resilience of estuarine environments has seldom been assessed [van der Heide et al., 2007]. As a result, we currently do not have a comprehensive understanding of the susceptibility of these systems to changes in climate drivers and disturbances, including sea-level rise, temperature increase, nutrient inputs, and seabed disturbance from storms and human activities. This limits the development and implementation of successful management and restoration strategies because the sensitivity of these systems to natural and anthropogenic drivers cannot be adequately predicted.

The following research investigates the strengths of positive feedbacks among seagrass cover, stabilization of bed sediments, turbidity of the water column, and the existence of a favorable light environment for continued growth of seagrasses. By assessing the strength of positive and negative feedbacks, the research investigates whether seagrass ecosystems are prone to catastrophic shifts to alternate "stable" states in response to gradual changes in environmental conditions and disturbance regime. 


\section{Research Questions}

1) To what extent does the feedback between seagrass meadows and their light environment in shallow coastal bays produce bistable behavior?

2) How does plant temporal morphology (e.g leaf growth, change in shoot density, rhizome biomass) affect the resilience, stability and bistability of seagrass meadows?

3) How do the increased stresses associated with climate change affect seagrass resilience

4) Are there leading indicators of regime shift between a seagrass covered bed and a bare sediment surface?

5) How does landscape patch density effect the general light environment, and subsequent stability of a collection of meadows?

\section{General Approach}

In order to address the above questions two different approaches were used. First, hydrodynamic model of vegetation-sediment-water flow interactions is developed (Chapter 2) to investigate the impact of changes in seagrass density on sediment resuspension, water column turbidity, and light environment. The hydrodynamic model was used to address presence or absence of bistability under varying shoot density, sediment characteristics, eutrophication and sea level rise. This model was then coupled with a morphologic seagrass vegetation growth model (Chapter 3) that encompasses the changes in shoot and leaf density, leaf length, and rhizome biomass within a meadow. The coupled model was used to investigate the resiliency of a seagrass meadow to 
changing environmental conditions both within a given year as well as across many years. The coupled model was then used not only to explore the effects of climate change on seagrass resilience, but to identify leading indicators of regime shift (Chapter 4).

The second approach develops speculative conceptual analytic models that examine changes in fractional cover of seagrasses on a larger scale (Chapter 5). This larger spatial approach was used to look at how the density seagrass meadows on the landscape affect the shear partitioning, and consequent sediment resuspension and light environment. It was also used to explore how patch density affects the stable and bistable depth ranges of the seagrass meadows under the stochastic drivers of wind waves and tidal currents. The chapters are written in manuscript format and then followed by a conclusion (Chapter 6) which discusses and summarizes the combined results of the studies.

\section{Study Site}

The models developed are applicable to many regions, but were specifically applied to investigate seagrass dynamics in Hog Island Bay (Figure 3), a shallow coastal bay within the Virginia Coast Reserve (VCR, $37^{\circ} 25^{\prime} \mathrm{N}, 75^{\circ} 46^{\prime} \mathrm{W}$ ). This reserve is a Long Term Ecological Research (VCR/LTER) site located on the Atlantic side of the Delmarva Peninsula and includes a number of bays bordered by Spartina alterniflora marshes both on the mainland and on the barrier islands. About $50 \%$ of the bays are less than 1 meter deep at mean low water [Oertel, 2000] and the tidal range is about 1.2 meters. Since the 1930's, the southern bays of the VCR have been dominated by benthic algae due to a seagrass die off that occurred when the seagrasses of the VCR, already under stress from 
disease, were severely impacted by a hurricane and became locally extinct [Orth et al., 2006]. In the 1990's small natural patches of seagrass were discovered, prompting both large-scale restoration efforts and attempts to understand the slow recovery of the seagrass populations in these bays. Currently, meadows exhibits shoot densities from 412 - 529 shoots $/ \mathrm{m}^{2}$ at depths up to $2 \mathrm{~m}$. This change in the trophic base from benthic algae to seagrass is expected to affect the entire system due to changes in production, nutrient cycling, water quality, sediment stability [Sfriso and Marcomini, 1997; Viaroli et al., 1996] and higher trophic levels [Lepoint et al., 2000; Norkko et al., 2000; Sfriso et al., 2001]. 


\section{References}

Abdelrhman, M. A. (2007), Modeling coupling between eelgrass Zostera marina and water flow, Mar. Ecol.-Prog. Ser., 338, 81-96.

Bach, H. K. (1993), A dynamic model describing the seasonal variations in growth and the distribution of eel grass (Zostera Marina), Ecological Modelling, 65(1-2), 31-50.

Biber, P. D., C. L. Gallegos, and W. J. Kenworthy (2008), Calibration of a bio-optical model in the North River, North Carolina (Albemarle-Pamlico sound): A tool to evaluate water quality impacts on seagrasses, Estuaries and Coasts, 31(1), 177-191.

Bocci, M., G. Coffaro, and G. Bendoricchio (1997), Modelling biomass and nutrient dynamics in eelgrass (Zostera marina L.): applications to the Lagoon of Venice (Italy) and Oresund (Denmark), Ecological Modelling, 102(1), 67-80.

Boynton, W. R., J. D. Hagy, L. Murray, C. Stokes, and W. M. Kemp (1996), A comparative analysis of eutrophication patterns in a temperate coastal bay, Estuaries, 19(2B), 408-421.

Campbell G., a. N. J. (1998), Introduction to Environmental Biophysics, 2nd ed., Springer, New York.

Cazenave, A., A. Lombard, and W. Llovel (2008), Present-day sea level rise: A synthesis, Comptes Rendus Geoscience, 340(11), 761-770.

Dennison, W. C., R. J. Orth, K. A. Moore, J. C. Stevenson, V. Carter, S. Kollar, P. W.

Bergstrom, and R. A. Batiuk (1993), Assessing water-quality with submersed aquatic vegetation Bioscience, 43(2), 86-94.

Dietrich, W. E. (1982), Settling velocity of natural particles, Water Resources Research, 18(6), $1615-1626$.

Duarte, C. M. (1991), Seagrass depth limits, Aquatic Botany, 40(4), 363-377. 
Fagherazzi, S., and P. L. Wiberg (2009), Importance of wind conditions, fetch, and water levels on wave-generated shear stresses in shallow intertidal basins, J. Geophys. Res., 114, F03022, doi:10.1029/2008JF001139.

Fagherazzi S., Carniello L., D'Alpaos L., Defina A. (2006), Critical bifurcation of shallow microtidal landforms in tidal flats and salt marshes Proceeding of the National Academy of Sciences, 103 (22): 8337-8341.

Folkard, A. M. (2005), Hydrodynamics of model Posidonia oceanica patches in shallow water, Limnology and Oceanography, 50(5), 1592-1600.

Gacia, E., and C. M. Duarte (2001), Sediment retention by a mediterranean Posidonia oceanica meadow: The balance between deposition and resuspension, Estuarine Coastal and Shelf Science, 52(4), 505-514.

Gacia, E., C. M. Duarte, N. Marba, J. Terrados, H. Kennedy, M. D. Fortes, and N. H. Tri (2003), Sediment deposition and production in SE-Asia seagrass meadows, Estuarine Coastal and Shelf Science, 56(5-6), 909-919.

Ghisalberti, M., and H. Nepf (2006), The structure of the shear layer in flows over rigid and flexible canopies, Environmental Fluid Mechanics, 6(3), 277-301.

Gunderson, L. H. (2000), Ecological resilience - in theory and application, Annual Review of Ecology and Systematics, 31, 425-439.

Harris, C. K., and P. L. Wiberg (1997), Approaches to quantifying long-term continental shelf sediment transport with an example from the Northern California STRESS mid-shelf site, Continental Shelf Research, 17(11), 1389-1418.

Hauxwell, J., J. Cebrian, C. Furlong, and I. Valiela (2001), Macroalgal canopies contribute to eelgrass (Zostera marina) decline in temperate estuarine ecosystems, Ecology, 82(4), 1007-1022. Havens, K. E., J. Hauxwell, A. C. Tyler, S. Thomas, K. J. McGlathery, J. Cebrian, I. Valiela, A. D. Steinman, and S. J. Hwang (2001), Complex interactions between autotrophs in shallow 
marine and freshwater ecosystems: implications for community responses to nutrient stress, Environmental Pollution, 113(1), 95-107.

Hayden, B. P. (1999), Climate change and extratropical storminess in the United States: An assessment, Journal of the American Water Resources Association, 35(6), 1387-1397.

Heiss, W. M., A. M. Smith, and P. K. Probert (2000), Influence of the smalt intertidal seagrass Zostera novazelandica on linear water flow and sediment texture, New Zealand Journal of Marine and Freshwater Research, 34(4), 689-694.

Keller, C. F. (2009), Global warming: a review of this mostly settled issue, Stoch. Environ. Res. Risk Assess., 23(5), 643-676.

Lawson, S. E., P. L. Wiberg, K. J. McGlathery, and D. C. Fugate (2007), Wind-driven sediment suspension controls light availability in a shallow coastal bay, Estuaries and Coasts, 30(1), 102112.

Lepoint, G., F. Nyssen, S. Gobert, P. Dauby, and J. M. Bouquegneau (2000), Relative impact of a seagrass bed and its adjacent epilithic algal community in consumer diets, Marine Biology, 136(3), 513-518.

Lightbody, A. F., and H. M. Nepf (2006), Prediction of near-field shear dispersion in an emergent canopy with heterogeneous morphology, Environmental Fluid Mechanics, 6(5), 477488.

Luhar, M., J. Rominger, and H. Nepf (2008), Interaction between flow, transport and vegetation spatial structure, Springer.

McGlathery, K. J., K. Sundback, and I. C. Anderson (2007), Eutrophication in shallow coastal bays and bays: the role of plants in the coastal filter, Mar. Ecol.-Prog. Ser., 348, 1-18.

Moore, K. A., and J. C. Jarvis (2008), Environmental Factors Affecting Recent Summertime Eelgrass Diebacks in the Lower Chesapeake Bay: Implications for Long-term Persistence, $J$. Coast. Res., 135-147. 
Najjar, R. G., H. A. Walker, P. J. Anderson, E. J. Barron, R. J. Bord, J. R. Gibson, V. S. Kennedy, C. G. Knight, J. P. Megonigal, R. E. O'Connor, C. D. Polsky, N. P. Psuty, B. A. Richards, L. G. Sorenson, E. M. Steele, and R. S. Swanson (2000), The potential impacts of climate change on the mid-Atlantic coastal region, Climate Research, 14(3), 219-233.

Nielsen, S. L., K. Sand-Jensen, J. Borum, and O. Geertz-Hansen (2002), Depth colonization of eelgrass (Zostera marina) and macroalgae as determined by water transparency in Danish coastal waters, Estuaries, 25(5), 1025-1032.

Nixon, S., B. Buckley, S. Granger, and J. Bintz (2001), Responses of very shallow marine ecosystems to nutrient enrichment, Human and Ecological Risk Assessment, 7(5), 1457-1481. Norkko, J., E. Bonsdorff, and A. Norkko (2000), Drifting algal mats as an alternative habitat for benthic invertebrates: Species specific responses to a transient resource, Journal of Experimental Marine Biology and Ecology, 248(1), 79-104.

Oertel, G., C. R. Carlson, and K. Overman. (2000), Hog Island Bay, Virginia Bathymetric Survey using Trimble DGPS and Innerspace Digital Fathometer.

Orth, R. J., M. L. Luckenbach, S. R. Marion, K. A. Moore, and D. J. Wilcox (2006), Seagrass recovery in the Delmarva Coastal Bays, USA, Aquatic Botany, 84(1), 26-36.

Pastres, R., D. Brigolin, A. Petrizzo, and M. Zucchetta (2004), Testing the robustness of primary production models in shallow coastal areas: a case study.

Sandjensen, K., and J. Borum (1991), Interactions among phytoplankton, periphyton, and macrophytes in temperate fresh-waters and estuaries, Aquatic Botany, 41(1-3), 137-175.

Sanford, L. P., and J. P. Y. Maa (2001), A unified erosion formulation for fine sediments, Marine Geology, 179(1-2), 9-23.

Scheffer, M., S. Carpenter, J. A. Foley, C. Folke, and B. Walker (2001), Catastrophic shifts in ecosystems, Nature, 413(6856), 591-596. 
Scheffer, M., and E. H. van Nes (2004), Mechanisms for marine regime shifts: can we use lakes as microcosms for oceans?, Progress in Oceanography, 60(2-4), 303-319.

Sfriso, A., and A. Marcomini (1997), Macrophyte production in a shallow coastal bay .1. Coupling with chemico-physical parameters and nutrient concentrations in waters, Marine Environmental Research, 44(4), 351-375.

Sfriso, A., T. Birkemeyer, and P. F. Ghetti (2001), Benthic macrofauna changes in areas of Venice bay populated by seagrasses or seaweeds, Marine Environmental Research, 52(4), 323349.

Valiela, I., J. McClelland, J. Hauxwell, P. J. Behr, D. Hersh, and K. Foreman (1997), Macroalgal blooms in shallow estuaries: Controls and ecophysiological and ecosystem consequences, Limnology and Oceanography, 42(5), 1105-1118.

van der Heide, T., E. H. van Nes, G. W. Geerling, A. J. P. Smolders, T. J. Bouma, and M. M. van Katwijk (2007), Positive feedbacks in seagrass ecosystems: Implications for success in conservation and restoration, Ecosystems, 10(8), 1311-1322.

Verhagen, J. H. G., and P. H. Nienhuis (1983), A simulation-model of production, seasonalchanges in biomass and distribution of eelgrass (Zostera Marina) in lake Grevelingen, Mar. Ecol.Prog. Ser., 10(2), 187-195.

Viaroli, P., M. Bartoli, C. Bondavalli, R. R. Christian, G. Giordani, and M. Naldi (1996), Macrophyte communities and their impact on benthic fluxes of oxygen, sulphide and nutrients in shallow eutrophic environments, Hydrobiologia, 329(1-3), 105-119.

Wilson, J. B., and A. D. Q. Agnew (1992), Positive-feedback switches in plant-communities, Advances in Ecological Research, 23, 263-336.

Zimmerman, R. C., J. L. Reguzzoni, and R. S. Alberte (1995), Eelgrass(Zostera Marina L) transplants in San Francisco Bay - Role of light availability on metabolism, growth and survival, Aquatic Botany, 51(1-2), 67-86. 
Figures

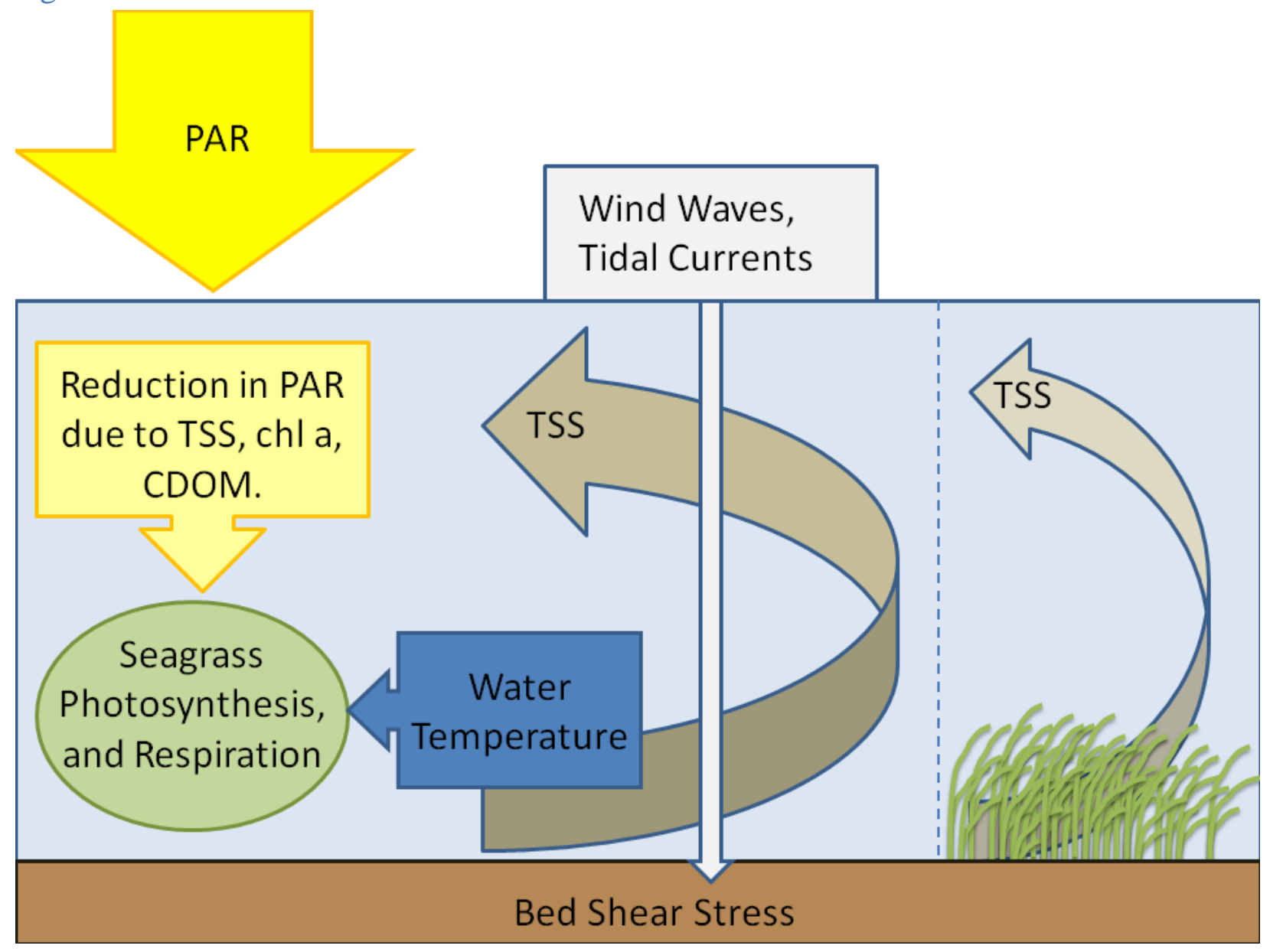

Figure 1. Conceptualization of the the effect of seagrass on total suspended solids (TSS) by reduction in bed shear and sediemnt resuspension resulting in the reduction in the attenuation of photosyntheticallya ctive radiation (PAR). 


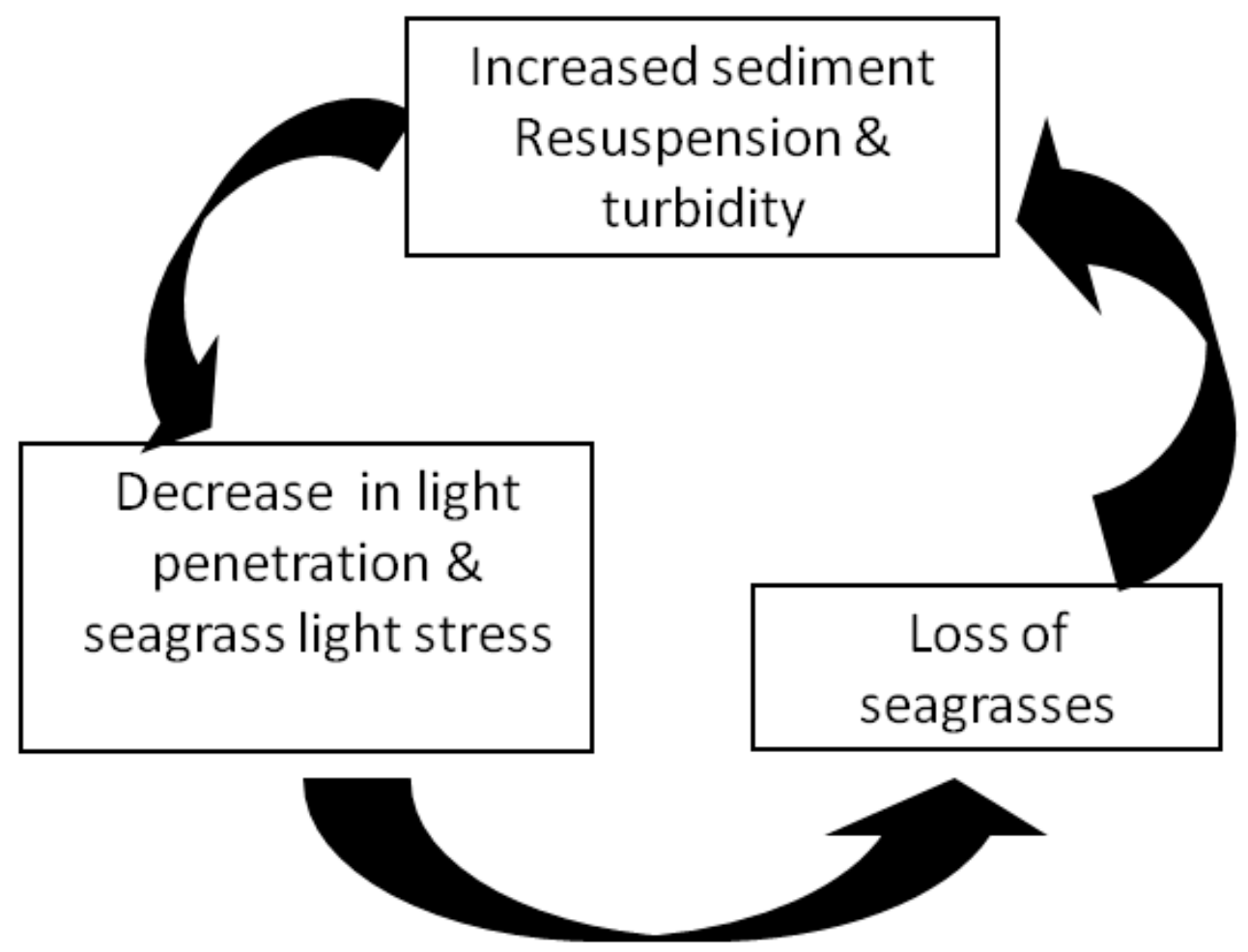

Figure 2. The positive feedback between seagrass, sediment resupension and the subseqeunct light environment. 


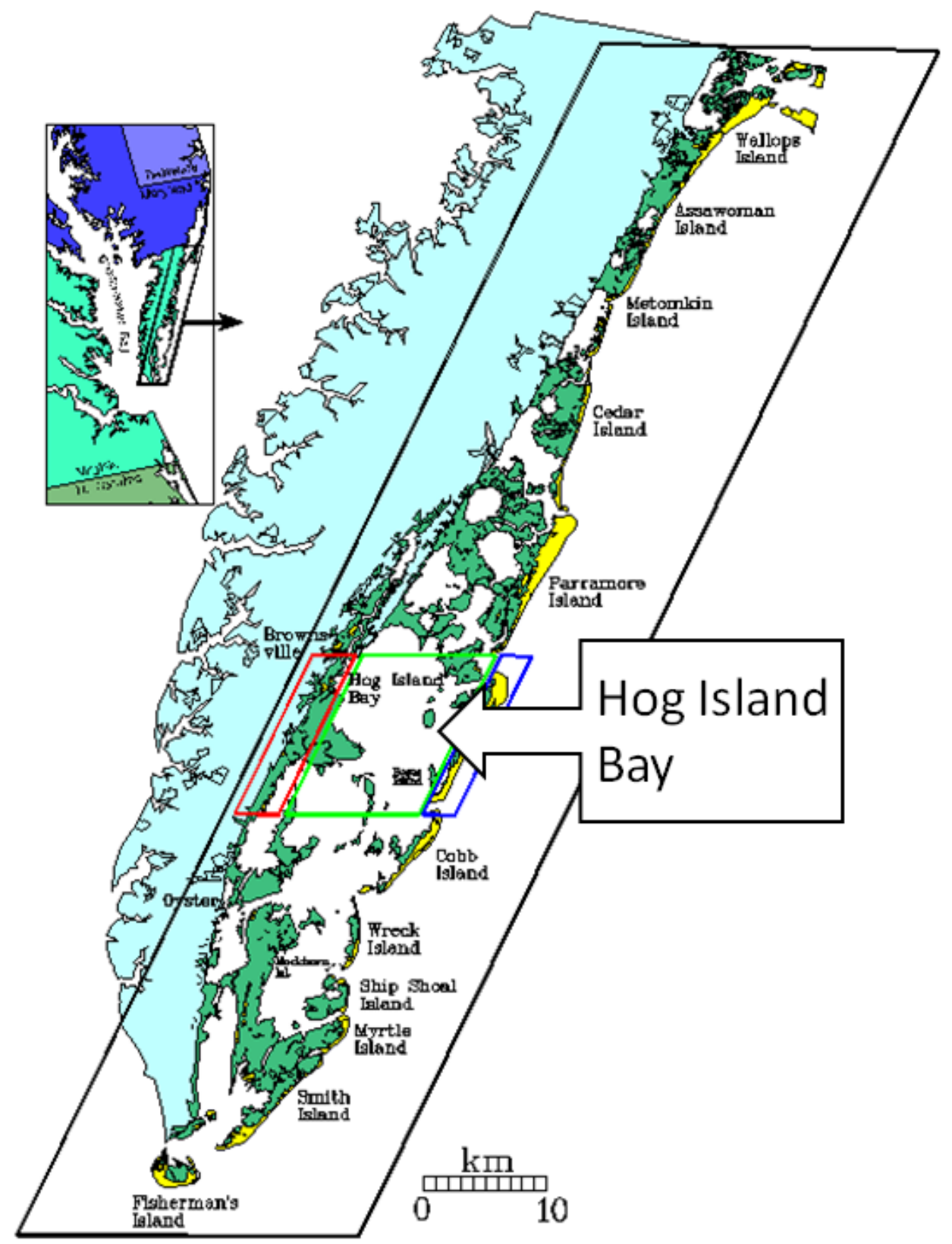

Figure 3. Hog Isalnd Bay, the study site used for this modeling effort located with the Virginia Coast Reserve Long term ecological research site (VCR-LTER). 


\section{Chapter 2: STABILITY AND BISTABILITY OF SEAGRASS ECOSYSTEMS}

\section{Abstract:}

Shallow coastal lagoons are environments where a dynamic equilibrium exists between water quality and seagrass cover. Dense seagrass canopies limit the resuspension of bed sediments thereby creating a clearer water column and a positive feedback for seagrass growth. Positive feedbacks are often associated with the existence of bistable dynamics in ecosystems. For example, a bare and a seagrass covered sediment bed could be both stable states of the system. This study describes a one-dimensional hydrodynamic model of vegetation-sediment-water flow interactions and uses it to investigate the strengths of positive feedbacks between seagrass cover, stabilization of bed sediments, turbidity of the water column, and the existence of a favorable light environment for seagrasses. The model is applied to Hog Island Bay, a shallow coastal lagoon on the eastern shore of Virginia. The effects of temperature, eutrophication, and bed grain size on bistability of seagrass ecosystems in the lagoon are explored. The results indicate that under typical conditions, seagrass is stable in water depths $<2.2 \mathrm{~m}$ ( $51 \%$ of the bay bottom deep enough for seagrass growth) and bistable conditions exist for depths of 2.2 - $3.6 \mathrm{~m}$ (23\% of bay) where the preferred state depends in initial seagrass cover. The remaining $26 \%$ of the bay is too deep to sustain seagrass. Decreases in sediment size and increases in water temperature and degree of eutrophication shift the bistable range to shallower depths, with more of the bay bottom unable to sustain seagrass. 


\section{Introduction}

Shallow coastal lagoons, which represent an important transition between terrestrial and aquatic ecosystems, are particularly vulnerable to the rapid changes in population and land use occurring in coastal areas [Havens et al., 2001; Nixon et al., 2001; Valiela et al., 1997]. The subtidal seagrass meadows and estuarine salt marshes that dominate land-margin systems are among the most productive ecosystems known, and provide critical ecosystem services that include providing of habitat to a diverse and economically important faunal community, sequestering carbon and nutrients, and stabilizing shorelines. Eutrophication caused by the rapid changes in population and land use occurring in coastal areas [Havens et al., 2001; McGlathery et al., 2007; Nixon et al., 2001; Valiela et al., 1997], increases in water temperature [Keller, 2009; Najjar et al., 2000], water depth [Cazenave et al., 2008; Najjar et al., 2000] and storminess due to climate change [Hayden, 1999] can detrimentally impact subtidal seagrass meadows [Moore and Jarvis, 2008].

Primary production in coastal lagoons is typically dominated by benthic plants (seagrasses and algae), except where external nutrient loading and phytoplankton populations can be high. [McGlathery et al., 2007; Sandjensen and Borum, 1991]. The shallow depths of coastal lagoons make the lagoon-bottom sediment susceptible to current and wave suspension. The resulting high light attenuation in the water column can limit benthic primary productivity, particularly for species with high light requirements, such as seagrasses, which typically require about $20 \%$ of incident light at the sediment surface [Dennison et al., 1993; Duarte, 1991; Zimmerman et al., 1995]. 
In general, turbidity in coastal lagoons is controlled by internal sediment resuspension [Lawson et al., 2007] because many coastal lagoons lack riverine discharge, a major control on turbidity in deeper estuaries. The magnitude and importance of resuspension may increase when rooted vegetation is absent because of the lack of the sediment stabilizing effects of the plants [Gacia and Duarte, 2001; Gacia et al., 2003; Heiss et al., 2000]. As such the dynamics of seagrass ecosystems may exhibit important positive feedbacks between vegetation and sediment suspension/deposition, and between nutrient loading and seagrass growth.

Seagrass slows flow and shelters underlying sediment, consequently reducing its susceptibility to resuspension, and enhancing deposition of fine sediment, which are both factors that increase the transparency of the water column [Folkard, 2005]. Additionally, seagrass immobilizes nutrients produced in the sediment through remineralization, thereby reducing availability of nutrients in the water column that could promote algal growth and reduce light penetration to the seafloor [McGlathery et al., 2007]. Thus, seagrass positively influences light penetration, which, in turn, supports further seagrass growth. An increase in water-column turbidity reduces light levels at the lagoon bottom with potentially detrimental effects on seagrass populations and consequent enhancement of sediment resuspension. It has been argued [van der Heide et al., 2007] that these positive feedbacks can rapidly shift a system from a state with clear water and a seagrasscovered bottom to an alternate state with turbid water and no seagrass cover. This state change can also be triggered by a loss in seagrass resilience associated with the reduction 
of light penetration resulting from increases in nutrient loads, with consequent algal growth and decreases in dissolved oxygen [McGlathery et al., 2007].

Positive feedbacks between the state of the system (e.g., seagrass cover) and limiting resources (e.g., light) can induce the emergence of alternate stable states in ecosystem dynamics [Wilson and Agnew, 1992]. In the case of sea grass ecosystems the alternate states would exhibit either bare sediment beds with high suspended loads and poor light environments for seagrass growth, or a seagrass meadow with relatively clear water and enough light penetration through the water column to sustain seagrass growth.

The emergence of bistability in ecosystems has important ecological implications. Bistable systems exhibit strong nonlinearities in their response to changes in environmental drivers and may undergo abrupt shifts from one state to the other as a result of only small environmental changes. Moreover, bistable ecosystems have only a limited resilience [Gunderson, 2000] in that they are able to recover from disturbances and return back to their pre-disturbance state only when the disturbance intensity (e.g., fraction of seagrass bed disturbed) is smaller than a critical value, while more severe disturbances would take the system into the attraction domain of the alternate stable state. Past the critical point, once the external forcing causing the disturbance is eliminated the system would not be able to recover its pre-disturbance configuration [Scheffer et al., 2001; Scheffer and van Nes, 2004].

In the case of shallow coastal lagoons, non-linear behavior could emerge from positive feedbacks between vegetation, sedimentation and environmental drivers [van der 
Heide et al., 2007]. However feedbacks between water quality and seagrass ecosystems are understudied and the impact of these feedbacks on the stability and resilience of estuarine environments has seldom been assessed [van der Heide et al., 2007]. As a result, we currently do not have a comprehensive understanding of the susceptibility of these systems to changes in climate drivers and disturbances, including sea-level rise, temperature increase, nutrient inputs, and seabed disturbance from storms and human activities. This limits the development and implementation of successful management and restoration strategies because the sensitivity of these systems to natural and anthropogenic drivers cannot be adequately predicted.

This study investigates the strengths of positive feedbacks among seagrass cover, stabilization of bed sediments, turbidity of the water column, and the existence of a favorable light environment for continued growth of seagrasses. By assessing the strength of positive and negative feedbacks, we investigate whether shallow estuarine ecosystems are prone to catastrophic shifts to alternate "stable" states in response to gradual changes in environmental conditions and disturbance regime.

\section{Hydrodynamic Model}

We develop a hydrodynamic model of vegetation-sediment-water flow interactions, and use this model to investigate the impact of changes in seagrass density on sediment resuspension, water column turbidity, and light environment under different conditions of sea level, bed sediment characteristics and eutrophication. The hydrodynamic model simulates the one-dimensional dynamics (in the vertical direction) of sediment entrainment/settling within the water column. It accounts for the effect of 
seagrass vegetation on these dynamics, including its effect on the velocity profile, eddy diffusivity, shear flow dispersion, and wave and current shear stress. At the same time it accounts for the effect of flow on the height of the deflected seagrass canopy. Values of suspended sediment concentrations calculated by the model ( $\S 2.1-2.4)$ are used to determine the degree of light attenuation within the water column (i.e., from the water surface to the top of the canopy, see $\S 2.5$ ) and to calculate light availability and the suitability of environmental conditions to maintain seagrass meadows (see $\S 2.6$ ). In the following subsections we describe the main components of the hydrodynamical model and its use in the calculation of light attenuation.

\subsection{Suspended sediment}

We use a one dimensional representation of the conservation of mass for suspended sediments in the form of the advection-diffusion equation where individual grain settling velocities, $w_{s, j}$, and concentrations, $C_{s, j}$, are calculated for each size class $j$ [Dietrich, 1982]

$$
\frac{\partial C_{s, j}}{\partial t}=w_{s, j} \frac{\partial C_{s, j}}{\partial z}+\frac{\partial}{\partial z}\left(\overline{K_{z}} \frac{\partial C_{s, j}}{\partial z}\right)
$$

where $\overline{K_{z}}$ is an average vertical diffusivity (see sections $\S 2$.3and $\S 2.4$ ) and $z$ is the height above the bed surface. The coupling of the suspended sediment concentrations to 
the bed sediment concentrations is expressed as a continuity of sediment flux boundary condition, where the entrainment flux, $E_{j}\left(\mathrm{~kg} \mathrm{~m}^{-2} \mathrm{~s}^{-1}\right)$ is

$$
E_{j}=\rho_{s, j} c_{b, j} \beta\left(\tau_{b}-\tau_{c r}\right)
$$

where $\rho_{s, j}$ is the density and $c_{b, j}$ is the bed fraction of sediment size class, $j$, while $\beta$ is a resuspension constant $\left(\mathrm{m}^{3} \mathrm{~s}^{-1} \mathrm{~Pa}^{-1}\right)$ [Sanford and Maa, 2001]. $\tau_{b}\left(\mathrm{~Pa} \mathrm{~m}^{-2}\right)$ is the shear stress applied to the bed, and $\tau_{c r}\left(\mathrm{~Pa} \mathrm{~m}^{-2}\right)$ is the critical shear stress for sediment erosion. The total amount of sediment in suspension may not exceed the total amount of sediment in an active layer at the bed surface [Harris and Wiberg, 1997], in which case the available bed concentration for size class $j$ is limited to

$$
C_{\text {bedavailable }, j}=\left(C_{b, j} d_{a c t i v e}-\int_{z_{a}}^{z} C_{s, j} d z\right)
$$

where $Z$ is water depth and $z a$ is bed roughness height.

\subsection{Shear stress exerted on bed sediment}

The bed shear stress, $\tau_{b}$, used in equation ((2)) is determined as the vectorial sum

of the shear stresses exerted by currents $\left(\tau_{b \text {-current }}\right)$ and waves $\left(\tau_{b \text {-wave }}\right)$. The former is calculated as a function of the average current velocity, $U_{a v}$, 


$$
\tau_{b-\text { current }}=\rho C_{d} U_{a v}{ }^{2}
$$

where $\rho$ is the fluid density; the drag coefficient $C_{d}$ is calculated following Lawson et al [2007].

Wave shear stress is determined from significant wave height, $H_{\text {sig }}$, wavelength, $L$, and period, $T$, generated from the fetch-limited shallow water wave model of Young and Verhagen [1996] as

$$
\tau_{\text {bwave }}=\rho\left(\frac{f}{2}\right) U_{b}^{2}
$$

where the wave orbital velocity, $U_{b}$, at the bed is given by

$$
U_{b}=\frac{\pi H_{s i g}}{T \sinh (2 \pi Z / L)}
$$

while the friction factor, $f$, is calculated following Lawson et al [2007]. Wave attenuation due to a seagrass canopy is incorporated by reducing the wave orbital velocity as a function of the number of shoots, $N$, using a Monad equation with a half saturation constant $N_{h s}$ of 1500 shoots $\mathrm{m}^{-2}$ [van der Heide et al., 2007] 
To combine the effect of waves and currents on total bed shear stress, the total shear stress applied to the bed by waves and currents is calculated as

$$
\tau_{b}=\sqrt[2]{\tau_{\text {bwave }}^{2}+\tau_{\text {bcurrent }}^{2}}
$$

Values of $\tau_{b}$ calculated with equation ((7)) are used in equation ((2)) to calculate the entrainment rate.

\subsection{Current flow and deflection of the seagrass canopy}

To account for flow-induced deflection of the seagrass canopy, the deflected canopy height, sheath velocity and stress acting on a seagrass blade are calculated as in Abdelherman [2007], i.e., by balancing the forces of drag, lift, skin friction and buoyancy along a segmented blade of seagrass protruding from an immobile sheath (see Appendix A).

The velocity profile is assumed to be logarithmic above the seagrass canopy, while within the canopy the velocity decreases non-logarithmically with decreasing height. Starting from the edges of a vegetated patch and moving a distance of one meter into the vegetation (in the direction of the flow), the velocity profile is calculated using an iterative procedure, that modifies the velocity profile for bare sediments to account for the effect of drag exerted by the seagrass blades upstream from the point in question (i.e., 
within one meter from the edges). Thus, although the model does not resolve the horizontal dimensions, it accounts for modification of flow by upstream vegetation.

Conserving fluid momentum between the logarithmic velocity profile when seagrass is absent, $U_{\text {bare }}$ and the flow modified by the drag imparted by the collection of seagrass blades allows for the velocity profile within the canopy and sheath layers, $U_{\text {veg }}$, to be calculated as

$$
\rho l \cos \theta \quad U_{\text {bare }}^{2}=\rho l \cos \theta \quad U_{\text {veg }}^{2}+F_{x} N_{m}
$$

where $N_{m}$ is a modified one-dimensional shoot density function (number of shoots and blades per unit length) defined in the following section, and $F_{x}$ is the horizontal component of the drag exerted by a single blade of seagrass (see equation (A2)). The velocity profile developed in the presence of seagrass, is then calculated solving equation ((8)) for $U_{\text {veg }}$.

The momentum lost within the canopy is added to the flow above the canopy and the velocity profile above the canopy is modified accordingly. The velocity, $U_{\text {transfer }}$, required by the flow above the canopy to conserve the fluid momentum is calculated from the momentum balance equation 


$$
\int_{0}^{z}\left\lceil\rho U_{\text {bare }}^{2} d z=\int_{0}^{k_{c}}\right\rceil \rho U_{\text {veg }}^{2} d z+\int_{k_{c}}^{z} \nmid \rho\left(U_{\text {bare }}^{2}+U_{\text {transfer }}^{2}\right) d z
$$

where $k_{c}$ is the height of the bent canopy (see Appendix A)

Using a displacement height of 70\% of the deflected canopy height (e.g Campbell [1998]), the momentum lost in the canopy is distributed to the velocity field above the canopy assuming a logarithmic distribution of $U_{v e g}$ above the canopy, with $U_{v e g}=0$ at the displacement height. Linear regression of the logarithm of the height above the bed, $z$, to the velocity above the canopy is used to determine the new shear velocity for the flow above the canopy. This approach takes an initial logarithmic velocity profile and runs it through a collection of blades to calculate the departing velocity profile. While this model is one-dimensional, the departing velocity depends on the distance into the seagrass meadow, allowing for calculation of velocities near both the middle and edge of a seagrass meadow.

\subsection{Vertical diffusivity with a canopy}

When a dense canopy is present, vertical diffusivity within the canopy can be modeled as a function of shoot morphology and velocity [Lightbody and Nepf, 2006].

$$
K_{\text {zcanopy }}=\alpha U w \sqrt[3]{C_{d} N_{m} w^{2}} \text { for }\left(0<z<k_{c}\right)
$$


with the coefficient $\alpha$ ranging from 0.1 to $0.2, w$ being average blade width, and where $N_{m}$ is a modified shoot density function

$$
N_{m}=3.9\left\lceil N \int_{l_{a v}+2 \sigma}^{z} \frac{1}{\sqrt{2 \pi} \sigma} e^{\frac{-\left(z-l_{a v}\right)^{2}}{2 \sigma^{2}}} d z\right.
$$

which accounts for the existence of an average of 3.9 blades/shoot above the sheath[Abdelrhman, 2007]. In equation ((11)), $l_{a v}$ is the average total blade length set to $80 \%$ of the total canopy height and $\sigma$ is the standard deviation of blade length set to $10 \%$ of the canopy height based on measured values from Abdelrhman [2007]. The density in the sheath layer $z<Z_{\text {sheath }}$ is set to the shoot density $N$.

The vertical diffusivity above the canopy is calculated as $K_{z}=\kappa u_{*} z\left(1-\frac{z}{Z}\right.$ ) (for $z$ $>k_{c}$ ) using the appropriate shear velocity from the modified logarithmic flow above the canopy. While the overall effect of vegetation is to reduce flow and decrease transport, a region of strong shear develops near the interface between the canopy and the overlying flow in which the velocity profiles exhibit the nature of a shear flow characterized by coherent Kelvin-Helmholtz vortices. While vortices may only attain a finite penetration, $\delta_{\mathrm{e}}$ into the canopy, they control the turbulent exchange of momentum between two distinct zones, a free zone above the canopy and a wake zone within the canopy. The diffusivity within the shear region is enhanced (Figure 1) due to the coherent vortices and 
the vertical diffusivity of this region scales with the depth of the shear layer, $\delta_{m l}$, and the shear in the average velocity profile $\Delta U$ [Ghisalberti and Nepf, 2004]. Thus, the vertical eddy diffusivity, Dtz, of the shear layer is calculated as a function of $\Delta U$ and $\delta_{m l}$ based on the curves in Ghisalberti and Nepf [2004, Figure 5].

$$
\frac{D_{t z}}{\Delta U \delta_{m l}}=\left\{\begin{array}{lr}
0.8 z^{*} & 0.1 \leq z^{*} \leq .35 \\
-0.2375 z^{*}+.032 \text { for } & 0.35<z^{*} \leq .8 \\
0.013 & 0.8<z^{*} \leq .1
\end{array}\right\}
$$

with $z^{*}=\frac{\left(z-z_{\text {sheath }}\right)}{\delta_{m l}}$ and $\delta_{m l}=\frac{\left(h_{\text {canopy }}-z_{\text {sheath }}\right)}{0.35}$.

Calculations of $D_{t z}$, and, $K_{\text {zcanopy }}$ apply only to the case of dense canopies. To model the transitional diffusivity within the canopy between the bare sediment scenario and the dense canopy scenario a weighted average is used.

$$
\overline{K_{z}}=\gamma\left(K_{\text {zcanopy }}+D_{t z}\right)+(1-\gamma) K_{z} \text { for }\left(0<z<k_{c}\right)
$$

In equation ((13)) the weighing coefficient, $\gamma$, is calculated as

$$
\gamma=\int_{0}^{N} \dddot{x} n\left(1-\frac{n}{N_{r e q}}\right) d n
$$


where $n$ is shoot density and $N_{\text {req }}$ is the required shoot density, i.e., the shoot density necessary for a given canopy to behave with diffusivities corresponding to equations ((10)) and ((12)). Dense aquatic canopies have a non-dimensional cross sectional area of $0.016=a d=0.051$ [Ghisalberti and Nepf, 2006]. Using the minimal value of 0.016 and given the calculated deflected canopy height, $k_{c}$, and plant morphology, $N_{\text {req }}$ is determined as

$$
N_{\text {req }}=\frac{0.016}{w^{2} k_{c}}
$$

$N_{\text {req }}$ is time dependent since the deflected canopy height is time dependent. Under typical blade widths of $0.007 \mathrm{~m}$ and a deflected canopy height ranging from $0.15 \mathrm{~m}$ to $0.30 \mathrm{~m}$, the modified shoot density required for the canopy to be considered dense varies from 280 shoots $\mathrm{m}^{-2}$ to 580 shoots $\mathrm{m}^{-2}$.

The average velocity profile, and the current shear stress applied to the bed in the transition from bare sediment to dense canopy are similarly averaged using the same weighting parameter $\gamma$ (equation 14).

\subsection{Light attenuation}

Light attenuation for photosynthetically active radiation (PAR), wavelengths (400-700nm), in the water column is modeled using the Lambert-Beer law, where the 
light attenuation coefficient, $K_{d}\left(\mathrm{~m}^{-1}\right)$ is a function of solar zenith, $\mu$, total suspended solids, phytoplankton (chl a) and colored dissolved organic matter (CDOM). For this study we determine $K_{d}$ based on the empirical relationship used by Lawson et al. [2007]

$$
K_{d}(\mu)=0.052 T S S+c h l a \times 0.0154+C D O M \times 0.28+0.0384
$$

The case study presented in this paper refers to Hog Island Bay ( $\S 2.7$ ) where values for chl $a$ and CDOM ( chl $a=2 \mathrm{mg} \mathrm{m}^{-3}$ and CDOM =0.4 ) are relatively low and show little effect on the light attenuation coefficient, while total suspended solids dominate $K_{d}$ [Lawson et al., 2007].

\subsection{Changes in seagrass biomass due to photosynthesis and respiration}

Growth and loss of biomass due to photosynthesis and respiration is a complex process involving a number of environmental controls. To simplify, we represent this process as a function of water temperature and available photosynthetically-active radiation. Using specific growth and loss rates we calculate an hourly net growth rate based on light availability and the temperature-dependent compensation and saturation curves for photosynthesis [Bocci et al., 1997; Pastres et al., 2004; Zharova et al., 2001].

The compensation irradiance, $I_{C}$, and saturation irradiance, $I_{K}$, are temperature dependant and modeled as 


$$
I_{K}=I_{K 20} \theta_{K}^{T-20} \text { and } I_{C}=I_{C 20} \theta_{C}^{T-20}
$$

where $I_{K 20}$ and $I_{C 20}$ are the saturation and compensation irradiance at $20{ }^{\circ} \mathrm{C}, \theta_{K}$ and $\theta_{C}$ are parameters that determine the shape of the saturation/compensation curves, and the temperature, $T$, is expressed in ${ }^{\circ} \mathrm{C}$. These values are then compared to incident radiation, $I$, at the canopy surface calculated as:

$$
I=I_{\text {surface }} e^{-K_{d} h_{d}}
$$

with $h_{d}=Z-k_{c}$ (Table 3).

To obtain a first order estimate of growth of plant biomass, $G_{p}$, we use the maximum specific growth rate $G_{p \max }$ scaled as a function of the incident radiation and temperature

$$
G_{p}=G_{p \max } F_{I}(I) F_{p h o t}(T)
$$

where the scaling functions, $F_{I}(I)$ and $F_{\text {phot }}(T)$ are calculated as in Bocci et al.[1997; Pastres et al., 2004; Zharova et al., 2001]. We compare $G_{p}$ to a respiratory loss term, $L_{p}$ , which is expressed as a function of the maximum respiration term $L_{\text {resp }}$ and temperature, to account for temperature effects on respiration reduction. 


$$
L_{p}=L_{\text {resp }} \theta_{\text {loss }}^{T-20}
$$

The daily maximum specific growth rate is assumed to correspond to a 10 hour day at optimum light and temperature conditions and is scaled to an hourly rate, whereas the respiratory loss is spread over the entire 24 hour day to acquire an hourly rate. Hourly net loss or growth is summed for the entire year to determine if a given set of conditions favors growth ( $G_{p}>0$ ), or loss of biomass $\left(G_{p}<0\right)$, for the year.

\subsection{Numerical solution and model application}

2.7.1 Study Site

The model was used to investigate seagrass dynamics in Hog Island Bay, a shallow coastal lagoon within the Virginia Coast Reserve (VCR, $37^{\circ} 25^{\prime} \mathrm{N}, 75^{\circ} 46^{\prime} \mathrm{W}$ ). This reserve is a Long Term Ecological Research (VCR/LTER) site located on the Atlantic side of the Delmarva Peninsula and includes a number of lagoons bordered by Spartina alterniflora marshes both on the mainland and on the barrier islands. About 50\% of the lagoons are less than 1 meter deep at mean low water [Oertel, 2000] and the tidal range is about 1.2 meters. Since the 1930's, the southern lagoons of the VCR have been dominated by benthic algae due to a seagrass die off that occurred when the seagrasses of the VCR, already under stress from disease, were severely impacted by a hurricane and 
became locally extinct [Orth et al., 2006]. In the 1990's small natural patches of seagrass were discovered, prompting both large-scale restoration efforts and attempts to understand the slow recovery of the seagrass populations in these lagoons. Currently meadows exhibits shoot densities from 412 - 529 shoots $\mathrm{m}^{-2}$ at depths up to $2 \mathrm{~m}$ (Table 1). This change in the trophic base from benthic algae to seagrass is expected to affect the entire system due to changes in production, nutrient cycling, water quality, sediment stability [Sfriso and Marcomini, 1997; Viaroli et al., 1996] and higher trophic levels [Lepoint et al., 2000; Norkko et al., 2000; Sfriso et al., 2001]. We are interested in both the potential for initial seagrass recovery in the VCR coastal lagoons and the resilience of restored seagrass meadows to stress associated with climate change (temperature, storminess) and eutrophication.

\subsubsection{Model simulations}

The model was run with an hourly time step (Figure 2) using hourly wind measurements from Hog Island Bay $\left(37^{\circ} 27^{\prime} \mathrm{N}, 75^{\circ} 40^{\prime} \mathrm{W}\right)$ and hourly tides from Red Bank $\left(37^{\circ} 26^{\prime} \mathrm{N}, 75^{\circ} 50^{\prime} \mathrm{W}\right)$. We used hourly water temperature and salinity measurements $\left(37^{\circ} 23^{\prime} \mathrm{N}, 75^{\circ} 43^{\prime} \mathrm{W}\right.$ 23) made by the Virginia Institute of Marine Science(VIMS), and PAR from the VCR-LTER flux tower at Fowling Point $\left(37^{\circ} 24^{\prime}\right.$ N, $75^{\circ} 50^{\prime} \mathrm{W}$ ). For each one-hour time step, sediment settling velocities were calculated based on water temperature, salinity and density. Velocity and diffusivity profiles were calculated with an iterative procedure to account for canopy deflection. The resultant 
diffusivity profile and excess shear were used in the implicit solution of the suspended sediment equation for all grain sizes on an hourly time step. The sediment concentrations were then integrated to determine the total suspended sediment. Light attenuation was calculated based on PAR at the water surface and the hourly-calculated light attenuation coefficient. Net growth or loss for that hour was then calculated. These hourly values were used to calculate total net yearly seagrass biomass growth/loss for a constant yearly shoot density. Parameters values were assigned using data available from literature as indicated in Table 2.

The model is limited to water depths where the assumption that a logarithmic velocity profile above the seagrass is appropriate. Thus, the model can be applied only in conditions of seagrass submergence. To maintain validity, the depth limit is set equal to twice the normal canopy height. Considering a canopy height of $30 \mathrm{~cm}$ and a lowest minimum tidal elevation of approximately $-1 \mathrm{~m}$ below mean sea level model application is limited to mean water depths $=1.6 \mathrm{~m}$. Due to deflection of the canopy, flow over the meadow occurs for roughly $70 \%$ of the water depth. Z. marina can withstand short durations of emergence [Duarte, 1991] and as such the actual range of suitable depths is dependent on canopy height, tidal range and light and nutrient availability. In most systems the typical depth range is 1-10 m with most meadows found from 2-3 m [Duarte, 1991]. Half of Hog Island Bay is deeper than $1.6 \mathrm{~m}$, and depths shallower than $1.15 \mathrm{~m}$ account for $36 \%$ of the bay (Figure 3). The bare sediment model can be run for mean water depths $\geq 1.15 \mathrm{~m}$. To fill the gap in depths between the applicability of the bare sediment model and the canopy model, an emergent vegetation hydrodynamic model 
would be needed that incorporates the transition from an above canopy logarithmic flow to a thin above canopy shear flow. The development of such a model is beyond the scope of this study.

\section{Results}

Modeled suspended sediment concentrations decreased significantly with increasing seagrass shoot densities with very little suspension occurring at high shoot densities due to the decrease in bed shear and vertical mixing. Even low shoot densities had a strong effect, with 100 shoots $\mathrm{m}^{-2}$ reducing total suspended sediments by $14 \%$ (with respect to the bare sediment case) for a $2 \mathrm{~m}$ mean water depth, and by up to $40 \%$ at $10 \mathrm{~m}$ mean water depth. Total suspended sediment is reduced by $98 \%$ at 1000 shoots $\mathrm{m}^{-2}$ . In addition the reduction in the vertical diffusivity due to the presence of a seagrass canopy decreased the time that sediment remained in suspension after large entrainment events. This allowed for faster clearing of the water column and a corresponding increase in the number of hours when light conditions were favorable for seagrass growth each year.

Hours of light saturation, compensation and partial saturation were totaled for the year (Figure 4). When a canopy is present there is a $50 \%$ reduction in compensation hours across all water depths with an average increase of 720 hours with partial saturation conditions, i.e., about 90 additional days of adequate growth conditions. At shallow water depths (i.e., $\mathrm{Z}<2 \mathrm{~m}$ ) the number of hours with saturation conditions doubled when a seagrass canopy was present. At 3 m water depths there are no saturation hours under bare sediment or canopy conditions indicating that even under clear water conditions, 
light attenuation does not allow for saturation at depths $>3 \mathrm{~m}$. However, there are enough partially saturated light hours ( i.e., hours with $I_{c}<I_{c o n}<I_{k}$ ) under typical conditions (i.e. typical winds, tides, water temperature, sediment, chl a, CDOM and light) in Hog Island Bay to allow for seagrass growth in water depths up to $3.6 \mathrm{~m}$.

\subsection{Alternate stable states and their water depth dependence}

Under typical conditions for Hog Island Bay, the system favors the presence of a stable seagrass bed ("vegetated state") at locations with water depths, $Z<2.2 \mathrm{~m}$. In this stable vegetated state, shoot density is not determined by light but by other limiting factors (e.g., nutrients). For $\mathrm{Z}>3.6 \mathrm{~m}$ the light availability is not sufficient for the growth and survival of seagrasses because partial light saturation would occur less than $50 \%$ of the time. In this case, bare sediment conditions are stable (Figure 5). For depths of $2.2 \mathrm{~m}$ $<\mathrm{Z}<3.6 \mathrm{~m}$ the system exhibits bistable behavior. Depending on the initial seagrass cover conditions, the system converges to a state with either bare sediment or vegetated conditions. Overall, the light environment depends on seagrass stem density, $N$. However, when $N$ exceeds the limiting value, $N$ req (equation (15)), an increase in stem density has only a minimal impact on suspended sediment concentrations and associated light attenuation.

Z. marina is typically found at depths in the range from 1 to $10 \mathrm{~m}$, with light availability limiting the lower depth limit [Duarte, 1991]. In the case of Hog Island Bay, using $1 \mathrm{~m}$ as the shallow depth growth limit for Z. marina, $23 \%$ of the area deeper than 
$1 \mathrm{~m}$ is found to be bistable, while seagrass beds are stable in $51 \%$ of the bay. The remaining $26 \%$ of the bay is unable to sustain seagrass.

\subsection{Effect of sediment grain size}

Bed sediment in Hog Island Bay is fine sand to fine silt with a D50=74 $\mu \mathrm{m}$ [Lawson et al., 2007]. Lagoons with finer bottom sediment exhibit higher suspended sediment concentrations at low water depths with no significant change in suspended sediment concentrations at water depths $>4 \mathrm{~m}$ due to the reduction of wave shear stress as water depth increases. This implies that sediment grain size is important at low water depths where wave action dominates bed shear stress. With a significantly finer bed, e.g. medium silt, $\mathrm{D} 50=15 \mu \mathrm{m}$, the system is bistable from the shallowest water depth of 1.15 m that can be investigated by this model (due to the submergence requirements discussed in $\S 2$, Figure 3), to $3.6 \mathrm{~m}$ (Figure 6). In the case of coarser bed sediments, suspended sediment concentrations are smaller and the transition from stable seagrass beds to bistable seagrass cover-bare sediment conditions occurs in deeper waters.

\subsection{Effect of Eutrophication}

Increasing the levels of $c h l a$ to reflect eutrophication due to increased nutrient loading causes a decrease in the depths at which the bistable transition occurs due to an increase in background water column turbidity (Figure 7). Values of chl $a$ in Hog Island Bay typically range from 0 to $9 \mathrm{mg} \mathrm{m}^{-3}$ [Lawson et al., 2007]. A set of simulations using different constant values of chl $a$ within this range (Figure 8) shows that the bistable 
transition zone changes from the water depth range of $2.3-3.6 \mathrm{~m}$ to $1.2-1.6 \mathrm{~m}$. The bistable transition zone reaches the minimum model-resolved water depth limit of $1.6 \mathrm{~m}$ at $c h l a$ concentrations of $5 \mathrm{mg} \mathrm{m}^{-3}$. When chl $a$ exceeds $12 \mathrm{mg} \mathrm{m}^{-3}$, the maximum measured value of chl $a$ in Hog Island Bay, the bistability range disappears and the system exhibits only a single stable state that supports no seagrass.

\subsection{Effect of water temperature}

Water temperature has an important influence on photosynthesis and respiration rates, thereby potentially exerting a control on the stability and bistability of the system. The conditions that determine light stress for seagrass depend on temperature ( $\S 2.6$ ). When chl $a$ is set to $0 \mathrm{mg} \mathrm{m}^{-3}$ bistable dynamics are observed for water depths in the range 2.2-3.6 m under current temperature conditions (i.e., using water temperature records from Hog Island Bay) (Figure 8). With a $3{ }^{\circ} \mathrm{C}$ increase in water temperature, this bistable range shifts to $1.4-2.7 \mathrm{~m}$. A $5{ }^{\circ} \mathrm{C}$ increase makes the system bistable for water depths below $2.1 \mathrm{~m}$. In this case, the stable vegetated state may exist only in conjunction with the alternate stable state of bare bed sediment. In contrast, decreasing the temperature favors growth and shifts the bistable transition zone to deeper water.

\subsection{Edge effects}

While this model does not resolve the horizontal dimension, the approach allows calculation of vertical profiles of diffusivity, sediment concentrations and light attenuation at varying distances from the edges of a seagrass meadow. Suspended 
sediment concentrations decrease as a function of distance from the edges of the meadow, with shoot density affecting the amount and rate of attenuation with depth into the meadow (Figure 9). Shoot densities of 100 shoots $\mathrm{m}^{-2}$ with a $30 \mathrm{~cm}$ canopy height reduce suspended concentrations by $17 \%$ at $1 \mathrm{~m}$ distance from the edge of the meadow while 500 shoots $\mathrm{m}^{-2}$ reduce suspended sediment concentrations by $96 \%$. For the case of 1000 shoots $\mathrm{m}^{-2}$, the canopy at $1 \mathrm{~m}$ distance from the edge has reduced suspended sediment concentrations by $99 \%$ when compared to the bare sediment. Closer to the edge of the meadow, however, the reduction is not as significant, with 1000 shoots $\mathrm{m}^{-2}$ reducing suspended sediment concentrations by $70 \%$.

\section{Discussion}

The results of this study shed light on the stability and bistability of seagrass meadows in shallow coastal lagoon ecosystems and their sensitivity to changing environmental conditions. Hog Island Bay, the focus site for this study, currently exhibits conditions favorable for the growth and maintenance of seagrass over most of the Bay. However, a change in light and temperature conditions that could be expected from climate change or eutrophication can induce bistability in much of the system. In the bistable regime, both vegetated and bare sediment conditions are possible stable states and the dynamics tend toward either one of these states depending on the initial seagrass cover. This shift from stable to bistable dynamics has profound implications for coastal ecosystems as a reduction in seagrass cover has a negative impact on water quality and the provision of habitat for fauna [van der Heide et al., 2007]. 
Our model shows that the stability and bistability of seagrass meadows in coastal lagoons such as Hog Island Bay depend on the environmental controls of water depth, temperature and light attenuation as it is influenced by phytoplankton concentrations and suspended sediments. Future sea-level rise in the region of the VCR lagoons is estimated at 3.6 to $10 \mathrm{~mm} \mathrm{yr}^{-1}$ [Najjar et al., 2000]. Even small depth changes in this shallow system $(0.1 \mathrm{~m})$ predicted over 30 years can have profound effects on light availability and seagrass survival, in large part because of the importance of sediment suspension on light attenuation and much of the bay will fall into a bistable regime. The negative impact of sea-level rise and increased water depth is partially mitigated by a secondary effect that benefits seagrass growth through a decrease in wave generated shear stress and hence turbidity. Eutrophication scenarios are expected to increase light attenuation by enhancing algal growth in the water column and on seagrass blades [McGlathery et al., 2007]. Our model gives a conservative estimate of eutrophication effects on seagrass cover and the change in stability of the system, as it only incorporates a modest increase in water column chlorophyll. Light attenuation by epiphytes on seagrass blades and benthic macroalgae can be equally important in shallow coastal systems [Hauxwell et al., 2001]. Regional climate change scenarios predict a $1.3{ }^{\circ} \mathrm{C}$ change in sea-surface temperatures over the next 30 years [Najjar et al., 2000]. Due to the larger effect of temperature on respiration than on photosynthesis in Z. marina, this increase in sea surface temperature will shift the bistable range to shallower depths with more of the bay unable to sustain seagrass. 
Although suspended sediment concentration is currently the primary factor controlling light attenuation in Hog Island Bay in its current low-nutrient state [Lawson et al., 2007],this control would be diminished if seagrass restoration was successful throughout the bay and a dense seagrass canopy covers the sediment surface. In this case, eutrophication induced increases in phytoplankton chl $a$ in the water column becomes the primary factor controlling light attenuation. Even a relatively moderate chl a concentration of $12 \mathrm{mg} \mathrm{m}^{-3}$, as long as it is sustained throughout the year, does not allow for conditions favoring seagrass growth in Hog Island Bay; a smaller constant value of 2 $\mathrm{mg} \mathrm{m}^{-3}$ induced bistability for $20 \%$ of the bay. Boynton et al. [1996] report water column chl a concentrations for the more eutrophic Maryland lagoons ranging from 20 $70 \mathrm{mg} \mathrm{m}^{-3}$, with summertime averages of $10-30 \mathrm{mg} \mathrm{m}^{-3}$.

Our model indicates that, like warming trends, eutrophication would shift the bistable range of seagrasses towards shallower water depths. This is consistent with previous large-scale surveys linking the depth distribution of $Z$. marina to eutrophication (measured as water column total nitrogen or chlorophyll concentrations; Nielsen et al [2002]). Because chl $a$ and CDOM have important effects on the bistable range, temporal changes in the concentration of chl $a$ and CDOM should be incorporated in future models.

The disappearance of the stable vegetated state in deeper water in scenarios that reflect changes related to both climate and eutrophication effects indicates that bare sediment conditions are the only stable state in the deeper parts of the bay. The emergence of bistable dynamics in shallow waters limits the resilience of seagrass beds in 
areas with low water depths. In fact, in these conditions the system could abruptly and irreversibly lose its seagrass beds. In this case, the bed would be susceptible to other physical processes not accounted for by this model, including bed scouring and associated changes in water depth, which would, in turn, modify currents and waves [e.g., Fagherazzi et al., 2005; Fagherazzi and Wiberg, 2009].

Some limitations of the methods used in this study need to be acknowledged. First, the model presented here provides a one-dimensional representation of sediment transport and deposition in the vertical direction within a seagrass meadow of varying shoot densities. Thus, important processes such as lateral transport of sediment are neglected. Advection and dispersion of sediment from barren sediment areas within the bay is a more likely source of suspended sediment above and within the canopy than is the bed below the canopy at shoot densities $>250$ shoots $\mathrm{m}^{-2}$. This implies that the suspended sediment dynamics at the edge of seagrass meadows are important to the growth and maintenance of the meadow. These three dimensional dynamics of suspended sediment cannot be investigated with the modeling framework developed in this study.

Second, a parameterization of flow in extremely sparse vegetation remains an important issue in environmental fluid dynamics [Luhar et al., 2008]. The approach utilized in this model treats the transition as a weighted average of two extremes with an increase in shoot density affecting turbulent diffusivity and the shape of the velocity profile. While this is a good first approximation, some measurements have shown an increase in resuspension at low shoot densities [Lawson et al., 2007] implying a more complicated transition than the one used in this study. 
Third, several aspects of seagrass growth and architecture were simplified in the model and could be further developed in future modeling efforts. The use of a yearly specific growth rate allows for a general understanding of vegetation growth and of the existence of alternate stable states in seagrass ecosystems. To simplify and explore feedbacks, the canopy height and shoot density were considered constant throughout the year, without accounting for important seasonal variations. Such variability implies greater susceptibility to light deficit during low density and low foliage time periods. Running the model with lower canopy heights would further limit the existence of stable vegetated conditions in deep water (i.e., the bistability range would be shifted towards shallower water) due to the decreased influence of the canopy on sediment resuspension. There was no inclusion of a rhizome biomass store which would allow for resilience of the seagrass under adverse conditions. Similarly, there was no incorporation of storm removal of biomass or other temporal variability in the plant morphology. Adding a timedependent model for seagrass growth and loss involving both above-ground and belowground biomass is needed to fully investigate the stability of the system. However, including a temporal growth model of seagrass would add additional parameters [Bocci et al., 1997; Zharova et al., 2001], not all of which are well constrained.

Direct grazing on seagrasses is not significant in temperate seagrass ecosystems as it is in tropical ecosystems, and so this is not an important factor in the accuracy of the model for these temperate lagoons. Previous work [McGlathery et al. 2001] has shown that the water column is typically net heterotrophic, except for short periods in midsummer. Grazing on phytoplankton populations would increase the accuracy of the model 
in some more nutrient-enriched systems, however, the coastal bays of Virginia are nutrient-poor and phytoplankton populations are extremely low, so that including grazing or nutrient competition in the model for the Virginia coastal bays would not significantly increase its accuracy.

Lastly, improvements in characterizing the light environment could be made, particularly with regards to incorporating grain size effects of light absorption, as both chl $a$ and CDOM are low in this system. A more sophisticated light attenuation model [Biber et al., 2008] that accounts for the nonlinearity of the attenuation process would improve the characterization of the light environment.

The model presented here allows for a physically-based resolution of canopy bending and the feedback of canopy structure on the fluid dynamics. This approach is well suited to investigate sediment dynamics and the corresponding impact on the light environment. This modeling of the light environment along with the temperature conditions allows for sensible estimation of the specific net growth/loss rates of seagrass and for investigation of the conditions controlling stability and bistability of seagrass ecosystems in shallow bays.

\section{Conclusion}

In general, the results of this modelling effort point toward the conditions that control the stability and bistability of seagrass meadows in shallow bays. The results show how the presence or absence of seagrass depends on water depth, sediment size, 
water temperature and degree of eutrophication. We found that (i) the response of the system to sea-level rise is highly non-linear and seagrass meadows located in relatively deep waters are likely to undergo abrupt shifts to a bare sediment state; (ii) regions of shallow coastal lagoons with finer sediment are more likely bistable than regions with coarser sediment; (iii) increases in both temperature and eutrophication lead to increases in the proportion of shallow bays that exhibit bistable behavior, with a consequent decrease in resilience. Moreover, both eutrophication and warming would cause the migration of seagrass toward shallower parts of the bay, leaving the deeper sediment bed without seagrass cover.

Partial support of this study was provided by the Virginia Coast Reserve LTER project, which was supported by National Science Foundation grants BSR-8702333-06, DEB9211772, DEB-9411974, DEB-0080381 and DEB-0621014 


\section{Appendix A: Method used for the iterative calculation of canopy bending}

The bending angle, $\theta$ (with respect to the vertical direction), of the uppermost stem segment was calculated from the force moment balance equation

$$
\frac{1}{2} C_{d} \rho w U^{2} \frac{l^{2}}{2} \cos ^{2} \theta+\frac{1}{2} C_{l} \rho U^{2} \frac{l^{2}}{2} \sin ^{2} \theta-\left(\rho-\rho_{p}\right) g w \delta \frac{l^{2}}{2} \sin \theta=0
$$

where $C_{d}, C_{l}, C_{f}$ are the coefficients for drag, lift and skin friction; $w, \delta, l$ are the width, thickness and length of the segment and $U$ is the velocity acting on the midpoint of the segment. $\rho_{p}$ is the density of the plant and set to $700 \mathrm{~kg} / \mathrm{m}^{3}$.

The drag coefficient of the blade segment to the flow was modeled to vary linearly from 1.2 to 0 for $0^{\circ} \leq \theta \leq 90^{\circ}$. Treating the blade segment as an airfoil, the lift coefficient was varied linearly from 0.8 to -0.8 for $15^{\circ} \leq \theta \leq 105^{\circ}$. For blade segments with angles outside this range the lift coefficient was assumed to be zero. The skin friction coefficient was calculated based on the blade segment Reynolds number, $R_{e}=\frac{u w \rho}{\mu}$, as $C_{l}=0.074 R_{e}^{-\frac{1}{5}} \quad[$ Abdelrhman, 2007].

Effects of the ensemble of blades on the lift drag and skin friction coefficients were incorporated assuming a linear density-dependent sheltering effect with the above coefficients being reduced by a factor of 3 at shoot densities of 2000 . Abdelherman[2007] used a reduction factor of 2 and reduction in terrestrial canopies due to sheltering have been found in the range of 3 to 4[Abdelrhman, 2007]. 
Once the bending angle was determined the forces acting on the uppermost segment were calculated as

$F_{x}=-\frac{1}{2} C_{d} \rho w l U^{2} \cos \theta-\frac{1}{2} C_{f} \rho w l U^{2} \sin ^{3} \theta$

(A2)

$$
F_{z=} \frac{1}{2} C_{l} \rho w l U^{2} \sin \theta-\left(\rho-\rho_{p}\right) g w \delta l-\frac{1}{2} C_{f} \rho w l U^{2} \sin ^{2} \theta \cos \theta
$$

and the deflection angle of the subsequent segment, $i$, was calculated accounting for force moments as in equation (A1) and of the effect of the reaction force of the segment, $i-1$, above exerted through the upper node of the segment, $i$. Thus, for the $i$-th segment the equilibrium equation becomes

$$
\begin{gathered}
\frac{1}{2} C_{d} \rho w U^{2} \frac{l^{2}}{2} \cos ^{2} \theta+\frac{1}{2} C_{l} \rho U^{2} \frac{l^{2}}{2} \sin ^{2} \theta-\left(\rho-\rho_{p}\right) g w \delta \frac{l^{2}}{2} \sin \theta+F_{x_{i-1}} l \cos \theta-F_{z_{i-1}} l \sin \theta=0 \\
F_{x}=-\frac{1}{2} C_{d} \rho w l U^{2} \cos \theta-\frac{1}{2} C_{f} \rho w l U^{2} \sin ^{3} \theta-F_{x_{i-1}} \\
F_{z=\frac{1}{2}} C_{l} \rho w l U^{2} \sin \theta-\left(\rho-\rho_{p}\right) g w \delta l-\frac{1}{2} C_{f} \rho w l U^{2} \sin ^{2} \theta \cos \theta-F_{z_{i-1}}
\end{gathered}
$$

The segment corresponding to the seagrass sheath was considered immobile in all flow conditions and maintained zero deflection in any flow. Numerical solution of the coupled deflected canopy and flow equations, require iteration because, as it gets 
deflected, each segment experiences a different flow velocity, which, in turn, changes the forces acting on the segment. 


\section{References}

Abdelrhman, M. A. (2007), Modeling coupling between eelgrass Zostera marina and water flow, Mar. Ecol.-Prog. Ser., 338, 81-96.

Bach, H. K. (1993), A dynamic model describing the seasonal variations in growth and the distribution of eel grass (Zostera Marina), Ecological Modelling, 65(1-2), 31-50.

Biber, P. D., C. L. Gallegos, and W. J. Kenworthy (2008), Calibration of a bio-optical model in the North River, North Carolina (Albemarle-Pamlico sound): A tool to evaluate water quality impacts on seagrasses, Estuaries and Coasts, 31(1), 177-191.

Bocci, M., G. Coffaro, and G. Bendoricchio (1997), Modelling biomass and nutrient dynamics in eelgrass (Zostera marina L.): applications to the Lagoon of Venice (Italy) and Oresund (Denmark), Ecological Modelling, 102(1), 67-80.

Boynton, W. R., J. D. Hagy, L. Murray, C. Stokes, and W. M. Kemp (1996), A comparative analysis of eutrophication patterns in a temperate coastal lagoon, Estuaries, 19(2B), 408-421. Campbell G., a. N. J. (1998), Introduction to Environmental Biophysics, 2nd ed., Springer, New York.

Cazenave, A., A. Lombard, and W. Llovel (2008), Present-day sea level rise: A synthesis, Comptes Rendus Geoscience, 340(11), 761-770.

Dennison, W. C., R. J. Orth, K. A. Moore, J. C. Stevenson, V. Carter, S. Kollar, P. W.

Bergstrom, and R. A. Batiuk (1993), Assessing water-quality with submersed aquatic vegetation Bioscience, 43(2), 86-94.

Dietrich, W. E. (1982), Settling velocity of natural particles, Water Resources Research, 18(6), $1615-1626$.

Duarte, C. M. (1991), Seagrass depth limits, Aquatic Botany, 40(4), 363-377. 
Fagherazzi, S., and P. L. Wiberg (2009), Importance of wind conditions, fetch, and water levels on wave-generated shear stresses in shallow intertidal basins, J. Geophys. Res., 114, F03022, doi:10.1029/2008JF001139.

Fagherazzi S., Carniello L., D'Alpaos L., Defina A. (2006), Critical bifurcation of shallow microtidal landforms in tidal flats and salt marshes Proceeding of the National Academy of Sciences, 103 (22): 8337-8341.

Folkard, A. M. (2005), Hydrodynamics of model Posidonia oceanica patches in shallow water, Limnology and Oceanography, 50(5), 1592-1600.

Gacia, E., and C. M. Duarte (2001), Sediment retention by a mediterranean Posidonia oceanica meadow: The balance between deposition and resuspension, Estuarine Coastal and Shelf Science, 52(4), 505-514.

Gacia, E., C. M. Duarte, N. Marba, J. Terrados, H. Kennedy, M. D. Fortes, and N. H. Tri (2003), Sediment deposition and production in SE-Asia seagrass meadows, Estuarine Coastal and Shelf Science, 56(5-6), 909-919.

Ghisalberti, M., and H. Nepf (2006), The structure of the shear layer in flows over rigid and flexible canopies, Environmental Fluid Mechanics, 6(3), 277-301.

Gunderson, L. H. (2000), Ecological resilience - in theory and application, Annual Review of Ecology and Systematics, 31, 425-439.

Harris, C. K., and P. L. Wiberg (1997), Approaches to quantifying long-term continental shelf sediment transport with an example from the Northern California STRESS mid-shelf site, Continental Shelf Research, 17(11), 1389-1418.

Hauxwell, J., J. Cebrian, C. Furlong, and I. Valiela (2001), Macroalgal canopies contribute to eelgrass (Zostera marina) decline in temperate estuarine ecosystems, Ecology, 82(4), 1007-1022. Havens, K. E., J. Hauxwell, A. C. Tyler, S. Thomas, K. J. McGlathery, J. Cebrian, I. Valiela, A. D. Steinman, and S. J. Hwang (2001), Complex interactions between autotrophs in shallow 
marine and freshwater ecosystems: implications for community responses to nutrient stress, Environmental Pollution, 113(1), 95-107.

Hayden, B. P. (1999), Climate change and extratropical storminess in the United States: An assessment, Journal of the American Water Resources Association, 35(6), 1387-1397.

Heiss, W. M., A. M. Smith, and P. K. Probert (2000), Influence of the smalt intertidal seagrass Zostera novazelandica on linear water flow and sediment texture, New Zealand Journal of Marine and Freshwater Research, 34(4), 689-694.

Keller, C. F. (2009), Global warming: a review of this mostly settled issue, Stoch. Environ. Res. Risk Assess., 23(5), 643-676.

Lawson, S. E., P. L. Wiberg, K. J. McGlathery, and D. C. Fugate (2007), Wind-driven sediment suspension controls light availability in a shallow coastal lagoon, Estuaries and Coasts, 30(1), 102-112.

Lepoint, G., F. Nyssen, S. Gobert, P. Dauby, and J. M. Bouquegneau (2000), Relative impact of a seagrass bed and its adjacent epilithic algal community in consumer diets, Marine Biology, 136(3), 513-518.

Lightbody, A. F., and H. M. Nepf (2006), Prediction of near-field shear dispersion in an emergent canopy with heterogeneous morphology, Environmental Fluid Mechanics, 6(5), 477488.

Luhar, M., J. Rominger, and H. Nepf (2008), Interaction between flow, transport and vegetation spatial structure, Springer.

McGlathery, K. J., K. Sundback, and I. C. Anderson (2007), Eutrophication in shallow coastal bays and lagoons: the role of plants in the coastal filter, Mar. Ecol.-Prog. Ser., 348, 1-18.

Moore, K. A., and J. C. Jarvis (2008), Environmental Factors Affecting Recent Summertime Eelgrass Diebacks in the Lower Chesapeake Bay: Implications for Long-term Persistence, $J$. Coast. Res., 135-147. 
Najjar, R. G., H. A. Walker, P. J. Anderson, E. J. Barron, R. J. Bord, J. R. Gibson, V. S. Kennedy, C. G. Knight, J. P. Megonigal, R. E. O'Connor, C. D. Polsky, N. P. Psuty, B. A. Richards, L. G. Sorenson, E. M. Steele, and R. S. Swanson (2000), The potential impacts of climate change on the mid-Atlantic coastal region, Climate Research, 14(3), 219-233.

Nielsen, S. L., K. Sand-Jensen, J. Borum, and O. Geertz-Hansen (2002), Depth colonization of eelgrass (Zostera marina) and macroalgae as determined by water transparency in Danish coastal waters, Estuaries, 25(5), 1025-1032.

Nixon, S., B. Buckley, S. Granger, and J. Bintz (2001), Responses of very shallow marine ecosystems to nutrient enrichment, Human and Ecological Risk Assessment, 7(5), 1457-1481. Norkko, J., E. Bonsdorff, and A. Norkko (2000), Drifting algal mats as an alternative habitat for benthic invertebrates: Species specific responses to a transient resource, Journal of Experimental Marine Biology and Ecology, 248(1), 79-104.

Oertel, G., C. R. Carlson, and K. Overman. (2000), Hog Island Bay, Virginia Bathymetric Survey using Trimble DGPS and Innerspace Digital Fathometer.

Orth, R. J., M. L. Luckenbach, S. R. Marion, K. A. Moore, and D. J. Wilcox (2006), Seagrass recovery in the Delmarva Coastal Bays, USA, Aquatic Botany, 84(1), 26-36.

Pastres, R., D. Brigolin, A. Petrizzo, and M. Zucchetta (2004), Testing the robustness of primary production models in shallow coastal areas: a case study.

Sandjensen, K., and J. Borum (1991), Interactions among phytoplankton, periphyton, and macrophytes in temperate fresh-waters and estuaries, Aquatic Botany, 41(1-3), 137-175.

Sanford, L. P., and J. P. Y. Maa (2001), A unified erosion formulation for fine sediments, Marine Geology, 179(1-2), 9-23.

Scheffer, M., S. Carpenter, J. A. Foley, C. Folke, and B. Walker (2001), Catastrophic shifts in ecosystems, Nature, 413(6856), 591-596. 
Scheffer, M., and E. H. van Nes (2004), Mechanisms for marine regime shifts: can we use lakes as microcosms for oceans?, Progress in Oceanography, 60(2-4), 303-319.

Sfriso, A., and A. Marcomini (1997), Macrophyte production in a shallow coastal lagoon .1. Coupling with chemico-physical parameters and nutrient concentrations in waters, Marine Environmental Research, 44(4), 351-375.

Sfriso, A., T. Birkemeyer, and P. F. Ghetti (2001), Benthic macrofauna changes in areas of Venice lagoon populated by seagrasses or seaweeds, Marine Environmental Research, 52(4), 323-349.

Valiela, I., J. McClelland, J. Hauxwell, P. J. Behr, D. Hersh, and K. Foreman (1997), Macroalgal blooms in shallow estuaries: Controls and ecophysiological and ecosystem consequences, Limnology and Oceanography, 42(5), 1105-1118.

van der Heide, T., E. H. van Nes, G. W. Geerling, A. J. P. Smolders, T. J. Bouma, and M. M. van Katwijk (2007), Positive feedbacks in seagrass ecosystems: Implications for success in conservation and restoration, Ecosystems, 10(8), 1311-1322.

Verhagen, J. H. G., and P. H. Nienhuis (1983), A simulation-model of production, seasonalchanges in biomass and distribution of eelgrass (Zostera Marina) in lake Grevelingen, Mar. Ecol.Prog. Ser., 10(2), 187-195.

Viaroli, P., M. Bartoli, C. Bondavalli, R. R. Christian, G. Giordani, and M. Naldi (1996), Macrophyte communities and their impact on benthic fluxes of oxygen, sulphide and nutrients in shallow eutrophic environments, Hydrobiologia, 329(1-3), 105-119.

Wilson, J. B., and A. D. Q. Agnew (1992), Positive-feedback switches in plant-communities, Advances in Ecological Research, 23, 263-336.

Young, I. R., and L. A. Verhagen (1996), The growth of fetch limited waves in water of finite depth .1. Total energy and peak frequency, Coastal Engineering, 29(1-2), 47-78. 
Zharova, N., A. Sfriso, A. Voinov, and B. Pavoni (2001), A simulation model for the annual fluctuation of Zostera marina biomass in the Venice lagoon, Aquatic Botany, 70(2), 135-150. Zimmerman, R. C., J. L. Reguzzoni, and R. S. Alberte (1995), Eelgrass(Zostera Marina L) transplants in San Francisco Bay - Role of light availability on metabolism, growth and survival, Aquatic Botany, 51(1-2), 67-86. 
Figures

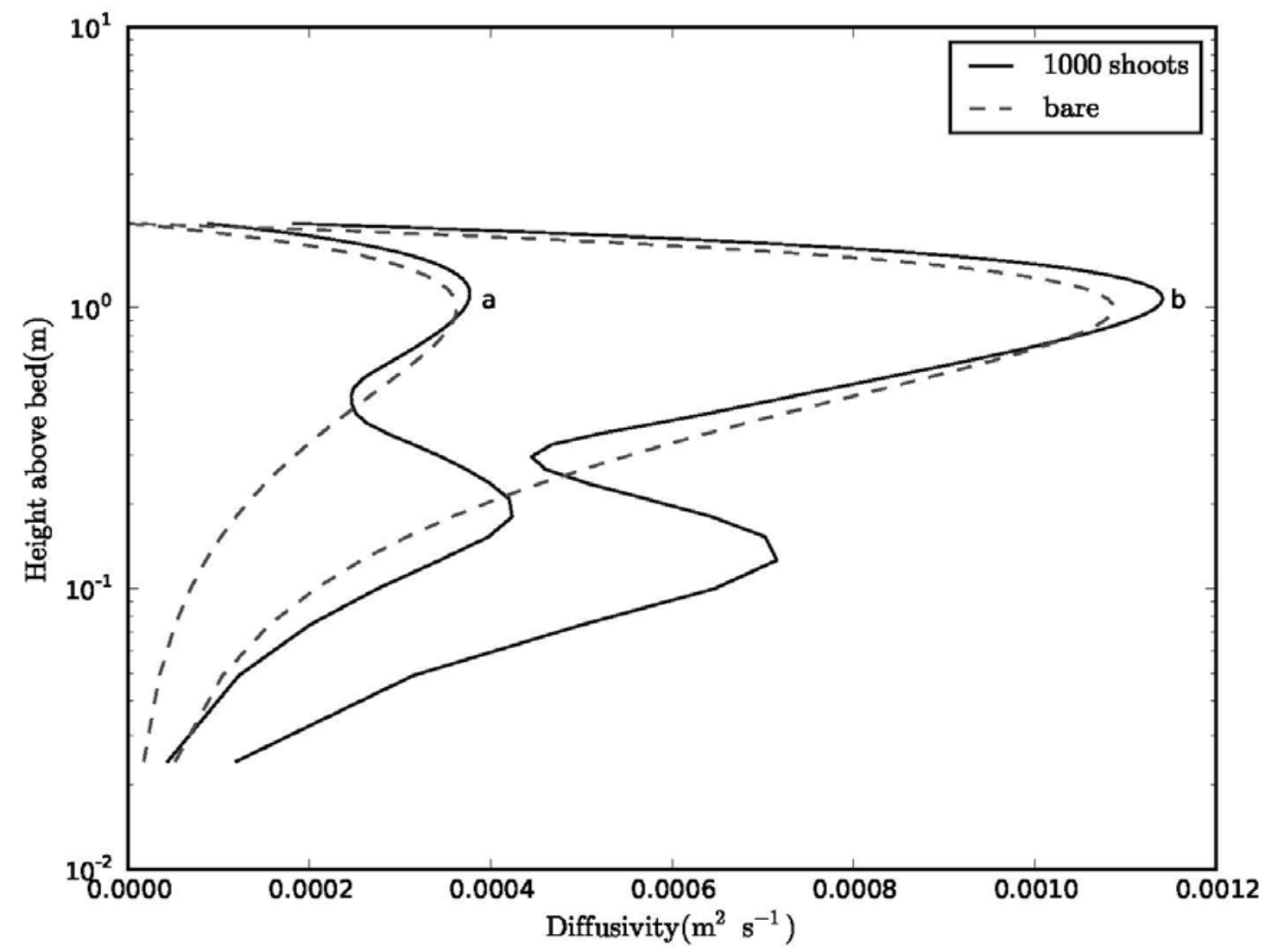

Figure 1: The enhancement of diffusivities within the shear layer when a dense canopy is present under currents of a) $0.05 \mathrm{~m} / \mathrm{s}$ and b) $0.15 \mathrm{~m} / \mathrm{s}$. 

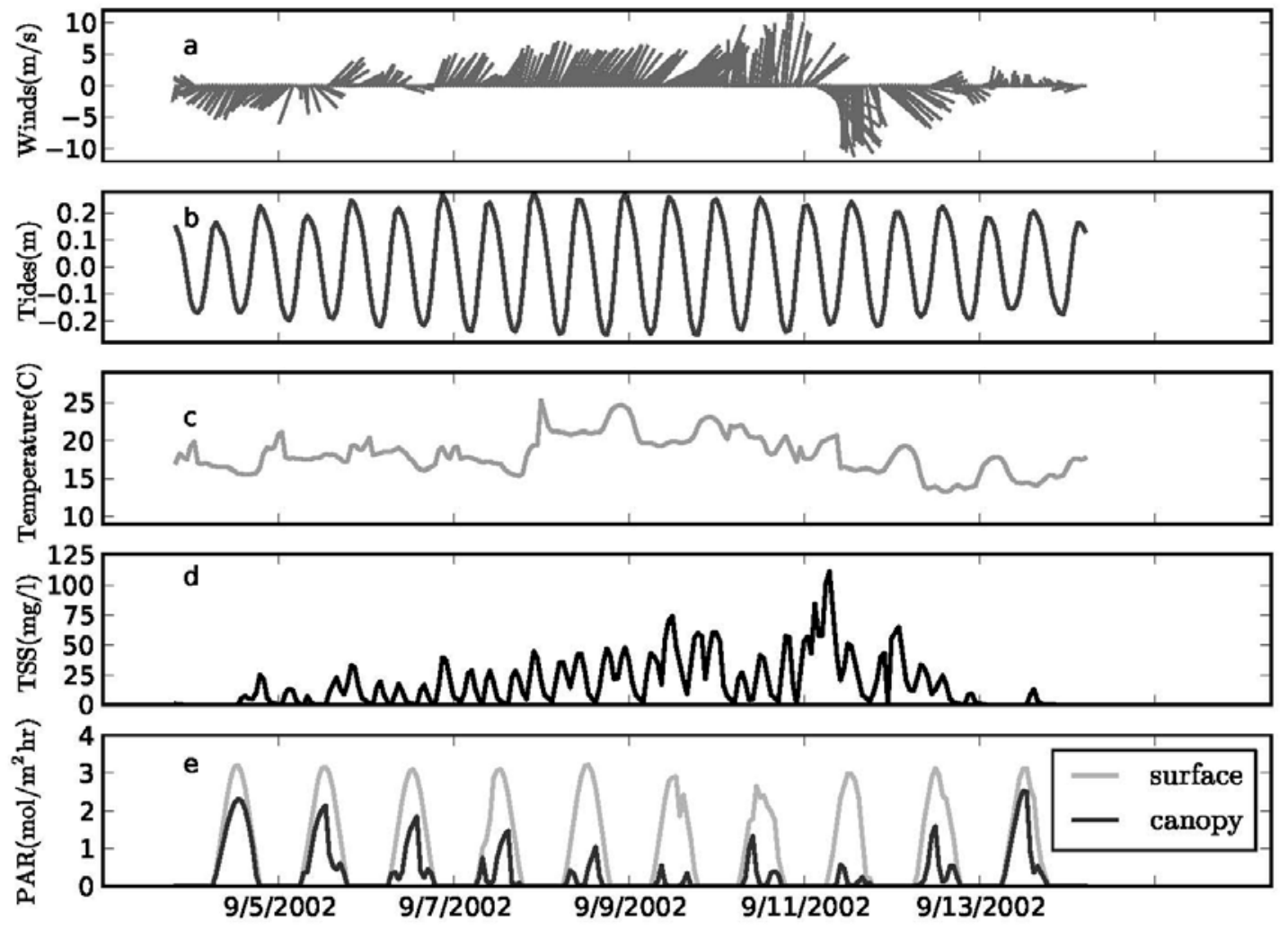

Figure 2: Subset of hourly measurements used in the model, including a) Wind speed (m/s) and direction at $5 \mathrm{~m}$ height. b) Tidal water level variation (m) around MSL from Red Bank. c) Water temperature ( ${ }^{\circ} \mathrm{C}$ ). Model simulations of d) total suspended sediment (mg/l). e) Comparison between PAR (mol m${ }^{-2} \mathrm{hr}^{-1}$ ) measurements from the VCRLTER flux tower at Fowling Point and modeled PAR( $\operatorname{mol~m}{ }^{-2} \mathrm{hr}^{-1}$ )reaching the top of the canopy due to light attenuation. 


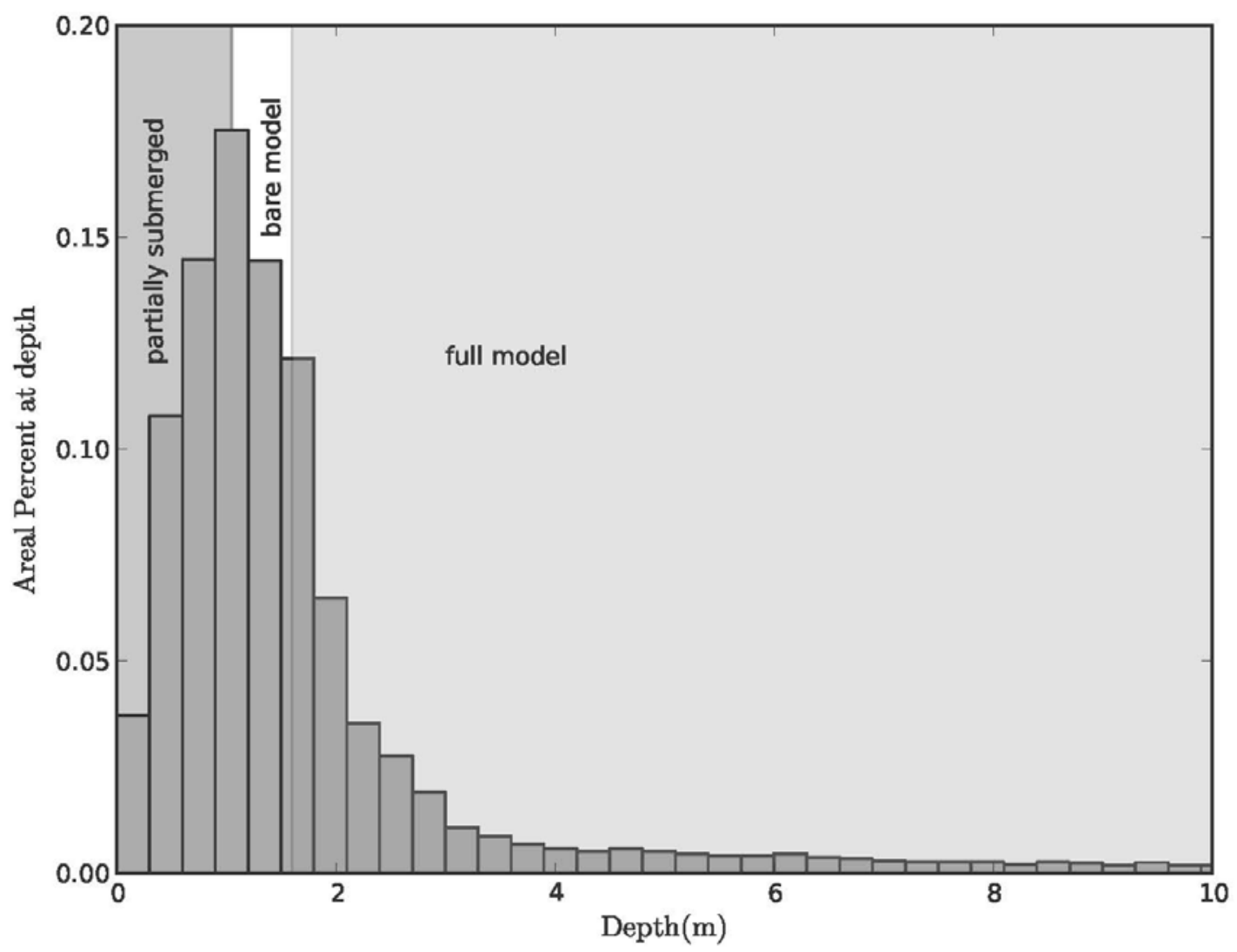

Figure 3: The distribution of depths in Hog Island Bay and the depths where the bare sediment model and the full model are applicable; the partially submerged area is at depths shallower than the tidal range such that full emergence of the seagrass would be expected at low tide. 

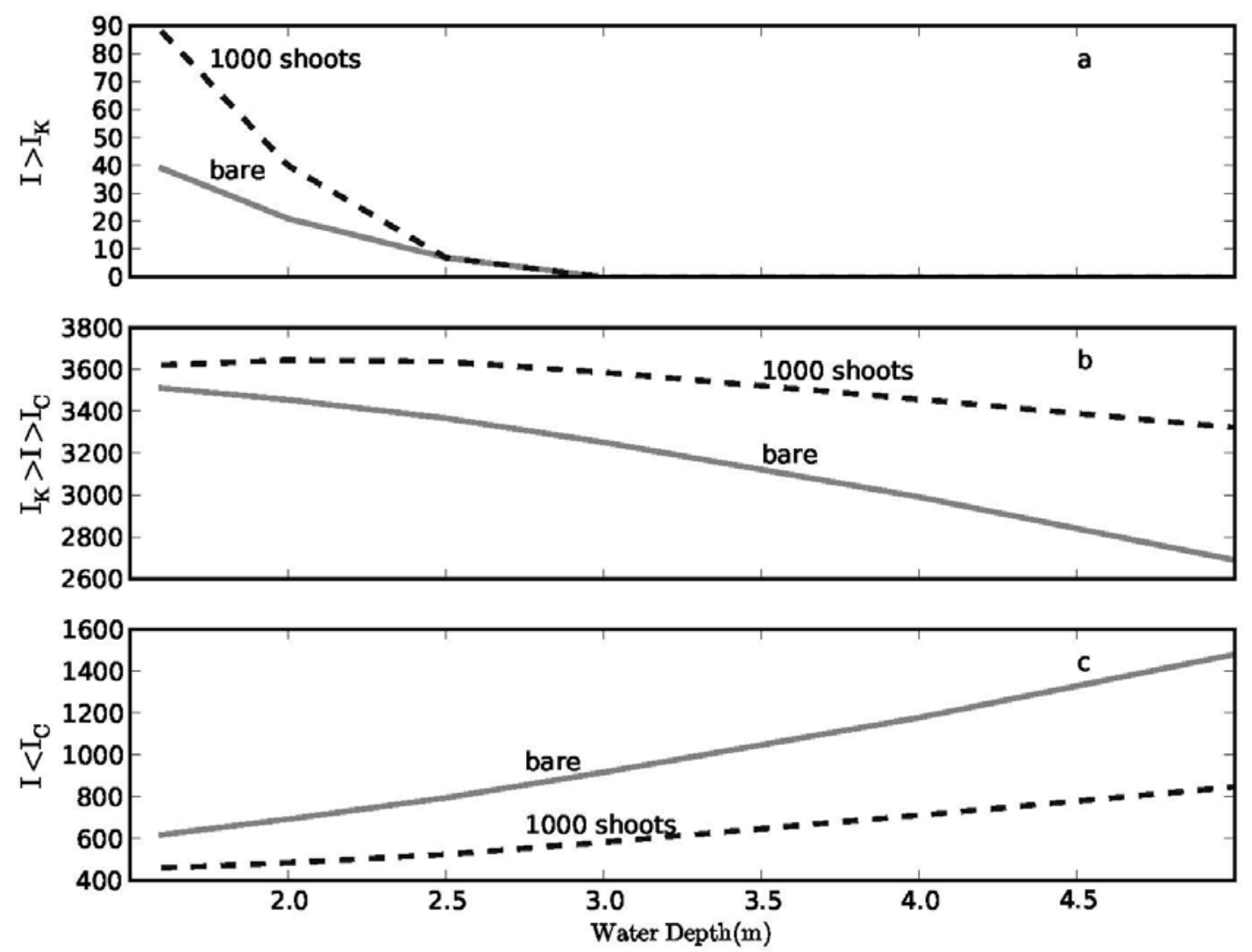

Figure 4: Total hours of a) saturation ,b) partial saturation, and c) compensation as a function of water depth and the presence or absence of seagrass. 


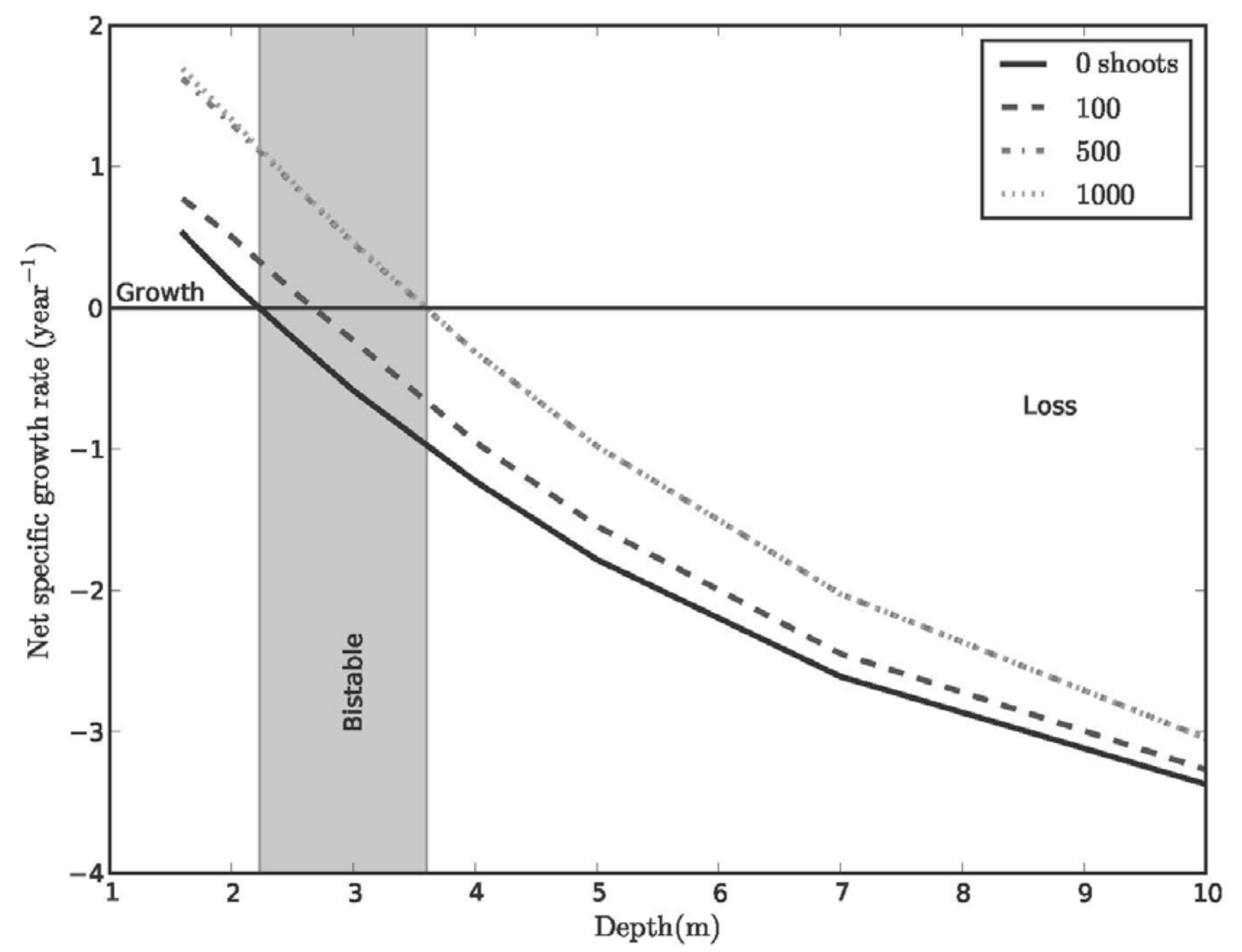

Figure 5: Specific growth rate as a function of depth for varying shoot densities. Conditions suitable/unsuitable for seagrass establishment and growth were evaluated by looking at the sign of the net annual growth rate (see $\S 2.6$ ). Positive (negative) values were associated with favorable (unfavorable) conditions for seagrass establishment and persistence. 

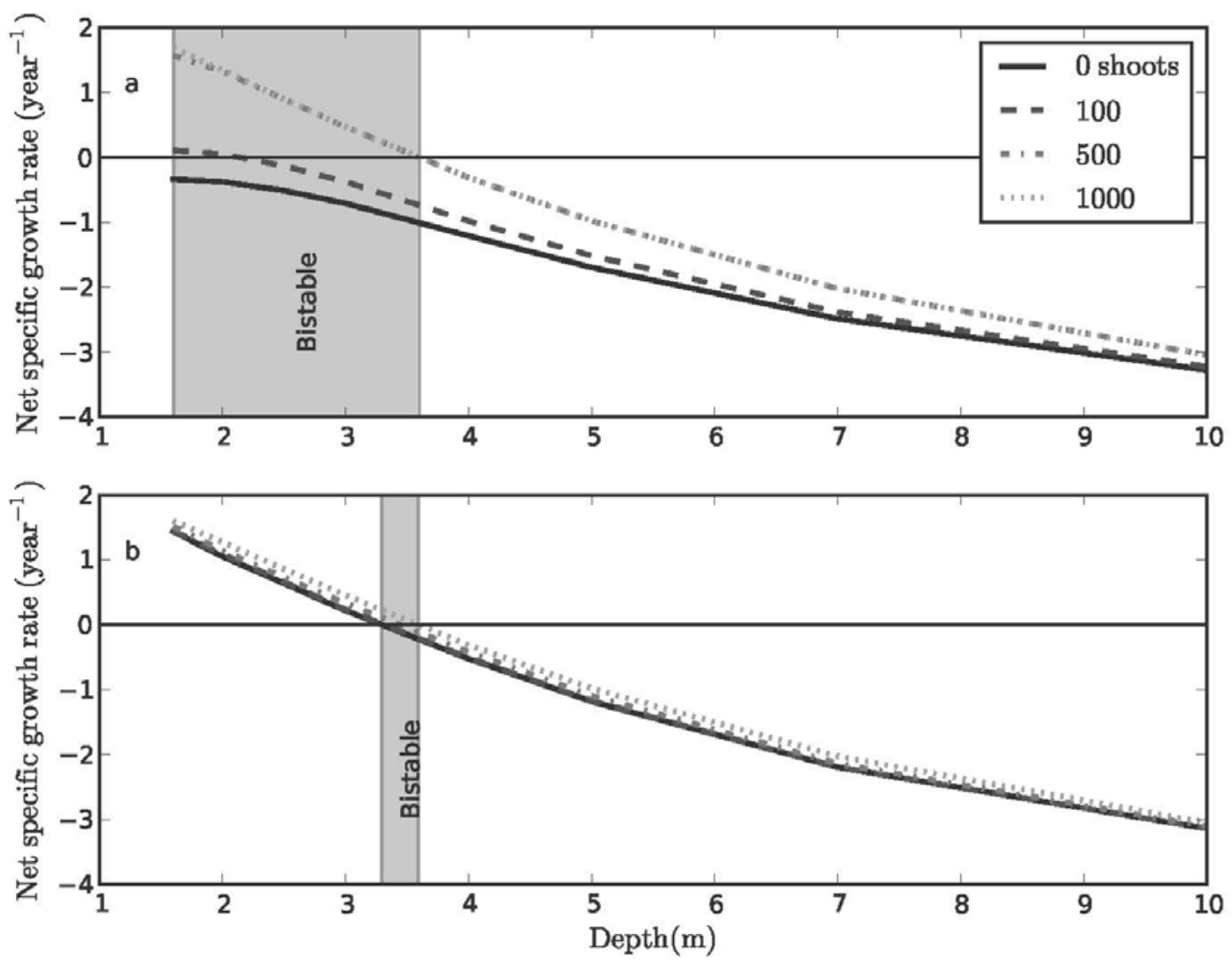

Figure 6: Yearly specific growth rate as a function of depth for varying shoot densities with a) medium silt sediment bed (mean $\varphi=5.5$, Table 1 ). b) Very fine grain sand sediment bed (mean $\varphi=3.5$, Table 2). 

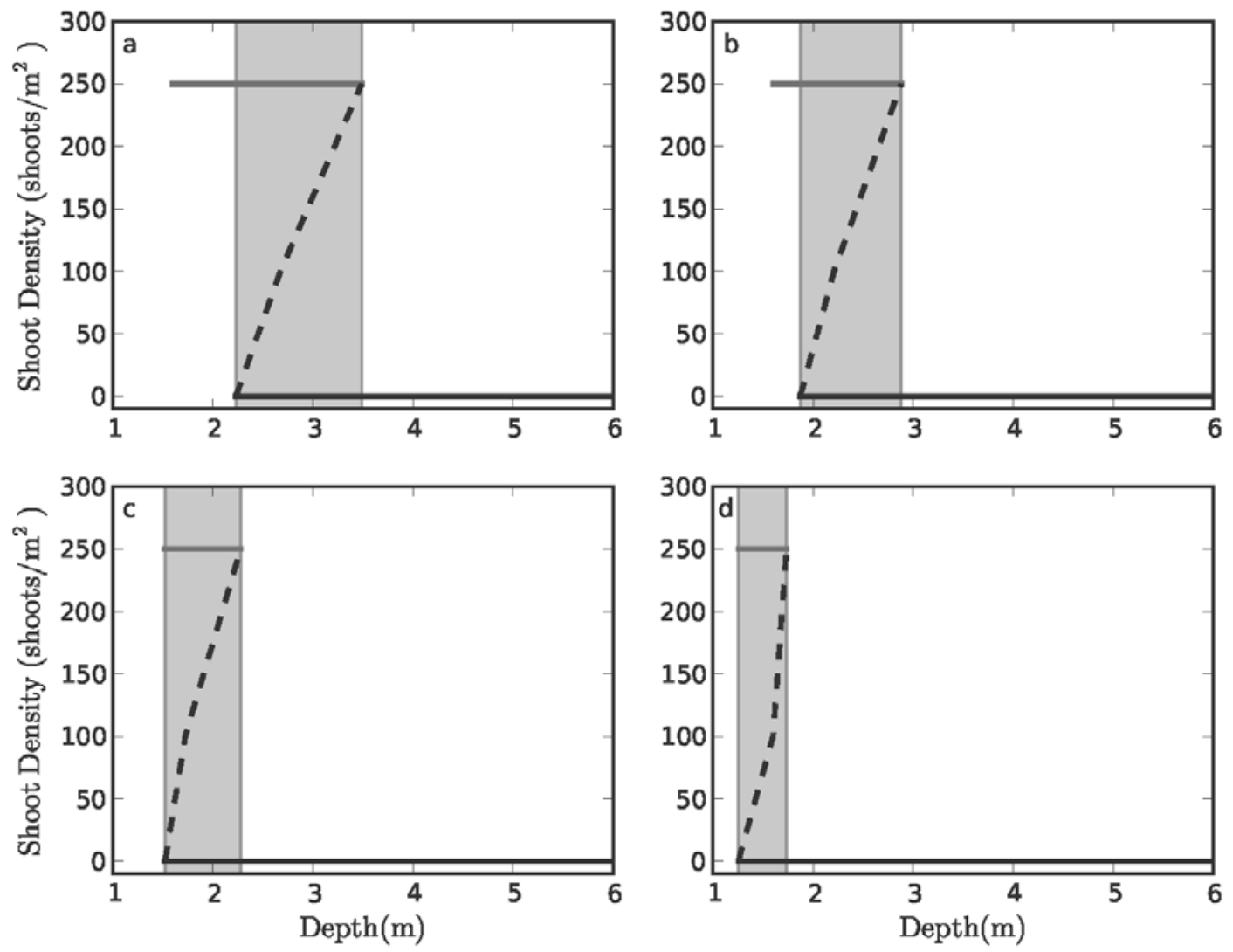

Figure 7: Changes in the region of bistable behavior due to eutrophication with chl $a$ equal to a) $0 \mathrm{mg} \mathrm{m}^{-3}$ b) $2 \mathrm{mg} \mathrm{m}^{-3}$ c) $5 \mathrm{mg} \mathrm{m}^{-3}$ d) $9 \mathrm{mg} \mathrm{m}^{-3}$. 

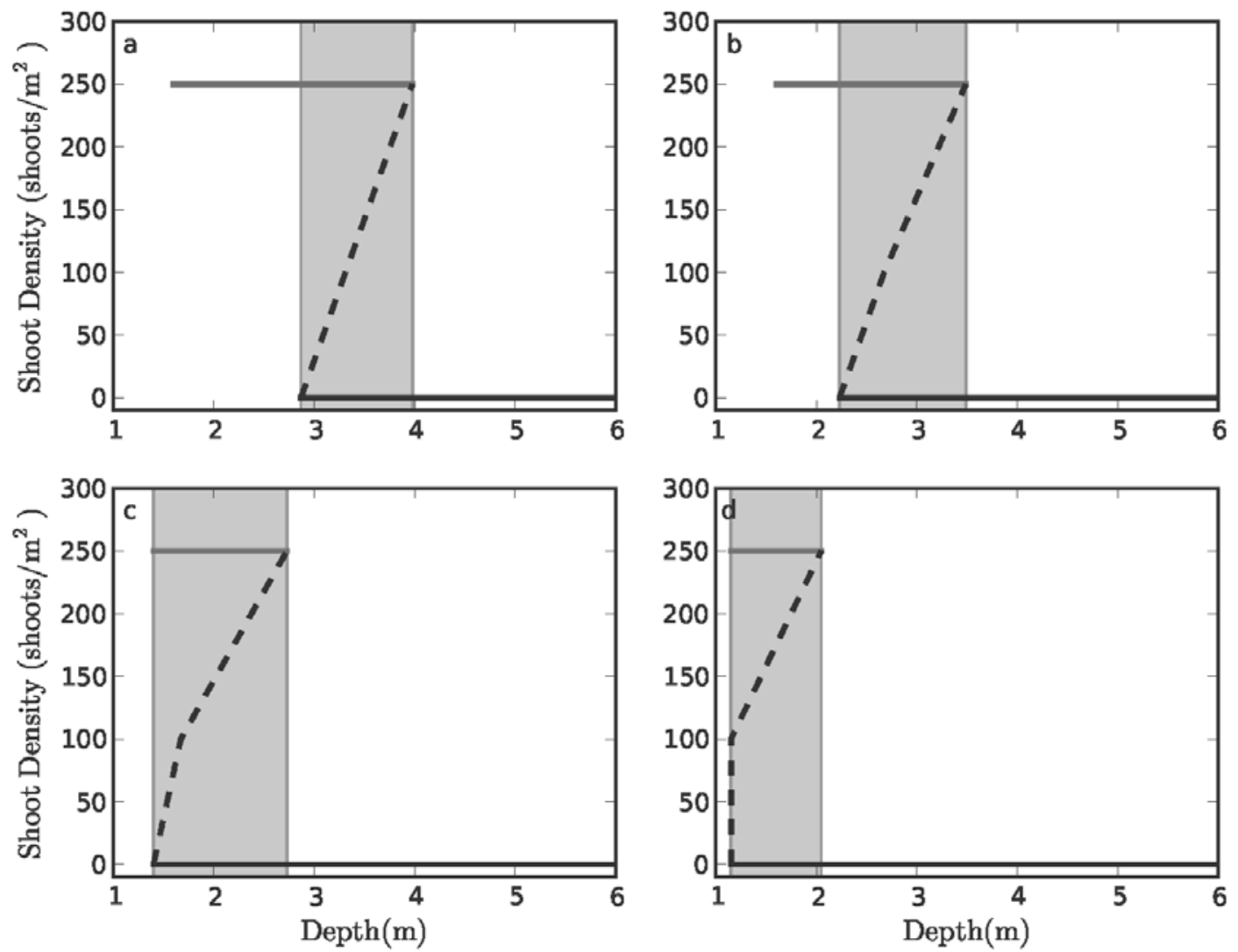

Figure 8: Changes in the region of bistable behavior with chl $a=0$ and water temperature changes of a) $-3{ }^{\circ} \mathrm{C}$, b) $0{ }^{\circ} \mathrm{C}$, c) $3{ }^{\circ} \mathrm{C}$ and, d) $5{ }^{\circ} \mathrm{C}$. 


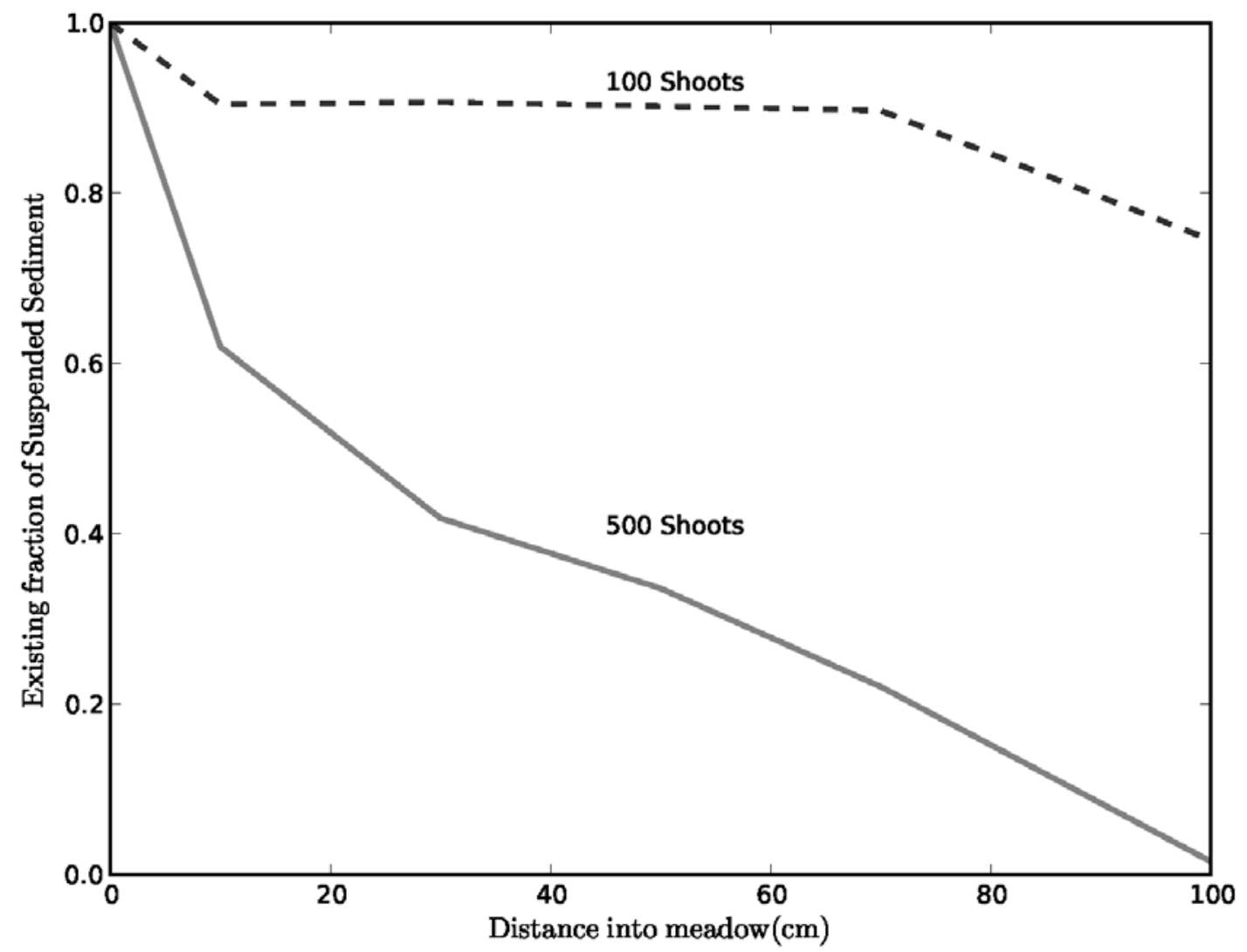

Figure 9: The existing fraction of suspended sediment as a function of distance into the meadow for 100 and 500 shoots $\mathrm{m}^{-2}$ at $2.5 \mathrm{~m}$ water depth. 


\section{Tables}

Table 1: Site specific values and modeled results.

\begin{tabular}{|c|c|c|c|c|c|}
\hline & Observed & Model & & & \\
\hline \multicolumn{6}{|l|}{$\begin{array}{l}\text { Bed grain } \\
\text { size } \\
\text { distributions }\end{array}$} \\
\hline$\varphi$ & $\%$ & $\varphi$ & $\begin{array}{l}\text { same as } \\
\text { VCR \% }\end{array}$ & finer \% & coarser \% \\
\hline 2.5 & 4 & 2.5 & 4 & 0 & 5 \\
\hline 3 & 10 & 3 & 10 & 0 & 20 \\
\hline 3.5 & 18 & 3.5 & 18 & 0 & 50 \\
\hline 4 & 32 & 4 & 32 & 0 & 20 \\
\hline 4.5 & 17 & 4.5 & 17 & 5 & 5 \\
\hline 5 & 10 & 5 & 10 & 20 & 0 \\
\hline 5.5 & 5 & 5.5 & 5 & 50 & 0 \\
\hline 6 & 3 & 6 & 3 & 20 & 0 \\
\hline \multirow[t]{2}{*}{6.5} & 1 & 6.5 & 1 & 5 & 0 \\
\hline & Observed & Model & & & \\
\hline $\begin{array}{l}\text { Shoot } \\
\text { densities }\end{array}$ & $\begin{array}{l}412-529 \text { shoots } \mathrm{m} \\
-2 .\end{array}$ & \multicolumn{4}{|c|}{ Set value ranging from $0-1000$ shoots $^{-2}$} \\
\hline $\begin{array}{l}\text { Depth of } \\
\text { meadows }\end{array}$ & $\begin{array}{l}\text { Up to } 2 \mathrm{~m} \text { water } \\
\text { depth relative to } \mathrm{MSL}\end{array}$ & \multicolumn{4}{|c|}{$\begin{array}{l}\text { Stable up to } 2.2 \mathrm{~m} \text {, bistable from } 2.2 \text { to } 3.6 \mathrm{~m} \text { water } \\
\text { depth relative to MSL }\end{array}$} \\
\hline $\begin{array}{l}\text { Average } \\
\text { annual chl } a\end{array}$ & $1.5-4.1 \mathrm{mg} \mathrm{m}^{-3}$ & \multicolumn{4}{|c|}{ Set value ranging from $0-12 \mathrm{mg} \mathrm{m}^{-3}$} \\
\hline $\begin{array}{l}\text { Light } \\
\text { attenuation } \\
\text { coefficient }\end{array}$ & $0.47-2.9 \mathrm{~m}^{-1}$ & \multicolumn{4}{|c|}{$0.28-2.7 \mathrm{~m}^{-1}$} \\
\hline
\end{tabular}


Table 2: Parameter values and sources.

\begin{tabular}{|c|c|c|}
\hline Parameter & Value and description & Source \\
\hline$\tau_{c r}$ & $\begin{array}{l}0.04\left(\mathrm{~Pa} \mathrm{~m}^{-2}\right) \text { is the critical shear } \\
\text { stress to erode sediment. }\end{array}$ & [Lawson et al., 2007] \\
\hline$T_{\text {opt }}$ & $\begin{array}{l}21^{\circ} \mathrm{C} \text { Optimum Photosynthetic } \\
\text { Temperature }\end{array}$ & $\begin{array}{l}\text { [Bach, 1993; Bocci et al., 1997; Pastres et al., } \\
\text { 2004; Verhagen and Nienhuis, 1983; Zharova } \\
\text { et al., 2001] }\end{array}$ \\
\hline$T_{\max }$ & $\begin{array}{l}34^{\circ} \mathrm{C} \text { Maximum Photosynthetic } \\
\text { Temperature }\end{array}$ & $\begin{array}{l}\text { [Bach, 1993; Bocci et al., 1997; Pastres et al., } \\
\text { 2004; Verhagen and Nienhuis, 1983; Zharova } \\
\text { et al., 2001] }\end{array}$ \\
\hline$I_{K 20}$ & $\begin{array}{l}2.8 \mu \text { mols } / \mathrm{m}^{2} \text { Saturation } \\
\text { irradiance at } 20^{\circ} \mathrm{C} \text { in PAR }\end{array}$ & $\begin{array}{l}\text { [Bach, 1993; Bocci et al., 1997; Pastres et al., } \\
\text { 2004; Verhagen and Nienhuis, 1983; Zharova } \\
\text { et al., 2001] }\end{array}$ \\
\hline$I_{C 20}$ & $\begin{array}{l}2.8 \mu \text { mols } / \mathrm{m}^{2} \text { Compensation } \\
\text { irradiance at } 20^{\circ} \mathrm{C} \text { in PAR }\end{array}$ & $\begin{array}{l}\text { [Bach, 1993; Bocci et al., 1997; Pastres et al., } \\
\text { 2004; Verhagen and Nienhuis, 1983; Zharova } \\
\text { et al., 2001] }\end{array}$ \\
\hline$\theta_{\text {loss }}$ & $\begin{array}{l}\text { effect of temperature on loss rate, } \\
\text { set to } 1.05\end{array}$ & $\begin{array}{l}\text { [Bach, 1993; Bocci et al., 1997; Pastres et al., } \\
\text { 2004; Verhagen and Nienhuis, 1983; Zharova } \\
\text { et al., 2001] }\end{array}$ \\
\hline$L_{\text {resp }}$ & $\begin{array}{l}\text { Respiratory loss rate } 0.000375 \text { per } \\
\text { hour }\end{array}$ & [Zharova et al., 2001] \\
\hline$G_{p \max }$ & $\begin{array}{l}\text { Maximum specific growth rate } \\
0.0095 \text { per hour }\end{array}$ & [Bach, 1993] \\
\hline
\end{tabular}


Table 3: Variables

\begin{tabular}{|c|c|}
\hline Variable & Description \\
\hline$h_{\text {canopy }}$ & Canopy height \\
\hline$k_{c}$ & Deflected canopy height \\
\hline$\tau_{b}$ & $\left(\mathrm{~Pa} \mathrm{~m} \mathrm{~m}^{-2}\right)$ is the shear stress applied to the bed, \\
\hline$U$ & Velocity (m/s) \\
\hline$u_{*}$ & Shear velocity(m/s) \\
\hline$T$ & Temperature \\
\hline$K_{d}$ & Light attenuation coefficient \\
\hline$I$ & Irradiance in PAR \\
\hline Z & Water depth (m) \\
\hline$U_{a v}$ & the average tidal current velocity $(\mathrm{m} / \mathrm{s})$ \\
\hline$K_{z}$ & vertical diffusivity \\
\hline$K_{\text {zcanopy }}$ & vertical emergent canopy diffusivity \\
\hline$D_{t z}$ & $\begin{array}{l}\text { vertical diffusivity due to vegetation induced shear layer and } \\
\text { coherent vortices. }\end{array}$ \\
\hline$\ddot{K_{z}}$ & weighted average vertical diffusivity for sparse canopies. \\
\hline$N$ & shoot density \\
\hline$N_{m}$ & modified shoot density incorporating blade density \\
\hline$N_{\text {req }}$ & the shoot density required to assume a dense flow \\
\hline
\end{tabular}




\section{Chapter 3: STABILITY AND RESILIENCE OF SEAGRASS MEADOWS TO SEASONAL AND INTERANNUAL DYNAMICS AND ENVIRONMENTAL STRESS}

\section{Abstract:}

Shallow coastal bays provide habitat for diverse fish and invertebrate populations and are an important source of sediment for surrounding marshes. The sediment dynamics of these bays are strongly affected by seagrass meadows, which limit sediment resuspension thereby provide a more favorable light environment for their own survival and growth. Due to this positive feedback between seagrass and light conditions, it has been suggested that bare sediment and seagrass meadows are potential alternate stable states of the benthos in shallow coastal bays. To investigate the stability and resilience of seagrass meadows subjected to variation in environmental conditions (e.g., light, temperature), a coupled model of vegetation-sedimentwater-flow interactions and vegetation growth was developed. The model was used to examine the effect of dynamically-varying seasonal and interannual seagrass density on sediment resuspension, water column turbidity, and the subsequent light environment on hourly time steps and then run over decadal time scales. A daily growth model was designed to capture both belowground biomass and the growth and senescence of aboveground biomass structural components (e.g., leaves and stems). This allowed us to investigate how the annual and seasonal variability in shoot and leaf density within a meadow affects the strength of positive feedbacks between seagrass and their light environment. The model demonstrates both the emergence of bistable behavior from 1.6-1.8 meters mean sea level due to the strength of the positive feedback, as well as the limited resilience of seagrass meadows within this bistable range. 


\section{Introduction}

Shallow coastal bays are a common feature of low-energy coastlines. The growth of seagrasses in coastal bays provides the trophic base for secondary production, affects nutrient cycling, water quality, sediment stability [McGlathery et al., 2007; Sfriso and Marcomini, 1997; Viaroli et al., 1996] and productivity of higher trophic levels [Lepoint et al., 2000; Norkko et al., 2000]. The dynamics of seagrass ecosystems are sensitive to important positive feedback mechanisms both between vegetation and sediment suspension/deposition, and between nutrient loading and seagrass growth. The presence of seagrass attenuates tidal- and wave-generated near-bed shear stresses in shallow bays, acting both to shelter the underlying sediment, thereby limiting resuspension, and to enhance deposition of fine sediment [de Boer, 2007; Gacia et al., 2003]. Reduction in the total amount of sediment in suspension enhances the transparency of the water column [Folkard, 2005] and produces more favorable light conditions for seagrass growth compared to a bare sediment bed. In the absence of seagrass, high water-column turbidity and the associated low-light environment may not allow for the establishment of seagrass in shallow bays. These types of positive feedbacks involving limiting resources (e.g. light) contribute to the complexity and nonlinearity of ecosystem dynamics and the emergence of alternate stable states [Wilson and Agnew, 1992]. Depending on initial conditions and environmental drivers, a bistable system will converge to either state (e.g., bare sediment or seagrass meadow). As such, the resilience of bistable systems is limited in that they are susceptible to some critical frequency and/or magnitude of disturbance from which recovery to the pre-disturbance state is not possible even after removal of the 
disturbance [Gunderson, 2000; Holling, 1973; Scheffer et al., 2001; Van De Koppel et al., 2001].

It has been suggested that clear water/seagrass-covered bottom conditions and turbid water/no seagrass cover represent alternate stable states for shallow bay ecosystems [Carr et al., 2010; van der Heide et al., 2007] due to the positive feedback between seagrasses and their light environment. However, these studies do not explore how the annual and interannual variability in shoot and leaf density affects the strength of positive feedback, the emergence of bistable states and the resilience of seagrass meadows to perturbations and stress. To address this, we coupled a hydrodynamic model of vegetation-sediment-water flow interactions (Carr et al., 2010) with a new vegetation growth model to investigate whether seagrass ecosystems are prone to catastrophic shifts to alternate stable states in response to gradual or drastic shifts in environmental conditions and disturbance regimes. We used this coupled model to investigate 1) the influence of the density of a seagrass meadow on hourly sediment resuspension, water column turbidity, and the subsequent light environment, and 2) the meadow response to these parameters under different seasonal and interannual conditions of temperature, waves and tidal currents up to decadal time scales.

The coupled model was used to investigate the dynamics of the seagrass Zostera marina in Hog Island Bay, a shallow coastal bay within the Virginia Coast Reserve Long Term Ecological Research Site on the Atlantic side of the Delmarva Peninsula (VCR/LTER, $37^{\circ} 25^{\prime} \mathrm{N}$, $\left.75^{\circ} 46^{\prime} \mathrm{W}\right)$. In the 1930 's, the seagrasses in the VCR coastal bays, already under stress from disease, were severely impacted by a hurricane and became locally extinct [Orth et al., 2006]. The bays were then dominated by benthic algae until the 1990's when small natural patches of 
seagrass were discovered, prompting large-scale restoration efforts by seeding. The reestablished meadows at the time the model was developed had peak shoot densities of $412-529$ shoots $/ \mathrm{m}^{2}$ at depths up to1.6 meters MSL, while bare sediments are found in deeper waters (McGlathery et al. submitted). This change in the trophic base from benthic algae to seagrass is expected to affect the entire system due to changes in nutrient cycling, light environment, sediment stability [McGlathery et al., 2007; Sfriso and Marcomini, 1997; Viaroli et al., 1996] and the dynamics of higher trophic levels [Lepoint et al., 2000; Norkko et al., 2000]. Here we investigate the potential for initial seagrass recovery in shallow coastal bays such as those at the VCR, and resilience of the restored seagrass meadows to interannual variations in forcing conditions (temperature, storminess).

\section{Methods}

A model of seagrass biomass growth was developed and coupled with a hydrodynamic model of vegetation-sediment-water flow interactions [Carr et al., 2010] to investigate the effects of seagrass vegetation density on sediment resuspension and water column turbidity, and the light environment under different water depths, water temperature, tidal and wave conditions.

The hydrodynamic model simulates the one-dimensional dynamics (in the vertical direction) of sediment entrainment/settling within the water column. It accounts for the effect of seagrass shoot density on these dynamics, including its effect on the velocity profile, eddy diffusivity, shear flow dispersion, and wave and current shear stresses. At the same time, it accounts for the effect of flow on the height of the deflected seagrass canopy. Values of suspended sediment concentration calculated by the model are used to determine the degree of light attenuation within the water column (i.e., from the water surface to the top of the deflected canopy, as in Lawson et al. [2007]) and to calculate light availability. The model is applicable to water depths where the canopy takes up no more than a third of the water column and remains 
submerged at low tide. Thus the model applicability is limited by tidal range and canopy heights (Carr et al., 2010). As such, based on average canopy heights of $30 \mathrm{~cm}$ and tidal range of $1 \mathrm{~m}$ for this study site, the shallowest conservative model depth is $1.6 \mathrm{~m}$ MSL.

The hydrodynamic/light model (Carr et al., 2010) is here coupled to a daily growth model developed in this study to capture the annual and interannual morphology of a seagrass meadow where biomass is allocated into individual leaves on a given shoot and belowground biomass across multiple years. This model builds upon and modifies prior efforts to model seagrass dynamics [Verhagen and Nienhuis, 1983; Zharova et al., 2001] by allocating growing and senescing aboveground biomass into distinct structural components (e.g., leaves and stem) for all shoots rather than modeling a single representative shoot and scaling it to the modeled shoot density. We define the stem as the rigid base of the shoot. Translocation of biomass from leaves to the roots and rhizomes accounts for growth of shared belowground biomass storage [Verhagen and Nienhuis, 1983; Zharova et al., 2001], whereas translocation of biomass from existing leaves on a given shoot to new leaf growth allows for increasing the number of leaves on that particular shoot. Shoot recruitment reduces the collective belowground biomass by drawing on stored resources. Mortality of an individual shoot in turn affects both the associated aboveground biomass (e.g., leaves) and some small fraction of the belowground biomass through uprooting.

Productivity, leaf elongation, and new shoot recruitment are functions of daily irradiance and average water temperature, whereas respiration is scaled only as a function of daily average water temperature [Verhagen and Nienhuis, 1983; Zharova et al., 2001]. Unlike prior models, we explicitly model the temporal dynamics of shoot and leaf density and their feedbacks with the hydrodynamic conditions and light environment. The model is sensitive to water temperature as water temperature determines the saturation and compensation irradiance as well as the carbon balance between photosynthetic productivity and respiration. We used this model to explore the 
effects of intra- and interseasonal temperature and wave-current conditions on the resilience and stability of a seagrass meadow.

Change in the total number of shoots $N=\sum n$, where $n$ is an individual shoot, is a product of the total number of shoots, and the difference between recruitment and loss (equation 1). The recruitment rate is a function of a maximum recruitment rate $\max _{\text {Ngrow }}$ and is constrained by irradiance $F_{I}(I)$, photosynthetic productivity as a function of temperature $F_{\text {pht }}(T)$ [Verhagen and Nienhuis, 1983; Zharova et al., 2001], a maximum meadow shoot density function $N_{\text {lim }}$, and a maximum aboveground to belowground biomass ratio $R_{\text {lim }}$. General shoot mortality is assumed for simplicity to be light- and temperature-independent and is set as a constant fraction of $N$ [Zharova et al., 2001]; however, shoot mortality can occur when individual shoot biomass drops below 50\% of its prior maximum value. Thus, the dynamics of $N$ are modeled as $\frac{d N}{d t}=N\left(\max _{\text {Ngrow }} F_{I}(I) F_{\text {pht }}(T) N_{\text {lim }} R_{\text {lim }}-N_{\text {loss }}\right)$

with scaling functions, $F_{I}(I)$ and $F_{p h t}(T)$, expressed as in Table 1 . While $N$ is written as a continuous quantity, the actual change in $N$ is tallied over time steps until a whole number of shoot(s) can be added or removed. Each new shoot is assumed to appear with a single leaf and a new aboveground biomass $P_{\text {new }}$ proportioned evenly into a stem and a leaf.

Aboveground biomass $P$ is modeled as a collection of up to four leaves ( $l=$ leaf number) associated with an individual shoot, $n$, with $P_{n, 0}$ being the biomass of the stem. Change in biomass of leaf $l$ belonging to shoot $n$ is defined as

$$
\frac{d P_{n, l}}{d t}=P_{n, l}\left(\max _{p h t} F_{I}(I) F_{p h t}(T) F_{\text {age }} P_{\text {lim }}-\max _{\text {resp }} F_{T}(T)\right)
$$

Similar to the number of shoots, photosynthetic growth of biomass is a function of a maximum photosynthetic growth rate $\max _{p h t}$ and is modulated as a function of irradiance $F_{I}(I)$, 
temperature-dependent photosynthetic productivity $F_{p h t}(T)$, leaf age $F_{\text {age }}$ and a maximum leaf biomass limitation function $P_{\text {lim }}$. Leaf respiration, accounting for loss of biomass, is a function of a maximum respiration rate, $\max _{\text {resp }}$, and temperature $F_{T}(T)$ as reported in Table 1.

After biomass growth and or loss is calculated, a fraction of the total growth is removed from the above ground biomass and translocated to the belowground biomass, $k_{t r a n f e r} \sum \frac{d P_{n, l}}{d t}$. The transfer coefficient, $k_{\text {tranfer }}$, can vary from $17 \%$ to as high as $40 \%$ [Zharova et al., 2001]; a moderate value of $30 \%$ is used in this study.

A small fraction, $L_{\text {lim }} k_{\text {newleaf }} \sum \frac{d P_{n, l}}{d t}$, of the biomass accumulation from the leaves of a single shoot is transferred into new leaf growth so long as the shoot does not have the maximum number of leaves. About $15 \%$ of above ground productivity is transferred into growing new leaves [Kemp et al., 1987]. A new leaf is added when enough biomass has been transferred to form a new leaf. As such, while the above ground biomass is written and calculated as a continuous quantity, growth of new leaves is a discrete event. Once the maximum number of leaves per shoot has been reached for shoot $n$, the transfer of biomass to new leaf production halts until a leaf is lost from that shoot. Leaf loss occurs when $P_{n, l}$, drops below $50 \%$ of its maximum attained value or due to age. Leaf loss also occurs when the shoot the leaf is attached to is lost. Zostera marina leaf ages range from 35-175 days [Hemminga and Duarte, 2000]. A value of 160 days is used as a maximum leaf age, and modeled mean leaf age throughout the year varied from 30-90 days. Leaf loss is dominated by shoot mortality, then biomass loss and finally senescence due to age.

For simplicity, leaf characteristics of width and thickness are held constant as both show only slight variation with leaf length [Abdelrhman, 2007]. A change in the length of leaf $l$ of shoot $n, L_{n . l}$ is modeled as a linear function of a maximum leaf elongation rate, max $_{\text {elong, }}$ 
modulated by light $F_{I}(I)$ and photosynthetic productivity as a function of temperature $F_{\text {pht }}(T)$ up to some maximum leaf length $L_{\text {lim }}$.

$\frac{d L_{n . l}}{d t}=\max _{\text {elong }} F_{I}(I) F_{p h t}(T) L_{\text {lim }}$

(3)

Belowground biomass associated with the root and rhizome structure of seagrass, $R$, is modeled as a bulk quantity with growth due to translocation of aboveground production

$k_{\text {transfer }} \sum_{n, l} \frac{d P_{n, l}}{d t}$, and loss due to respiration, $\gamma F_{T}(T)$, translocation of biomass to a new shoot,

$\frac{d N_{n}^{+}}{d t} P_{n n e w, 0}$, and loss of biomass to uprooting when a shoot is lost, $k_{\text {uproot }} \frac{d N_{n}{ }^{-}}{d t}$.

$\frac{d R}{d t}=k_{\text {transfer }} \sum_{n, l} \frac{d P_{n, l}}{d t}-\gamma F_{T}(T) R-\frac{d N_{n}^{+}}{d t} P_{\text {nnew }, 0}+k_{\text {uproot }} \frac{d N_{n}{ }^{-}}{d t}$

Parameter values, descriptions, and limitation functions can be found in Tables 1 and 2.

\section{Model application and environmental drivers}

For a given depth ranging from $1.6 \mathrm{~m}$ to $2.8 \mathrm{~m}$ MSL, the hydrodynamic model was run with an hourly time step using hourly wind, tide and water temperature measurements for the years 1996 through 2004 from the NOAA Wachapreague station, Virginia (WAHV2, 37³6'24" N, $75^{\circ} 41 ' 12 " W$ ). Hourly measurements of photosynthetically active radiation (PAR) from the VCR-LTER flux tower at Fowling Point, Virginia (372 $24^{\prime}$ N, $75^{\circ} 50^{\prime} \mathrm{W}$ ) were used to provide incident radiation at the water surface. For each one-hour time step, PAR reaching the canopy was calculated following Carr et al. (2010). Average daily water temperature and net daily PAR 
were then used to drive the growth model on a daily time step. Literature values were used for all model parameters (Tables 1, 2). The model was validated by comparing calculated seagrass parameters to the existing restored seagrass population (Table 5).

Each year in the period of record was classified on the basis of the number of days of net biomass growth or loss, as well as of the number of hours in which the shear stress acting on the sediment bed exceeded the threshold shear stress for bare sediment erosion. 'Loss days' were classified as those with water temperatures above $28{ }^{\circ} \mathrm{C}$ or below $5{ }^{\circ} \mathrm{C}$, as these are the temperatures at which the difference of the scaled specific growth and loss rates, $\max _{\text {pht }} F_{I}(I) F_{\text {pht }}(T)-\max _{\text {resp }} F_{T}(T)$, become negative at full light saturation. Days with temperatures above $30^{\circ} \mathrm{C}$, the temperature above which meristem tissues become anoxic [Greve et al., 2003] and large summer die offs have been witnessed [Moore and Jarvis, 2008], were also separately counted to examine the different effect on seagrass dynamics of long winters versus hot summers. Similarly, the total number of days with a positive scaled specific growth rate growth, when temperatures are between $5{ }^{\circ} \mathrm{C}$ and $28^{\circ} \mathrm{C}$ - were totaled for each year. Years were also evaluated by both the average excess shear stress for a given year as well as the total number of hours when the shear stress acting on a bare sediment bed exceeds the erosion threshold critical shear stress (Table 3). This provides an estimate of storminess, or at least the sediment transport potential of the various years.

The model was used to explore the steady-state conditions attained in the long run by the system with the environmental conditions characteristic of each year. To this end, the model was repeatedly forced for up to fifty simulation years with the records of wind, tide, water temperature, and light (i.e., PAR) measured in a certain year until "steady-state” conditions were achieved. Two initial meadow states were used for each year's conditions: an extremely sparse meadow with no hydrodynamic influence $\left(3\right.$ shoots $\mathrm{m}^{-2}$ ) and a dense meadow (640 shoots $\mathrm{m}^{-2}$ ). 
The number of simulation years required for an initial meadow state to reach steady-state conditions was tallied for each year of driving data.

Similarly, we estimated the response and state of a meadow under varying conditions, by randomly selecting a sequence of 50 years from the nine years for which data records were available (Tables 2 and 3) and using specific water depth ranging from $1.6 \mathrm{~m}$ to $2.8 \mathrm{~m}$ MSL both with the sparse and dense meadow initial conditions. This was iterated four times and the yearly outputs were averaged to achieve an estimate of average seasonal growth patterns (Figure 3).

\section{Results}

Comparison and classification of each individual year as a driver was based on the stable state winter shoot densities calculated at the shallowest water depth $1.6 \mathrm{~m}$ (Table 4). In general, the years exhibiting a single attractive domain of a stable seagrass meadow were years when the number of growing days were relatively high and the number of loss days low (Table 4).

We looked at the difference between days of growth and loss across all the years. The year 2004 was unable to sustain any amount of seagrass due to the low number of growing days as well as significant light attenuation due to sediment resuspension (Tables 3 and 4). In 1996, the days of loss account for a third of the year. The best year, 2001, had fewer hours of transport conditions, a high number of growing days, a low number of days of loss, and had no days with temperatures exceeding $30^{\circ} \mathrm{C}$ (Table 3 and 4). In general, the best years had fewer days exceeding $30{ }^{\circ} \mathrm{C}$ and a large number of growing days. The exceptions were the years 2002 and 1998. 2002 had lower temperatures during the spring growing period, resulting in low net growth even though the total number of days of growth was high. 1998 had a moderate number (285) of days of growth; however the higher shear stresses increased water column turbidity, thereby impacting net growth. 
The steady-state seasonal above- and belowground biomass calculated (Figure 1) demonstrates similarities and differences between the years. Most years undergo a significant above- and belowground biomass loss during the hot water temperature periods followed by a regrowth during the fall. During this fall regrowth, the belowground biomass was essentially constant as the new leaves and shoots were produced prior to the winter loss (Figure 1). For most years, the summer biomass loss was greater than the loss during the winter, the exception of 2001 when the spring growth extended until early August rather than late June, with a short summer die off followed by a longer winter (Figure 1 panel f ).

We drove the model to steady-state for individual years so that we could describe the attraction domain(s) for each year across water depths. At the shallowest modeled depth of 1.6 m MSL, 2004 was unable to sustain any amount of seagrass and bare sediment was the attraction domain for this year. The years 1996, 1997, 1998, and 2002 exhibited bistable behavior, in that the attractor was either bare sediment or a steady-state seagrass meadow depending on whether the initial condition was a dense meadow or a sparse meadow (Table 4). These years were also years with more days in the summer when the temperature exceeded $30^{\circ} \mathrm{C}$ (Table 4). The years 1999, 2000, 2001 and 2003 all exhibited a single attraction domain of a seagrass meadow. As water depth increased, the attraction domains shifted; years with bistable behavior at sites when the water depth was $1.6 \mathrm{~m}$ exhibited only one attractor (i.e., bare sediment) in deeper water, whereas the years in which there was only one stable state (i.e., seagrass meadow) at $1.6 \mathrm{~m}$ depth, exhibited bistable dynamics with deeper waters (Figure 2). By a water depth of $2.6 \mathrm{~m}$, seagrass was not able to be maintained (Figure 2).

Evaluating the number of years it took a seagrass meadow to reach steady-state, we estimated the strength of the domain of attraction and how fast a meadow responded to that attractor. Therefore, time to steady-state is a possible measure of the resilience of that state, i.e., 
of the system's ability to recover that configuration after a disturbance (experiencing a year with poor growing conditions). From the dense meadow initial condition it took 18 successive years of 2004 conditions to drive the system to a bare sediment state at 1.6 m water depth (Table 4) However, declines from higher to lower shoot density states took far less time. For example, losses of 100 shoots $\mathrm{m}^{-2}$ took only a year, and losses of 200 shoots $\mathrm{m}^{-2}$ took 3 years. In contrast to the rapid rate at which meadow density declined, meadow growth took many years. For 2001, growth from the sparse meadow initial condition to the steady-state took 7 years, while for 2003, steady-state conditions were achieved after 23 years. In both 2002 and 1997, seagrass exhibited initial growth and then loss as the seagrass used up their belowground storage, accounting for the 10 years it took for the system to reach the bare sediment steady-state. These model runs illustrated that a meadow that is relatively healthy and dense could grow rapidly if conditions allow, in comparison to a meadow that is relatively sparse.

While these steady-state model simulations allowed for understanding how an individual year may affect a meadow in terms of net growth or loss, actual meadows are subjected to continually changing environmental conditions. Significant deviations from the average random behavior (Figure 3) appeared when a meadow randomly underwent multiple poor or good years in sequence. Initiating the meadow from a dense and a sparse meadow initial condition, as well as interspersing sequences of poor years, allowed for examination of both the resilience and bistability of a "natural” meadow.

Growth from the sparse meadow initial condition, and maintenance of a meadow from a dense meadow initial condition under random drivers indicated that with this random forcing seagrass meadows were stable at $1.6 \mathrm{~m}$ depth (Figure 4). However, between $1.6 \mathrm{~m}$ and $1.8 \mathrm{~m}$ MSL, the system exhibited bistable behavior and was unable to develop from the sparse meadow initial condition but was able to maintain a dense meadow. Deeper than $1.8 \mathrm{~m}$, the system was 
stable only in the bare sediment state. Stable initially dense meadows at $1.6 \mathrm{~m}$ displayed strong resilience to perturbations (i.e. randomly experiencing a year with poor growing conditions), with rebound to within two standard deviations of the mean shoot density occurring within a minimum of 4 years and a maximum of 10 (Figure 5a). Total collapse occurred only under severe forcing by repeatedly forcing the meadow to experience years with poor growing conditions (Table 3, Table 4). In contrast, a meadow exhibiting bistable behavior had limited resilience. It took only a minimum of 3 forced years of poor conditions in row for an initially dense meadow at $1.8 \mathrm{~m}$ depth to cross the critical threshold for collapse, with total collapse occurring within 10 years (Figure 5b). Collapse from a dense meadow state in all waters deeper than $1.6 \mathrm{~m}$ during these random runs was relatively slow, with quicker progression to the bare sediment state only occurring when the meadow randomly experienced another or multiple poor years of growth.

\section{Discussion}

The model developed here allowed us to simulate structural growth and loss within a seagrass meadow and to explore the intra- and interseasonal dynamics and resilience of the meadow. The seagrass-sediment-light feedback investigated in this paper was previously investigated by Carr et al. (2010) using the same hydrodynamic model but without the seagrass growth model. That study prescribed a set of static seagrass cover conditions and determined whether the associated light environment was suitable for seagrass survival and growth. Here we model seagrass dynamics in detail over a 50-year period, accounting for the temporal variability in the number of shoots, leaves per shoot, and belowground carbon storage in response to environmental conditions. The model is able to capture the behavior of a meadow based on literature parameter values and local measurements of sediment characteristics, wind, tides, temperature and PAR as driving parameters. Modeled shoot densities match observed values 
with peak modeled densities of around 600 shoots $\mathrm{m}^{-2}$ and observed peak densities of 562 shoots $\mathrm{m}^{-2}$. Modeled blade lengths correspond well to photographic measurements (Table 4).

Model simulations showed that the seagrass meadows were stable with respect to seasonal and interannual environmental fluctuations (i.e., fluctuations in tides, winds, light, and water temperature) at $1.6 \mathrm{~m}$ (see Fig. 4). At depths of $1.6 \mathrm{~m}$ MSL and shallower, a loss of seagrasses resulted only in a temporary deterioration of the light environment, without preventing seagrass re-growth. In deeper waters (up to $1.8 \mathrm{~m}$ ), both seagrass meadows (with good light environment) and bare bed sediment (with higher sediment suspension and poor light environment) were stable configurations of the system, indicating that the system is bistable in this depth range (1.6 - 1.8 m MSL). Thus, seagrass dynamics in this range exhibited some threshold in meadow density beyond which the system diverged towards the alternative stable state of bare sediment. Multiple years of poor light and/or temperature conditions were able to push a dense meadow beyond this threshold. Because of the higher water column turbidity and adverse light environment associated with the bare sediment state, the system would not be able to return to its initial configuration with seagrass cover. Therefore, seagrass meadows in this depth range have a relatively low resilience. In even deeper waters (i.e., > 1.8 m MSL) seagrass meadows were never stable and the system always tended to a bare sediment state. These modeling results are consistent with field results from seagrass restoration efforts in the VCR showing no survival of restored seagrass in depths exceeding 1.6 m MSL after 4 years (McGlathery et al., submitted), corresponding with the bistable range indicated by the model.

Our results point toward a very narrow, 1.6 to $1.8 \mathrm{~m} \mathrm{MSL}$, band of depths exhibiting bistability under randomized conditions. In comparison, the bistable regions found under the steady-state runs show a wide depth range of behavior with regards to bistability. This indicates that interannual variability in water temperature and irradiance playing an important role in 
controlling ecosystem state in shallow bays, as the presence of vegetation acts to mitigate the effects of waves and currents limiting the role of turbidity. It also indicates that increasing MSL and water temperature will strongly influence the success or failure of the restoration effort. In general, while prior studies have indicated that meadow density and light availability control survivability or establishment of the meadow [van der Heide et al., 2007], this study indicates that for seagrasses systems near their temperature limits, the role of the positive feedback in meadow establishment or survival may be compounded by the sensitivity and rapid response of the meadows to temperature conditions.

Convergence times to steady-state varied with initial condition and year used for the environmental forcing (Table 4). In this case study it took only 3 to 4 bad years in a row to cause the complete loss of an initially sparse seagrass meadow at $1.8 \mathrm{~m}$ MSL and even fewer years in deeper waters. In comparison, dense seagrass meadows at $1.6 \mathrm{~m}$ MSL were much more resilient and could be lost only if a consecutive sequence of many (>18) very severe years like 2004 occurred (Table 4). Similarly, dense meadows reached steady-state conditions rapidly (Table 4), implying rapid adaptability of a dense meadow to the environmental conditions of a given year. However, these rapid transitions were always declining, from a dense to less dense meadow, whereas an increase in meadow density as a response to a shift in environmental conditions (a year exhibiting good growth conditions), was slower. This hysteresis in adaptability to shifting environmental conditions poses significant implications for resilience and restoration of seagrass meadows. For example, an initially sparse meadows were unable to adapt as readily to beneficial light and temperature conditions due to limited biomass resources. Those same meadows may then undergo a year with adverse growing conditions and collapse due to their inability to support enough growth the prior year. Thus both meadow state (density, biomass) and environmental drivers (light, temperature) affect both the stability and resilience of the meadow. For all depths 
less than $1.8 \mathrm{~m}$ MSL, modeled seagrass meadows recovered from a single year of adverse growing conditions in 1 - 5 years. However, if the loss in biomass is great enough, past some critical threshold, an initially dense meadow may not be able to recover, regardless of future environmental conditions.

The model also indicates that while meadow density plays a significant role in modifying the light environment, the timing of storms in the late fall and winter for this study site, typically occur during periods where low temperatures already limits seagrass growth. Similarly, summer growth rates, and meadow density is strongly affected by excessive summer temperatures [Moore and Jarvis, 2008]. This points towards temperature playing a more significant role in the growth and maintenance of seagrass for this study site.

Under climate change scenarios involving increased sea level it is likely that the increase in MSL will slowly push a meadow into the bistable depth range, and eventually past the critical bifurcation point. Depending on the local rate of relative sea level rise the meadow may keep pace with increasing MSL by migrating through rhizome branching and seedling establishment towards shallower water, with the deeper meadow edge dying off. If rates of sea-level rise outpace the ability of the meadow to migrate toward shallower water, the meadows will be lost. Increased water depth also allows for larger waves (Mariotti et al., 2010), and more significant wave resuspension, indicating that an increase in storminess may play significant role in the light environment. Depending on location, an increase in water temperature may play a more significant role in the potential for sudden and irreversible collapse of meadows. These questions are explored further in Carr et al. (submitted).

The model structure is based on prior models [Verhagen and Nienhuis, 1983; Zharova et al., 2001] and as such has similar limitations. First, the model does not incorporate nutrient 
cycling or nutrient limitation. The role of, and shift in, nitrogen cycling within seagrasses meadows (McGlathery et al 2007) can be another important feedback further promoting, and or inhibiting growth. However, the coastal bays of the VCR are minimally impacted by humans and have low water column nutrients (VCR LTER data base, www1.vcrlter.virginia.edu/home1/?q=data_wq), and as such nutrient over-enrichment and high water-column chlorophyll concentrations are not an issue. Second, because the case study presented in this paper refers to a site near the southernmost limit for Zostera marina (Dennison 1987), temperature may play a more significant role in controlling the growth in this system than in other parts of its range. Third, the model uses a constant growth rate per shoot for shoot density as well as a set mortality rate. Similarly, the model assumes no shoot establishment through seedling recruitment. This limits the growth of new shoots when very few or no shoots are present, even if the belowground storage is present to allow for explosive growth. As such, exploration of how to link new shoot growth to belowground biomass and seedling establishment, rather than existing shoot structure, is needed to better parameterize new shoot recruitment. The constant shoot mortality rate acts to decouple the shoot mortality from environmental conditions. To mitigate this effect, we also accounted for the loss of a shoot when it lost half of its peak biomass, however, the ratio of structural versus labile carbon in various plant structures is not well known. Regardless, the approach here allows us to incorporate the feedback of plant morphology on fluid flow, and provides modeled estimates of relatively easily and nondestructively measured leaf and shoot density counts that facilitate model - data comparisons. 


\section{Conclusion}

The model presented here allows for exploring the complex interactions between hydrodynamics and the annual and interannual cycles of seagrass vegetation. Under both constant and randomized environmental drivers, bistable dynamics emerge as a function of water depth due to the positive feedback between seagrass and their light environment. The bistable depth range is a function of both meadow state, and environmental conditions. Seagrass meadows in shallower water $(<1.6 \mathrm{~m} \mathrm{MSL})$ are stable, and have associated strong resilience to disturbances. Within the bistable range( 1.6 - 1.8 m MSL), the seagrass meadows display limited resilience in that they are susceptible to shifts into the attractive domain of the bare sediment state when they experience sequences of poor light and temperature conditions. Irrecoverable collapse of these meadows can take many years.

Acknowledgments: We thank Jenny Romanowich for her seagrass shoot and leaf length measurements. Partial support of this study was provided National Science Foundation grant DEB-0621014 to the Virginia Coast Reserve LTER project. 


\section{References:}

Abdelrhman, M. A. (2007), Modeling coupling between eelgrass Zostera marina and water flow, Mar. Ecol.-Prog. Ser., 338, 81-96.

Bach, H. K. (1993), A dynamic model describing the seasonal variations in growth and the distribution of eel grass (Zostera Marina), Ecological Modelling, 65(1-2), 31-50.

Carr, J., et al. (2010), Stability and bistability of seagrass ecosystems in shallow coastal lagoons: Role of feedbacks with sediment resuspension and light attenuation, J. Geophys. Res.-Biogeosci., 115, 14.

de Boer, W. (2007), Seagrass-sediment interactions, positive feedbacks and critical thresholds for occurrence: a review, Hydrobiologia, 591(1), 5-24.

Folkard, A. M. (2005), Hydrodynamics of model Posidonia oceanica patches in shallow water, Limnology and Oceanography, 50(5), 1592-1600.

Gacia, E., et al. (2003), Sediment deposition and production in SE-Asia seagrass meadows, Estuarine Coastal and Shelf Science, 56(5-6), 909-919.

Greve, T. M., et al. (2003), Meristematic Oxygen Variability in Eelgrass (Zostera marina), Limnology and Oceanography, 48(1), 210-216.

Gunderson, L. H. (2000), Ecological resilience - in theory and application, Annual Review of Ecology and Systematics, 31, 425-439.

Hemminga, M. A., and C. M. Duarte (2000), Frontmatter Seagrass Ecology, Cambridge University Press.

Holling, C. S. (1973), Resilience and Stability of Ecological Systems, Annual Review of Ecology and Systematics, 4, 23. 
Kemp, W., et al. (1987), Diel growth in eelgrass Zostera marina Marine ecology progress series, Vol. 41(1), 79-86.

Lawson, S. E., et al. (2007), Wind-driven sediment suspension controls light availability in a shallow coastal lagoon, Estuaries and Coasts, 30(1), 102-112.

Lepoint, G., et al. (2000), Relative impact of a seagrass bed and its adjacent epilithic algal community in consumer diets, Marine Biology, 136(3), 513-518.

McGlathery, K. J., et al. (2007), Eutrophication in shallow coastal bays and lagoons: the role of plants in the coastal filter, Mar. Ecol.-Prog. Ser., 348, 1-18.

Moore, K. A., and J. C. Jarvis (2008), Environmental Factors Affecting Recent Summertime Eelgrass Diebacks in the Lower Chesapeake Bay: Implications for Longterm Persistence, J. Coast. Res., 135-147.

Norkko, J., et al. (2000), Drifting algal mats as an alternative habitat for benthic invertebrates: Species specific responses to a transient resource, Journal of Experimental Marine Biology and Ecology, 248(1), 79-104.

Orth, R. J., et al. (2006), Seagrass recovery in the Delmarva Coastal Bays, USA, Aquatic Botany, 84(1), 26-36.

Scheffer, M., et al. (2001), Catastrophic shifts in ecosystems, Nature, 413(6856), 591596.

Sfriso, A., and A. Marcomini (1997), Macrophyte production in a shallow coastal lagoon .1. Coupling with chemico-physical parameters and nutrient concentrations in waters, Marine Environmental Research, 44(4), 351-375.

Van De Koppel, J., et al. (2001), Do alternate stable states occur in natural ecosystems? Evidence from a tidal flat, Ecology, 82(12), 3449-3461. 
van der Heide, T., et al. (2007), Positive feedbacks in seagrass ecosystems: Implications for success in conservation and restoration, Ecosystems, 10(8), 1311-1322.

Verhagen, J. H. G., and P. H. Nienhuis (1983), A simulation-model of production, seasonal-changes in biomass and distribution of eelgrass (Zostera Marina) in lake Grevelingen, Mar. Ecol.-Prog. Ser., 10(2), 187-195.

Viaroli, P., et al. (1996), Macrophyte communities and their impact on benthic fluxes of oxygen, sulphide and nutrients in shallow eutrophic environments, Hydrobiologia, 329(13), 105-119.

Wilson, J. B., and A. D. Q. Agnew (1992), Positive-feedback switches in plantcommunities, Advances in Ecological Research, 23, 263-336.

Zharova, N., et al. (2001), A simulation model for the annual fluctuation of Zostera marina biomass in the Venice lagoon, Aquatic Botany, 70(2), 135-150. 
Figures
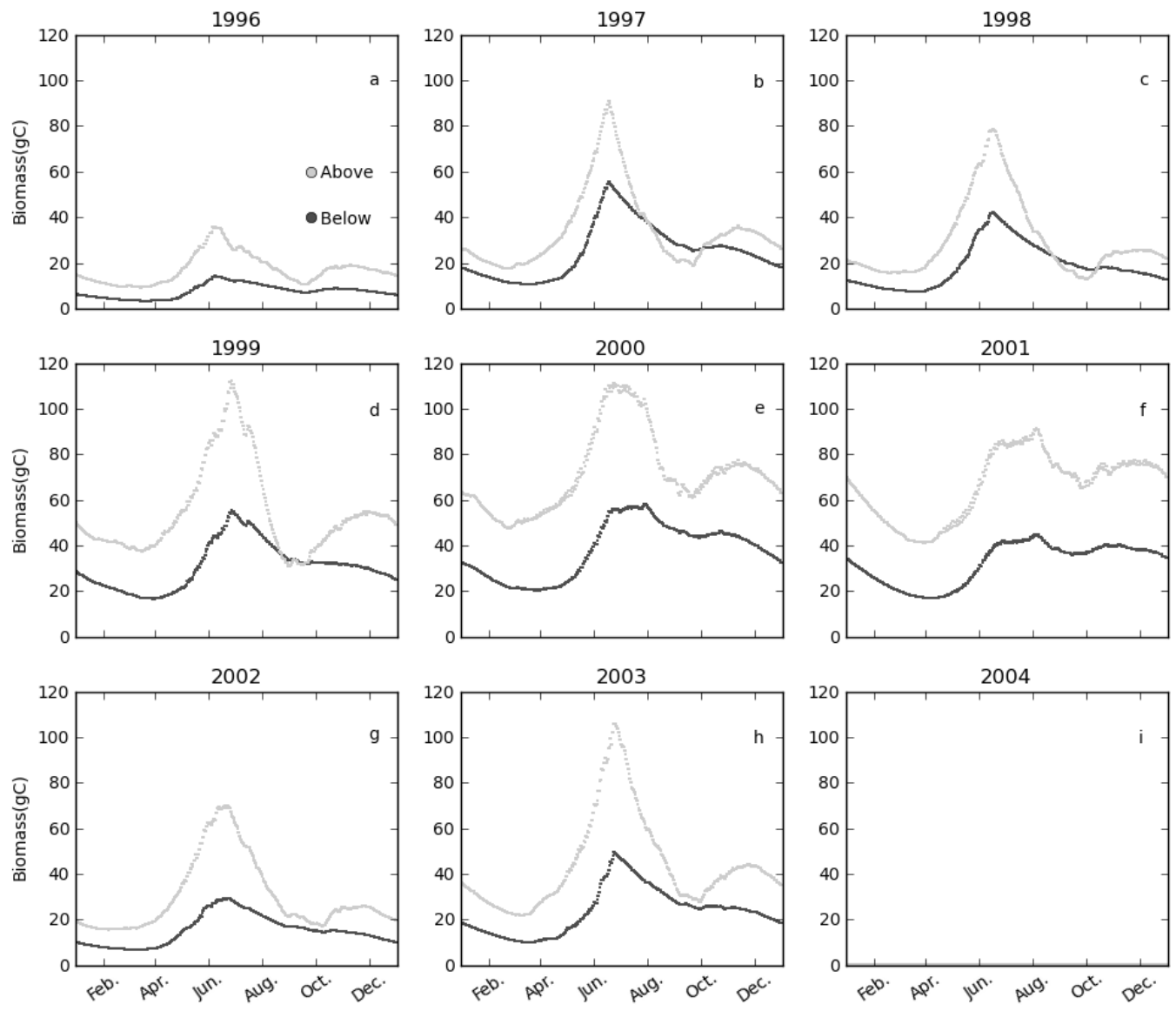

Figure 1. Seasonal steady-state aboveground and belowground biomass for each year 1996-2004 (panels a-i) at 1.6 m MSL. Years 1999, 2000, 2001, and 2003 all exhibited stable growth, and aboveground and belowground biomass is identical regardless of the initial meadow state. For the years 1996, 1997, 1998, and 2002, steady-state aboveground and belowground biomass is reached only from the dense initial meadow state, with the sparse meadow initial condition collapsing to the bare sediment state. From both a sparse and dense meadow initial condition, the year 2004 collapsed to the bare sediment state. 

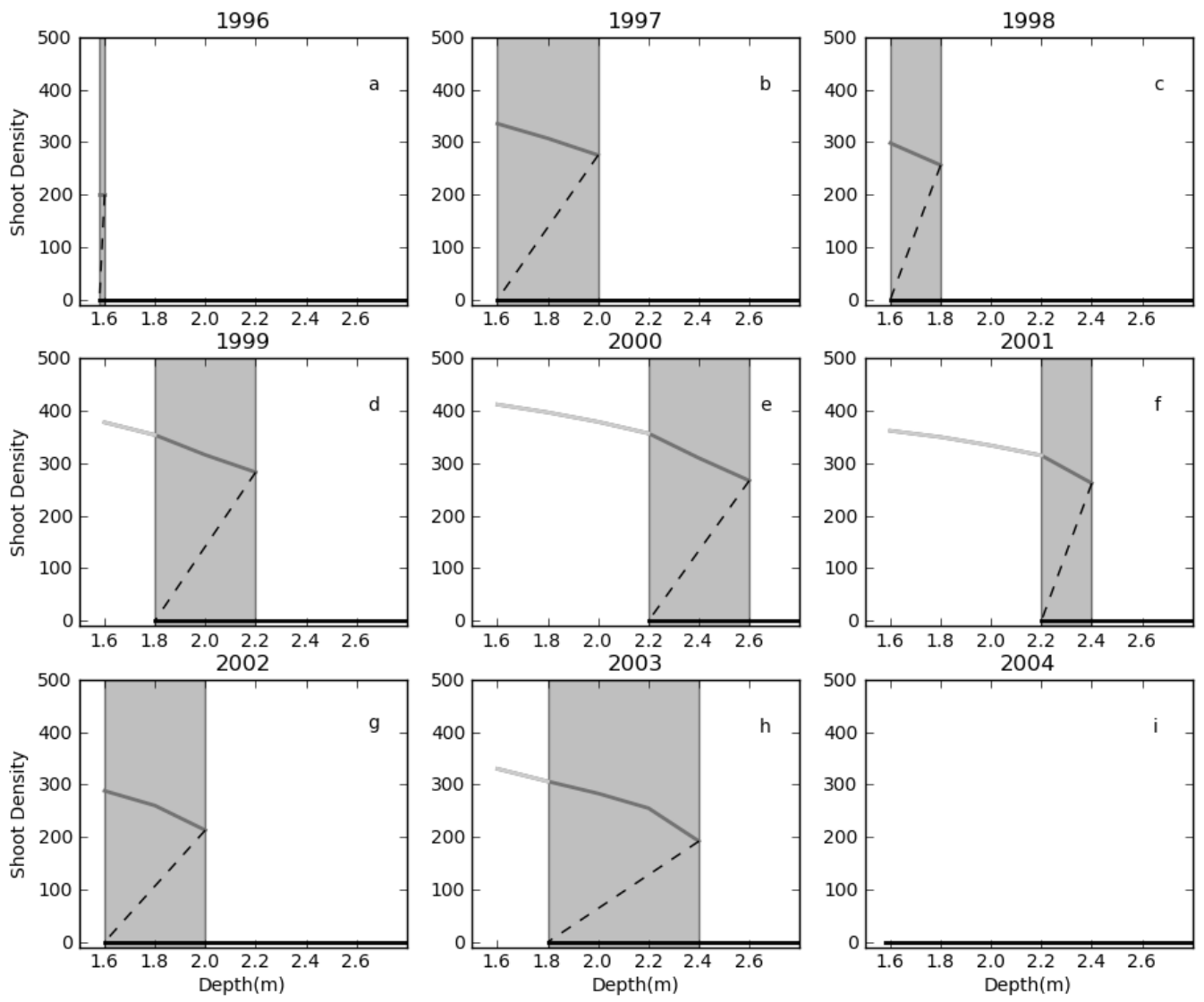

Figure 2. Stability and bistability as a function of depth for the steady-state runs of years 19962004 (panels a-i). 

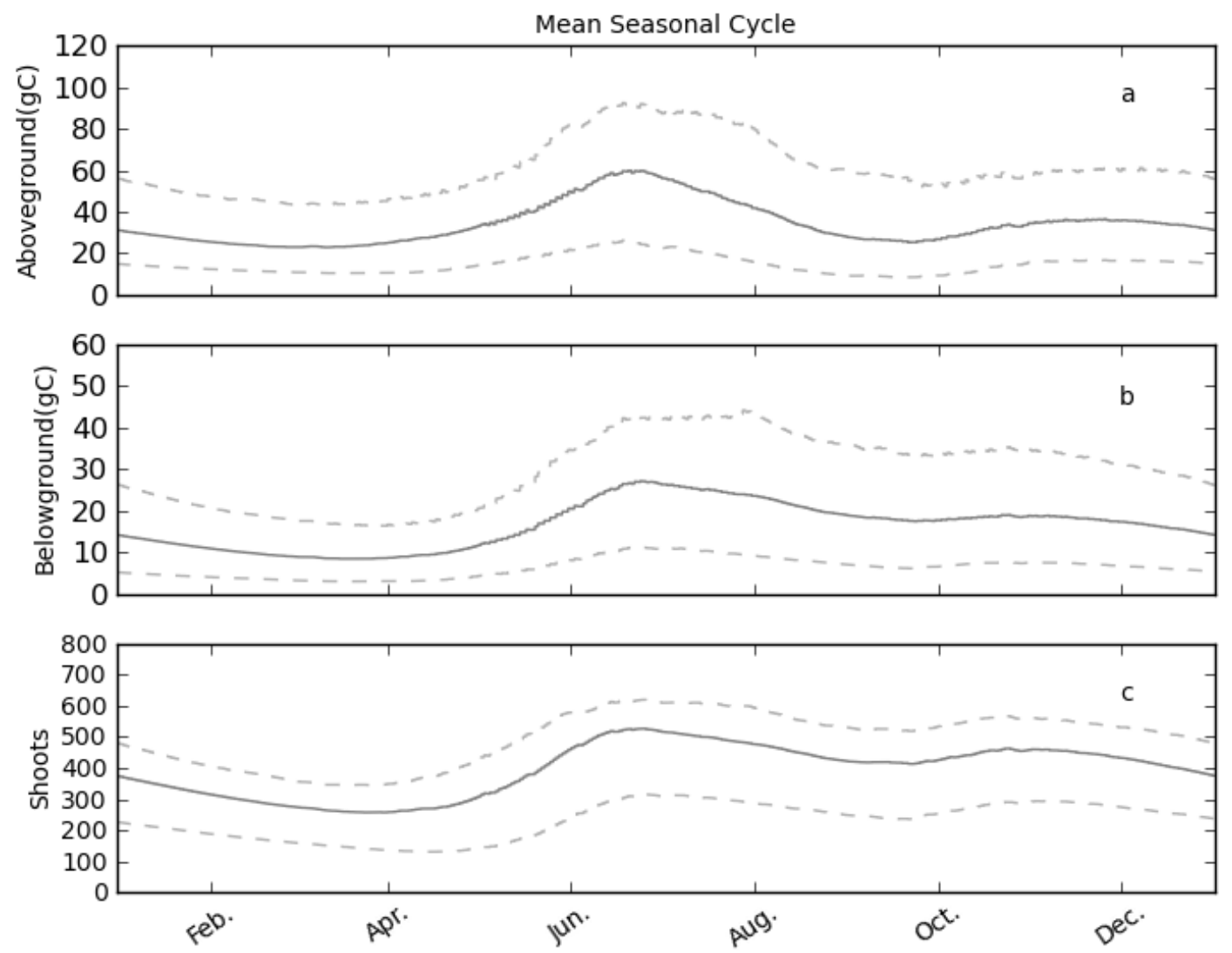

Figure 3. Mean seasonal a) aboveground biomass (gC), b) belowground biomass (gC), and c) shoot densities (shoots $\mathrm{m}^{-2}$ ) at $1.6 \mathrm{~m}$ depth for 200 randomly driven simulation years. Dashed lines indicate maximum and minimum values. 


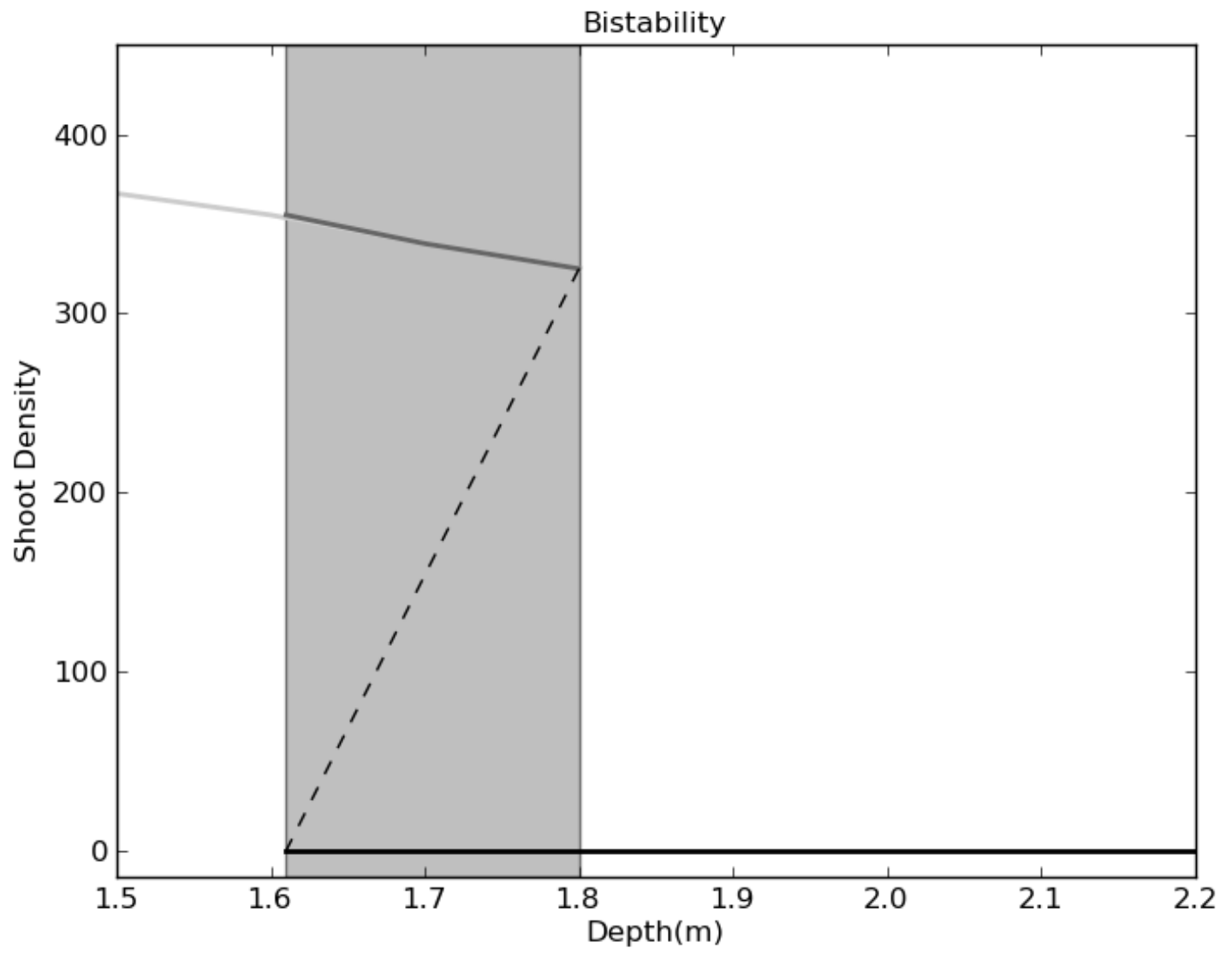

Figure 4. Bistability as a function of water depth, under random drivers. 

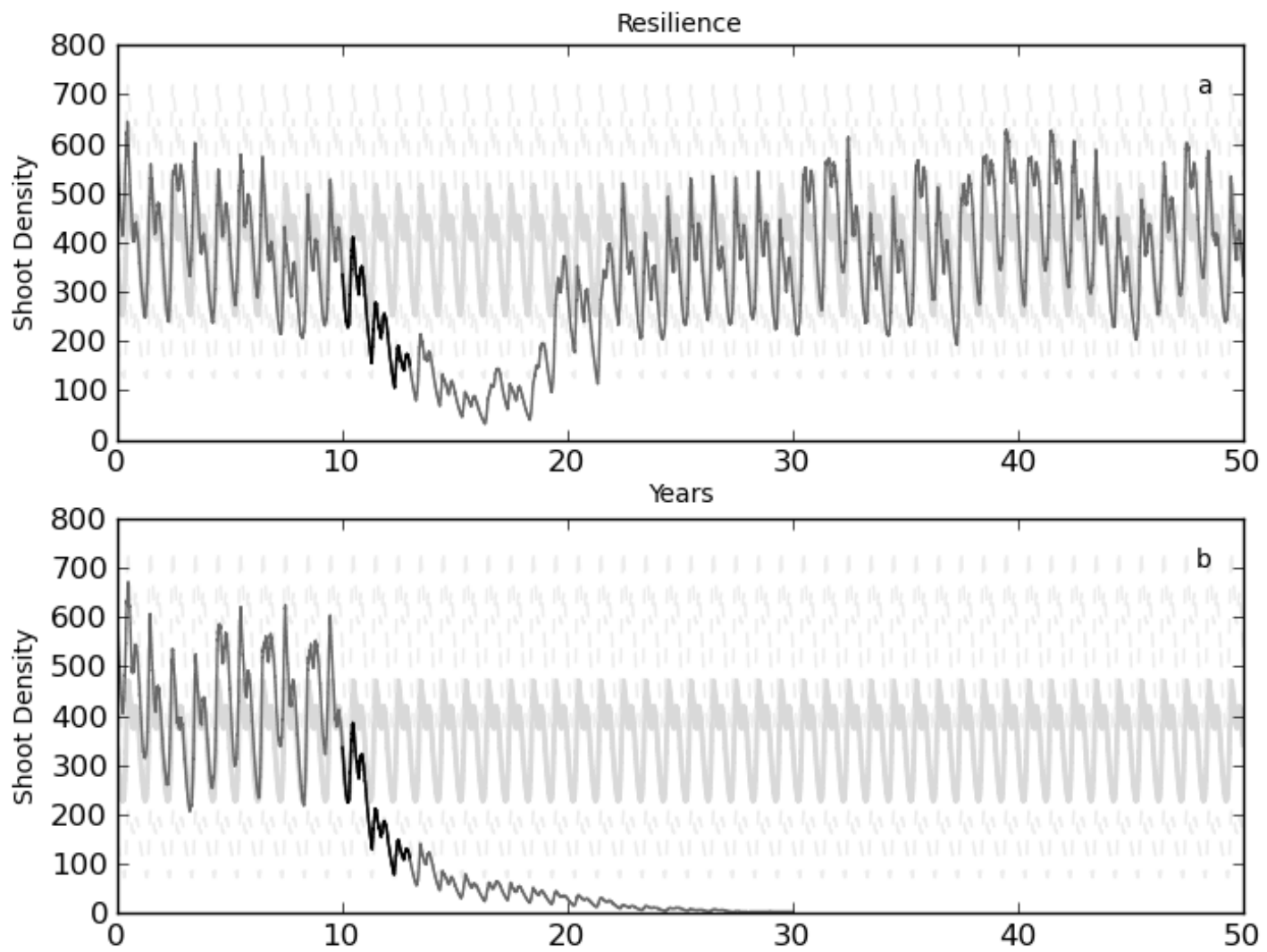

Figure 5 a) Resilience of an initially dense meadow at 1.6 m MSL under three consecutive bad years initiated at simulation year 10. b) Collapse of a meadow at 1.8 m MSL undergoing the same three consecutive poor years. Gray solid line indicates shoot densities corresponding to the seasonal mean with gray dashed lines indicating plus or minus two standard deviations. 


\section{Tables}

\section{Table 1. Limitation Functions and Parameters}

\begin{tabular}{|c|c|}
\hline Limitation function & Description, values and source \\
\hline$I=I_{\text {surface }} e^{-K_{d} \square d}$ & $\begin{array}{l}\text { Irradiance at depth where } h_{d} \text { is the distance from the water surface to the } \\
\text { deflected canopy and } K_{d} \text { is the light attenuation coefficient. [Lawson et al., } \\
\text { 2007] }\end{array}$ \\
\hline$I_{K}=I_{K 20} \theta_{K}^{T-20}$ & $\begin{array}{l}\text { Saturation irradiance as a function of temperature where } I_{K 20} \text { is saturation } \\
\text { value at } 20^{\circ} \mathrm{C} \text { set to } 25.5 \text { and } \theta_{K} \text { is shape value set to } 1.04 \text {. [Zharova et al., } \\
\text { 2001] }\end{array}$ \\
\hline$I_{C}=I_{C 20} \theta_{C}^{T-20}$ & $\begin{array}{l}\text { Compensation irradiance as a function of temperature where } I_{C 20} \text { is } \\
\text { compensation value at } 20^{\circ} \mathrm{C} \text { set to } 2.4 \text { and } \theta_{C} \text { is shape value set to } \\
1.17 \text { [Zharova et al., 2001] }\end{array}$ \\
\hline $\begin{array}{ll}F_{I}(I)=0 . & \text { for } I \leq I_{C} \\
F_{I}(I)=1 . & \text { for } I \geq I_{K} \\
F_{I}(I)=\frac{I-I_{C}}{I_{K}-I_{C}} & \text { for } I_{C} \leq I \leq I_{K}\end{array}$ & Light limitation function. [Zharova et al., 2001] \\
\hline $\begin{array}{l}F_{p \sqsubset o t}(T)=K_{0 p \square o t}^{\left(\frac{T_{o p t-T}}{T_{o p t}}\right)^{2}} \text { for } T \leq T_{o p t} \\
F_{p \sqsubset o t}(T)=K_{m p \square o t}^{\left(\frac{T-T_{o p t}}{T_{m a x}-T_{o p t}}\right)^{2}} \text { for } T>T_{o p t}\end{array}$ & $\begin{array}{l}\text { Temperature photosynthesis limitation function. } T_{\text {opt }} \text { is the optimum } \\
\text { temperature for photosynthesis set to } 21.5^{\circ} \mathrm{C} . T_{\max } \text { is the maximum } \\
\text { temperature for photosynthesis set to } 34^{\circ} \mathrm{C} \text {. } K_{0 \text { phot }} \text { is a shape coefficient set } \\
\text { to 0.01and } K_{\text {mphot }} \text { a shape coefficient set to } 0.00001 \text {. [Zharova et al., 2001] }\end{array}$ \\
\hline $\begin{array}{l}F_{a g e}=1 \text { for ages }<=\min _{\text {age }} \text { days and } P_{n, 0} \\
F_{\text {age }}=1-.99\left(\text { age- }-\min _{\text {age }}\right) /\left(\max _{\text {age }}-\min _{\text {age }}\right) \text { for } \\
\min _{\text {age }}<\text { ages }<=\max _{\text {age }} \text { days } \\
F_{\text {age }}=.01 \text { for ages }>\max _{\text {age }} \text { days }\end{array}$ & $\begin{array}{l}\text { Leaf age limitation function. } \text { min }_{\text {age }}=70, \max _{\text {age }}=160 \text { [Hemminga and } \\
\text { Duarte, 2000; Verhagen and Nienhuis, 1983] }\end{array}$ \\
\hline$F_{T}(T)=\theta_{\text {loss }}^{T-20}$ & $\begin{array}{l}\text { Temperature respiration scaling function. } \theta_{\text {loss }} \text { is shape value set to } 1.05 \\
\text { [Zharova et al., 2001] }\end{array}$ \\
\hline$L_{\text {lim }}$ & $\begin{array}{l}\text { Maximum leaf length limit, set to } 1 \text { if leaf length is less than } 1 \mathrm{~m} \text {, } \\
\text { otherwise set to } 0\end{array}$ \\
\hline$R_{\lim }$ & $\begin{array}{l}\text { Above to below ground biomass ratio limitation, set to } 1 \text { if the ratio is less } \\
\text { than } 4.0 \text {, otherwise set to } 0\end{array}$ \\
\hline$N_{\text {lim }}$ & $\begin{array}{l}N_{l i m}=1-\left(\frac{N}{N_{c c}}\right)^{2} \text { for } N \text { less than } N_{c c} \text { otherwise set to } 0 \text {. Maximum shoot } \\
\text { density, } N_{c c} \text { set to } 1000 \text { shoots } \mathrm{m}^{-2} \text {. }\end{array}$ \\
\hline
\end{tabular}




\begin{tabular}{|l|l|}
\hline$P_{\text {lim }}$ & $\begin{array}{l}\text { Maximum biomass of a single leaf set to } 0.12 \mathrm{gC} \text { corresponding to a } \\
\text { maximum above ground single shoot biomass of } .5 \mathrm{gC} \text { with } 4 \text { leaves of } \\
\text { equal biomass. }\end{array}$ \\
\hline
\end{tabular}

Table 2. Model Parameters and Sources

\begin{tabular}{|c|c|}
\hline Parameter & Description and Source \\
\hline$\tau_{c r}$ & $\begin{array}{l}0.04\left(\mathrm{~Pa} \mathrm{~m}^{-2}\right) \text { is the critical shear stress to erode } \\
\text { sediment. [Lawson et al., 2007]. }\end{array}$ \\
\hline max $_{\text {resp }}$ & Respiratory loss rate 0.014 per day [Bach, 1993]. \\
\hline $\max _{\text {pht }}$ & $\begin{array}{l}\text { Maximum specific growth rate } 0.095 \text { per day [Bach, } \\
\text { 1993]. }\end{array}$ \\
\hline $\max _{\text {elong }}$ & $\begin{array}{c}\text { Maximum elongation rate } 0.00164 \mathrm{~m} \text { per hour [Kemp et } \\
\text { al., 1987] }\end{array}$ \\
\hline $\max _{\text {Ngrow }}$ & $\begin{array}{l}\text { Maximum shoot recruitment .028 [Zharova et al., } \\
\text { 2001]. }\end{array}$ \\
\hline$N_{\text {loss }}$ & $\begin{array}{l}\text { Shoot mortality rate } 0.0065 \text { per day [Zharova et al., } \\
\text { 2001]. }\end{array}$ \\
\hline$P_{\text {new }}$ & $\begin{array}{c}\text { Biomass of a new shoot and single leaf set to } .0024 \\
\text { gC[Zharova et al., 2001] }\end{array}$ \\
\hline$\gamma$ & $\begin{array}{l}\text { Belowground respiration rate set to } 0.009 \text { per day } \\
\text { [Zharova et al., 2001]. }\end{array}$ \\
\hline Sparse Meadow & $\begin{array}{c}3 \text { shoots } \mathrm{m}^{-2}, \mathrm{R}=2 \mathrm{gC}, \quad 3 \text { leaves per shoot, } \mathrm{P}=.08 \mathrm{gC} \text { per } \\
\text { leaf }\end{array}$ \\
\hline Dense Meadow & $\begin{array}{c}640 \text { shoots } \mathrm{m}^{-2}, \mathrm{R}=40 \mathrm{gC}, \sim 3 \text { leaves per shoot, } \mathrm{P}=.09 \\
\text { gC per leaf }\end{array}$ \\
\hline
\end{tabular}


Table 3. Effects of the presence or absence of a canopy on the bottom shear stress, and the number of growing hours undergoing transport events for steady-state arriving from the sparse (3 shoots $\mathrm{m}^{-2}$ )and dense meadow (640 shoots $\mathrm{m}^{-2}$ ) initial conditions. Years were sorted based on the number of growths hours with transport events.

\begin{tabular}{|c|c|c|c|c|c|}
\hline & $\tau_{b}>\tau_{\text {crit }}$ & Mean $\tau_{b}>\tau_{\text {crit }}$ & $\begin{array}{c}\text { Mean } \tau_{b}>\tau_{\text {crit }} \text { with } \\
\text { canopy }\end{array}$ & \multicolumn{2}{|c|}{ Hours of growth with $\tau_{b}>\tau_{\text {crit }}$} \\
\hline Year & hours & $\left(\mathrm{Pa} \mathrm{m}^{-2}\right)$ & $\left(\mathrm{Pa} \mathrm{m}^{-2}\right)$ & Sparse (hours) & Dense(hours) \\
\hline 2004 & 1969 & 0.0570 & - & 1056 & 1056 \\
\hline 1996 & 2003 & 0.0481 & 0.0419 & 1080 & 816 \\
\hline 2002 & 1661 & 0.0441 & 0.0361 & 984 & 528 \\
\hline 1998 & 1922 & 0.0497 & 0.0336 & 936 & 264 \\
\hline 1997 & 2041 & 0.0478 & 0.0322 & 912 & 240 \\
\hline 2003 & 1806 & 0.0457 & 0.0306 & 408 & 288 \\
\hline 1999 & 2144 & 0.0461 & 0.0298 & 312 & 312 \\
\hline 2000 & 2121 & 0.0476 & 0.0280 & 0.0248 & \\
\hline 2001 & 1912 & 0.0471 & & & 288 \\
\hline
\end{tabular}


Table 4. Steady-state wintering shoot density at $1.6 \mathrm{~m} \mathrm{MSL}$, and the number of years to reach steady-state from the sparse ( 3 shoots $\mathrm{m}^{-2}$ ) and dense meadow (640 shoots $\mathrm{m}^{-2}$ ) initial conditions along with days of growth and loss for the nine driving years.

\begin{tabular}{|l|c|c|c|c|c|c|c|c|}
\hline & Sparse & Sparse & Dense & Dense & Stability & Growth & Loss & T $>30$ \\
\hline Year & shoots $\mathrm{m}^{-2}$ & Years to SS & shoots $\mathrm{m}^{-2}$ & Years to SS & & days & days & days \\
\hline 2004 & 0 & 4 & 0 & 18 & Bare & 280 & 85 & 2 \\
\hline 1996 & 0 & 3 & 309 & 11 & Bistable & 247 & 119 & 15 \\
\hline 2002 & 0 & 10 & 385 & 5 & Bistable & 301 & 64 & 11 \\
\hline 1998 & 0 & 6 & 417 & 3 & Bistable & 285 & 80 & 11 \\
\hline 1997 & 0 & 10 & 461 & 2 & Bistable & 288 & 77 & 18 \\
\hline 2003 & 496 & 23 & 497 & 1 & Seagrass & 276 & 89 & 0 \\
\hline 1999 & 547 & 13 & 546 & 1 & Seagrass & 302 & 63 & 5 \\
\hline 2000 & 568 & 7 & 569 & 1 & Seagrass & 334 & 31 & 0 \\
\hline 2001 & 602 & 7 & 603 & 1 & Seagrass & 309 & 56 & 0 \\
\hline
\end{tabular}


Table 5. Comparison between model output and site measured values.

\begin{tabular}{|c|c|c|c|}
\hline \multirow{3}{*}{ Maximum Blade Lengths (cm) } & \multicolumn{2}{|c|}{ Measured } & Modeled \\
\cline { 2 - 4 } & January & 13.9 & 19.0 \\
\cline { 2 - 4 } & Jay & 28.0 & 32.3 \\
\cline { 2 - 4 } Shoot density (shoots $\mathrm{m}^{-2}$ ) & January & 261 & 340 \\
\cline { 2 - 4 } & May & 409 & 400 \\
\cline { 2 - 4 } & June & 562 & 520 \\
\hline
\end{tabular}




\section{Chapter 4: MODELING THE EFFECTS OF CLIMATE CHANGE ON SEAGRASS STABILITY AND RESILIENCE: FUTURE SCENARIOS AND LEADING INDICATORS OF COLLAPSE}

\section{Abstract}

Seagrass meadows influence local hydrodynamics in coastal bays, resulting in a decrease in the shear stress acting on the underlying bed sediment. The reduced sediment suspension and water column turbidity creates a more favorable light environment for further seagrass growth. This positive feedback is strong enough to induce depthdependent bistable dynamics with two possible stable states, an extant meadow and a bare sediment surface. A coupled vegetation-growth hydrodynamic model was used to investigate seagrass stability and leading indicators of ecosystem shift under the effects of sea-level rise and increases in water temperature associated with climate change. The model was applied to Hog Island Bay, a shallow coastal bay within the Virginia Coast Reserve (VCR) where seagrass restoration efforts are ongoing. The results indicate that while extant seagrass meadows are likely to tolerate sea-level rise, an increase in the frequency of days when summer water temperature exceeds $30^{\circ} \mathrm{C}$ will cause more frequent summer die offs. This increase in the number of higher temperature disturbance events is likely to push a dense meadow initially located within the bistable depth range (1.6 - $1.8 \mathrm{~m}$ mean sea level) toward and eventually past a critical bifurcation point, from which recovery is not possible. We identified two leading indicators of a meadow nearing this bifurcation point, both associated with the number of leaves per shoot: “flickering”, which reflects conspicuous fluctuations from one attractor to the other across the threshold, and "slowing down", which is the increased persistence of the fluctuations as a system gets close to a threshold due to its inability to recover. Our model indicates that 
the seagrass in these coastal bays have limited resilience to increases in water temperatures predicted from current climate change models.

\section{Introduction}

While subtidal seagrass meadows and the surrounding salt marshes are highly productive ecosystems that provide critical ecosystem services, they are also susceptible to changes in nutrient, sediment and freshwater delivery due to changes in land use and population density (Viaroli et al. 1996, Havens et al. 2001, Nixon et al. 2001). Increased water temperature and depth associated with climate change also pose potential threats to the health of seagrass meadows (Najjar et al. 2000, Cazenave et al. 2008, Keller 2009). The shallow depths of coastal bays provide a good environment for benthic primary productivity of species with high light requirements, such as seagrasses (Duarte 1991, Dennison et al. 1993, Zimmerman et al. 1995). However, these shallow depths also increase the vulnerability of the bed sediment to resuspension by waves and currents, increasing water column turbidity and adversely affecting the light environment. In coastal bays that lack a significant river sediment supply, internal sediment resuspension is typically the dominant control on water column turbidity (Lawson et al. 2007).

The presence of seagrass reduces the wave and current shear stresses acting on the underlying bed sediment, reducing resuspension, and enhancing deposition of fine sediment (Folkard 2005). This can lead to less turbid waters and a more favorable light environment. This positive feedback whereby a decrease in seagrass density decreases favorable light conditions, causing further loss of seagrass has been shown to induce bistable dynamics (van der Heide et al. 2007, Carr et al. 2010). The emergence of 
bistability in ecosystems has important implications. Bistable systems exhibit nonlinear behavior in their response to environmental drivers, and can undergo rapid shifts between states due to only small changes in environmental conditions. Similarly, bistable systems are associated with limited resilience in that if the system is perturbed past a critical threshold, the system collapses to the alternate state (Wilson \& Agnew 1992). In this case, a seagrass meadow undergoing a disturbance, either in magnitude, duration, or frequency, may pass into a state from which it cannot recover, resulting in loss of the seagrass meadow. The high turbidity environment of the now bare sediment inhibits establishment of new meadows, and the system is locked in the alternate stable state, even if the conditions improve. Because of the abrupt and often irreversible character of these transitions, ecosystem managers need to be able to recognize whether a system is about to shift from a seagrass-covered bottom to a bare sediment state. However, such ecosystem shifts, may or may not be associated with early warning signs (Hastings 2010). As such, it is important to not only identify the threshold between the two attraction domains (Brock \& Carpenter 2010), but also to recognize early warning signs, if they exist, that the system is about to cross the threshold between regimes.

It is difficult to predict these transition points because the state of the system may display little change prior to the transition (Scheffer et al. 2009). In some systems there is a critical slowing down effect (van Nes and Scheffer, 2007), whereby as the system approaches the bifurcation point, its response to small perturbations (i.e., small displacement from stable equilibrium) becomes increasingly slow. This slowing down results in an increased autocorrelation of the state variable and possibly an increase in 
variance when nearing the critical threshold (Scheffer et al. 2009). Another possible symptom of being near the critical bifurcation point is flickering, which occurs when environmental or stochastic drivers are strong enough to induce relatively rapid oscillations between attraction domains of a system near the critical bifurcation point (Scheffer et al. 2001, Scheffer et al. 2009, Brock \& Carpenter 2010) (Fig. 1). Regardless of the specific metric, evidence of a system being near catastrophic collapse is important for mitigation management practices, and also provides insight to guide and monitor successful restoration efforts. However, the sensitivity of these systems to natural and anthropogenic drivers complicates the development and implementation of successful management strategies.

To guide restoration and management efforts as well as to improve our understanding of the susceptibility of shallow coastal bays to changes in climate drivers and disturbances - including sea-level rise and temperature increase - we apply a coupled seagrass growth and hydrodynamic model (Carr et al. submitted) to a set of scenarios reflecting expected future increases in sea level and water temperature in a shallow coastal bay. This model is used to investigate the strength of the feedback between water quality and seagrass ecosystems, the impact of these feedbacks on the stability and resilience of estuarine seagrass meadows (van der Heide et al. 2007), and possible leading indicators of a ecosystem shift. 


\section{Methods}

\section{Study area:}

The model was applied to coastal bays of the Virginia Coast Reserve Long Term Ecological Research site, located on the Atlantic side of the Delmarva Peninsula (VCR LTER, $\left.37^{\circ} 25^{\prime} \mathrm{N}, 7^{\circ} 46^{\prime} \mathrm{W}\right)$. The coastal bays in this system were dominated by seagrasses (Zostera marina) until the 1930’s when the seagrasses, under stress from disease, were extirpated by a hurricane (Orth et al. 2006). Restoration efforts were prompted when small natural patches of seagrass were discovered in the late 1990's. Seagrass meadows now cover some 1700 ha in the VCR coastal bays (Orth et al., this issue). Nutrient loading of the coastal bays is low and water column chlorophyll levels are also very low (Cole and McGlathery, submitted; VCR LTER data base, www1.vcrlter.virginia.edu/home1/?q=data_wq).

Hog Island Bay is representative of the shallow bays in the VCR and serves as our study site. Hog Island Bay has a tidal range of roughly $1.2 \mathrm{~m}$ with half the bay less than a meter deep at mean low water (Oertel 2001). The sediment at the bay bottom ranges from fine sand to fine silt. Wind-driven resuspension dominates sediment transport in the bay, with dominant storms occurring from October to April (Lawson et al. 2007). Restored seagrass meadows exist in Hog Island Bay between 0.6 and $1.6 \mathrm{~m}$ depths at mean sea level (MSL) (McGlathery et al, this issue). Locally, climate change is expected to generate a 30-year increase in MSL of $12 \mathrm{~cm}$ and an increase of $1.3{ }^{\circ} \mathrm{C}$ in mean water temperature (Najjar et al. 2000). 


\section{Modeling framework:}

The model couples a hydrodynamic/light model (Carr et al. 2010) with a daily

growth model (Carr et al, submitted; Tables 1, 2, and 3) and is used to estimate the annual and interannual morphology of a $1 \mathrm{~m}^{2}$ patch of a seagrass meadow one meter in from the edge of the meadow. The seagrass growth model is built upon prior efforts to model seagrass dynamics (Verhagen \& Nienhuis 1983, Zharova et al. 2001). The primary difference in our approach is that biomass is allocated and kept track of by accounting for the distinct structural components (e.g., leaves and stem, where stem is defined as the rigid base of the shoot) for each shoot (Carr et al., submitted).

The hydrodynamic model (Carr et al. 2010) simulates the one-dimensional dynamics (in the vertical direction) of sediment entrainment/settling within the water column. It accounts for the effect of seagrass vegetation on these dynamics, including its effect on the velocity profile, eddy diffusivity, shear-flow dispersion, and wave and current shear stress. At the same time it accounts for the effect of flow on the height of the deflected seagrass canopy. Values of suspended sediment concentrations calculated by the model are used to determine the degree of light attenuation within the water column (from the water surface to the top of the canopy) and to calculate light availability for the seagrass meadow.

Growth of the seagrass meadow was modeled (Carr et al., submitted.) based on available irradiance and water temperature conditions. Seagrass biomass is allocated among individual leaves and shoots, which transfer a fraction of aboveground production to a combined rhizome biomass. The growth model utilizes rhizome biomass storage to 
form a new shoot and leaf. Based on leaf productivity of that shoot, biomass is then transferred into new leaf growth, leaf elongation and back to rhizome storage. Senescence of aboveground biomass is due to: a) leaves reaching a maximum age, b) respiratory losses, and/or c) shoot mortality. Rhizome biomass is lost due to: a) respiration, b) new shoot recruitment, or c) uprooting when a shoot is lost. As productivity is a direct function of water temperature and available irradiance (which, in turn, depends on suspended sediment concentration), the model was used to explore the effects of annual and interannual temperature and wave-current conditions on the resilience and stability of a seagrass meadow.

\section{Model simulations:}

For any given year hourly measured tides, winds, and water temperatures from the NOAA Wachapreague Station (WAHV2, 37³6'24" N, 75²41'12" W) and photosynthetically-active radiation (PAR) from the VCR-LTER flux tower at Fowling Point (372 $24^{\prime} \mathrm{N}, 75^{\circ} 50^{\prime} \mathrm{W}$ ) were used as external drivers for the model. For each onehour time step, PAR reaching the canopy was calculated following Carr et al. (2010). Average daily water temperature and net daily PAR reaching the canopy were then used to drive the growth model on a daily time step. Summary statistics of growth conditions of the various years can be found in Table 4.

Combined with a specified sediment grain size distribution (Table 5), water depth relative to MSL and an initial seagrass meadow state of above and belowground biomass, shoot and leaf densities (Table 3), the model calculated annual growth or senescence of the seagrass within a meadow. The modeled meadow state at the end of any given year 
was used as the input meadow state for the following year, allowing us to model longterm changes in the meadow, investigate the ecosystem's stability and emergent bistability due to the hydrodynamic feedback, and explore how an expected 30-year increase in MSL of $12 \mathrm{~cm}$ and mean water temperature of $1.3{ }^{\circ} \mathrm{C}$ will affect the stability of seagrass meadows.

Years of forcing conditions (winds, tides, water temperature and PAR) were selected from data records from 1996 through 2004 to form randomized 150 year-long sequences. Using these sequences at initial water depths ranging from 1.5 to $2.0 \mathrm{~m}$ MSL in $0.1 \mathrm{~m}$ increments, and by starting a meadow from both an initial dense and sparse meadow state (Table 3), we explored the attractors of the system (seagrass meadow or bare sediment state) as a function of water depth and meadow state. To investigate the sensitivity of these attractors to sea-level rise and warming, 5 randomized-30 year sequences of forcing conditions were used to drive the model with an identical initial dense meadow of 640 shoots $\mathrm{m}^{-2}$, for the same depth range. Two of the five 30-year sequences of drivers were identical across water depths to allow for direct behavioral comparison of how meadows initiated at different water depths react to the same sequence of environmental drivers. Averaging the five runs allowed for exploring the general behavior of the meadow. Three scenarios were explored in these simulations: 1) sea-level rise of $4 \mathrm{~mm}$ per year for 30 years, 2) increase of $0.046{ }^{\circ} \mathrm{C}$ per year in water temperature for 30 years, and 3) combined sea-level rise and temperature increase for 30 years. 


\section{Results}

\section{Overview}

Meadows between 1.6 and 1.8 m MSL were found to display bistable behavior, with meadows initiated from a sparse canopy state unable to grow in waters deeper than 1.6 m MSL and dense meadows shallower than 1.8 m MSL able to maintain a favorable light environment. Meadows within this bistable range exhibited limited resilience such that a sequence of disturbances (years with poor light and temperature conditions) could shift a meadow into the attraction domain of the bare sediment state (Fig. 2). Thus, simulations aimed at exploring the effect of sea-level rise and increasing water temperatures were expected to show that meadows initialized at 1.5 and $1.6 \mathrm{~m}$ m MSL remain dense under an increase in MSL of $4 \mathrm{~mm}$ per year for 30 years (total increase of $0.12 \mathrm{~m}$ ), whereas meadows initiated at $1.8 \mathrm{~m}$ MSL or deeper should show slow decline in shoot density. We also expected the meadow initiated at $2.0 \mathrm{~m}$ to decline within 40 years as at that water depth the only attraction domain of the dynamics is bare sediment. Similarly, across all water depths an increase in water temperature was expected to decrease net productivity of the seagrass meadows with catastrophic losses when summer temperature exceeded $30^{\circ} \mathrm{C}$ for weeks at a time.

\section{Seagrass stability and resilience under sea-level rise and warming scenarios}

Annual shoot densities were averaged for the five random 30-year simulations to examine the general effect of sea-level rise, increased temperature and the combined effects of sea-level rise and temperature as a function of initial starting depth. Under sealevel rise only, for water depths of 1.5 and $1.8 \mathrm{~m} \mathrm{ML}$, a extant meadow was present on average at the end of the 30 years (Fig. 3a). Meadows initiated in deeper water on 
average showed a general slow decline with two of the five meadows initiated at $2.0 \mathrm{~m}$ MSL collapsing to the bare sediment state by the end of the 30 year period. The meadows initiated at $1.9 \mathrm{~m}$ MSL did not begin to show decline until after 20 years with an extant although declining meadow for each of the five runs at the end of the 30 -year period (data not shown).

Increased water temperature caused meadows to experience sudden collapses sometime after 20 years due to the increased frequency of high summer temperature events (Table 1, Fig. 3b); this occurred for all water depths including some sequences at $1.5 \mathrm{~m}$ MSL (Fig. 4b). These collapses resulted in the abrupt loss of approximately 100 shoots in shallower water, with wholesale loss possible in water deeper than $1.7 \mathrm{~m}$ MSL. In one run (Fig. 4b) shoot loss at $1.5 \mathrm{~m}$ MSL occurred as a result of encountering two significant disturbance events (years with high summer temperatures) with only three years of recovery in between. Initial depths less than 1.7 m MSL all displayed some residual meadow at the end of 30 years, indicating still favorable growth conditions (i.e., the meadow remains in the attraction domain of a dense meadow). However with increasing frequency and magnitude of disturbance due to increased temperature alone, it is unlikely that a dense meadow would be able to reestablish. Meadows initiated at $1.7 \mathrm{~m}$ MSL and deeper exhibited collapse to bare sediment after a single disturbance event. In all cases this significant disturbance event corresponded with increased temperatures (Table 4), where the duration of extremely high water temperatures in the summer months results in significant loss of leaves and shoots (Fig. 3b) 
Under the combined increase in MSL and water temperature, meadows which fell into the bistable range between 1.6m MSL and 1.8 m MSL when sea-level rise alone was considered, all collapsed to the bare state as a result of limited resilience to the now more frequent disturbance events (Fig. 3c, 4c). Time to collapse varied but was predominantly a function of initial meadow depth, with meadows in deeper waters being more susceptible (Table 6.)

\section{Leading indicators of ecosystem shift}

We explored whether leading indicators of an ecosystem shift can be found in 1) the change in standard deviation of the number of leaves per shoot for each day of the year and 2) trends in the mass distribution of empirical distribution functions (edf's) approaching the bifurcation point. Unlike other authors (Carpenter 2006, Guttal \& Jayaprakash 2008) we did not find any leading indicators of state shift in standard deviation, skewness or autocorrelation. While standard deviation and suitable metrics of multimodality increase as the system temporarily enters into the domain of attraction of bare sediment, these metrics were not good leading indicators of state change, in that they did not exhibit any symptomatic changes as the system approached the bifurcation point. However, close to this point, seagrass meadow behavior exhibited conspicuous fluctuations from one attractor to the other across the threshold, a phenomenon known as “flickering” (Scheffer et al., 2009) (Fig. 1). Every time the system shifted into the domain of attraction of bare sediment, the probability distribution of the number of leaves per shoot exhibited an increase at the lower leaf-per-shoot end of the distribution. This increase was due to leaf loss and/or high new shoot mortality. 
In a meadow near the critical bifurcation point, an increase the number of shoots with $<2$ leaves was not only more significant (Fig. 6b), but became more persistent until the meadow collapsed (Fig. 7b, 8b). This increasing persistence is a typical indicator of a system slowing down close to a threshold due to its inability to recover (Scheffer et al., 2009). Under these conditions, a meadow which initially is oscillating back and forth across the threshold, begins to remain more frequently in the attractive domain of the bare sediment state (Fig. 7b, 8b). Therefore, the emergence of substantial flickering (evidenced by oscillation in the mass distribution less than 2 leaves per shoot) appears to be a leading indicator of proximity to a fold bifurcation. As the flickering diminished and the mass distribution of shoots with $<2$ leaves remained relatively high (Fig. 7b, 8b), the meadow was susceptible to fully crossing into an unrecoverable bare sediment state.

\section{Discussion}

Prior efforts have examined the loss of resilience, the existence of alternate stable states and possible leading indicators of ecosystem shift in various systems (Gunderson 2000, Scheffer \& van Nes 2004). Here we demonstrate that the emergence of bistable dynamics due to the prior established positive feedback between seagrass and its light environment (de Boer 2007, van der Heide et al. 2007, Carr et al. 2010) plays an important role regarding the resilience of these meadows to the increased stresses of climate change, namely sea-level rise and warmer temperatures. The results indicate that while meadows shallower than 1.6 m MSL for our study site are currently stable and can be expected to remain within the stable light growth environment, the onset of increased water temperatures is likely to cause significant, but reversible collapse of these meadows. The expected effect of increased sea level is to push a meadow initially 
located within the attraction domain of a dense meadow towards the bistable depth range whereby the meadows will possess limited resilience. Frequent disturbances (e.g. years with poor growing conditions) may push the meadow into the attraction domain of the bare sediment state. Thus, as sea level increases, these meadows will begin to show limited resilience to disturbance events. Increases in water temperature (Moore \& Jarvis 2008) effectively increase the frequency of disturbance, as more years exhibit extended periods of high summer temperatures (Table 4) associated with significant die off. As such, the more frequent occurrence of high-temperature events in the summer can rapidly push a meadow located within the bistable depth range past the critical bifurcation point and into the attraction domain of the bare sediment state from which irreversible collapse occurs. Sea-level rise alone can push a meadow into the attractive domain of the bare sediment state for depths that increase below the bistable range, however, collapse of these meadows are slow (Fig. 3a, 4a) in contrast to the rapid losses brought about by summer high temperature events (Fig. 3b, 3c, 4b and 4c).

Our results indicate that extant seagrass meadows in the VCR LTER are unlikely to fail due to increases in sea-level rise alone, as rhizome branching rates and seed dispersal should be able to maintain migration of the meadows toward shallower waters. A benefit of sea-level rise for the seagrasses in Hog Island Bay is that the area of suitable habitat (area deeper than 0.6 m MSL and shallower than 1.6m MSL) will increase over the next thirty years based on hypsometry (Fig. 9). The area of the bay exhibiting bistable behavior (area between 1.6 m MSL and 1.8 m MSL) will also increase. However, the results also indicate that the seagrass meadows of the VCR LTER are likely 
to undergo severe die offs due to extended summer periods with increased water temperatures. This is consistent with observed high temperature effects on Zostera marina (Duarte 2002, Moore \& Jarvis 2008). With a continued increase in water temperature, eventually the coastal bays of the VCR will not be suitable habitat for Zostera marina. Thus, while the meadows are able to moderate their light environment and increasing sea level increases the total area of suitable habitat, an increase in water temperature is likely to have significant and catastrophic effects.

From the ecosystem management standpoint, knowledge of whether seagrass meadows are approaching a bifurcation point is crucial to timely seagrasses conservation efforts. A bifurcation point is not readily measureable or identifiable as it is a function of both the current meadow state and the environmental drivers. As such, we attempted to identify what traits a seagrass meadow exhibits when it approaches or crosses the transition point to the bare sediment state. We focused on meadow characteristics that are most readily measured, such as leaf density, shoot density and number of leaves per shoot. We found that, while density metrics are not adequate to predict the location of the critical bifurcation point, the number of leaves per shoot for a meadow may be a useful indicator.

Comparing simulations of seagrass meadows initiated at depths of $1.5 \mathrm{~m} \mathrm{MSL}$, 1.8 $\mathrm{m} \mathrm{MSL}$ and $2.0 \mathrm{~m}$ MSL experiencing the same sequence of randomized forcing under varying temperature and sea-level conditions allowed us to examine the dynamics of shoot and leaf populations in stable meadows, bistable beds, and stable bare sediment regimes. Similarly this allowed for investigation of leading indicators of a ecosystem 
shift as the meadows approach the depth for which they fall within the attractive domain of the bare sediment state. The edf's of the number of leaves per shoot calculated in an individual year exhibited multimodal behavior, particularly when a meadow was under duress (Fig. 4b). Multimodality tended to disappear in the case of dense meadows. This is comparable to a change in properties of the state variables distribution, such as variance or skewness, witnessed in some systems (Carpenter 2006, Guttal \& Jayaprakash 2008). Similarly, the emergence of significant multimodality can be considered as an indicator of seagrass stress. This multimodality may happen for various reasons: in some cases, it is due to a year when all the young shoots established but were continuously being lost, while the "middle aged" shoots were able to increase leaf density, thereby creating a multimodal distribution. Alternatively, the occurrence of multiple modes may be due to patterns of seagrass loss and regrowth associated with the seasonal cycle. The presence of multimodal distributions in number of leaves per shoot generally resulted in a larger standard deviation in leaves per shoot.

The measures of stability investigated herein allow for the possibility of nondestructive monitoring of the viability of extant seagrass meadows, through repeated photographic sampling to assess leaf and shoot counts, during quiescent times throughout the year. The emergence of annual multimodality and a significant decrease in the variability of number of leaves per shoot are indicators of stress and possible future collapse. Synoptic sampling of these parameters within a year and cross comparison of years would allow for identification of the flickering or persistent increase in the number of shoots with low leaf counts that may be indicative of being close to the threshold of collapse. 
Our approach assumed a constant linear increase in both local relative sea-level rise and water temperature. For the 30 years considered in this study, a linear increase is an acceptable approximation. However, the omission of possible increases in storminess must be noted. Increased storminess (Hayden 1999), is likely to increase light stress due to enhanced resuspension, especially since seagrass has less an effect on attenuating of near bed wave orbital velocities than current velocities (Luhar 2010). Regarding the effects of climate change and identification of leading indicators of collapse, the model is primarily limited by the length of available data sets of environmental drivers, however, the strong symptoms of flickering and slowing down were robust across all model simulations.

While the detailed coupled model used in this study provides many insights into the stability, bistability, and indicators of meadow stress and collapse, there are limitations. The vegetation growth model is sensitive to temperature (Zharova et al. 2001, Pastres et al. 2004), due to the involvement of temperature both in the saturation irradiance compensation curves as well as photosynthetic and respirations rates. Summer die-offs due to high temperature are typically observed when the water temperatures exceed $30{ }^{\circ} \mathrm{C}$ for a long period of time in July and August (Moore \& Jarvis 2008). The modeled values indicate this temperature threshold to be around $28.5^{\circ} \mathrm{C}$ and as such effects of temperature modeled herein may be overestimated. If so, however, these results would hold for a period in time further in the future in terms of increased water temperature. Other vegetation growth parameters in the model such as leaf elongation rates, labile to structural carbon ratios, and biomass characteristics of the various plant 
structures could be adapted to be more site specific. Regardless, using literature values, modeled shoot densities and depth ranges align well with field observations in the restored seagrass meadows (McGlathery et al. this issue).

\section{Conclusion}

Both water temperature and the emergence of bistable dynamics due to the positive feedback between seagrasses and their light environment play important roles regarding the survivability of seagrass meadows. Meadows that fall within the bistable depth range display limited resilience to increased environmental stressors associated with climate change. Seagrass meadows shallower than this bistable range can withstand the increased sea-level projections for the next 30 years, as will meadows at the shallower end of the bistable range. Meadows at the deeper end of the bistable range will be pushed into the attraction domain of the bare sediment state. Increases in water temperature will likely result in more frequent and severe high summer temperature stress resulting in significant summer die-offs for meadows at all depths. Meadows within the bistable depth range display limited resilience, and as they decrease in density, they approach the critical bifurcation point beyond which the meadows are unable to recover. Both flickering, and slowing down are seen as a leading indicators of collapse.

\section{Acknowledgments:}

Partial support of this study was provided by the Virginia Coast Reserve LTER project, which was supported by National Science Foundation grant DEB-0621014. 


\section{References}

Bach HK (1993) A dynamic model describing the seasonal variations in growth and the distribution of eel grass (Zostera Marina). Ecological Modelling 65:31-50

Brock WA, Carpenter SR (2010) Interacting regime shifts in ecosystems: implication for early warnings. Ecological Monographs 80:353-367

Carpenter SR (2006) Rising variance: a leading indicator of ecological transition. Ecology letters 9:311-318

Carr J, D'Odorico P, McGlathery K, Wiberg P (2010) Stability and bistability of seagrass ecosystems in shallow coastal lagoons: Role of feedbacks with sediment resuspension and light attenuation. J Geophys Res-Biogeosci 115:14

Cazenave A, Lombard A, Llovel W (2008) Present-day sea level rise: A synthesis. Comptes Rendus Geoscience 340:761-770

de Boer WF (2007) Seagrass-sediment interactions, positive feedbacks and critical thresholds for occurrence: a review. Hydrobiologia 591:5-24

Dennison WC, Orth RJ, Moore KA, Stevenson JC, Carter V, Kollar S, Bergstrom PW, Batiuk RA (1993) Assessing water-quality with submersed aquatic vegetation Bioscience 43:86-94

Duarte CM (1991) Seagrass depth limits. Aquatic Botany 40:363-377

Duarte CM (2002) The future of seagrass meadows. Environmental Conservation 29:192206

Folkard AM (2005) Hydrodynamics of model Posidonia oceanica patches in shallow water. Limnology and Oceanography 50:1592-1600 
Gunderson LH (2000) Ecological resilience - in theory and application. Annual Review of Ecology and Systematics 31:425-439

Guttal V, Jayaprakash C (2008) Changing skewness: an early warning signal of regime shifts in ecosystems. Ecology letters 11:450-460

Hastings A (2010) Regime shifts in ecological systems can occur with no warning. Ecology letters 13:464-472

Havens KE, Hauxwell J, Tyler AC, Thomas S, McGlathery KJ, Cebrian J, Valiela I, Steinman AD, Hwang SJ (2001) Complex interactions between autotrophs in shallow marine and freshwater ecosystems: implications for community responses to nutrient stress. Environmental Pollution 113:95-107

Hayden BP (1999) Climate change and extratropical storminess in the United States: An assessment. Journal of the American Water Resources Association 35:1387-1397

Hemminga MA, Duarte CM (2000) Frontmatter

Seagrass Ecology, Vol. Cambridge University Press

Keller CF (2009) Global warming: a review of this mostly settled issue. Stoch Environ Res Risk Assess 23:643-676

Lawson SE, Wiberg PL, McGlathery KJ, Fugate DC (2007) Wind-driven sediment suspension controls light availability in a shallow coastal lagoon. Estuaries and Coasts 30:102-112

Luhar M (2010) Wave induced velocities inside a model seagrass bed. Journal of geophysical research 115 
Moore KA, Jarvis JC (2008) Environmental Factors Affecting Recent Summertime Eelgrass Diebacks in the Lower Chesapeake Bay: Implications for Long-term Persistence. J Coast Res:135-147

Najjar RG, Walker HA, Anderson PJ, Barron EJ, Bord RJ, Gibson JR, Kennedy VS, Knight CG, Megonigal JP, O'Connor RE, Polsky CD, Psuty NP, Richards BA, Sorenson LG, Steele EM, Swanson RS (2000) The potential impacts of climate change on the mid-Atlantic coastal region. Climate Research 14:219-233

Nixon S, Buckley B, Granger S, Bintz J (2001) Responses of very shallow marine ecosystems to nutrient enrichment. Human and Ecological Risk Assessment $7: 1457-1481$

Oertel G (2001) Hypsographic, hydro-hypsographic and hydrological analysis of coastal bay environments, Great Machipongo Bay. J Coast Res 17:775-783

Orth RJ, Luckenbach ML, Marion SR, Moore KA, Wilcox DJ (2006) Seagrass recovery in the Delmarva Coastal Bays, USA. Aquatic Botany 84:26-36

Pastres R, Brigolin D, Petrizzo A, Zucchetta M (2004) Testing the robustness of primary production models in shallow coastal areas: a case study, p 221-233

Scheffer M, Bascompte J, Brock WA, Brovkin V, Carpenter SR, Dakos V, Held H, van Nes EH, Rietkerk M, Sugihara G (2009) Early-warning signals for critical transitions. Nature 461:53-59

Scheffer M, Carpenter S, Foley JA, Folke C, Walker B (2001) Catastrophic shifts in ecosystems. Nature 413:591-596

Scheffer M, van Nes EH (2004) Mechanisms for marine regime shifts: can we use lakes as microcosms for oceans? Progress in Oceanography 60:303-319 
van der Heide T, van Nes EH, Geerling GW, Smolders AJP, Bouma TJ, van Katwijk MM (2007) Positive feedbacks in seagrass ecosystems: Implications for success in conservation and restoration. Ecosystems 10:1311-1322

Verhagen JHG, Nienhuis PH (1983) A simulation-model of production, seasonal-changes in biomass and distribution of eelgrass (Zostera Marina) in lake Grevelingen. Mar Ecol-Prog Ser 10:187-195

Viaroli P, Bartoli M, Bondavalli C, Christian RR, Giordani G, Naldi M (1996) Macrophyte communities and their impact on benthic fluxes of oxygen, sulphide and nutrients in shallow eutrophic environments. Hydrobiologia 329:105-119

Wilson JB, Agnew ADQ (1992) Positive-feedback switches in plant-communities. Advances in Ecological Research 23:263-336

Zharova N, Sfriso A, Voinov A, Pavoni B (2001) A simulation model for the annual fluctuation of Zostera marina biomass in the Venice lagoon. Aquatic Botany $70: 135-150$

Zimmerman RC, Reguzzoni JL, Alberte RS (1995) Eelgrass(Zostera Marina L) transplants in San Francisco Bay - Role of light availability on metabolism, growth and survival. Aquatic Botany 51:67-86 


\section{Figures}

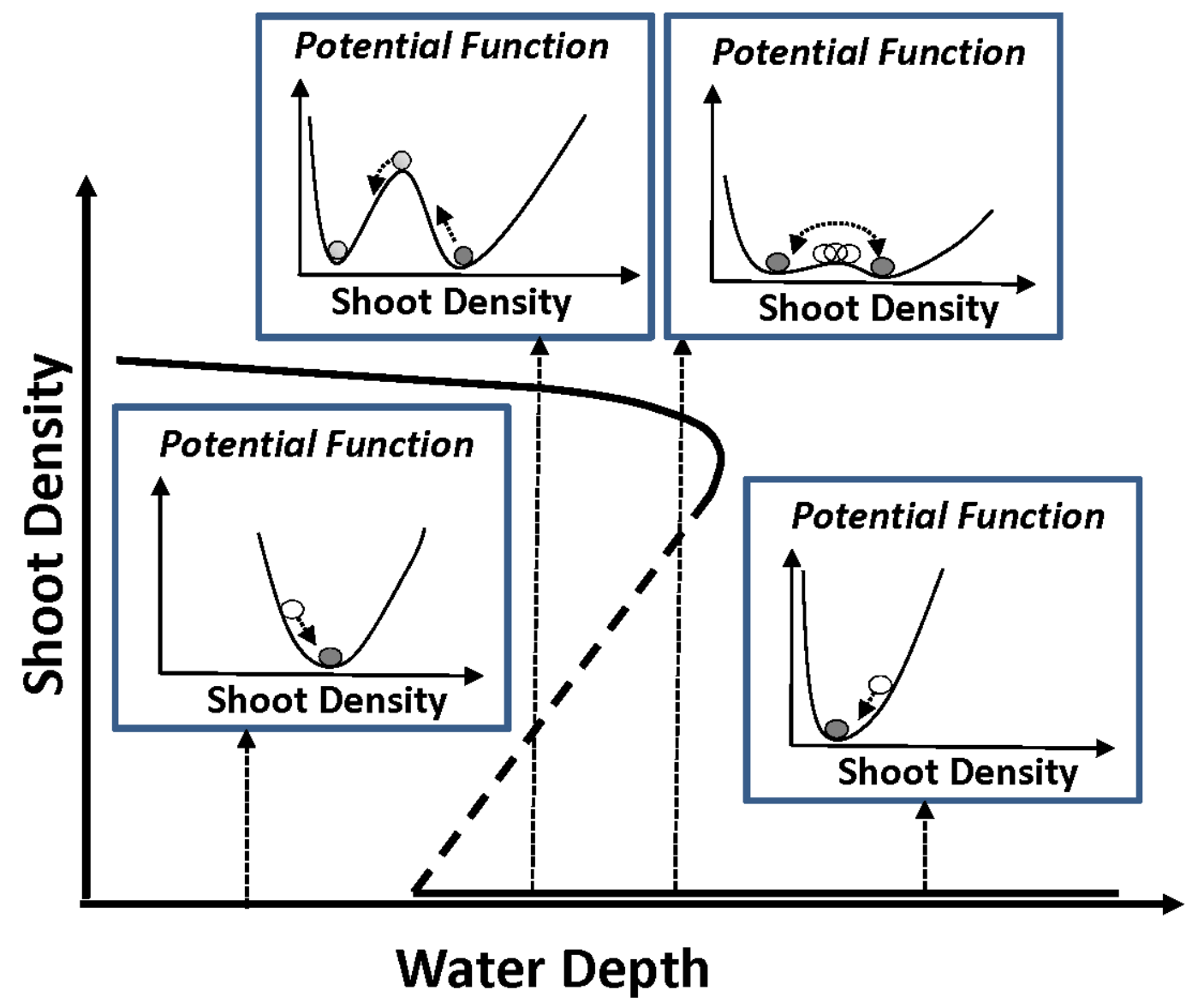

Figure. 1. Schematic representation of the "fold-type" bifurcation of seagrass dynamics. Stable (solid) and unstable (dashed) states of the system are shown as a function of water depth. In shallow waters the light environment is sufficient for seagrass establishment and survival regardless of the initial existence of a seagrass canopy stabilizing the benthic sediments. In relatively deep waters the light penetrating through the water column is insufficient for seagrass growth. In intermediate conditions the system may be stable either with or without a seagrass bed. These stability and bistability conditions are shown in terms of minima of the potential function which is qualitatively plotted in the insets. Close to the critical fold bifurcation point the potential barrier between the stable states is small and the system may repeatedly fluctuate between these two states ("flickering"). 


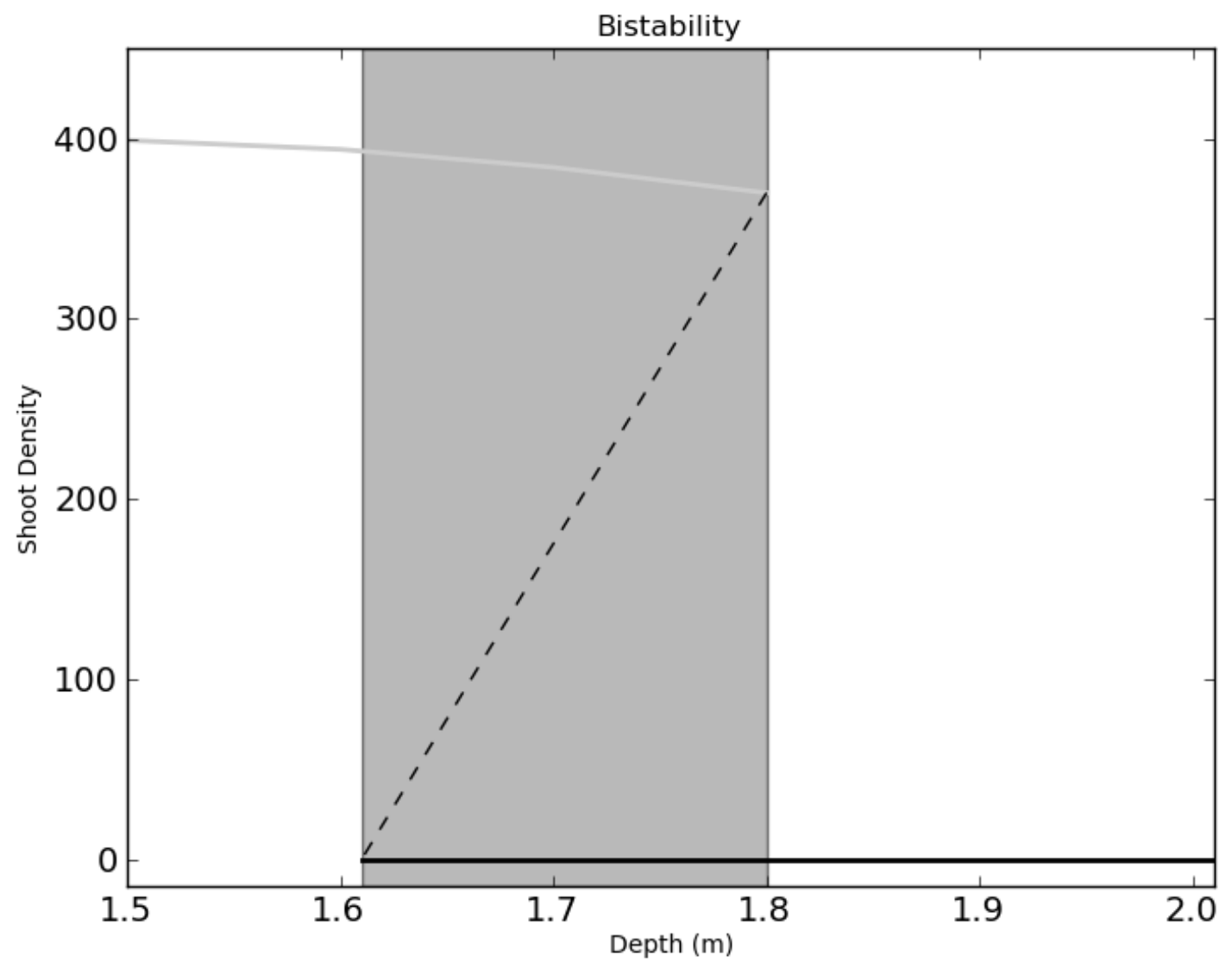

Figure 2. Fold bifurcation plot exhibiting the bistable depth range for Zostera marina as a function of water depth and wintering shoot density (shoots $\mathrm{m}^{-2}$ ), under random drivers. Meadows at water shallower than 1.6 m MSL exhibit a single attraction domain of a dense meadow state (gray line). Meadows initiated deeper than $1.8 \mathrm{~m}$ MSL display a single attraction domain of the bare sediment state (black line). In between 1.6 and $1.8 \mathrm{~m}$ MSL, depending on shoot density, depth and environmental forcing conditions, a meadow may be within the attractive domain of either the dense meadow state or the bare sediment state (shaded area). 

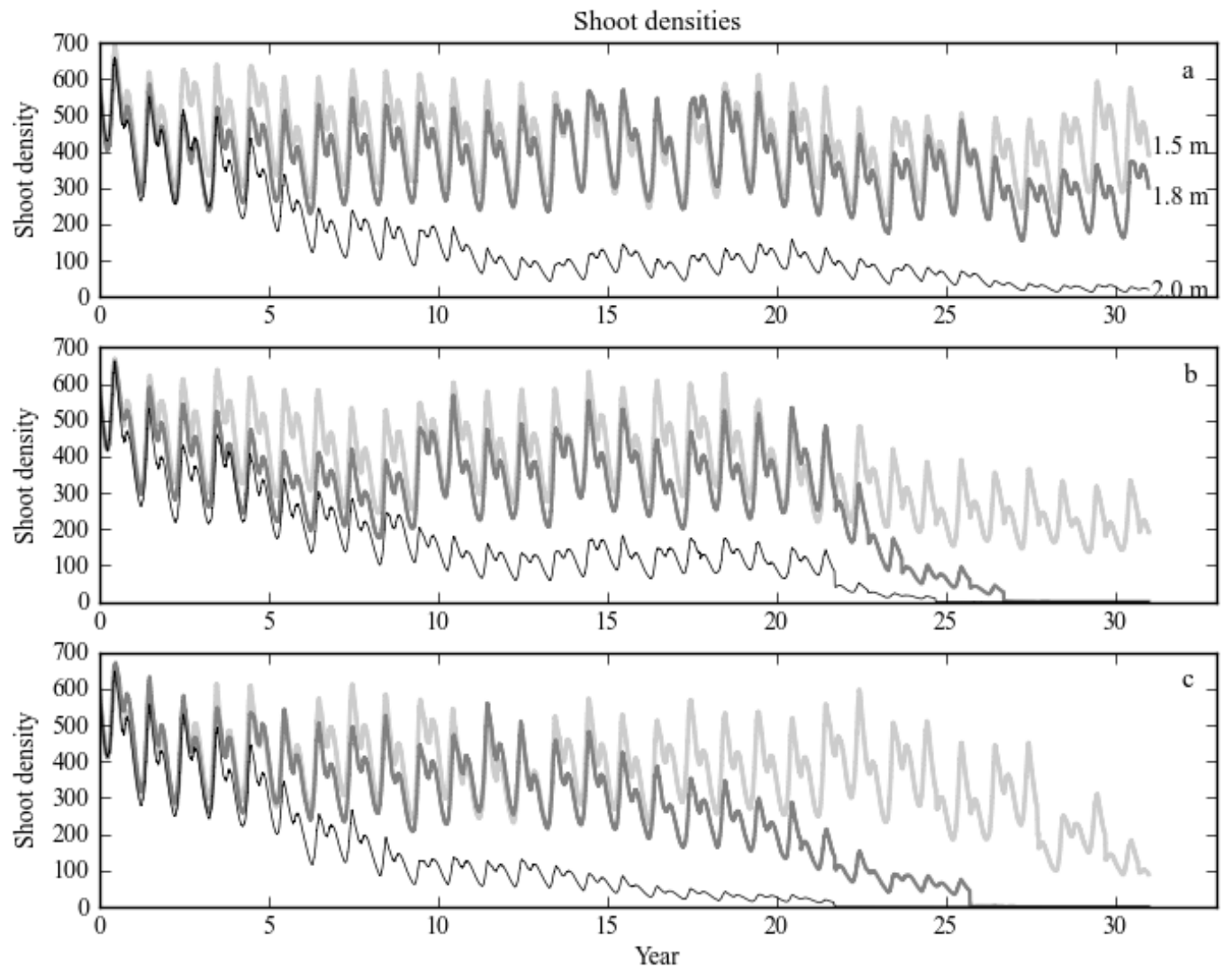

Figure 3. Zostera marina shoot densities averaged over all runs initiated at water depths 1.5, 1.8 and 2.0 m MSL, under a) increase in sea-level b) increase in temperature and c) both increased temperature and sea-level. 

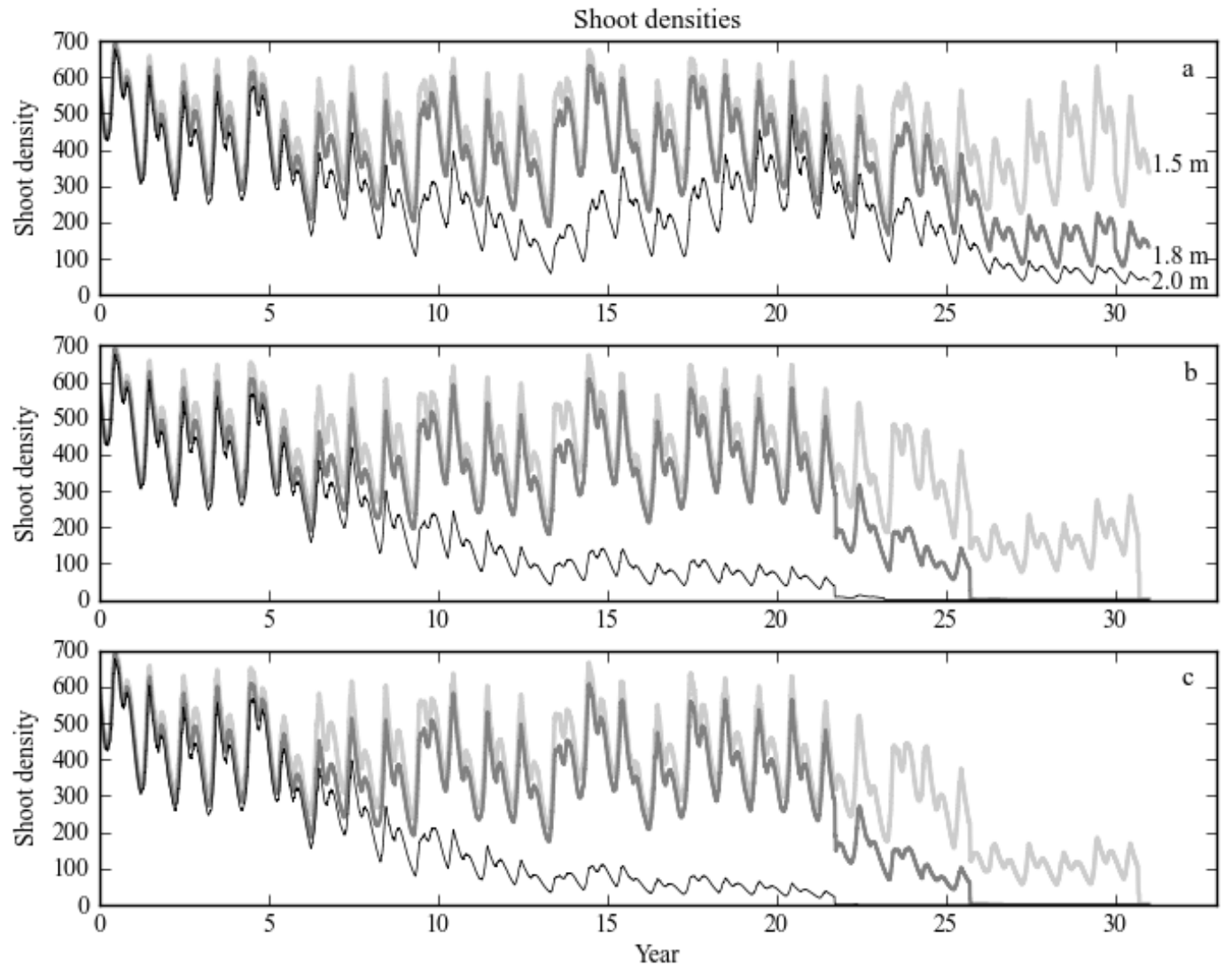

Figure 4. Zostera marina shoot densities for run 4 initiated at water depths 1.5, 1.8 and 2.0 m MSL, under a) increase in sea-level b) increase in temperature and c) both increased temperature and sea-level. 

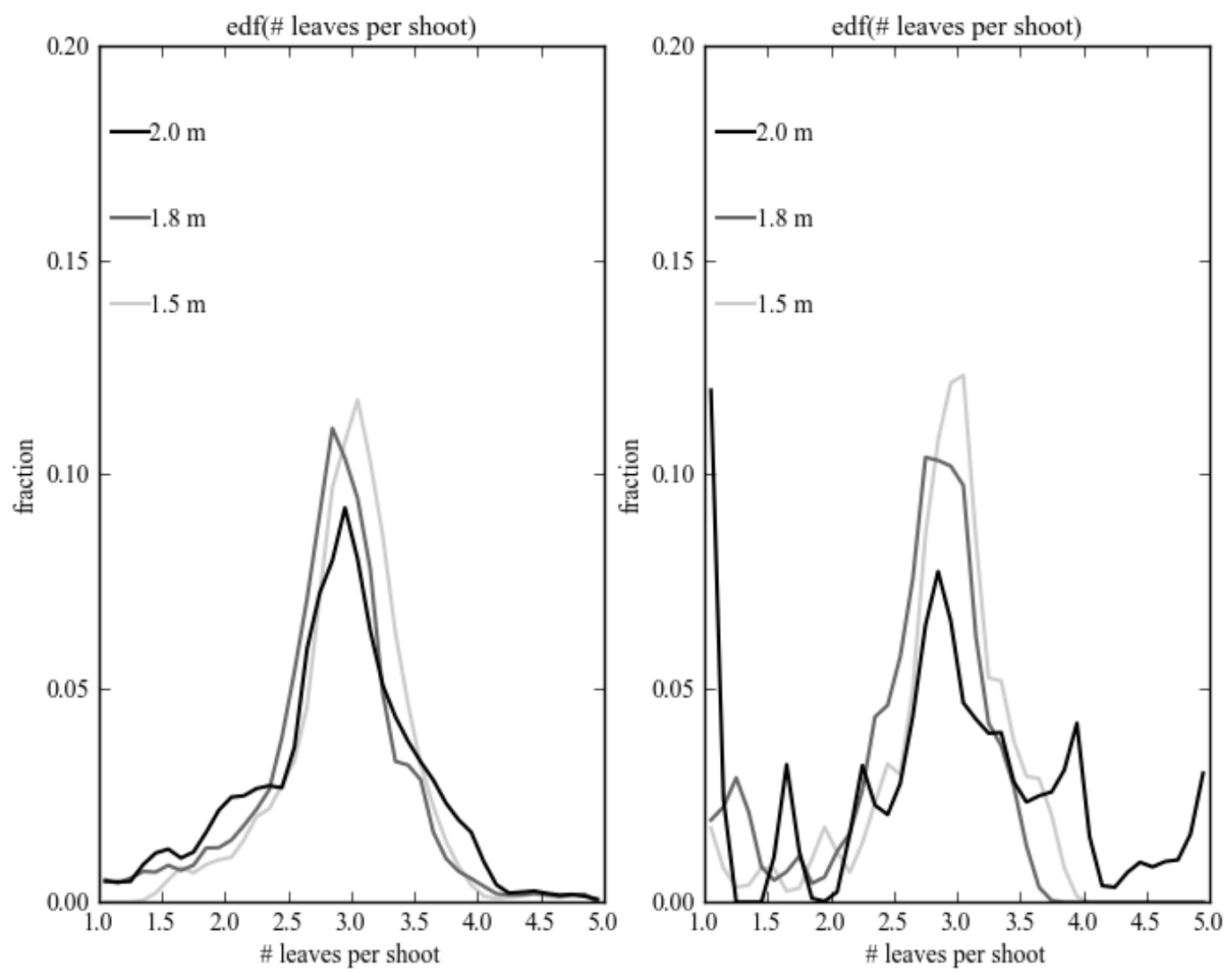

Figure 5. a) Empirical distribution function (edf) for number of leaves per shoot for Zostera marina across all 5 sequences $(n=1357800)$ with increased sea-level rise for meadows initiated at 1.5, 1.8 and 2.0 m MSL. b) Multimodal behavior and increase in the mass fraction less than 2 shoots per leaf in the edf for meadows initiated at 1.5, 1.8 and 2.0 m MSL for an individual year ( $\mathrm{n}=8760)$ with poor growing conditions due to elevated temperatures. 

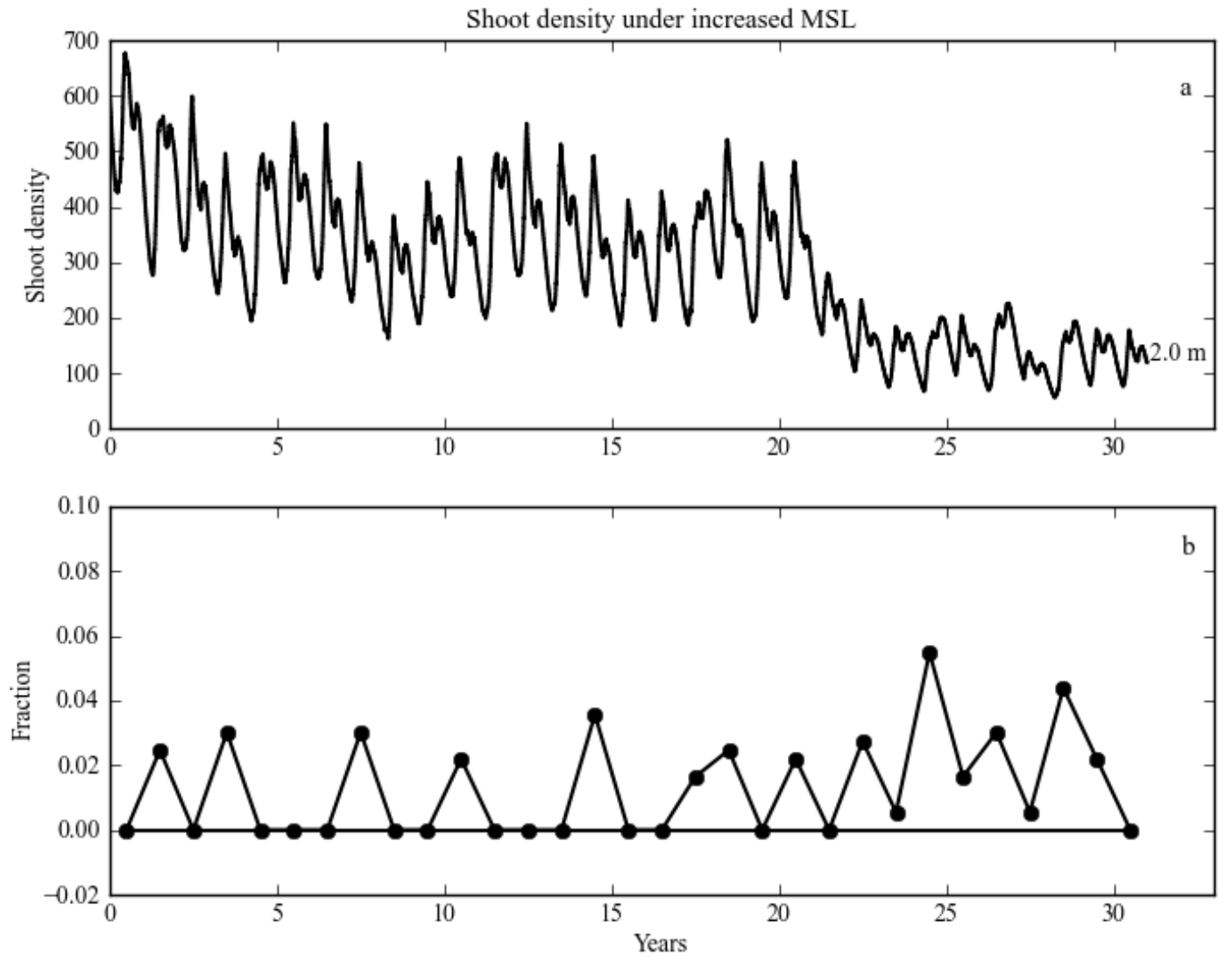

Figure 6. a) Zostera marina shoot densities for meadow initiated at $2.0 \mathrm{~m}$ MSL under sea-level rise already within the attractive domain of the bare sediment state. b) The evidence of flickering and slowing down, in the fraction of mass less than 2 leaves per shoot in the meadow initiated at 2.0 m MSL under increasing sea-level rise. 

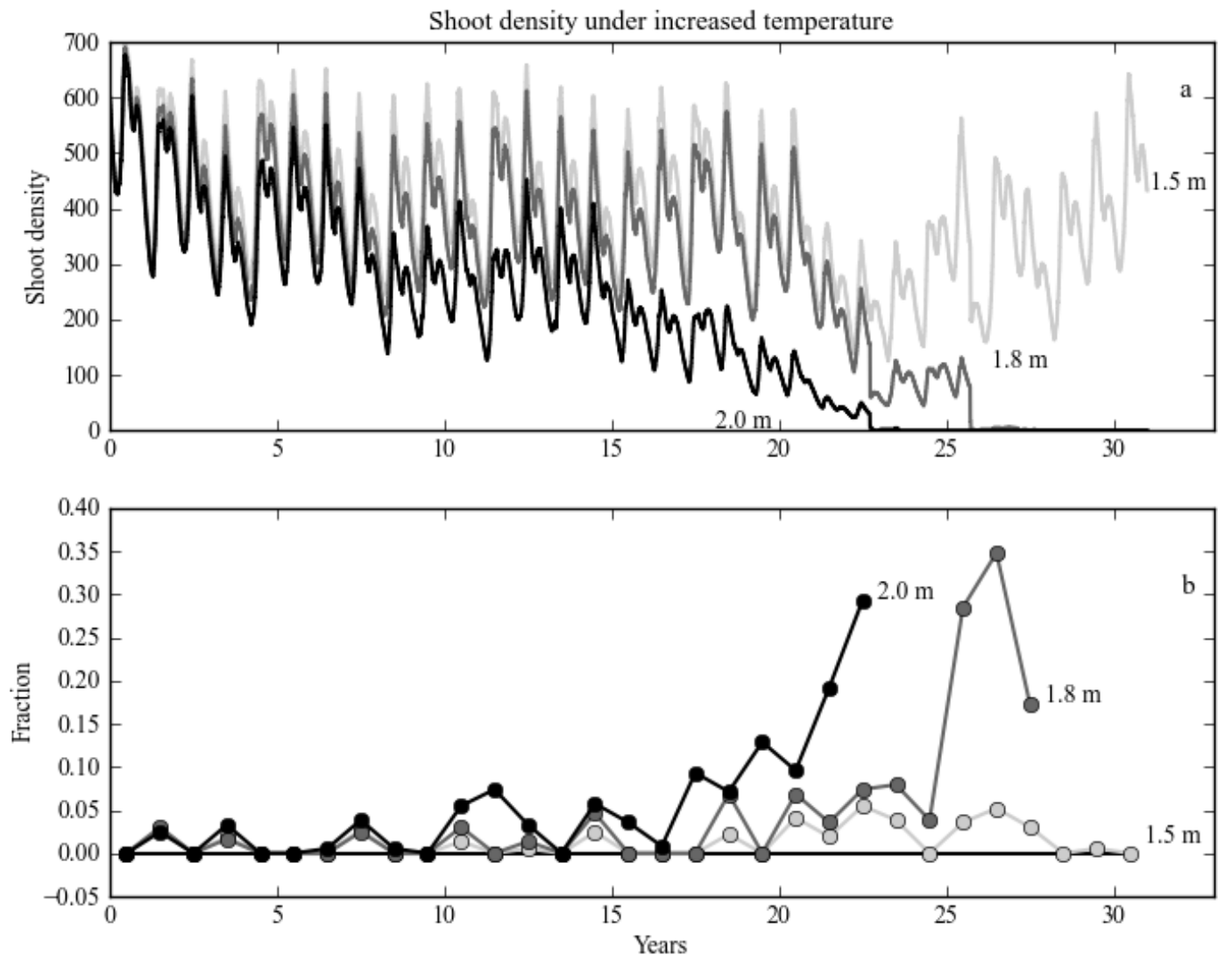

Figure 7. a) Zostera marina shoot densities for meadows initiated at 1.5, 1.8 and $2.0 \mathrm{~m}$ MSL under increased temperature. b) The appearance of flickering and slowing down prior to loss for the meadows initiated at 1.8 and 2.0 m MSL. Flickering, slowing down, but resilience of the meadow initiated at $1.5 \mathrm{~m}$ MSL. 

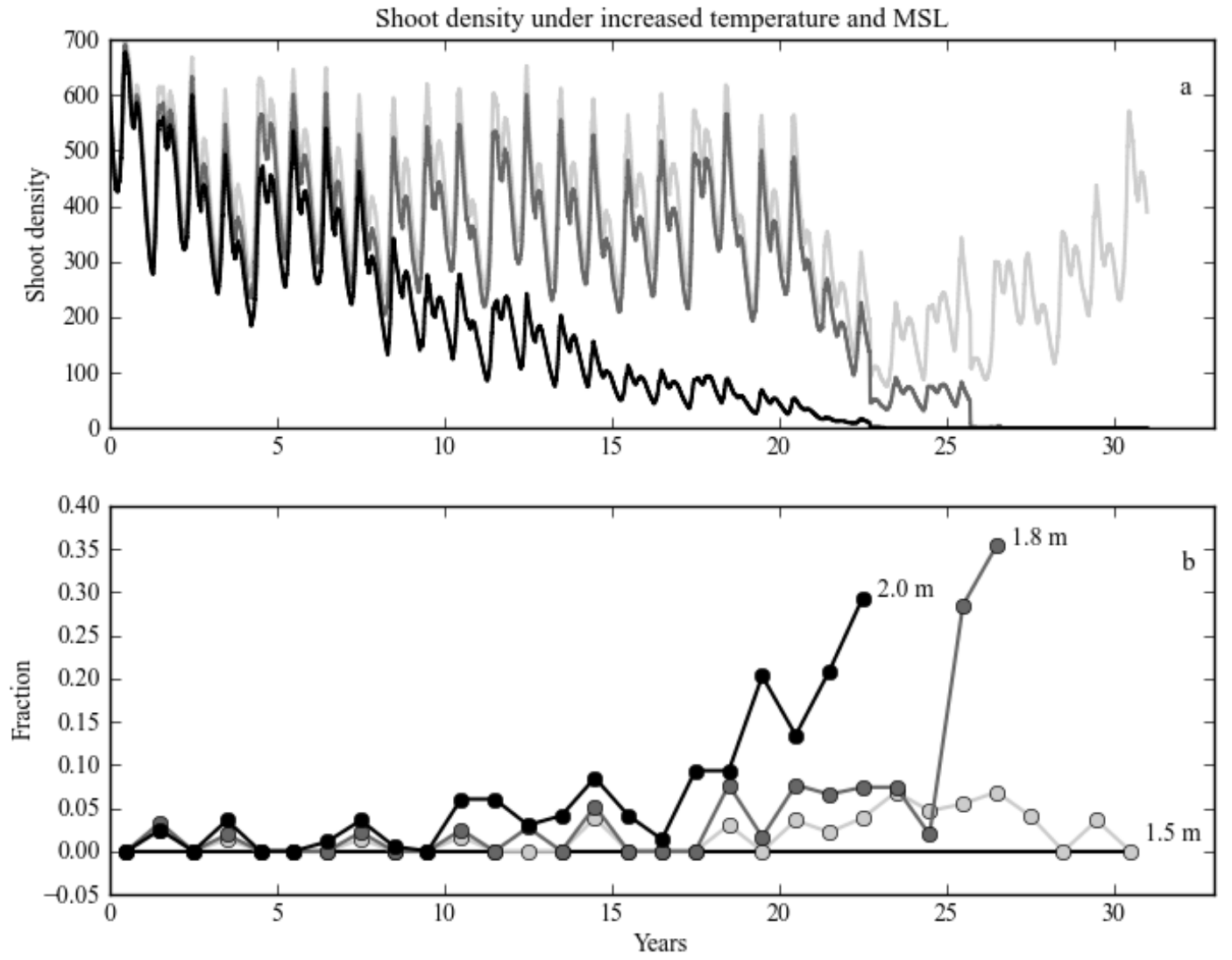

Figure 8. a) Zostera marina shoot densities for meadows initiated at 1.5, 1.8 and $2.0 \mathrm{~m}$ MSL under increased temperature and sea-level. b) The appearance of flickering and slowing down prior to loss for the meadows initiated at 1.8 and $2.0 \mathrm{~m}$ MSL. Flickering, slowing down, but then recovery of the meadow initiated at $1.5 \mathrm{~m}$ MSL. 

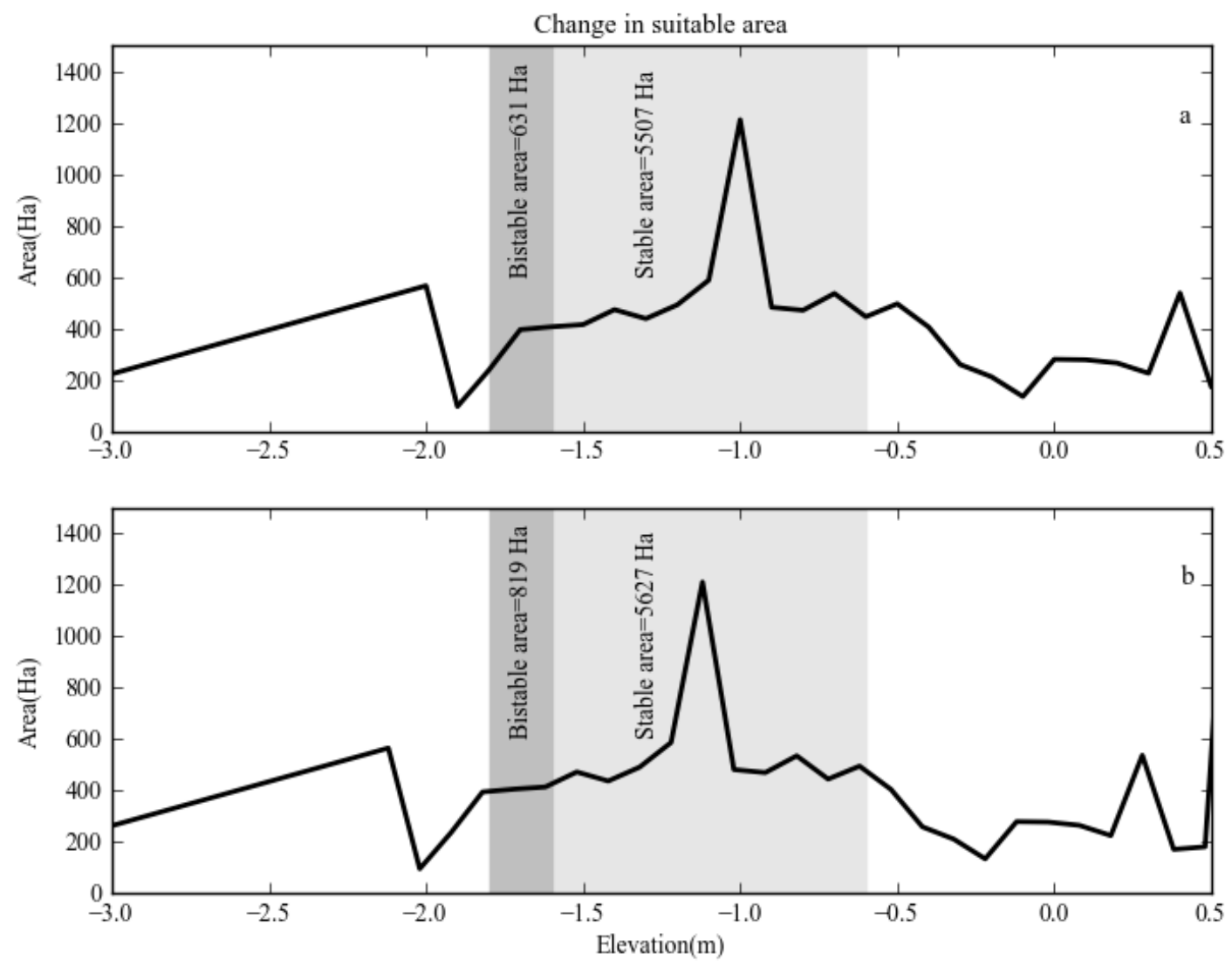

Figure 9. a) Current area of Hog Island Bay suitable for seagrass establishment or maintenance. b) Increase in suitable area under an increase in sea-level of $0.12 \mathrm{~m}$ in 30 years. 


\section{Tables}

Table 1: Seagrass growth model, where ecosystem dynamics are represented through the following state variables: $N$ (total number of shoots), $P_{n, l}$ (biomass of leaf $l$ belonging to shoot $n$ ), and Rhizome biomass, $R$. The dynamics of these state variables are expressed by the following equations, with functions and parameters reported in Table 2.

\begin{tabular}{|c|c|}
\hline Equation & Description \\
\hline$\frac{d N}{d t}=N\left(\max _{\text {Ngrow }} F_{I}(I) F_{\text {pht }}(T) N_{\text {lim }} R_{\text {lim }}-N_{\text {loss }}\right)$ & $\begin{array}{l}\text { Change in the total number of shoots } \\
N=\sum n \text {, where } n \text { is an individual } \\
\text { shoot, is a product of the total number of } \\
\text { shoots, and the difference between } \\
\text { recruitment and loss }\end{array}$ \\
\hline$\frac{d P_{n, l}}{d t}=P_{n, l}\left(\max _{p h t} F_{I}(I) F_{p h t}(T) F_{a g e} P_{l i m}-\max _{\text {resp }} F_{T}(T)\right)$ & $\begin{array}{l}\text { Change in biomass of leaf } l \text { belonging to } \\
\text { shoot } n \text {, modeled as a collection of up to } \\
\text { four leaves ( } l=\text { leaf number), with } P_{n, 0} \\
\text { being the biomass of the stem. }\end{array}$ \\
\hline$\frac{d R}{d t}=k_{\text {transfer }} \sum_{n, l} \frac{d P_{n, l}}{d t}-\gamma F_{T}(T) R-\frac{d N_{n}^{+}}{d t} P_{\text {nnew }, 0}+k_{\text {uproot }} \frac{d N_{n}^{-}}{d t}$ & $\begin{array}{l}\text { Belowground biomass associated with } \\
\text { the rhizome structure of seagrass, } R \text {, is } \\
\text { modeled as a bulk quantity with rhizome } \\
\text { growth due to translocation of above } \\
\text { ground production, and loss due to } \\
\text { respiration, translocation of biomass to a } \\
\text { new shoot, and loss of biomass to } \\
\text { uprooting when a shoot is lost. }\end{array}$ \\
\hline$\frac{d L_{n . l}}{d t}=\max _{\text {elong }} F_{I}(I) F_{\text {pht }}(T) L_{\text {lim }}$ & $\begin{array}{l}\text { Width and thickness are held constant, } \\
\text { and change in the length of leaf } l \text { of } \\
\text { shoot } n, L_{n . l} \text { is modeled as a linear } \\
\text { function of a maximum leaf elongation } \\
\text { rate, modulated by light, and } \\
\text { photosynthetic productivity as a function } \\
\text { of temperature up to some maximum leaf } \\
\text { length. }\end{array}$ \\
\hline
\end{tabular}


Table 2. Limitation functions, description, and sources.

\begin{tabular}{|c|c|c|}
\hline Limitation function & Description and values & Sources \\
\hline$I=I_{\text {surface }} e^{-K_{d} h_{d}}$ & $\begin{array}{l}\text { Irradiance at depth. } h_{d} \text { is the distance from } \\
\text { the water surface to the deflected canopy. } \\
K_{d} \text { is the light attenuation coefficient. }\end{array}$ & $\begin{array}{l}\text { (Lawson et al. } \\
\text { 2007) }\end{array}$ \\
\hline$I_{K}=I_{K 20} \theta_{K}^{T-20}$ & $\begin{array}{l}\text { Saturation irradiance as a function of } \\
\text { temperature. } I_{K 20} \text { is saturation value at } 20^{\circ} \\
C \text { set to } 25.5 \text { and } \theta_{K} \text { is shape value set to } \\
1.04\end{array}$ & $\begin{array}{l}\text { (Zharova et al. } \\
\text { 2001) }\end{array}$ \\
\hline$I_{C}=I_{C 20} \theta_{C}^{T-20}$ & $\begin{array}{l}\text { Compensation irradiance as a function of } \\
\text { temperature. } I_{C 20} \text { is compensation value at } \\
20^{\circ} \mathrm{C} \text { set to } 2.4 \text { and } \theta_{C} \text { is shape value set to } \\
1.17\end{array}$ & $\begin{array}{l}\text { (Zharova et al. } \\
\text { 2001) }\end{array}$ \\
\hline $\begin{array}{l}F_{I}(I)=0 . \quad \text { for } I \leq I_{C} \\
F_{I}(I)=1 . \quad \text { for } I \geq I_{K} \\
F_{I}(I)=\frac{I-I_{C}}{I_{K}-I_{C}} \quad \text { for } I_{C} \leq I \leq I_{K}\end{array}$ & Light limitation function. & $\begin{array}{l}\text { (Zharova et al. } \\
\text { 2001) }\end{array}$ \\
\hline $\begin{array}{l}F_{p h o t}(T)=K_{0 \text { phot }}^{\left(\frac{T_{o p t-T}}{T_{o t}}\right)^{2}} \text { for } T \leq T_{o p t} \\
F_{p h o t}(T)=K_{m p h o t}^{\left(\frac{T-T_{o p t}}{T_{\text {max }}-T_{\text {opt }}}\right)^{2}} \text { for } T>T_{\text {opt }}\end{array}$ & $\begin{array}{l}\text { Temperature photosynthesis limitation } \\
\text { function. } T_{\text {opt }} \text { is the optimum temperature } \\
\text { for photosynthesis set to } 21.5^{\circ} \mathrm{C} . T_{\text {max }} \text { is the } \\
\text { maximum temperature for photosynthesis } \\
\text { set to } 34^{\circ} \mathrm{C} \text {. } K_{\text {ophot }} \text { is a shape coefficient set } \\
\text { to } 0.01 \text { and } K_{\text {mphot }} \text { a shape coefficient set to } \\
0.00001\end{array}$ & $\begin{array}{l}\text { (Zharova et al. } \\
\text { 2001) }\end{array}$ \\
\hline 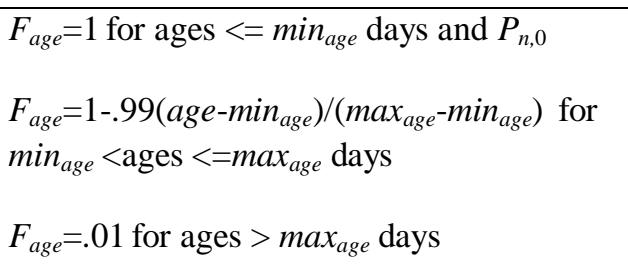 & $\begin{array}{l}\text { Leaf age limitation function. } \min _{\text {age }}=70 \text {, } \\
\max _{\text {age }}=175\end{array}$ & $\begin{array}{l}\text { (Verhagen \& } \\
\text { Nienhuis 1983, } \\
\text { Hemminga \& } \\
\text { Duarte 2000) }\end{array}$ \\
\hline$F_{T}(T)=\theta_{\text {loss }}^{T-20}$ & $\begin{array}{l}\text { Temperature respiration scaling function. } \\
\theta_{\text {loss }} \text { is shape value set to } 1.05\end{array}$ & $\begin{array}{l}\text { (Zharova et al. } \\
\text { 2001) }\end{array}$ \\
\hline
\end{tabular}


Table 3. Parameters and sources

\begin{tabular}{|c|c|c|}
\hline Parameter & Description and values & Sources \\
\hline$\tau_{c r}$ & $\begin{array}{l}0.04(\mathrm{~Pa}) \text { is the critical shear stress to erode } \\
\text { sediment. }\end{array}$ & (Lawson et al. 2007) \\
\hline max $_{\text {resp }}$ & Respiratory loss rate 0.014 per day & (Bach 1993) \\
\hline $\max _{\text {pht }}$ & Maximum specific growth rate 0.095 per day & (Bach 1993) \\
\hline $\max _{\text {elong }}$ & Maximum elongation rate $0.00164 \mathrm{~m}$ per hour & Kemp \\
\hline max $_{\text {Ngrow }}$ & Maximum shoot recruitment .028 & (Zharova et al. 2001) \\
\hline$N_{\text {loss }}$ & Shoot mortality rate 0.0065 per day & (Zharova et al. 2001) \\
\hline$L_{\text {lim }}$ & $\begin{array}{l}\text { Maximum leaf length limit, set to } 1 \text { if leaf } \\
\text { length is less than } 1 \mathrm{~m} \text {, otherwise set to } 0\end{array}$ & \\
\hline$R_{\text {lim }}$ & $\begin{array}{l}\text { Above to below ground biomass ratio } \\
\text { limitation, set to } 1 \text { if the ratio is less than } 4.0 \text {, } \\
\text { otherwise set to } 0\end{array}$ & \\
\hline$N_{\text {lim }}$ & $\begin{array}{l}N_{\text {lim }}=1-\left(\frac{N}{N_{c c}}\right)^{2} \text { for } N \text { less than } N_{c c} \text { otherwise } \\
\text { set to } 0 . \text { Maximum shoot density, } N_{c c} \text { set to } \\
1000 \text { shoots } \mathrm{m}^{-2} \text {. }\end{array}$ & \\
\hline$P_{\text {lim }}$ & $\begin{array}{l}\text { Maximum biomass of a single leaf set to } 0.12 \\
\text { gC corresponding to a maximum above ground } \\
\text { single shoot biomass of } .5 \text { gC with } 4 \text { leaves of } \\
\text { equal biomass. }\end{array}$ & \\
\hline$P_{\text {new }}$ & $\begin{array}{l}\text { Biomass of a new shoot and single leaf set to } \\
.0024 \text { gC }\end{array}$ & (Zharova et al. 2001) \\
\hline$\gamma$ & Rhizome respiration rate set to 0.009 per day & (Zharova et al. 2001) \\
\hline $\begin{array}{l}\text { Sparse } \\
\text { Meadow }\end{array}$ & $\begin{array}{l}3 \text { shoots } \mathrm{m}^{-2}, \mathrm{R}=2 \mathrm{gC}, 3 \text { leaves per shoot, } \\
\mathrm{P}=.08 \mathrm{gC} \text { per leaf }\end{array}$ & \\
\hline $\begin{array}{l}\text { Dense } \\
\text { Meadow }\end{array}$ & $\begin{array}{l}640 \text { shoots } \mathrm{m}^{-2}, \mathrm{R}=45 \mathrm{gC}, \sim 3 \text { leaves per } \\
\text { shoot, } \mathrm{P}=.09 \text { gC per leaf }\end{array}$ & \\
\hline
\end{tabular}


Table 4 Comparison of days of growth loss and days for exceeding $30{ }^{\circ} \mathrm{C}$ under measured and expected climate change conditions based on temperature records for years 19962004 for Zostera marina.

\begin{tabular}{|l|l|l|l|l|l|l|}
\hline Year & \multicolumn{2}{|l|}{ Days of Growth } & \multicolumn{2}{l|}{ Days of Loss } & \multicolumn{2}{l|}{ Days exceeding $30^{\circ} \mathrm{C}$} \\
\hline & & $+1.3^{\circ} \mathrm{C}$ & & $+1.3^{\circ} \mathrm{C}$ & & $+1.3^{\circ} \mathrm{C}$ \\
\hline 1996 & 247 & 232 & 119 & 133 & 15 & 47 \\
\hline 1997 & 288 & 271 & 77 & 94 & 18 & 47 \\
\hline 1998 & 285 & 265 & 80 & 100 & 11 & 43 \\
\hline 1999 & 302 & 292 & 63 & 73 & 5 & 37 \\
\hline 2000 & 334 & 311 & 31 & 54 & 0 & 9 \\
\hline 2001 & 309 & 307 & 56 & 58 & 0 & 0 \\
\hline 2002 & 301 & 283 & 64 & 82 & 11 & 39 \\
\hline 2003 & 276 & 269 & 89 & 96 & 0 & 19 \\
\hline 2004 & 280 & 246 & 85 & 119 & 2 & 30 \\
\hline
\end{tabular}


Table 5 Sediment grain size distribution

\begin{tabular}{|l|l|l|l|l|l|l|l|l|l|}
\hline$\varphi$ & 2.5 & 3 & 3.5 & 4 & 4.5 & 5 & 5.5 & 6 & 6.5 \\
\hline$\%$ & 4 & 10 & 18 & 32 & 17 & 10 & 5 & 3 & 1 \\
\hline
\end{tabular}


Table 6. Years to collapse as a function of water depth for the five model runs under combined conditions of sea-level rise and increased water temperature.

\begin{tabular}{|l|l|l|l|l|l|l|}
\hline & $1.5 \mathrm{~m}$ MSL & $\begin{array}{l}1.6 \mathrm{~m} \\
\text { MSL }\end{array}$ & $\begin{array}{l}1.7 \mathrm{~m} \\
\text { MSL }\end{array}$ & $\begin{array}{l}1.8 \mathrm{~m} \\
\text { MSL }\end{array}$ & $\begin{array}{l}1.9 \mathrm{~m} \\
\text { MSL }\end{array}$ & $\begin{array}{l}2.0 \mathrm{~m} \\
\text { MSL }\end{array}$ \\
\hline Run & \multicolumn{5}{|c|}{ Years to collapse } \\
\hline 1 & - & 28 & 28 & 24 & 21 & 17 \\
\hline 2 & 27 & 30 & 30 & 26 & 25 & 18 \\
\hline 3 & 30 & 27 & 26 & 26 & 24 & 22 \\
\hline 4 & 30 & 26 & 26 & 26 & 26 & 22 \\
\hline 5 & - & 26 & 26 & 24 & 23 & 23 \\
\hline mean & 29 & 27.4 & 27.2 & 25.2 & 23.8 & 20.4 \\
\hline
\end{tabular}




\section{Chapter 5: SPATIALLY EXPLICIT FEEDBACKS BETWEEN SEAGRASS MEADOWS SEDIMENT AND LIGHT: HABITAT SUITABILITY FOR SEAGRASS GROWTH}

\section{Introduction}

In shallow costal bays that lack riverine discharge, sediment dynamics are dominated by internal resuspension due to wind-waves and tidal currents [Lawson et al., 2007]. When nutrient loading and riverine inputs are low, turbidity in shallow bays and the consequent light environment are controlled by resuspension of bed sediments. When sediment resuspension is high, resultant low light environments can limit benthic primary productivity. This is more important for high light requirement species such as seagrass which need about $20 \%$ of incident light at the sediment surface for survival [Dennison et al., 1993; Duarte, 1991; Zimmerman and Alberte, 1995; Zimmerman et al., 1995].

However, both currents and waves are affected by the presence of benthic plants [de Boer, 2007] which dominate primary productivity in shallow coastal bays with low external nutrient loading [McGlathery et al., 2007; Sandjensen and Borum, 1991]. The reduction in turbidity due to the presence of benthic primary producers results in a positive feedback between vegetation and sediment suspension/deposition and a more beneficial light environment for seagrass growth [de Boer, 2007]. This positive feedback has been shown to induce bistable dynamics [Carr et al., 2010; van der Heide et al., 2007] with implications for restoration, maintenance, and resilience of these ecosystems [Carr et al in review].

While a number of authors have investigated the dependence of hydrodynamic conditions on shoot density within homogeneous seagrass meadows [Abdelrhman, 2003; 2007; Carr et al., 2010; Ghisalberti and Nepf, 2006], only few studies [Chen et al., 2007; Luhar et al., 2008; van der Heide, 2010] have addressed these interactions on a larger scale within a mosaic of seagrass patches and bare sediment. Some authors have linked disturbances and environmental conditions 
to meadow patchiness and general meadow landscape patterns [Bell, 1997; 2008; Fonseca, 2002; Fonseca, 1998; 2007; 2008; Larkum et al., 2006; Olesen, 1994], however the consequential effect of meadow patch density on sediment resuspension and the resultant light environment as it pertains to seagrass maintenance, growth and the emergence of bistable dynamics has been neglected. Here, we develop a simplistic approach to explore how the patchy structure of seagrass meadows may affect sediment resuspension and the consequent light environment under tidal and wind-wave forcing.

\section{Methods}

\subsection{Landscape generation:}

In order to investigate seagrass modified hydrodynamics in shallow coastal bays we generated a heterogeneous vegetation cover comprised of a mosaic of circular patches randomly distributed according to a 2-dimensional Poisson process, with rate $\lambda$ (or “density”, i.e., number of patches per unit area). Thus, in an area $A$ the centers of $\lambda A$ disks were randomly placed. (Figure 1). The radius of each circular region was sampled from a normal distribution with a set mean $r$, ranging from $0.5 \mathrm{~m}$ to $2.5 \mathrm{~m}$ and standard deviation of $0.15 \mathrm{~m}$. Overlaps between circular regions were allowed. Two approaches were used to generate heterogeneous seagrass landscapes. First, circular patches were randomly placed on a bare landscape; each circular patch was assumed to be a seagrass meadow with shoot density of 500 shoots $\mathrm{m}^{-2}$ (“meadow scattering scenario”). Second, starting from a landscape assumed to be homogenous meadow with shoot density 500 shoots $\mathrm{m}^{-2}$, circular gaps were randomly generated; each gap was considered as a disturbance that completely removed all seagrass from the circular region ("gap scattering scenario”). In order to facilitate comparisons across landscape realizations $R(\lambda, r)$, with differing sample mean radii of the disks, fractional cover, $f_{\text {cover }}(\lambda, r)$, of disks on the landscape was calculated (Figure 2). 
Each landscape realization was then used to partition wave and current shear stresses on the landscape (sections 2.2-2.4). Total suspended sediment (section 2.5) and light attenuation (section 2.6) characteristics were then calculated for each grid location and averaged over the landscape to examine how fractional cover and mean water depth affect the bulk sediment and light environment for meadow or gap scattering scenarios.

\subsection{Velocity and shear stresses over bare sediment and meadows:}

For an average tidal current on the landscape, over bare sediment regions the vertical velocity profile is assumed to be logarithmic. Thus, the shear stress acting on the sediment surface [Lawson et al., 2007] can be calculated as

$$
\tau_{\text {bcurrent }}=\rho C_{d}{\overline{U_{\text {curr }}}}^{2}
$$

where $\overline{U_{\text {curr }}}$ is the average velocity of the tidal current, $\rho$ is the water density, $g$ the gravitational acceleration, $C_{d}=\frac{g n^{2}}{H^{1 / 3}}$ is the drag coefficient, $H$ is water depth, and the Manning's roughness coefficient is determined as

$$
n=\left[\frac{2 \sqrt{8 g}}{H^{1 / 6}} \log _{10}\left(\frac{H}{D_{84}}\right)+1\right]^{-1} .
$$

In equation (2) $\mathrm{D}_{84}$ is the $84^{\text {th }}$ percentile grain size diameter of the bed sediment.

In order to estimate the shear stress acting on the bed within a seagrass patch, the near bed velocity gradient is necessary. Given the same average tidal current condition on the landscape $\overline{U_{\text {curr }}}$, a canopy of height $h_{c}$, and a flow depth $H$, the vertical velocity profile within a meadow is significantly modified by a dense seagrass patch. The average velocity on the 
landscape, $\overline{U_{\text {curr }}}$, can be related to the average velocity within the canopy, $\overline{U_{\text {can }}}$, and the average current above the canopy, $\overline{U_{\text {above }}}$, following [Huthoff, 2007] where $s$ is the average spacing between shoots within a vegetated area

$\overline{U_{c a n}}=\overline{U_{c u r r}} \sqrt{\frac{h_{c}}{H}}\left(\sqrt{\frac{h_{c}}{H}}-\frac{\left(H-h_{c}\right)}{H} \frac{\left(H-h_{c}\right)^{\frac{2}{3}}}{s}\left(1-\left(\frac{H}{h_{c}}\right)^{-5}\right)\right)^{-1}$,

$\overline{U_{\text {above }}}=\overline{U_{\text {curr }}} \frac{\left(H-h_{c}\right)^{\frac{2}{3}\left(1-\left(\frac{H}{h_{c}}\right)^{-5}\right)}}{S}\left(\sqrt{\frac{h_{c}}{H}}-\frac{\left(H-h_{c}\right)}{H} \frac{\left(H-h_{c}\right)^{\frac{2}{3}}}{S}\left(1-\left(\frac{H}{h_{c}}\right)^{-5}\right)\right)^{-1}$,

with the shear in the velocity profile defined as $\Delta U=\overline{U_{\text {above }}}-\overline{U_{c a n}}$.

To better approximate the near bed velocity gradient we assume that the flow within the canopy exponentially decays from the velocity at the top of the canopy $U_{h_{c}}$ [Abdelrhman, 2003]

$U_{\text {can }}(z)=U_{h_{c}} e^{\alpha\left(\frac{z}{h_{c}}-1\right)}$.

The attenuation coefficient $\alpha$ is dependent on drag coefficient, $C_{d}$, the average spacing between shoots, the frontal area per unit volume, and the height of the canopy [Abdelrhman, 2003]. Here we define $\alpha$ as a self consistency parameter between flow within the canopy and flow above the canopy. Setting the mean of equation 6 equal to the result from 4, allows for determination of the velocity at the top of the canopy thereby dictating the velocity profile within the canopy given knowledge of $\alpha$ 
$U_{h_{c}}=\frac{\alpha \overline{U_{c a n}}}{\left(1-e^{-\alpha}\right)}$.

Flow above the canopy is expected to follow a logarithmic profile, with a shear velocity, $u_{*_{n}}$, displacement height $d$, and roughness $z_{0}$

$U_{\text {above }}(z)=\frac{u_{*_{n}}}{\kappa} \log \left(\frac{z-d}{z_{0}}\right)$.

At the top of the canopy, both the velocity and the slope of the velocity profiles determined from equations 6 and 8 must be equal. Setting the derivatives equal, and solving for $u_{*_{n}}$ results in

$u_{*_{n}}=\kappa \alpha U_{h_{c}}\left(1-\frac{d}{h_{c}}\right)$.

The displacement height, $d$, is calculated following [Luhar et al., 2008]

$d=h_{c}-\frac{0.12}{C_{d} a}$

where $a$, is the frontal area per unit volume of the meadow, and $C_{d}$ is a meadow drag coefficient assumed to be close to one [Luhar et al., 2008]. To determine the proper attenuation parameter $\alpha$, equation 8 is solved in terms of the roughness height $z_{0}$, given velocities $U_{h_{c}}$ at height $h_{c}$, and knowing that $\overline{U_{\text {above }}}$ is the average velocity of a log profile at height $\frac{(H-d)}{e}+d$ (Appendix A). With the determination of $\alpha$, the entire velocity profile (Figure 3), from the sediment surface to the height of the water column is readily calculated from equations 6 through 
9, and the shear stress acting on the sediment surface within the meadow can be calculated based on the near bed velocity gradient.

$$
\tau_{\text {bcurrent }, \text { veg }}=\mu \frac{d U}{d z}
$$

\subsection{Shear partitioning.}

A landscape in the model is comprised of patches of meadows and bare areas with the properly associated bed shear stresses for any given current condition. However, a meadow imparts an area of shelter in the region lying behind each meadow based on flow direction. This region, while barren of seagrass, exhibits reduced shear stresses until boundary layer reformation occurs. Following Markfort [2010], Walker [2003] and Folkard [2011] we assume the length of the reduced shear region to be roughly 30 times the canopy height of the meadow. Within this region the shear stress is assumed to recover over this distance. Here we use a Gompertz type function

$$
\tau_{b c u r r e n t, x}\left(x, h_{c}\right)=\tau_{\text {bcurrent }}\left(1-e^{b e^{c x}}\right)
$$

The parameters $b=\ln \left(1-\frac{\tau_{\text {bcurrent,veg }}}{\tau_{\text {bcurrent }}}\right)$ and $c=\frac{\ln \left(\frac{\ln 0.01}{b}\right)}{30 h_{c}}$ are determined assuming $99 \%$ recovery

from the vegetated shear stress, $\tau_{b c u r r e n t, v e g}$, to the bare sediment shear stress, $\tau_{b c u r r e n t}$, at 30 canopy heights, $h_{c}$, downstream (Figure 4 ). The canopy height is assumed to remain constant at $0.2 \mathrm{~m}$. As such, the distribution of shear stress on the surface becomes a function of downstream gap size distances in terms of meadow height, similar to Okin [2008], but here also depend on tidal flow direction. Assuming bidirectional flow, each transect within a landscape realization is characterized in terms of downstream gap distances in both the ebb and flood flow directions and provided the vegetation and bare sediment shear stresses for a given tidal current condition 
(equations 1, 11), in combination with equation (12), shear stresses along a transect can be calculated (Figure 5). This is performed for all transects across the landscape (Figure 6).

\subsection{Waves:}

Wave shear stress is determined from significant wave height, $H_{\text {sig }}$, water depth, $H$, wavelength, $L$, and period, $T$, generated from the fetch-limited shallow water wave model of Young and Verhagen [1996] as

$$
\tau_{\text {bwave }}=\rho\left(\frac{f}{2}\right) U_{b}^{2}
$$

where the depth dependent wave orbital velocity, $U_{b}$, at the bed is given by

$$
U_{b}=\frac{\pi H_{s i g}}{T \sinh (2 \pi H / L)}
$$

while the friction factor, $f$, is calculated following Lawson et al [2007]. Wave attenuation due to a seagrass canopy is incorporated by reducing the wave orbital velocity assuming a Monod

equation, $U_{\text {bmeadow }}=U_{b}\left(\frac{N}{N+N_{h s}}\right)$, with half saturation constant, $N_{h s}$ of 1500 shoots $\mathrm{m}^{-2}$ [van der Heide et al., 2007]. With the constant shoot density, $N=500$ shoots $\mathrm{m}^{-2}$, a $25 \%$ reduction of near bed wave orbital velocities is obtained, similar to site specific results found [Hanson and Riedenbach, in review]. Wave attenuation is only performed over the landscape where seagrass is present. The combined effect of waves and currents on total bed shear stress is calculated as

$$
\tau_{b}=\sqrt[2]{\tau_{\text {bwave }}^{2}+\tau_{\text {bcurrent }}^{2}}
$$




\subsection{Sediment Resuspension}

In order to characterize the light environment, calculation total suspended sediments is required. In areas without seagrass roughness elements (e.g., bare sediment), a Rouse profile is used assuming a parabolic eddy diffusivity,

$C_{s}(z)=C_{a}\left[\frac{z\left(H-z_{a}\right)}{z_{a}(H-z)}\right]^{-\frac{w_{s}}{\kappa u_{*}}}$

where $u_{*}$ is the shear velocity, $w_{s}$ is the settling velocity, $c_{a}$ is the reference concentration near the bed at height $z_{a}$. However the vertical mixing above the patches of seagrass is more complicated. The mixing within and above the canopy can be dominated by shear scale vortices and the diffusivity of this region scales with the depth for the shear layer $t_{m l}$, and the shear, $\Delta U$ [Ghisalberti and Nepf, 2004]. Using the dimensionless results from Ghisalberti and Nepf [2004] we note that the top of the shear layer roughly corresponds to three times the canopy height with the maximum diffusivity occurring halfway through the shear layer. This can be simply modeled as a parabolic diffusivity which has a maximum of $0.0125 t_{m l} \Delta U$ at the height $t_{m l} / 2$, where $t_{m l}$ is the thickness of the shear layer

$$
K_{\text {shear }}=-0.05 \Delta U z\left(\frac{Z}{t_{m l}}-1\right)
$$

As noted in section 2.2, above the shear layer the velocity profile with a shear velocity $u_{*_{n}}$ , diffisuvity, $K_{\log }$, and displacement height, $d$,

$$
K_{\text {log }}=\kappa u_{*_{n}}(z-d)\left(1-\frac{(z-d)}{(H-d)}\right)
$$


The vertical diffusivity from the bottom of the shear layer to the top of the water column can be considered as a piecewise curve where from the reference concentration height $z_{a}$ to $z_{i}$ the diffusivity is modeled as in equation (17), and from $z_{i}$ to $H$ the diffusivity is modeled as in equation (18), where $z_{i}$ is the height at which the profiles given by equations equation (17) and (18) intersect, with, $z_{i}$ lying between $z_{a}$ and $H$.

\section{Letting}

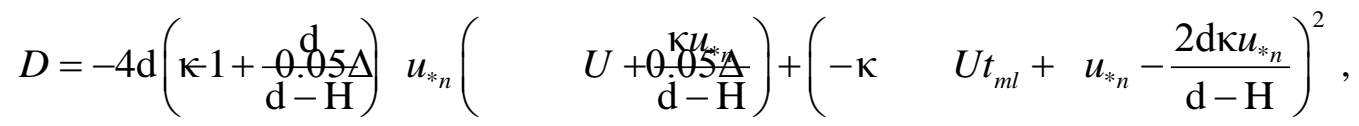

then

$$
\mathrm{z}_{\mathrm{i}}=\frac{0.05 \Delta U t_{m l}-\kappa u_{*_{n}}+\frac{2 \mathrm{~d} \kappa u_{*_{n}}}{\mathrm{~d}-\mathrm{H}} \pm \sqrt{D}}{0.1 \Delta U+\frac{\kappa u_{*_{n}}}{\mathrm{~d}-\mathrm{H}}} .
$$

Assuming steady state and integrating the one dimensional advection diffusion equation we find that the downward settling is equal to the upward mixing due to the diffusivity.

$$
-w_{s} c_{s}=K \frac{d C_{s}}{d z}
$$

Integration of equation (20) using equations (17) and (18) leads to a piecewise modified Rouse profile, where the mixing in the shear layer scales with $\Delta U$ and the mixing in the logarithmic layer scales with $u_{*_{n}}$. 


$$
C_{s}(z)=\left\{\begin{array}{cc}
C_{a}\left[\frac{z\left(t_{m l}-z\right)}{z_{a}\left(t_{m l}-z_{a}\right)}\right]^{-\frac{20 w_{s}}{\Delta U}} & Z_{a} \leq z \leq Z_{i} \\
C_{a 2}\left[\frac{\left(z-d_{0}\right)\left(H-z_{i}\right)}{(H-z)\left(z_{i}-d_{0}\right)}\right]^{-\frac{w_{s}}{\kappa u_{*_{n}}}} & Z_{i}<z<H
\end{array}\right.
$$

The reference concentration, $c_{a}$ drives the lower profile, while the upper reference concentration, $c_{a 2}$ is related to $c_{a}$ :

$C_{a 2}=C_{a}\left[\frac{Z_{i}}{\left(t_{m l}-z_{i}\right)}\right]^{-\frac{20 w_{s}}{\Delta U}}$

The reference concentration is determined following Lawson et al.[2007; Smith and McLean, 1977], but also includes an active bed layer determined by shear stress [Harris and Wiberg, 1997], for a bed comprised of three grain size classes (Table 1). Integration of equation (21) for each size class gives total suspended sediment (TSS) based on shear velocity, bed shear, mixing layer thickness, water depth, velocity shear, settling velocity, displacement height and bed sediment concentration.

Applying equation (21) to time dependent scenarios requires maintenance of fine grained sediment in suspension. Here, based on a bed load transport Rouse number, $\frac{w_{s}}{\kappa u_{*}}=2.5$, sediment is allowed to remain in suspension until the shear velocity and settling velocities are equal. This depositional stress is calculated from the tidal current shear stress acting on the bed. As such, meadows and the protected region behind the meadow become deposition favoring environments in comparison to the bare sediment areas. As the velocity changes direction the duration of time when the depositional stress is met allows for calculation of a partial flux of sediment in each size class out of the water column based on settling velocity for each grid location. Size class mass 
balance with the sediment bed is not performed; rather, the total volume of sediment in suspension is limited based on an active bed layer with a constant grain size distribution [Harris and Wiberg, 1997].

Advection of sediment in the flow direction is incorporated as linear weighted average. Each node on the grid exhibits the sediment concentration of the nodes some distance upstream. This distance is a function of average current, settling velocity and water depth or time step length.

$d_{\text {advect }}=\overline{U_{\text {curr }}}\left(\min \left[\frac{H}{w_{s}}, \Delta t\right]\right)$

Weights are determined linearly based on the advective distance and the number of nodes upstream involved in the average. As the boundary of the landscape is harmonic, TSS is advected out one boundary and in the boundary opposite. No lateral dispersion is allowed, and scenarios with and without advection were explored.

\subsection{Light environment}

An empirical relationship relating TSS, concentrations of $c h l a$, and colored dissolved organic matter (CDOM) to a light attenuation coefficient was used [Lawson et al., 2007].

$K_{d}=0.052 T S S+c h l a \times 0.0154+C D O M \times 0.28+0.0384$

Using the Lambert-Beer law, and the light attenuation coefficient, $K_{d}\left(\mathrm{~m}^{-1}\right)$ we calculate the percent of incident radiation reaching the sediment surface under varied flow and seagrass conditions. We assume non-varying minimal values of $\operatorname{chl} a=5 \mathrm{mg} \mathrm{m}^{-3}$ and $C D O M=0.4$ corresponding to the low nutrient environment associated with Hog island Bay (VCR LTER data 
base, www1.vcrlter.virginia.edu/home1/?q=data_wq), and thus look at the change in the bulk light environment as a function of sediment resuspension and water depth.

\subsection{Realizations}

For a given landscape realization $R(\lambda, r)$ with corresponding fractional cover, $f_{\text {cover }}(\lambda, r)$ and mean water depth, $H$; hourly time series of winds, tides and currents corresponding to Spring, Summer, Fall and Winter for the year 2000, were used to construct cumulative distributions(cdf's) of 1) mean shear stress on the surface (Pa), 2) mean TSS (mg/l) over the bed surface, and 3) the mean fraction of incident light reaching the sediment surface over each time period. Modification of average patch density $\lambda$ (i.e., number of patches per unit area), average patch size, $r$, and $H$, for multiple $R(\lambda, r)$, allowed for exploration of how landscape structure (expressed as a function of $\lambda, r$ ) and water depth affect surface shear stresses and the consequent sediment and light environment. As explained in Section 2.1, the heterogeneous meadow landscape was generated either by randomly scattering seagrass patches of circular shape (hereafter indicated as "meadows”) or by opening circular gaps within an initially uniform seagrass meadow (hereafter indicated as “disturbances”).

\subsection{Study area:}

While the general model formulation is applicable to a broad array of locations, we use as a case study the coastal bays of the Virginia Coast Reserve Long Term Ecological Research site located on the Atlantic side of the Delmarva Peninsula (VCR LTER $37^{\circ} 25^{\prime}$ N, $75^{\circ} 46^{\prime}$ W). These bays lack major river outlets and their suspended sediments are originated by resuspension by waves and currents. During the 1930's the seagrasses (Zostera marina) of the VCR LTER coastal bays became locally extinct when already under duress by disease were extirpated by a hurricane [Orth et al., 2006]. In the late 1990’s small natural patches of seagrass were found which initiated restoration efforts and seagrasses cover now 1700 ha in the VCR coastal bays 
[Orth et al., in review] from $0.6 \mathrm{~m}$ to $1.6 \mathrm{~m}$ depths relative to mean sea level (MSL) [McGlathery et al, in review]. We utilize hourly tidal currents, wind speed and direction from the year 2000 from the NOAA Wachapreague station, Virginia (WAHV2, 37³6'24" N, 7541'12" W), and bed grain size characteristics (fine sand to silt, Table 1) from Hog Island Bay which is a shallow coastal bay with half the bay less than a meter deep at mean low water and $1.2 \mathrm{~m}$ tidal range [Oertel, 2001].

\section{Results}

\subsection{Seasonal effects:}

For this study site, fall and winter storms generate higher wind wave shear stresses on the sediment surface. As a result the cdf's of the mean shear stress at the bed surface, mean TSS (mg/l) and mean percent of incident light reaching the sediment surface show distinct seasonal variations (Figure 7). The two jumps in the light cdf at $\mathrm{P}($ Light $\leq 65 \%$ incident light) and $\mathrm{P}($ Light $\leq 75 \%$ incident light) reaching the sediment surface correspond to times of slack water and the median tidal current in the tidal forcing respectively. Due to high temperature limits on seagrass growth in the mid summer [Duarte, 2002; Moore and Jarvis, 2008], the growing season is split into a Spring growth followed by a Summer die off and then a Fall recovery with storms typically arriving October through April [Lawson et al., 2007]. In order to better examine the combined effects of tidal currents and wind waves over various depths relative to MSL, we limited the rest of the investigation to the Fall season (September 21 to December 20, 2000).

\subsection{Radius and fractional cover:}

To determine the effects of mean patch radius, on the cumulative distributions, we maintained a constant $f_{\text {cover }}=0.5$ across meadow realizations with the mean radius varying from $0.5 \mathrm{~m}$ to $2.5 \mathrm{~m}$ in 0.5 meter increments. For a $f_{\text {cover }}=0.5$, as the mean radius increases the required intensity $\lambda$ decreases (Figure 2). In general as meadow radius increases, the average shear 
stress on the surface increases, with consequent increase in TSS, and decrease in light conditions (Figure 8). This is due to relative increase in the presence of longer distances between meadows as meadow radius increases while holding fractional cover constant. Thus in terms of sediment resuspension and holding fractional cover constant, scattering multiple smaller meadows has a larger effect on reducing TSS, than scattering fewer larger disks due to the sheltering area behind patches. This indicates that the distributions of shear stress, sediment and light are not scale invariant.

\subsection{Advection:}

The incorporation of advection of sediment (section 2.5), while not significantly affecting the total sediment mass in suspension for any given time step time step across the realization (Figure 9), changes the distribution of that mass across the surface. This shift allows for a current and settling velocity dependent change in the sediment above a region in terms of the mass limiting active layer (section 2.5) on the following time step. It also reduces the total sediment in suspension as higher concentrations over bare patches are shifted over meadows which favor deposition. This overall leads to slight decrease of mass in suspension when currents are falling and vegetation is present (Figure 10) along with a decrease in the extreme values due to averaging, though both of these effects of advection seem to be overall modest. However, advection not only changes the light environment (Figure 10) but changes the spatial distribution of light on the bed surface (Figure 11 and 12), leading to a more spatially homogeneous light environment due to mixing associated with a time varying advective velocity. Note that the banding in Figures 11 and 12 is due to lack of horizontal dispersion.

\subsection{Waves, and depth relative to MSL:}

Wave shear stress is a function of near bed orbital velocity, which diminishes with increasing water depth. As a result, the light attenuation due the sediment in suspension decreases, whereas the total depth for light penetration increases. The added effect of the 
presence of seagrass cover is to decrease the wave generated near bed shear stress. As a result, for a fully vegetation covered landscape between $1 \mathrm{~m}$ and $6.8 \mathrm{~m}$ below MSL light availability exceeds $20 \%$ incident light when the sediment is covered by seagrasses. However, the available light decreases with depth, until this improvement in the light environment associated with the decrease in orbital velocity and sediment resuspension is no longer able to offset the light loss due to light attenuation through a deeper water column. With no suspended sediment, the light reaching in the sediment surface reaches $20 \%$ at $8 \mathrm{~m}$ MSL (equation 24). The significant decrease in bed shear stress results in lack of resuspension and the cdf's of light become dependent only on tidal elevation resulting in an extremely narrow distribution when mean water depths are larger than 4 m MSL (Figure 13). For bare landscapes, the P[Light $\leq 20 \%$ incident light] increases with depth (Figure 14). While there is significant decline in shear stress and TSS as water depth increases due to wave orbital decay, without seagrasses, the tidal generated shear stress is enough to generate TSS and reduction in light penetration of the water column, with a negative effect on light conditions. This implies that landscapes with high fractional cover strongly inhibit current driven resuspension with wave generated shear stress controlling resuspension across the landscape (Figure 15).

\subsection{Meadows and gaps}

There exists a distinct difference between cases in which a certain fractional cover is attained by randomly scattering patches of meadows or by opening gaps in a uniform seagrass meadow (Figure 16). This difference is minimal at high fractional covers, but is more significant at lower covers. For $f_{\text {cover }}=0.25$, landscapes with circular meadows generated with $\mathrm{R}\left(0.35 \mathrm{~m}^{-}\right.$

$\left.{ }^{2}, 0.5 \mathrm{~m}\right)$ exhibit better light conditions at the sediment surface than landscapes with circular gaps obtained with $\mathrm{R}\left(1.69 \mathrm{~m}^{-2}, 0.5 \mathrm{~m}\right)$. From the meadow perspective the probability $\mathrm{P}[$ Light $\leq 20 \%$ incident light] ranges from 0.16 at $1 \mathrm{~m}$ MSL to 0.47 at $4 \mathrm{~m} \mathrm{MSL}$. The corresponding 
probabilities for gaps range from 0.13 to 0.33 . This indicates that there is a hysteresis in the light environment depending on how fractional cover is obtained.

\section{Discussion:}

In the simulations presented in the previous sections the minimum mean patch or gap radius was $0.5 \mathrm{~m}$, which corresponds to minimum gap size able to effect the hydrodynamics [Luhar et al., 2008] as well as observed minimum patch sizes [Fonseca, 1998; Olesen, 1994]. Larger radii are representative of larger reseeding areas or disturbances. Thus, the mean radius used in this study is a size from which larger more contiguous meadows or gaps could be generated by multiple partly overlapping disks in the spatial Poisson process described in Section 2.1. While prior work involved various landscape metrics [Larkum et al., 2006] including those from percolation theory [Luhar et al., 2008] to set thresholds for percent cover and pattern formation, this study incorporates downstream shear partitioning [Okin, 2008] and effective shelter area [Folkard, 2011].

This paper investigated how vegetated patches influence a larger area than their footprint, including an adjacent downstream area. We have shown how this effective fractional cover affects the bulk sediment and light environment. The effective fractional cover (Figure 17) can be calculated based on downstream gap distances for both flood and ebb flow directions (Figure 6), with a simple assumption of equal temporal distribution of sheltered areas in each flow direction. For $f_{\text {cover }}=0.5, R\left(0.858 \mathrm{~m}^{-2}, 0.5 \mathrm{~m}\right)$, the effective fractional cover for the same realization $f_{\text {cover,eff }}=0.9$ for the meadows and $f_{\text {cover,eff }}=0.93$ for disturbances. In general, the effective fractional covers from the meadow and gap perspectives are equal at a slightly higher intensity on the landscape than when fractional covers are equal (Figure 17, 18). For most other fractional covers, there is a large discrepancy between addition and subtraction of cover on the effective fractional cover of the landscape. This has significant implications for the resilience, bulk light 
and sediment environment of a landscape as it takes a far larger number of disturbed areas (gaps) to adversely affect the effective fractional cover and the light environment in an initially uniform seagrass meadow. Alternately, it takes the establishment of few meadows on an initially bare landscape to cause significant change in the effective fractional cover (Figure 17). This becomes less pronounced as radius of disturbance or meadow increases (Figure 18). The effective fractional cover, from the two perspectives are roughly equivalent only when fractional cover approaches 0.5, implying that any individual patch affects an area larger than itself, should be incorporated when utilizing landscape metrics and looking at controls of pattern and landscape formation.

Sediment bed grain size plays an important role in determining the transport and light environment. Prior work has similarly demonstrated the collapse of the positive feedback between seagrass and their light environment and consequent decrease in bistable dynamics [Carr et al., 2010] as the bed grain size distribution coarsens. In a sandy substrate environment, this positive feedback is likely to be negligible, whereas as the bed sediment concentrations increase in silt and clay content, this positive feedback becomes important. With the inclusion of advection, as the bed sediment grains size coarsens the advective distance decreases, and the light environment within that advective distance is also modified. Using maximum settling time based on hourly water column depth, settling velocity by grain size, and tidal velocities, a distribution of maximum advective distances can be generated (Figure 19) similar to Chen [2010]. In general, suspended sediment concentrations are less likely to be locally controlled due to significant advection. As water depth decreases and grains size distributions coarsen, suspended sediment control shifts towards a more localized region. Thus, a larger area than the identified suitable habitat along with effective fractional cover on the landscape needed to maintain suitable light environment may need to be considered in terms of examining suitable restoration locations. 
These results differ from prior work [Carr et al., 2010; van der Heide et al., 2007] in the sense that the suitable habitat depth range produced here is 1) a function of the total landscape rather than an individual meadow. 2) Actual light constraints are relative to actual incident photosynthetically active radiation, not included. 3) Temperature effects on light requirements, photosynthesis and respiration are also not incorporated. 4) Average meadow shoot densities decline with depth lessening the influence of meadows on hydrodynamics. Similarly this study is limited to conditions of Fall 2000, which may not be representative of general environmental conditions. The emergence of bistable dynamics has significant consequences in that a system, which undergoes a relatively strong disturbance, can fall into the attraction domain of an alternate state from which it cannot recover [Gunderson, 2000; Scheffer and van Nes, 2004; Van De Koppel et al., 2001]. Such disturbances can occur from a variety of causes [Bell, 2008; Fonseca, 2007; Larkum et al., 2006] and recovery of bare patches can take years [Boese et al., 2009]. The results here indicate that even when disturbances open a relatively large number of gaps (e.g., $\lambda$ $=10 \mathrm{~m}^{-2}$ ) in a seagrass meadow a favorable light environment may still exist because the effective fractional cover is larger than the actual vegetation cover (Figure 17). This indicates that in fine sediment environments where light availability limits seagrass growth, carpeted seagrass landscapes are likely more resilient to disturbances.

\section{Conclusion:}

The effective fractional cover of seagrasses on a landscape has important controls on the distributions of shear stress, suspended sediment and consequent light environment across the landscape. The strength of the positive feedback between effective fractional cover and the bulk light environment is strongly related to the grain size distribution on the landscape. As fractional cover increases, the effective fractional cover increases dramatically, whereas, given a homogenous meadow landscape, disturbances on that landscape, the effective fractional cover 
diminishes slowly. This hysteresis in effective fractional cover has significant implications regarding the resilience of contiguous seagrass landscapes to disturbances that remove fractional cover.

\section{References}

Abdelrhman, M. A. (2003), Effect of eelgrass Zostera marina canopies on flow and transport, Mar. Ecol.-Prog. Ser., 248, 67-83.

Abdelrhman, M. A. (2007), Modeling coupling between eelgrass Zostera marina and water flow, Mar. Ecol.-Prog. Ser., 338, 81-96.

Bell, S. S. (1997), Linking Restoration and Landscape Ecology, Restoration ecology, 5(4), 318323.

Bell, S. S. (2008), Dynamics of a subtropical seagrass landscape: links between disturbance and mobile seed banks, Landscape ecology, 23(s1), 67-74.

Boese, B. L., et al. (2009), Recolonization of intertidal Zostera marina L. (eelgrass) following experimental shoot removal, Journal of Experimental Marine Biology and Ecology, 374(1), 6977.

Carr, J., et al. (2010), Stability and bistability of seagrass ecosystems in shallow coastal lagoons: Role of feedbacks with sediment resuspension and light attenuation, J. Geophys. Res.-Biogeosci., 115, 14.

Chen, S.-N., et al. (2010), Sediment transport and deposition on a river-dominated tidal flat: An idealized model study, J. Geophys. Res., 115(C10), C10040.

Chen, S. N., et al. (2007), A nearshore model to investigate the effects of seagrass bed geometry on wave attenuation and suspended sediment transport, Estuaries and Coasts, 30(2), 296-310. de Boer, W. F. (2007), Seagrass-sediment interactions, positive feedbacks and critical thresholds for occurrence: a review, Hydrobiologia, 591, 5-24. 
Dennison, W. C., et al. (1993), Assessing water-quality with submersed aquatic vegetation Bioscience, 43(2), 86-94.

Duarte, C. M. (1991), Seagrass depth limits, Aquatic Botany, 40(4), 363-377.

Duarte, C. M. (2002), The future of seagrass meadows, Environmental Conservation, 29(02), 192-206.

Folkard, A. (2011), Flow regimes in gaps within stands of flexible vegetation: laboratory flume simulations, Environmental Fluid Mechanics, 11(3), 289-306.

Fonseca, M. (2002), Modeling seagrass landscape pattern and associated ecological attributes, Ecological Applications, 12(1), 218-237.

Fonseca, M. S. (1998), Influence of physical setting on seagrass landscapes near Beaufort, North Carolina, USA, Marine ecology. Progress series (Halstenbek), 171, 109.

Fonseca, M. S. (2007), Biomechanical factors contributing to self-organization in seagrass landscapes, Journal of Experimental Marine Biology and Ecology, 340(2), 227.

Fonseca, M. S. (2008), Factors influencing landscape pattern of the seagrass Halophila decipiens in an oceanic setting, Estuarine, coastal and shelf science, 76(1), 163.

Ghisalberti, M., and H. M. Nepf (2004), The limited growth of vegetated shear layers, Water Resources Research, 40(7).

Ghisalberti, M., and H. Nepf (2006), The structure of the shear layer in flows over rigid and flexible canopies, Environmental Fluid Mechanics, 6(3), 277-301.

Gunderson, L. H. (2000), Ecological resilience - in theory and application, Annual Review of Ecology and Systematics, 31, 425-439.

Harris, C. K., and P. L. Wiberg (1997), Approaches to quantifying long-term continental shelf sediment transport with an example from the Northern California STRESS mid-shelf site, Continental Shelf Research, 17(11), 1389-1418. 
Huthoff, F. (2007), Analytical solution of the depth-averaged flow velocity in case of submerged rigid cylindrical vegetation, Water Resources Research, 43(6), W06413.

Larkum, A. W. D., et al. (2006), Seagrass Ecology: New Contributions from a Landscape Perspective, in Seagrasses: Biology, Ecology and Conservation, edited, pp. 625-645, Springer Netherlands.

Lawson, S. E., et al. (2007), Wind-driven sediment suspension controls light availability in a shallow coastal lagoon, Estuaries and Coasts, 30(1), 102-112.

Luhar, M., et al. (2008), Interaction between flow, transport and vegetation spatial structure, Springer.

Markfort, C. D. (2010), Wind sheltering of a lake by a tree canopy or bluff topography, Water Resources Research, 46(3), W03530.

McGlathery, K. J., et al. (2007), Eutrophication in shallow coastal bays and lagoons: the role of plants in the coastal filter, Mar. Ecol.-Prog. Ser., 348, 1-18.

Moore, K. A., and J. C. Jarvis (2008), Environmental Factors Affecting Recent Summertime Eelgrass Diebacks in the Lower Chesapeake Bay: Implications for Long-term Persistence, $J$. Coast. Res., 135-147.

Oertel, G. (2001), Hypsographic, hydro-hypsographic and hydrological analysis of coastal bay environments, Great Machipongo Bay, J. Coast. Res., 17, 775-783.

Okin, G. S. (2008), A new model of wind erosion in the presence of vegetation, Journal of geophysical research, 113.

Olesen, B. (1994), Patch dynamics of eelgrass Zostera marina, Marine ecology. Progress series (Halstenbek), 106, 147.

Orth, R. J., et al. (2006), Seagrass recovery in the Delmarva Coastal Bays, USA, Aquatic Botany, 84(1), 26-36. 
Sandjensen, K., and J. Borum (1991), Interactions among phytoplankton, periphyton, and macrophytes in temperate fresh-waters and estuaries, Aquatic Botany, 41(1-3), 137-175.

Scheffer, M., and E. H. van Nes (2004), Mechanisms for marine regime shifts: can we use lakes as microcosms for oceans?, Progress in Oceanography, 60(2-4), 303-319.

Smith, J. D., and S. R. McLean (1977), Spatially Averaged Flow Over a Wavy Surface, Journal of geophysical research, 82(12), 1735-1746.

Van De Koppel, J., et al. (2001), Do alternate stable states occur in natural ecosystems? Evidence from a tidal flat, Ecology, 82(12), 3449-3461.

van der Heide, T., et al. (2007), Positive feedbacks in seagrass ecosystems: Implications for success in conservation and restoration, Ecosystems, 10(8), 1311-1322.

van der Heide, T. (2010), Spatial self-organized patterning in seagrasses along a depth gradient of an intertidal ecosystem, Ecology (Durham), 91(2), 362-369.

Walker, I. J. (2003), Simulation and measurement of surface shear stress over isolated and closely spaced transverse dunes in a wind tunnel, Earth surface processes and landforms, 28(10), 11111124.

Young, I. R., and L. A. Verhagen (1996), The growth of fetch limited waves in water of finite depth .1. Total energy and peak frequency, Coastal Engineering, 29(1-2), 47-78.

Zimmerman, R. C., and R. S. Alberte (1995), Light availability, root anoxia and patterns of carbon allocation in the marine angiosperm Zostera Marina L (eelgrass), Plant Physiology, 108(2), 24-24.

Zimmerman, R. C., et al. (1995), Eelgrass(Zostera Marina L) transplants in San Francisco Bay Role of light availability on metabolism, growth and survival, Aquatic Botany, 51(1-2), 67-86. 
Figures

Poisson scattering of disks of radius $r$

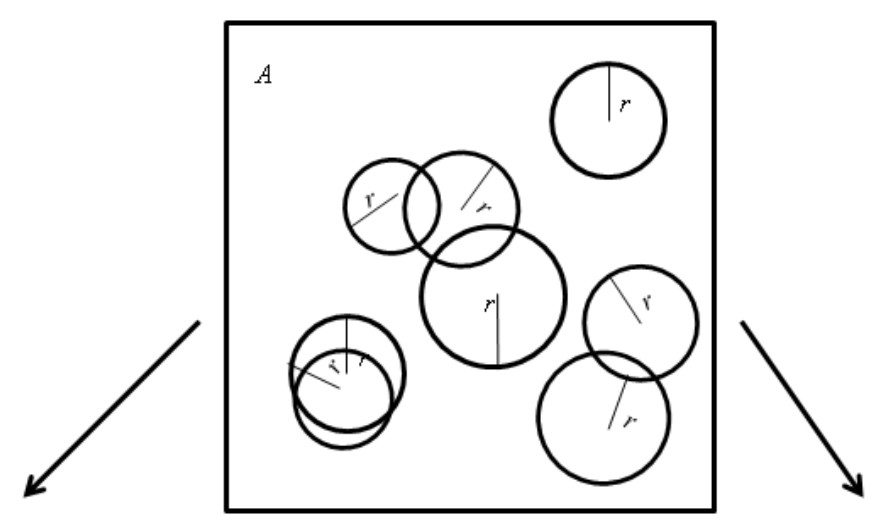

A. Adding Meadows

B. Adding Disturbances

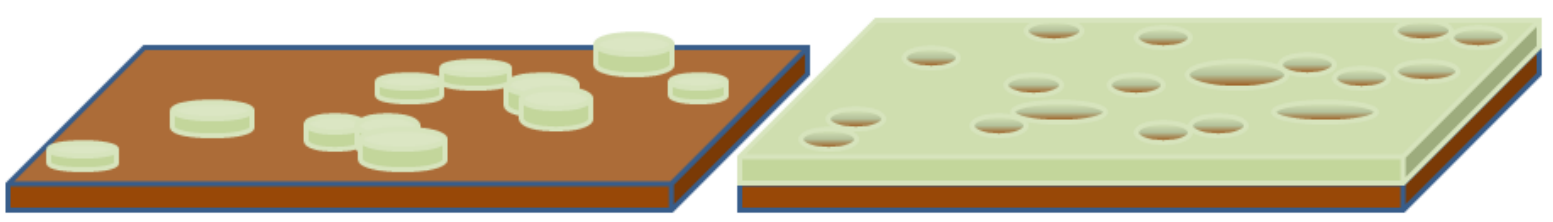

Figure 1. Generation of landscape realizations from a spatial Poisson point process, scattering overlapping disks or radius $r$, on an area $A$, and then interpreting those disks as either A. meadows on a bare sediment surface or B. disturbances on a continuous meadow landscape. 


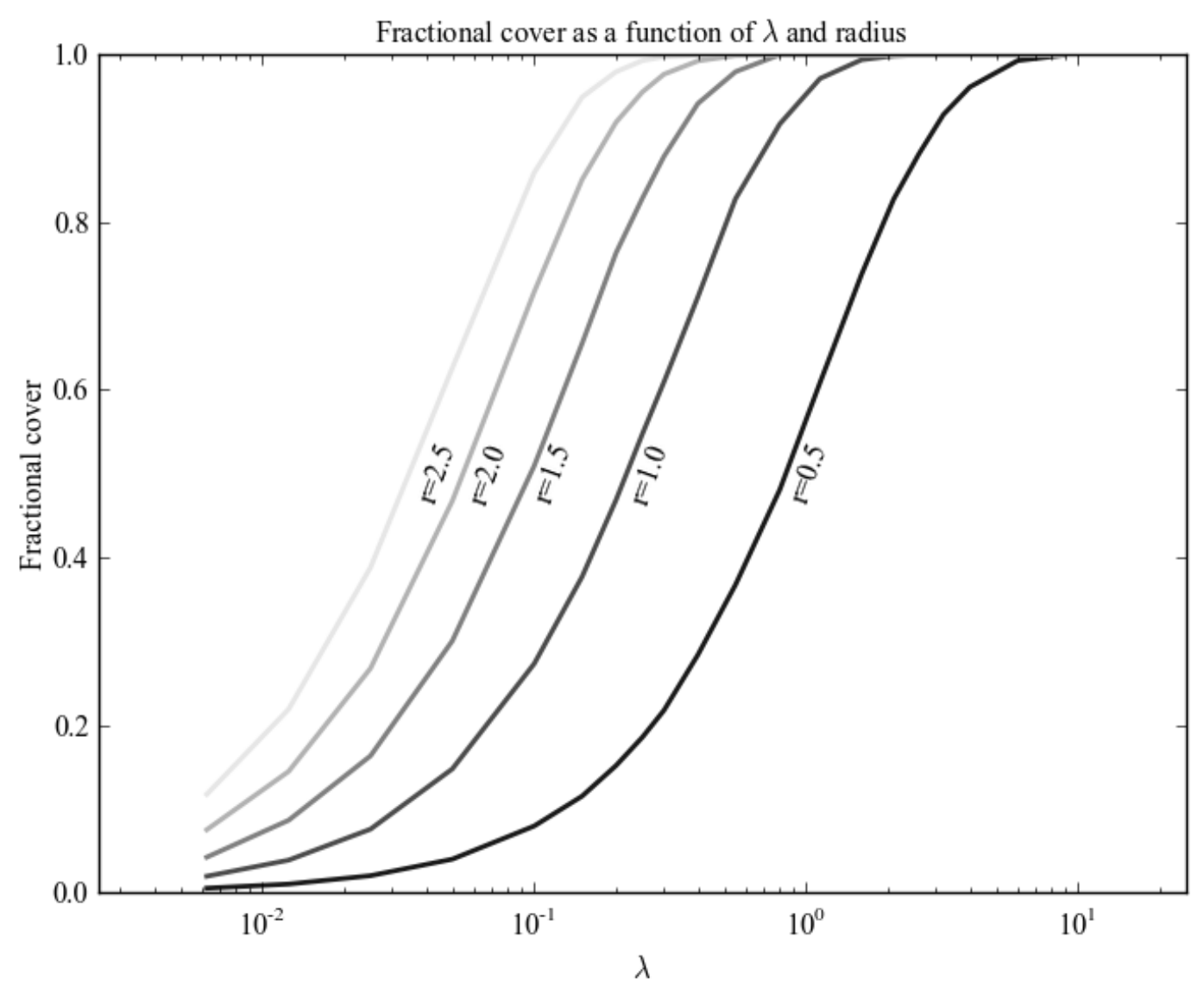

Figure 2. Fractional cover as a function of meadow intensity and meadow radius on a 200 m by 200 m landscape. The curves represent either fractional cover of meadows over the landscape in the case of circular seagrass patches randomly scattered on a bare sediment background. In the case of circular gaps opened in an initially uniform seagrass meadow, the vegetation fractional cover is one minus the values shown in this diagram. 


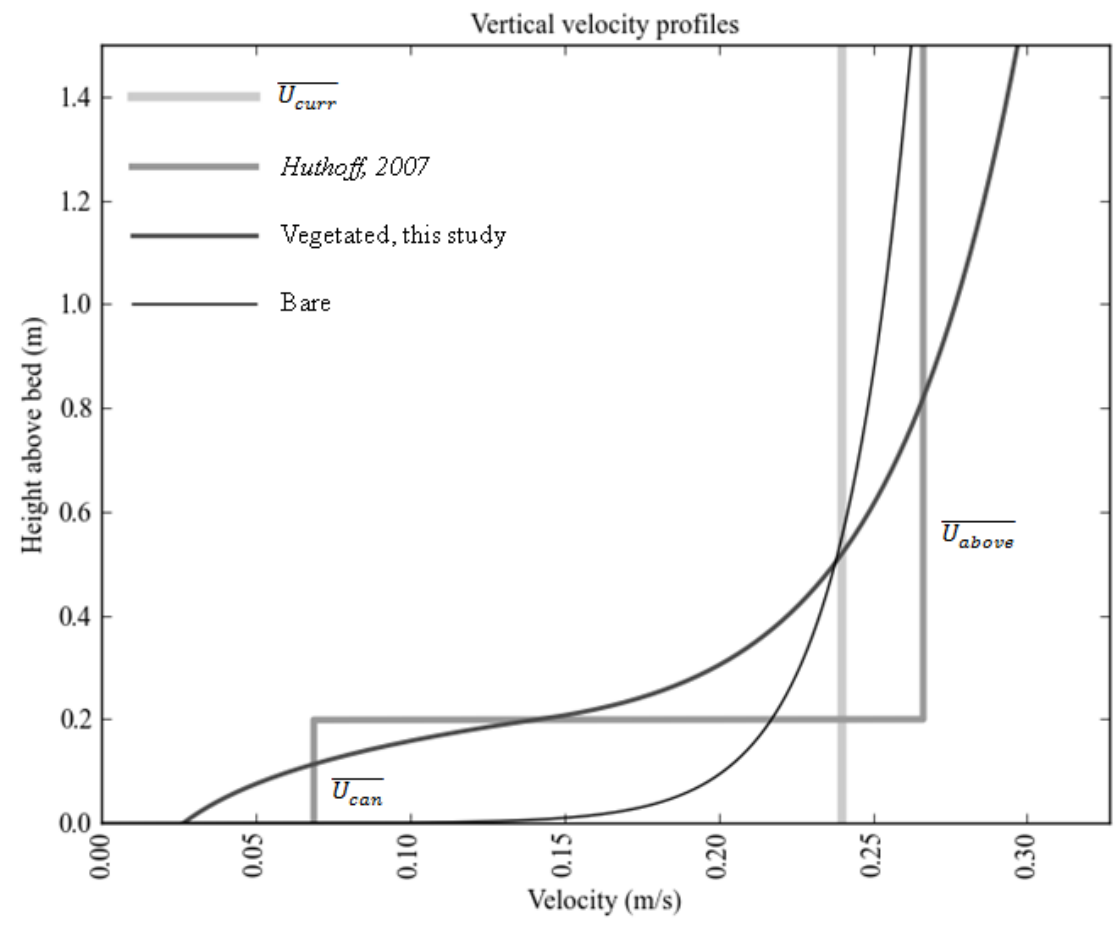

Figure 3. The vertical velocity profiles generated from an average tidal current of 0.24 $\mathrm{m} / \mathrm{s}$, bed grain size distribution (Table 1), and a water depth of $1.5 \mathrm{~m} \mathrm{MSL.} \mathrm{The}$ vegetated profiles assume canopy height of $0.2 \mathrm{~m}$, and shoot density of 500 shoots $\mathrm{m}^{-2}$. 


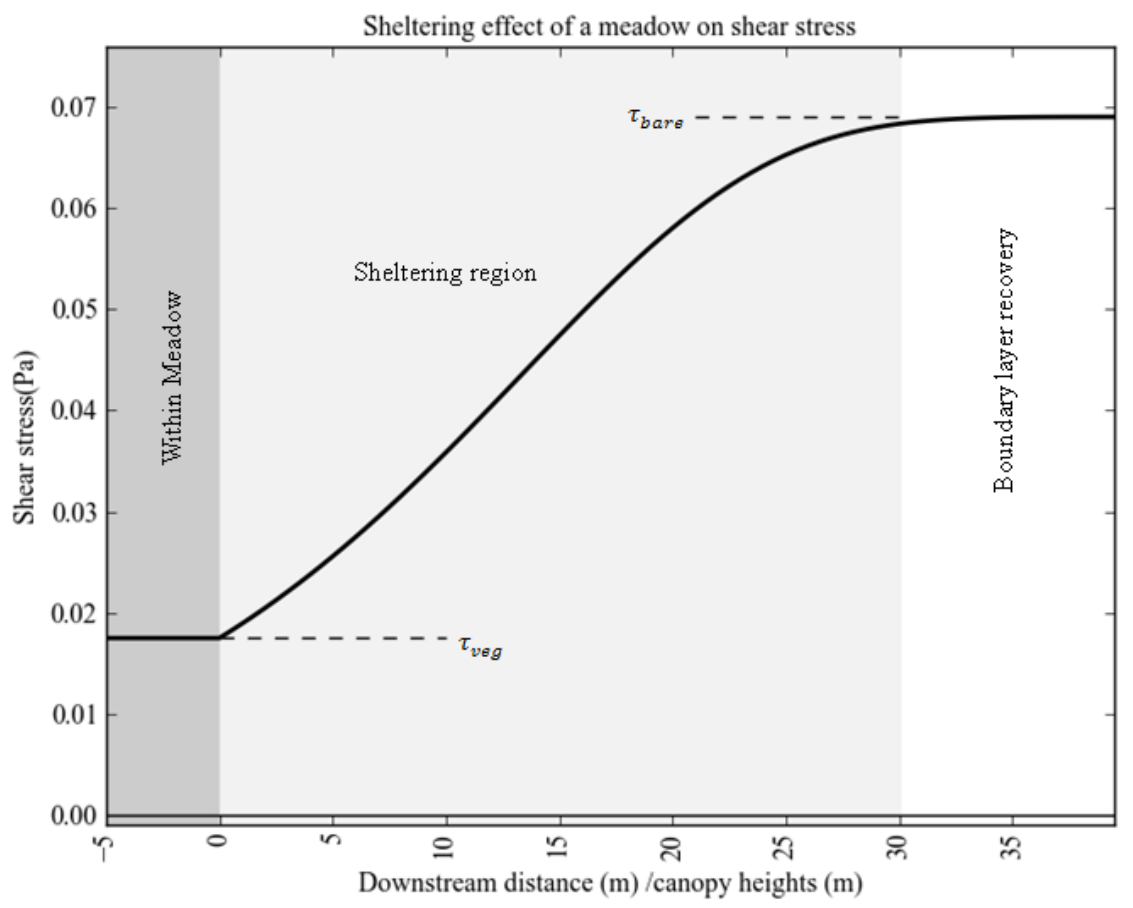

Figure 4. The sheltering effect of a meadow in the downstream direction. Recovery of shear stresses occurs within 30 canopy heights downstream. Shear stress here are those generated by the a $0.24 \mathrm{~m} / \mathrm{s}$ tidal current acting on the landscape with depth $1.5 \mathrm{~m} \mathrm{MSL}$, following the Gompertz function (equation 12) 


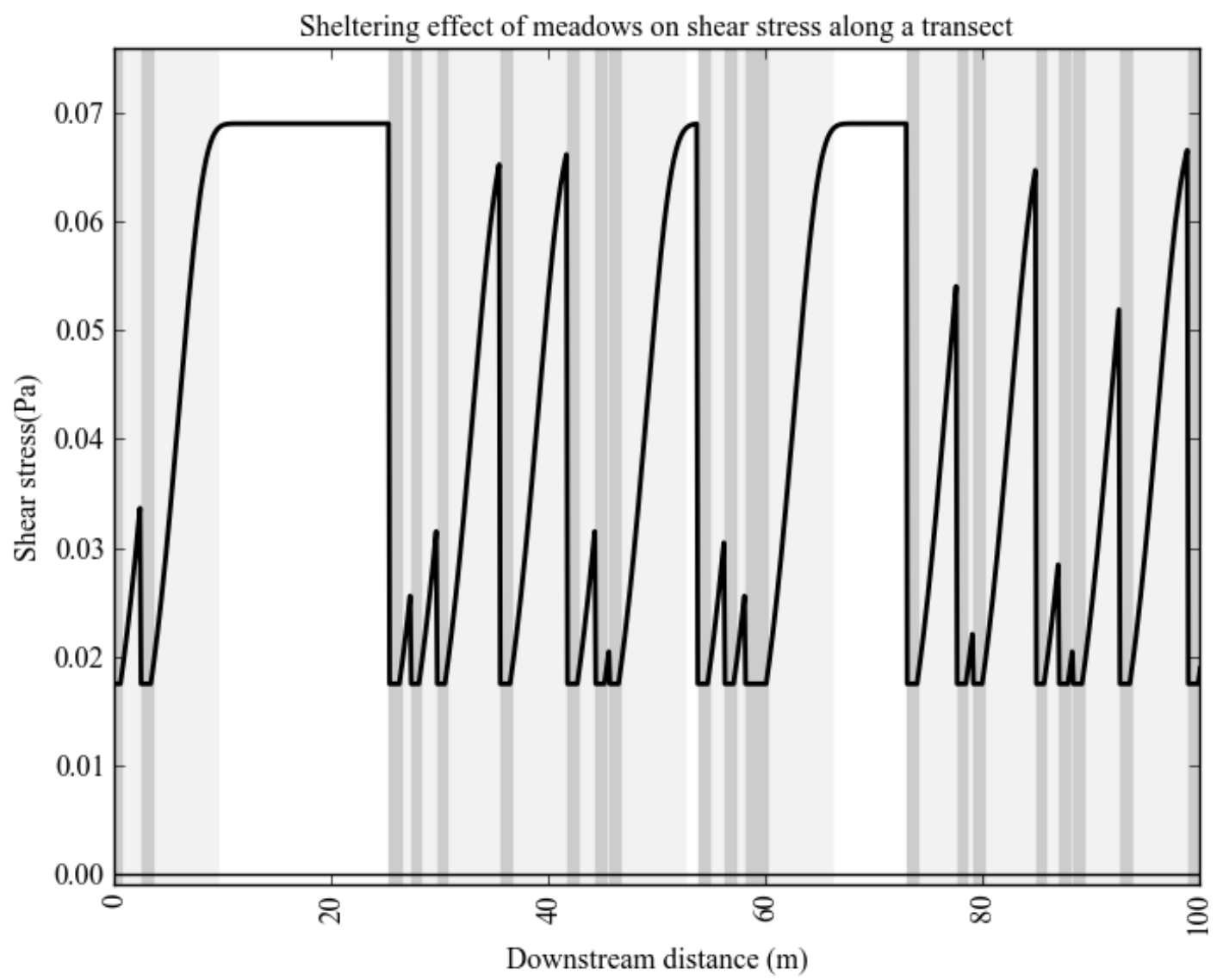

Figure 5. The sheltering effect of meadows in the downstream direction along a transect.

Dark gray regions are vegetated sections, sheltered regions are light gray, bare unsheltered zones where boundary layer reformation has occurred are white. Shear stresses here are those generated by a $0.24 \mathrm{~m} / \mathrm{s}$ tidal current acting on the landscape. 


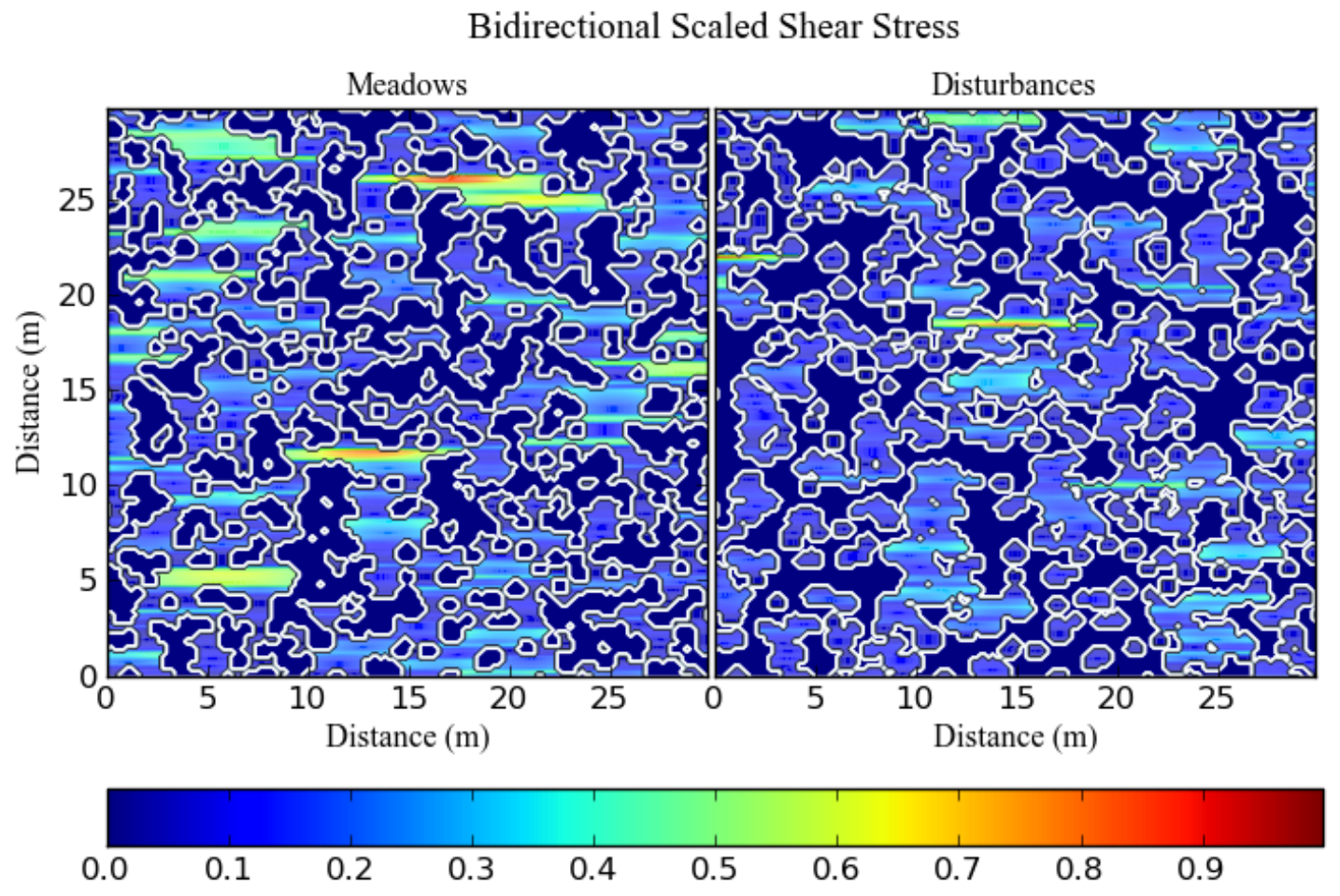

Figure 6. Shear stresses for the wave current conditions of a single time step, acting on two $30 \mathrm{~m}$ by $30 \mathrm{~m}$ plots with the same vegetation fractional cover $f_{\text {cover }}=0.5, R\left(0.858 \mathrm{~m}^{-2}\right.$, $0.5 \mathrm{~m}$ ), obtained either by randomly scattering circular seagrass patches (A) or circular gaps within a seagrass meadow (B). Shear stress values are normalized with respect to the minimum and maximum values on the landscape for any given hour. Even though the fractional cover is the same, larger magnitude shear stresses exist in the case (A), due to shorter gaps between vegetated areas. Simulations were run with a mean water depth of $1.5 \mathrm{~m}$. 

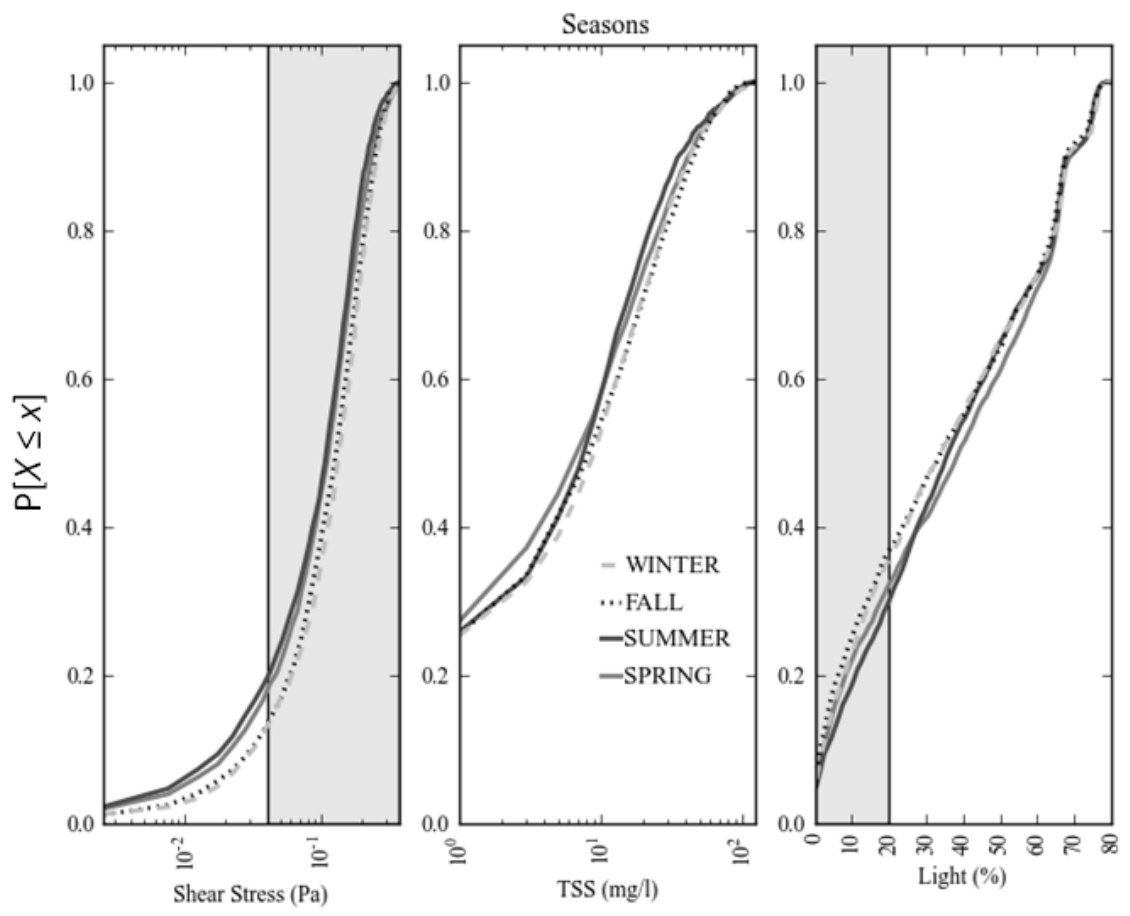

Figure 7. Cumulative distributions of mean shear stress, mean total suspended sediment, and mean percent light reaching the sediment surface calculated for different seasons on a $200 \mathrm{~m}$ by $200 \mathrm{~m}$ bare sediment landscape $\left(f_{\text {cover }}=0.0\right)$ at $1.5 \mathrm{~m}$ MSL. Shaded regions correspond to $\tau_{b}>\tau_{c r i t}$ and less than $20 \%$ light reaching the sediment surface. 


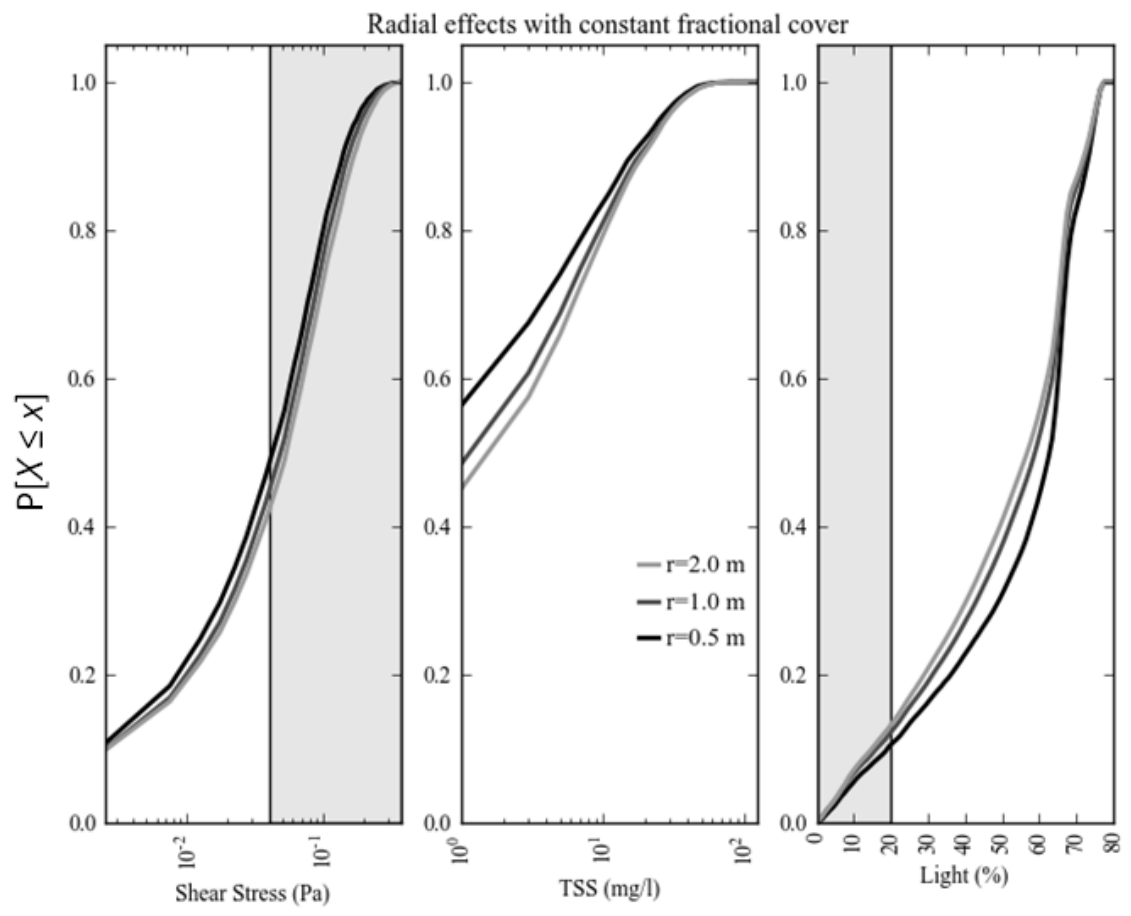

Figure 8. The effect of changing the mean radius of disks scattered on a $200 \mathrm{~m}$ by $200 \mathrm{~m}$ landscape holding fractional cover constant $\left(f_{\text {cover }}=0.5\right)$ on the cumulative distributions of mean shear stress, mean total suspended sediment, and mean percent light reaching the sediment surface. Shaded regions correspond to $\tau_{b}>\tau_{c r i t}$ and less than $20 \%$ light reaching the sediment surface. 


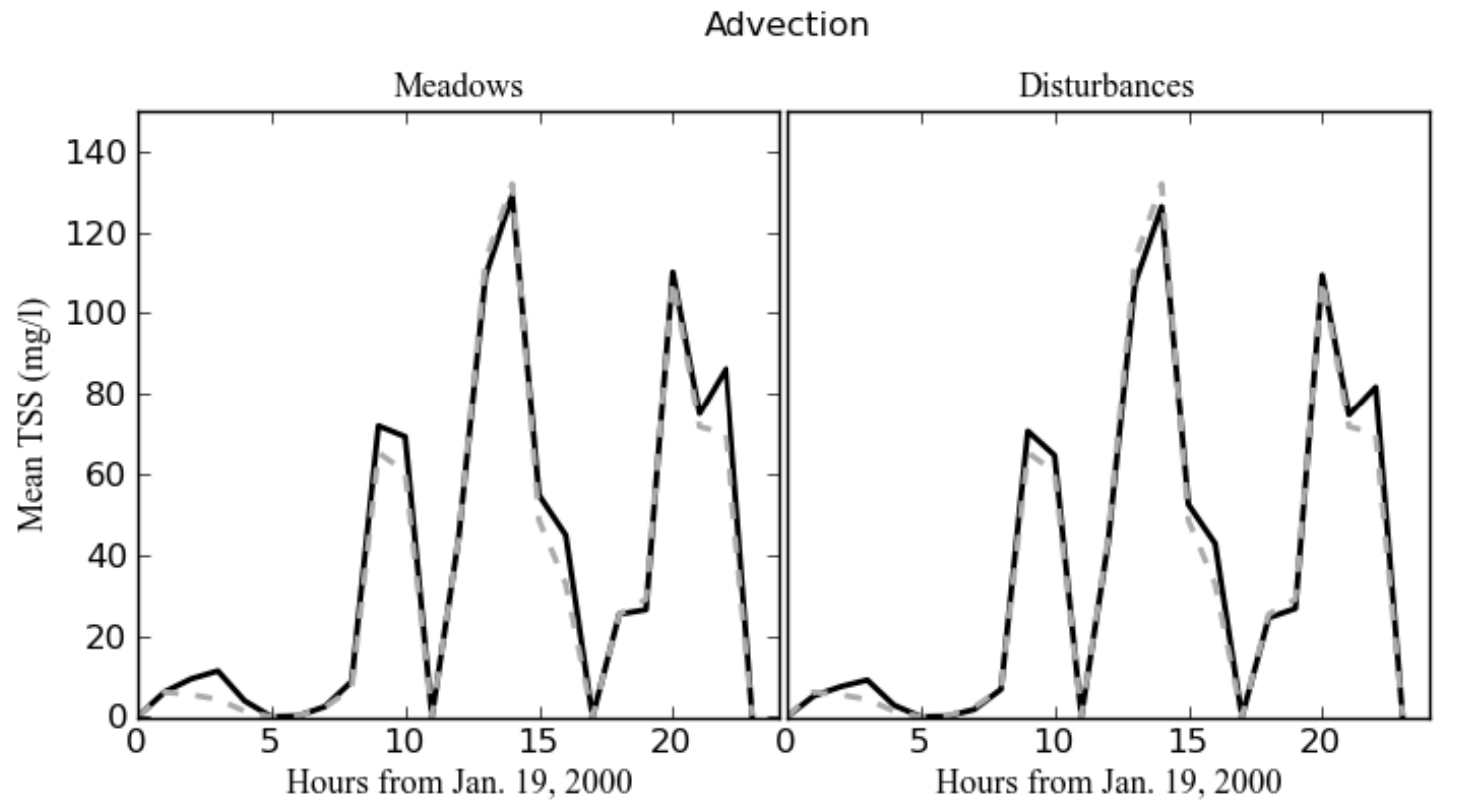

Figure 9. Effects of advection (dashed lines): slight changes in the mean TSS (mg/l) over the surface with slight enhancement in deposition. Simulations run with $f_{\text {cover }}=0.5$, $R\left(0.858 \mathrm{~m}^{-2}, 0.5 \mathrm{~m}\right)$ and water depth $=1.5 \mathrm{~m} \mathrm{MSL}$. 

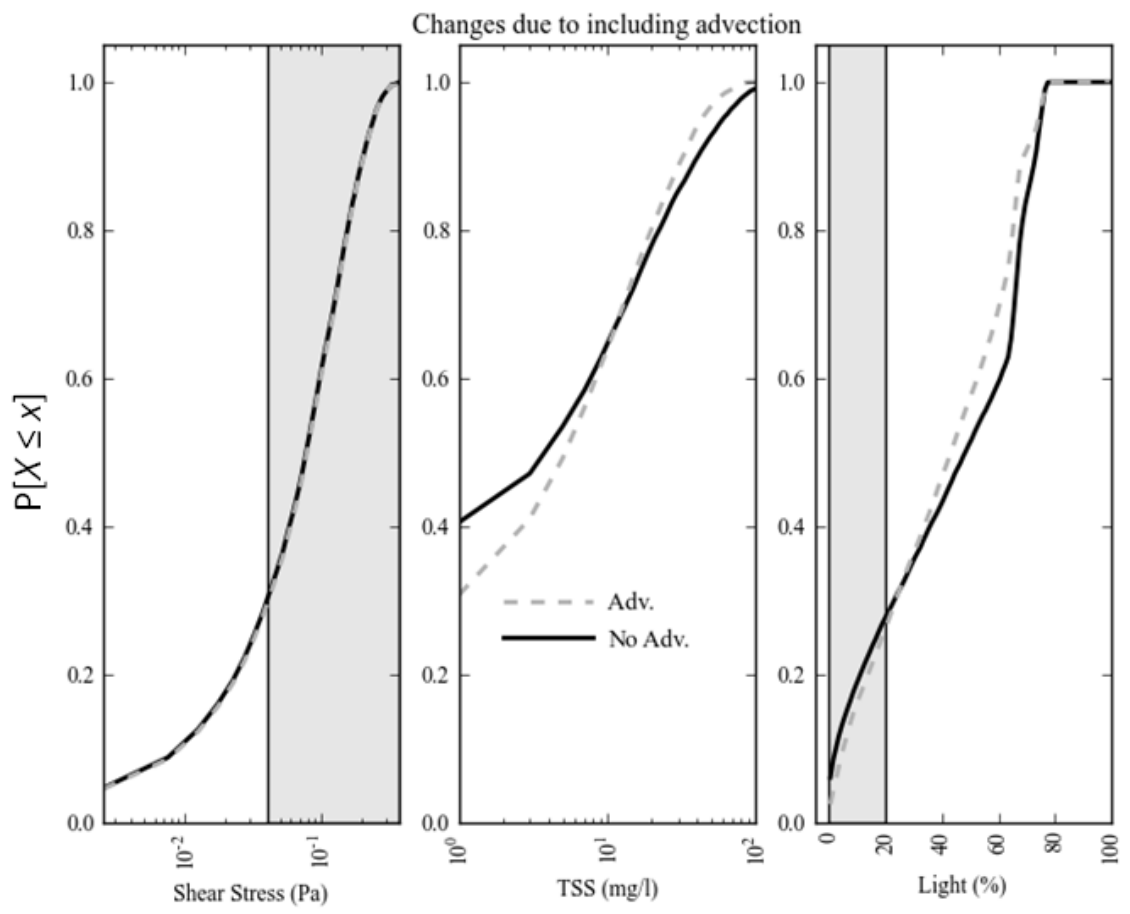

Figure 10. The effect of including advection on a $200 \mathrm{~m}$ by $200 \mathrm{~m}$ landscape holding fractional cover constant $\left(f_{\text {cover }}=0.1\right)$ on the cumulative distributions of mean shear stress, mean total suspended sediment, and mean percent light reaching the sediment surface. Shaded regions correspond to $\tau_{b}>\tau_{\text {crit }}$ and less than $20 \%$ light reaching the sediment surface. Inclusion of advection reduces TSS and decreases extreme values in the suspended sediment distribution, enhancing the light environment. 
Percent of Light reaching the sediment surface

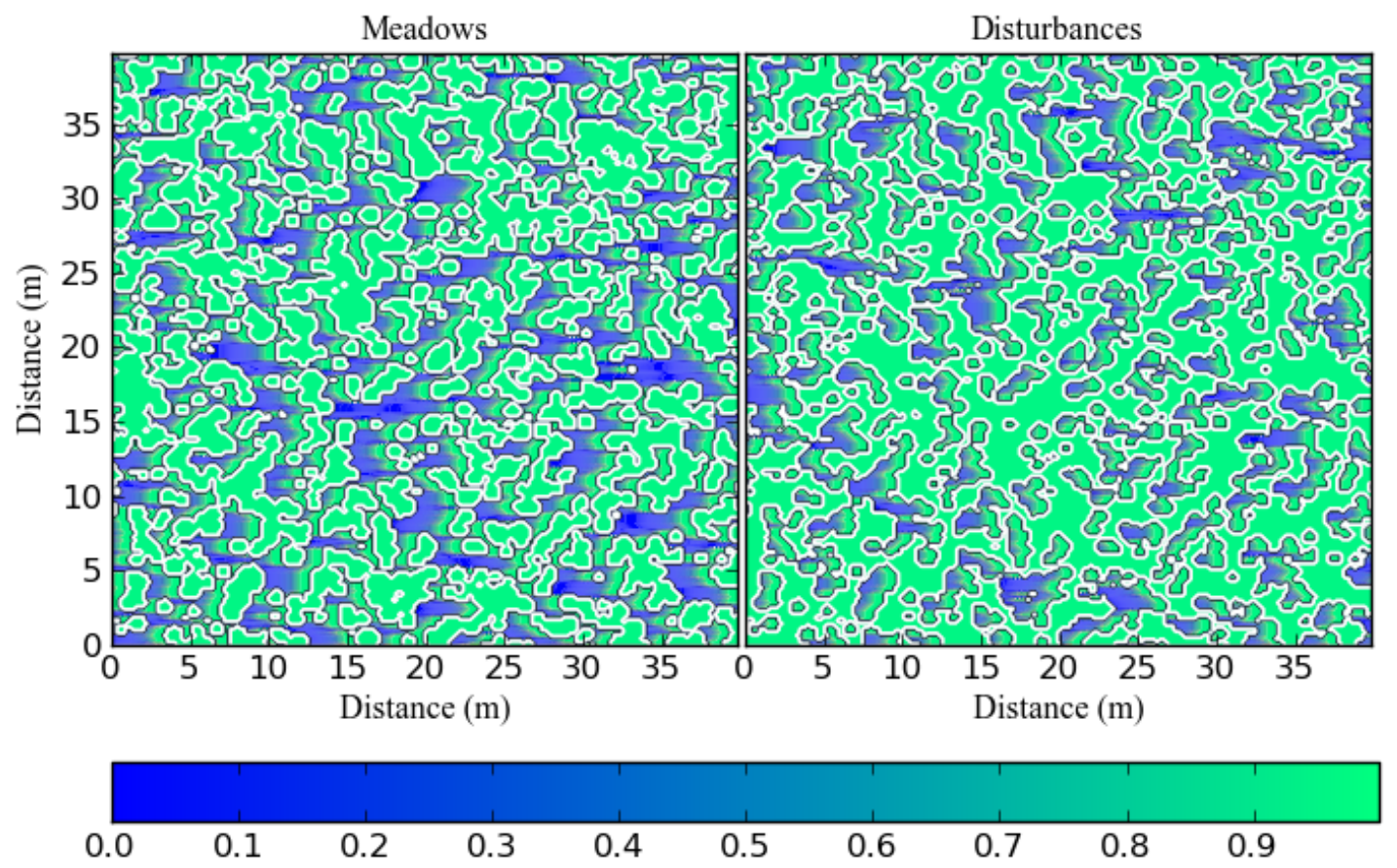

Figure 11. Percent light reaching the surface in a $40 \mathrm{~m}$ by $40 \mathrm{~m}$ plot, for a single hour with $f_{\text {cover }}=0.5, R\left(0.858 \mathrm{~m}^{-2}, 0.5 \mathrm{~m}\right)$. Vegetation landscape generated by scattering disks over a bare sediment background (A) or gaps within a seagrass meadow (B). Simulations refer to the case with waves but without advection. The area of higher light penetration extends beyond the meadow boundary corresponding to the region of decreased shear stress downstream of a meadow. 
Percent of Light reaching the sediment surface

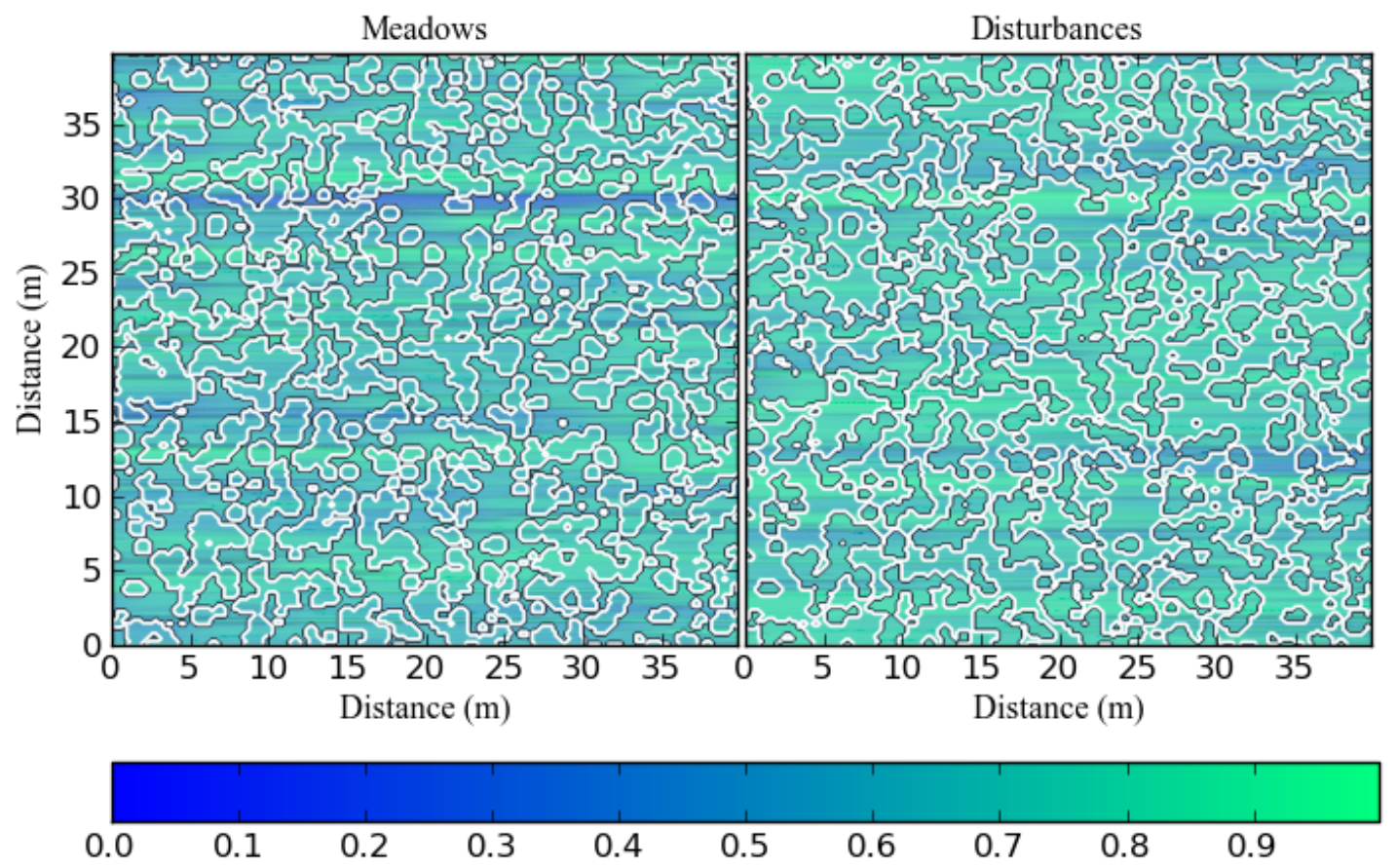

Figure 12. Percent light reaching the surface in a $40 \mathrm{~m}$ by $40 \mathrm{~m}$ plot, for a single hour with $f_{\text {cover }}=0.5, R\left(0.858 \mathrm{~m}^{-2}, 0.5 \mathrm{~m}\right)$. Vegetation landscape generated by scattering disks over a bare sediment background (A) or gaps within a seagrass meadow (B). Simulations refer to the case with both waves and advection. Banding patterns are an effect of advection in the absence of horizontal mixing. 


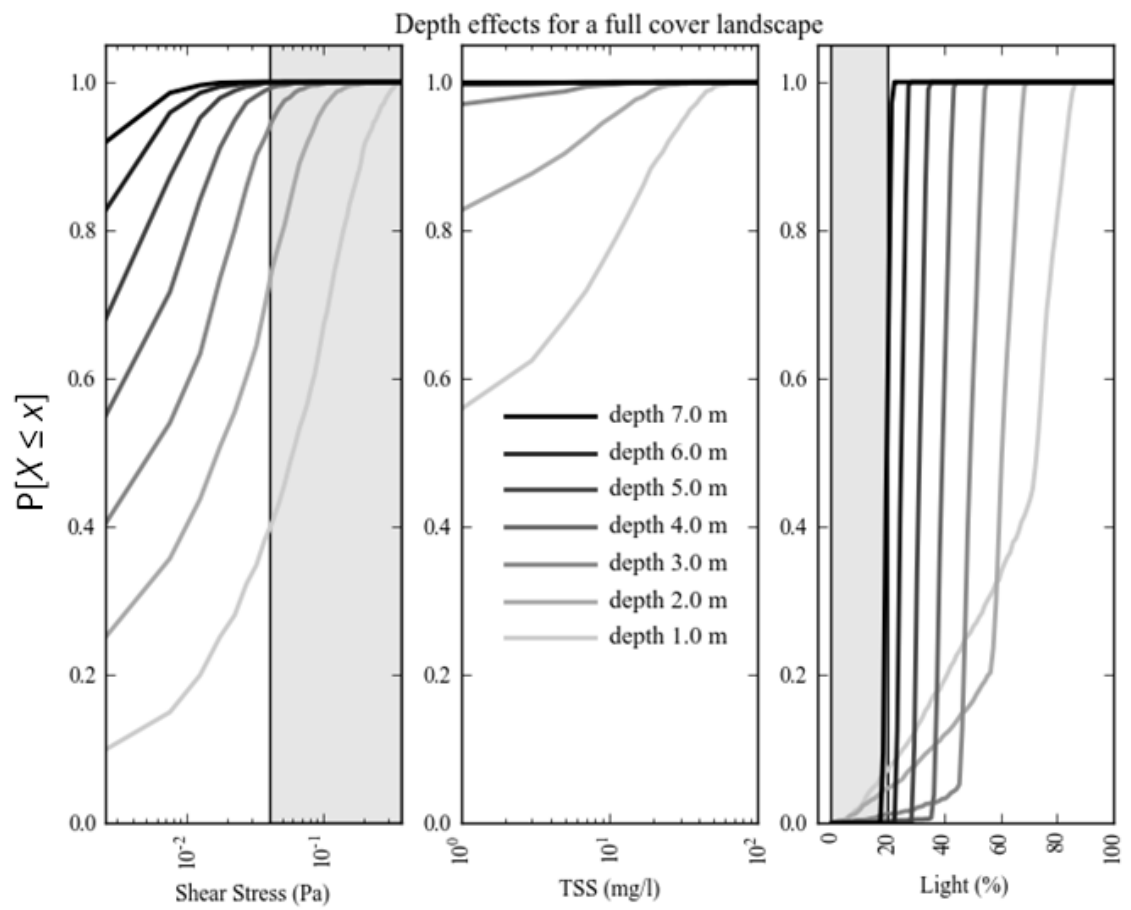

Figure 13. The difference in the cumulative distributions of mean shear stress, mean total suspended sediment, and mean percent light reaching the sediment surface as a function of water depth on a $200 \mathrm{~m}$ by $200 \mathrm{~m}$ full cover sediment landscape $\left(f_{\text {cover }}=1.0\right)$. Shaded regions correspond to $\tau_{b}>\tau_{\text {crit }}$ and less than $20 \%$ light reaching the sediment surface. 

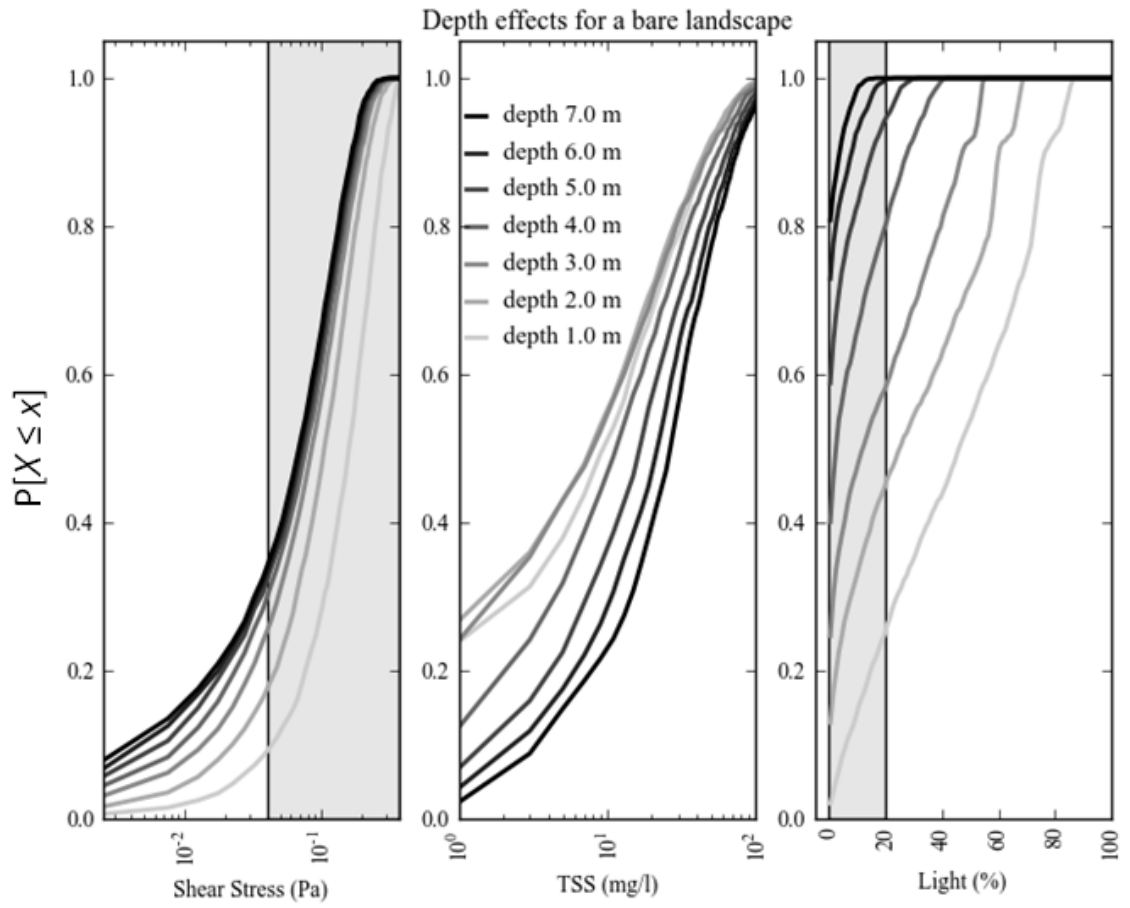

Figure 14. The difference in the cumulative distributions of mean shear stress, mean total suspended sediment, and mean percent light reaching the sediment surface as a function of water depth on a $200 \mathrm{~m}$ by $200 \mathrm{~m}$ bare sediment landscape $\left(f_{\text {cover }}=0.0\right)$. Shaded regions correspond to $\tau_{b}>\tau_{c r i t}$ and less than $20 \%$ light reaching the sediment surface. 


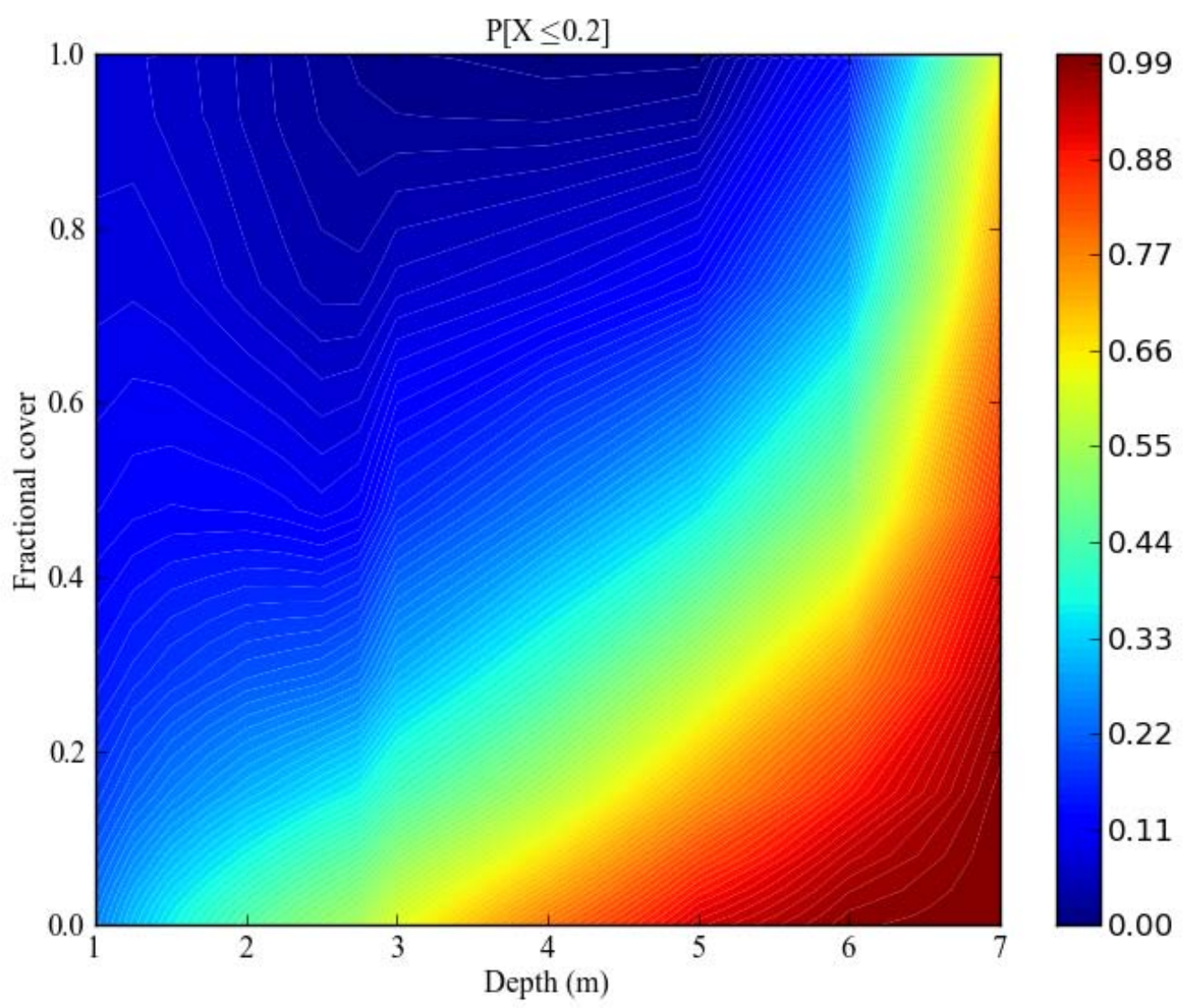

Figure 15 . The $\mathrm{P}[$ Light $\leq 20 \%$ incident light $]$ as a function of water depth and fraction cover. There is a strong decrease in the occurrence of poor light conditions between 2.4 $\mathrm{m}$ at $4.0 \mathrm{~m}$ at higher fractional covers (Figure 12). This is due to the decrease in wave energy acting on the surface as near bed orbital velocities decay with depth. 


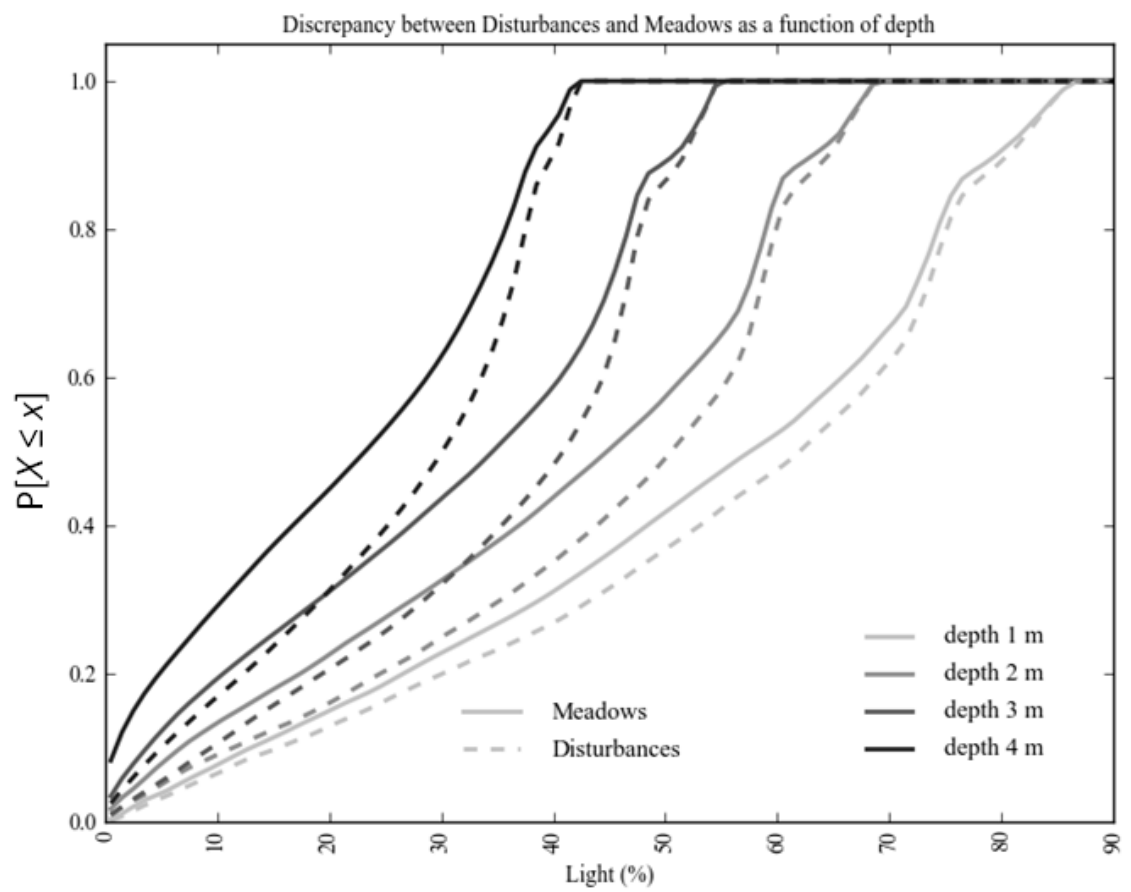

Figure 16. The difference in the cdf's of light reaching the sediment surface as a function of depth between the meadow and disturbance scattering perspective for fractional cover $=0.25$. The difference between perspectives is more pronounced as water depths increase. 


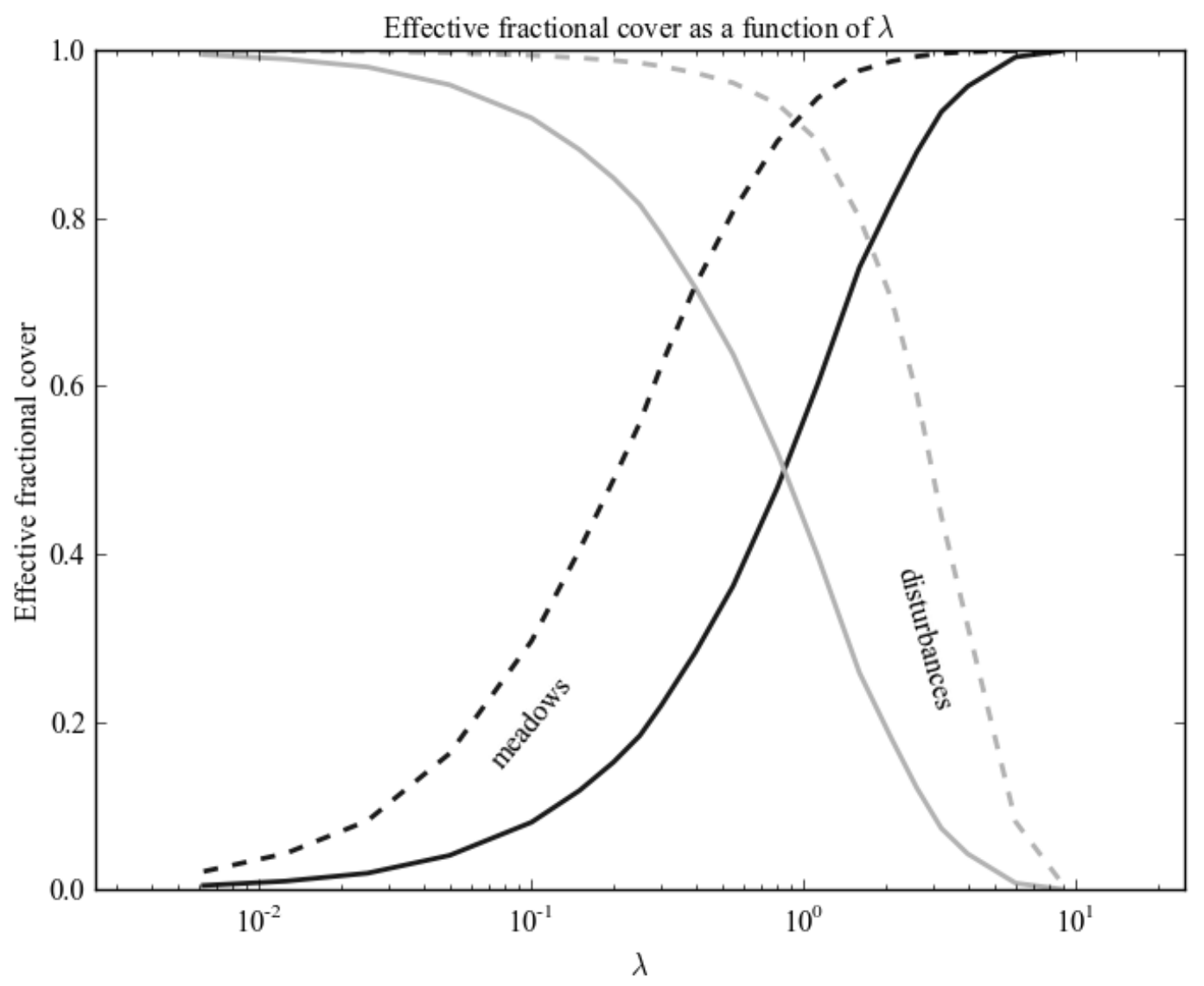

Figure 17. The discrepancy between fractional cover (solid lines) and effective fractional cover as a function of $\lambda$ and the perspectives of adding or removing meadows. Effective fractional cover is the same from either perspective at higher $\lambda$, than for fractional cover. The hysteresis in effective fractional cover between meadow building and disturbances implies seagrass meadow landscapes may be more resilient than individual meadows. 

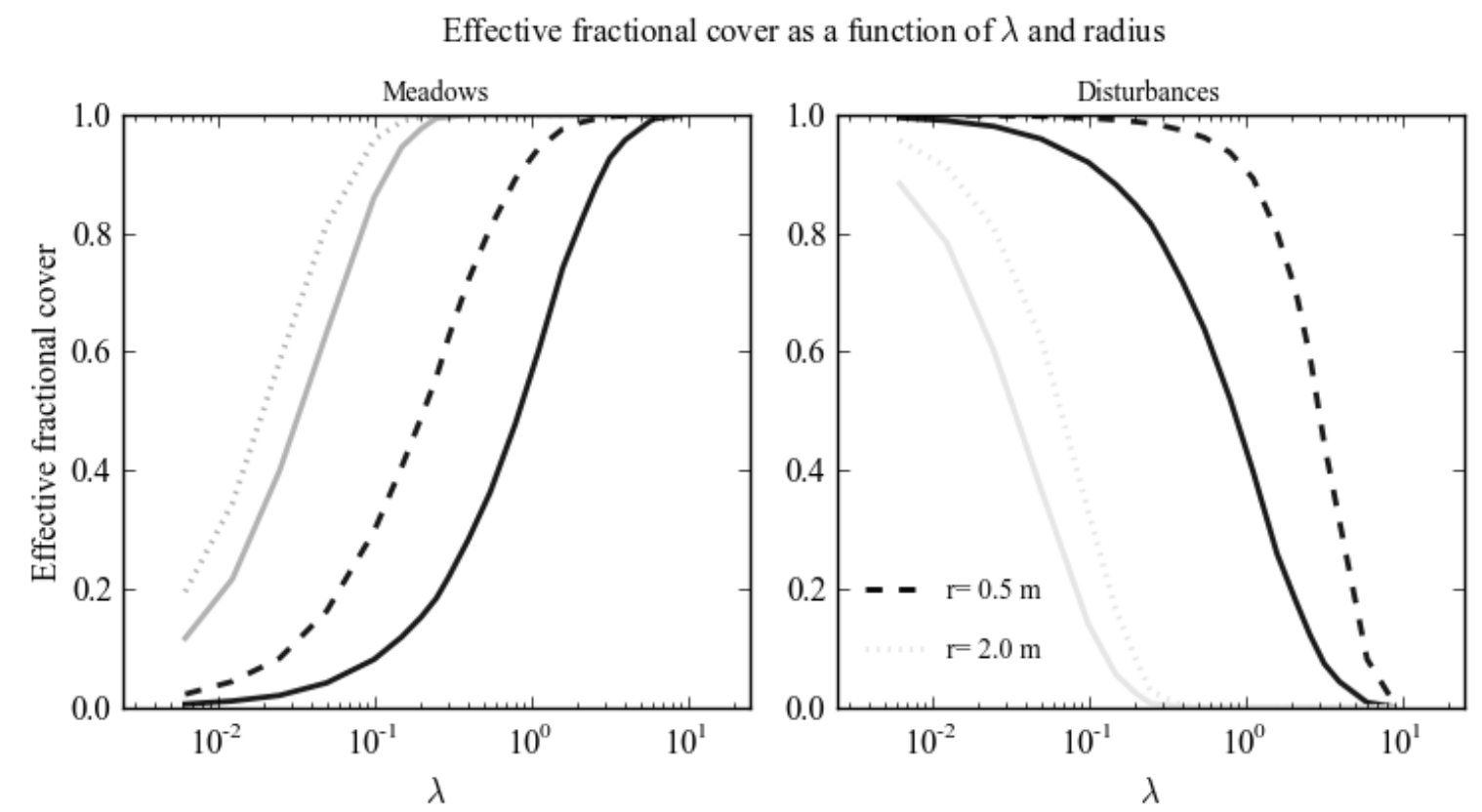

Figure 18. Fractional cover and effective fractional cover for meadow and disturbance scenarios area as a function of intensity and radius. The difference between effective fractional cover from meadow or disturbance perspective decays as radius increases. Effective fractional cover is expected to collapse to fractional cover as radius tends towards infinity. 


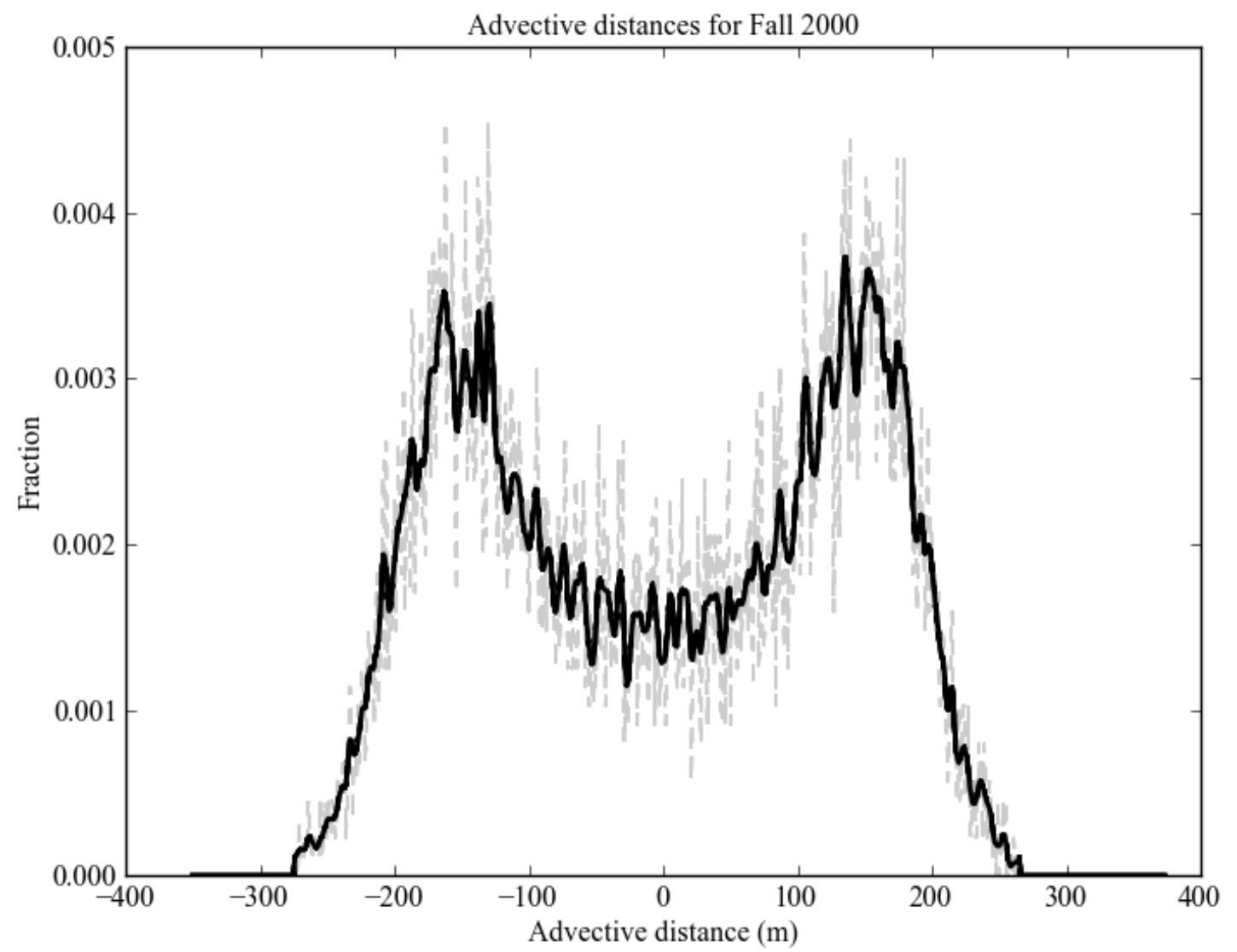

Figure 19. Weighted average advective distances based on settling time for Fall 2000, with mean depth of $1.5 \mathrm{~m}$ MSL using bed fraction (Table 1) as weights. This advective distance increases with increasing mean water depth and decreasing grain size. 
Tables

Table 1 Grain size distributions used in this study and the resultant bistable depth range relative to MSL.

\begin{tabular}{|c|c|c|c|}
\hline Bed Fraction & Base & Finer & Coarser \\
\hline Sand $(125 \mu \mathrm{m})$ & 0.4 & 0.1 & 0.7 \\
\hline Silt $(63 \mu \mathrm{m})$ & 0.5 & 0.2 & 0.2 \\
\hline Clay $(32 \mu \mathrm{m})$ & 0.1 & 0.7 & 0.1 \\
\hline & Base & Finer & Coarser \\
\hline Bistable range & $2.35-6.8 \mathrm{~m}$ & $1-6.8 \mathrm{~m}$ & $3.5-6.8 \mathrm{~m}$ \\
\hline
\end{tabular}




\section{APPENDIX A}

Solution for attenuation parameter: Setting the roughness heights equal to each other results in

$$
\frac{\kappa}{u_{*_{n}}}\left[\overline{U_{a b o v e}}-U_{h_{c}}\right]=\log \left[\frac{\frac{(H-d)}{e}+d}{h_{c}-d}\right]
$$

Substituting equation 9 for $u_{*_{n}}$ and equation 7 for $U_{h_{c}}$ and we arrive at an equation which dictates $\alpha$ as a function of known parameters.

$$
\frac{\overline{U_{\text {above }}}\left(1-e^{-\propto}\right)}{\overline{U_{\text {can }}} \propto^{2}}-\frac{1}{\alpha}-\left(\frac{h_{c}-d}{h_{c}}\right) \log \left[\frac{\left.\frac{(H-d)}{h_{c}-d}\right] d}{h}\right]=0
$$

In order to solve equation A2 for $\alpha$, letting $C=\left(\frac{h_{c}-d}{h_{c}}\right) \log \left[\frac{\frac{(H-d)}{e}+d}{h_{c}-d}\right], \mathrm{A}=\frac{\overline{U_{\text {above }}}}{\overline{U_{c a n}}}$, and

Taylor expansion of $e^{-\infty}$ about an initial guess of $\alpha=\alpha_{i}$ results

$$
\begin{aligned}
\left(-\frac{1}{\alpha_{i}}-\right. & \left.C+\frac{A\left(1-\mathrm{e}^{-\alpha_{i}}\right)}{\alpha_{i}^{2}}\right)+\left(\frac{1}{\alpha_{i}^{2}}+A\left(\frac{\mathrm{e}^{-\alpha_{i}}}{\alpha_{i}^{2}}-\frac{2\left(1-\mathrm{e}^{-\alpha_{i}}\right)}{\alpha_{i}^{3}}\right)\right)\left(x-\alpha_{i}\right) \\
& +\left(-\frac{1}{\alpha_{i}^{3}}+A\left(-\frac{2 \mathrm{e}^{-\alpha_{i}}}{\alpha_{i}^{3}}-\frac{\mathrm{e}^{-\alpha_{i}}}{2 \alpha_{i}^{2}}+\frac{3\left(1-\mathrm{e}^{-\alpha_{i}}\right)}{\alpha_{i}^{4}}\right)\right)\left(x-\alpha_{i}\right)^{2}+O\left[x-\alpha_{i}\right]^{3}=0
\end{aligned}
$$

Solution of equation A3 ignoring higher order errors reduces to a quadratic form with two roots. 
$\propto=\frac{8 \alpha_{i} A+5 \alpha_{i}^{2} A+\alpha_{i}^{3} A+3 \alpha_{i}^{2} \mathrm{e}^{\alpha_{i}}-8 \alpha_{i} A \mathrm{e}^{\alpha_{i}} \pm \sqrt{B}}{2 \alpha_{i} \mathrm{e}^{\alpha_{i}}+A\left(6+4 \alpha_{i}+\alpha_{i}-6 \mathrm{e}^{\alpha_{i}}\right)}$

where

$$
\begin{aligned}
B=\alpha_{i}^{2}( & \left(3 \alpha_{i} \mathrm{e}^{\alpha_{i}}+A\left(8+5 \alpha_{i}+\alpha_{i}^{2}-8 \mathrm{e}^{\alpha_{i}}\right)\right)^{2}-\left(2 \alpha_{i}\left(3+\alpha_{i} C\right) \mathrm{e}^{\alpha_{i}}\right. \\
& \left.\left.+A\left(12+6 \alpha_{i}+\alpha_{i}^{2}-12 \mathrm{e}^{\alpha_{i}}\right)\right)\left(2 \alpha_{i} \mathrm{e}^{\alpha_{i}}+A\left(6+4 \alpha_{i}+\alpha_{i}^{2}-6 \mathrm{e}^{\alpha_{i}}\right)\right)\right)
\end{aligned}
$$

Solution of equation A4 requires iteration of the value $\alpha_{i}$ for the Taylor expansion. Of the two real roots, the solution closest to zero provides the proper solution. Re-expanding around this new estimate of $\alpha$ results in rapid convergence as $\alpha_{i} \rightarrow \alpha$. 


\section{Chapter 6: CONCLUSIONS}

\section{Emergence of bistable dynamics, controls and limitations:}

A positive feedback exists between seagrass and the light environment due to the ability of seagrasses to modify hydrodynamic conditions, sediment dynamics, and the light environment. The feedback can be strong enough to induce bistable dynamics (Chapter 2-5). The presence and strength of the feedback is interdependent on: 1) Bed grain size distribution and composition 2) Environmental drivers (photosynthetically active radiation (PAR), currents, waves, temperature). 3) Meadow morphology (shoot density, leaf density) and sediment effective fractional cover.

In the presence of a seagrass meadow, the combined effects of the bed sediment grain size distribution and the seagrass modified wave-current environment determine the suspended sediment environment. As transport in coarse beds is dominated by bed load, the positive feedback described in this study between seagrass and the light environment, only emerges with fine sand to clay size sediment beds (Chapter 2, Chapter 5). The specific grain size distribution necessary to affect the light environment depends also on bed characteristics (bed consolidation, biofilms, bioturbation) as well as the transport environment generated by tidal currents and waves. In general, higher energy environments may be able to exhibit a strong positive feedback under relatively coarser beds, whereas low energy environments, the positive feedback exists only in fine grained sediment environments. Even within the same environment there can be a large difference among years with regards to the combined meadow-wave- current conditions (Chapter 3). 
This role of stochastic environmental drivers (Chapter2, Chapter 3), and changing attributes of those drivers (Chapter 4), on the meadow-current-wave resuspension conditions also includes the growth environment (PAR reaching the canopy, water temperature, meadow density) (Chapter 3, 4) and directly affects the strength of the positive feedback. As the reduction in tidal and wave shear stresses acting on the bed depends on meadow shoot and leaf density, the strength of the positive feedback varies temporally along with these characteristics (Chapter 3, 4). Photosynthesis, respiration, as well as the saturation-compensation irradiance curves are all temperature dependent. As a result, variations in temperature can cause large shifts in meadow density, resulting in large shifts in the feedback response (Chapter 3). Given the right conditions (depth, substrate, environmental drivers), alternate stable state dynamics (seagrass covered, or bare sediment) can emerge from this positive feedback. The presence and range of depths in which bistable dynamics occur depend on the strength of the positive feedback (Chapter 2, 3).

The modeled bistable range for Hog Island Bay varies among the two models. The hydrodynamic model (Chapter 2) demonstrated a bistable range from 2.2 -3.6 m MSL. The coupled hydrodynamics-seagrass model (Chapter 3, 4) calculated a narrow range from 1.6-1.8 m MSL, corresponding well with observed seeding depth limits. All these ranges fit within the typical 1-10 m depth range associated with Zostera Marina.

The discrepancy between the bistable ranges between the hydrodynamic model alone and the coupled model is dependent primarily on shoot and leaf density differences, with the hydrodynamic model holding shoot density constant at twice the maximum modeled value in the coupled model. Similarly, the shoot densities in the coupled model 
varied significantly throughout between years, within years and with depth, resulting in an overall decrease in the strength of the positive feedback and narrower bistable depth range.

However, regardless of the shifts in the bistable range, both models demonstrate that the positive feedback that exists between seagrass and their light environment may be strong enough to induce bistable dynamics. Moreover, each modeled bistable depth range suggests that there is a shallow enough depth in which seagrass can establish, and a higher depth at which seagrass is unable to survive due to light limitation. This implies that: 1) Even with a catastrophic wholesale loss of seagrass in Hog Island Bay such as the 1930 extirpation event, reestablishment can occur. 2) Once reestablished within a stable depth range, the larger landscape scale modification of the light and sediment environment would allow for seagrass to establish in nearby, slightly deeper, waters.

Above, 2), acts as a larger scale positive feedback in which a fully covered landscape, from a shallow depth limit to the deeper end of the bistable range, could result. This process would be limited by both the effective fractional cover of seagrass on the landscape, as well as the spatial and temporal nature of disturbance events (high temperature events, large storms, propeller scouring).

\section{Seagrass effects on sediment resuspension:}

The three models presented here have significant differences in terms of sediment resuspension formulation. While both the hydrodynamic model and coupled vegetation growth model utilize a 1-D advection diffusion equation linked to a bed entrainment function $1 \mathrm{~m}$ into a seagrass meadow, 1) the hydrodynamic model (Chapter 2) holds 
shoot density, leaf density and leaf length constant, whereas 2) the coupled model (Chapter 3, 4) allows for variable meadow morphology. In contrast, the spatially explicit model holds within meadow shoot density constant similar the hydrodynamic model, but utilizes a reference concentration approach combined with a Rouse type equation (Chapter 5) to determine suspended sediment concentrations. The concentrations are further mixed in the down flow direction by advection. Using a common grain size distribution, the models presented here can be compared in terms of the cumulative distribution of suspended sediment from Fall 2000 (Figure 4). Running the spatially explicit model with full cover and the hydrodynamic model with the same shoot density of 500 shoots $\mathrm{m}^{-2}$, there is little difference in the cumulative distributions (Figure 1). This is due to the strong influence of the vegetation on the wave and current generated shear stresses (Figure 1). With the coupled model however, there is significantly more sediment in suspension due to the variable shoot and leaf densities throughout the Fall time period modeled. The difference between the spatially explicit model runs with full cover, fractional cover of 0.5 , and no cover, demonstrate both effects of meadow sheltering of nearby bare areas as well as the need to incorporate the advection of sediment from neighboring bare areas. There is a discrepancy between the bare sediment resuspension between the hydrodynamic model and the spatially explicit model as 1) the different boundary condition and simplified suspended sediment profiles, and 2) the maintenance of sediment in suspension until a depositional shear stress is met allows for more sediment maintained in suspension resulting in higher suspended sediment values. The differences between full cover and partial covered landscapes indicate that advection of sediment is an important process. More importantly, 
differences between the runs holding shoot density constant (hydrodynamic and spatially explicit) and the coupled model indicate that temporal variability in the shoot and leaf density of meadows is important to consider.

\section{Resilience of seagrasses to stress:}

Once seagrass meadows are established, through rhizome branching they may be able to spread into the bistable depth range. Alternately, due to sea level rise, meadows that exist in a stable depth range may shift into a bistable depth range. Meadows within this range possess limited resilience to disturbances (high temperature events, large storms, propeller scouring) in that they may be pushed beyond some threshold density (within meadow and/or landscape density) from which the loss of seagrass cover results in poorer light environment, This positive feedback causes an eventual collapse to a bare sediment state. Ignoring landscape scale effects, this collapse is likely irreversible and the system would remain locked in a bare sediment state. Results for the coupled model (Chapter 3,4) indicate that the threshold number of disturbances for a single meadow can be as few as 3 years to initiate collapse of the meadow with total collapse requiring up to decades. However, the landscape model demonstrates that even with collapse of many individual meadows on a landscape, the number of these "disturbances" that is required to significantly change the bulk sediment-light environment is quite large. This, combined with the concept that the distance in which any individual meadow affects the sediment and light environment can be upward of $250 \mathrm{~m}$ (Chapter 5) indicates that there is a larger scale control on resilience. Moreover, model results indicated that only when landscape percent cover reaches 50\% do large changes in the sediment-light environment occur, indicating that well established seagrass landscapes are likely to be resilient to 
smaller scale disturbances (loss of a smaller patch). However, the strong more ubiquitous effects of temperature (Chapter 3,4$)$ on total meadow survivability across a landscape may outweigh these beneficial larger scale effects.

\section{Leading indicators of collapse:}

The development of the coupled hydrodynamic-growth model allowed for examination of the dynamics of shoot and leaf populations within the attraction domain of stable meadows and stable bare sediment regimes, along with those meadows which fall within the bistable depth range. This allowed for investigation of leading indicators of an ecosystem shift as the meadows approach the depths for which they transition from being a metastable state of the bistable system to conditions in which bare sediment is the only stable state. This transition could occur under sea level rise scenarios. The distributions of the number of leaves per shoot calculated in an individual year exhibited strong multimodal behavior when a meadow was under duress and tended to disappear when meadows were dense. This is comparable to a change in properties of the state variables distribution, such as variance or skewness, witnessed in some systems [Carpenter, 2006; Guttal and Jayaprakash, 2008]. While standard deviation and suitable metrics of multimodality increase as the system temporarily enters into the domain of attraction of bare sediment, these metrics were not good leading indicators of state change, in that they did not exhibit any symptomatic changes as the system approached the critical bifurcation point. However, close to this point, seagrass meadow behavior exhibited conspicuous fluctuations from one attractor to the other across the threshold, a phenomenon known as "flickering" [Scheffer et al., 2009]. Similarly as a meadow neared the bifurcation the state of the system tended to remain more within the attraction domain 
of the bare sediment state. This increasing persistence away from the stable vegetated state is a typical indicator of a system slowing down close to a threshold due to its inability to recover [Scheffer et al., 2009]. Therefore, the emergence of substantial flickering appears to be a leading indicator of proximity to a fold bifurcation with slowing down witnessed prior to the meadow fully crossing into an unrecoverable bare sediment state. These metrics were not applicable to the landscape scale model (Chapter 5) as meadow densities were held constant, however, in a spatially explicit system spatial statistics and seagrass patterns may provide interesting leading indicators.

\section{CONCLUSION:}

The positive feedback that exists due to the seagrass modified hydrodynamics is strong enough to induce bistable dynamics in limited depth range. This range is dependent on sediment characteristics, stochastic environmental drivers (irradiance, water temperature, water depth, wind waves, tidal currents, and water column eutrophication), within meadow seagrass morphology (shoot density, leaf density, above and belowground biomass, and leaf length), as well as seagrass effective fractional cover on the landscape. Within this bistable range, seagrasses have limited resilience, such that a disturbance or sequences of disturbances in space and/or time, can push the system past some critical threshold resulting in collapse to a stable bare sediment system. Both flickering, and slowing down are seen as leading indicators of this collapse with full collapse taking up to decades to occur. Collections of meadows are likely to be more resilient to disturbances than any individual meadow due to their combined effect on the bulk sediment and light environment. 


\section{References:}

Carpenter, S. R. (2006), Rising variance: a leading indicator of ecological transition, Ecology letters, 9(3), 311-318.

Guttal, V., and C. Jayaprakash (2008), Changing skewness: an early warning signal of regime shifts in ecosystems, Ecology letters, 11(5), 450-460.

Scheffer M, Bascompte J, Brock WA, Brovkin V, Carpenter SR, Dakos V, Held H, van Nes EH, Rietkerk M, Sugihara G (2009) Early-warning signals for critical transitions. Nature 461:53-59 
Figures

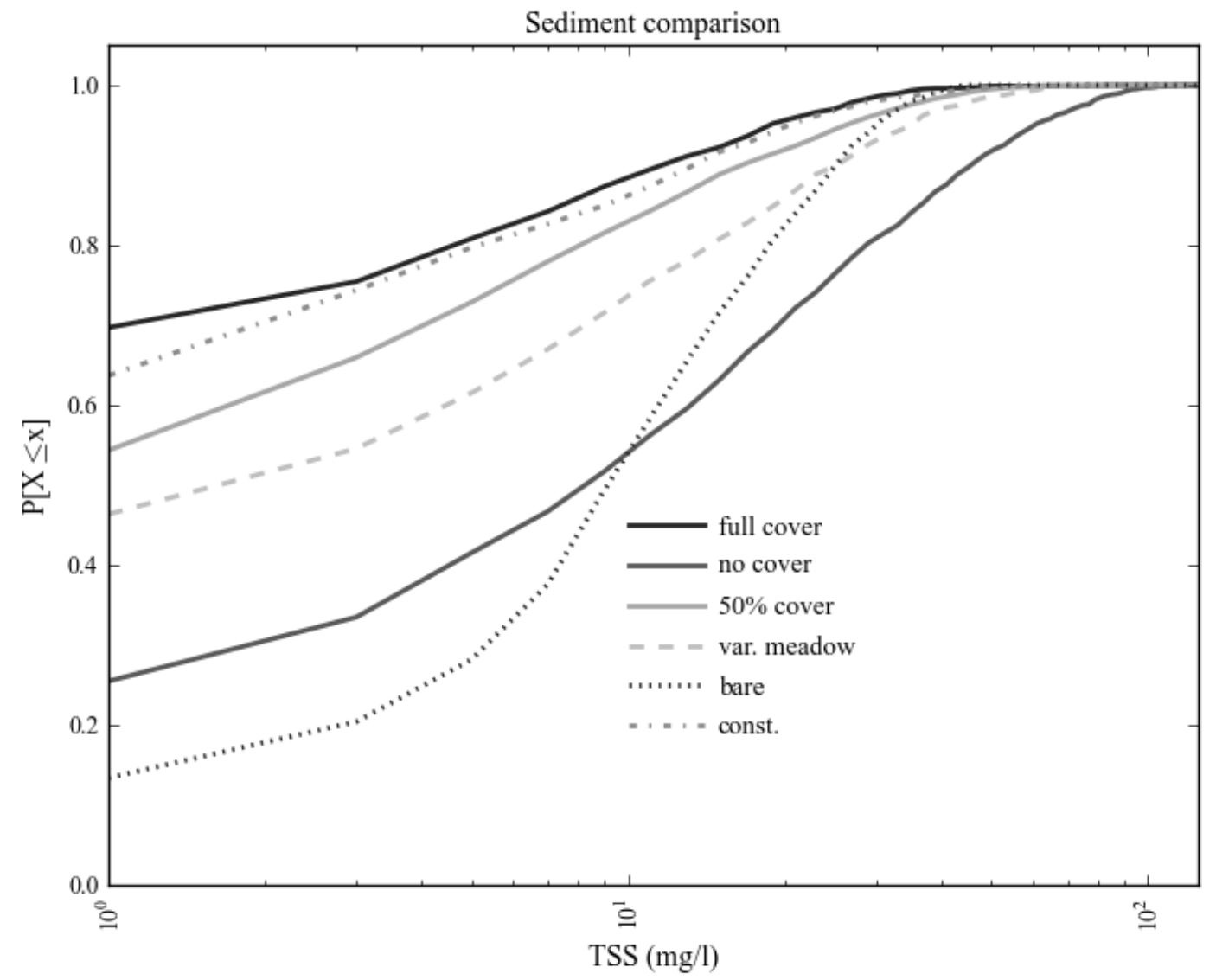

Figure 1. Cumulative distributions of suspended sediment concentration for Fall 2000 amongst the three models presented here. Solid lines are generated with the spatially explicit model (Chapter 5) and dashed and dotted lines are generated from the hydrodynamic (constant with 500 shoot $\mathrm{m}^{-2}$, bare) (Chapter 2) and coupled models (variable meadow shoot density) (Chapter 3-4). 